\title{
Structural Responses and Finite Element Modeling of Hakka Tulou Rammed Earth Structures
}

\author{
Daniel Sranislawski \\ West Virginia University
}

Follow this and additional works at: https://researchrepository.wvu.edu/etd

\section{Recommended Citation}

Sranislawski, Daniel, "Structural Responses and Finite Element Modeling of Hakka Tulou Rammed Earth Structures" (2011). Graduate Theses, Dissertations, and Problem Reports. 2229.

https://researchrepository.wvu.edu/etd/2229

This Thesis is protected by copyright and/or related rights. It has been brought to you by the The Research Repository @ WVU with permission from the rights-holder(s). You are free to use this Thesis in any way that is permitted by the copyright and related rights legislation that applies to your use. For other uses you must obtain permission from the rights-holder(s) directly, unless additional rights are indicated by a Creative Commons license in the record and/ or on the work itself. This Thesis has been accepted for inclusion in WVU Graduate Theses, Dissertations, and Problem Reports collection by an authorized administrator of The Research Repository @ WVU. For more information, please contact researchrepository@mail.wvu.edu. 


\title{
Structural Responses and Finite Element Modeling of Hakka Tulou Rammed Earth Structures
}

\author{
Daniel Stanislawski \\ Thesis submitted to the \\ College of Engineering and Mineral Resources at \\ West Virginia University in \\ partial fulfillment of the requirements \\ for the degree of
}

\section{Master of Science \\ in \\ Civil Engineering}

Approved by

Hota V. S. GangaRao, PhD, Chair

Ruifeng Liang, PhD

P V. Vijay, $\mathrm{PhD}$

\section{Department of Civil and Environmental Engineering}

\author{
Morgantown, West Virginia \\ 2011
}

Keywords: Rammed Earth, Hakka, Tulou, Field Testing, Finite Element Modeling, LEED Certification, Green Building 


\section{ABSTRACT \\ Structural Responses and Finite Element Modeling of Hakka Tulou Rammed Earth Structures \\ Daniel Stanislawski}

Hakka Tulous are rammed earth structures that have survived the effects of aging and natural elements upwards of even over a thousand years. These structures have housed the Hakka people of the Fujian Province, China in natural yet modern housing that has provided benefits over newer building materials. The key building material, rammed earth, which is used for the walls of the Hakka Tulou structures, has provided structural stability along with thermal comfort to the respective inhabitants of the Hakka Tulous.

Through material testing and analysis this study has examined how the Tulou structures have maintained their structural stability while also providing thermal comfort. Reports of self healing cracks in the rammed earth walls were also analyzed for their validity in this study. The study has found that although the story of the self healing crack cannot be validated, there is reason to believe that with the existence of lime, some type of autogenous healing could occur on a small scale. The study has also found, through the use of nondestructive testing, that both the internal wooden systems (flooring, roof, and column support) and the rammed earth walls, are still structurally sound. Also, rammed earth's high thermal mass along with the use of sufficient shading has allowed for a delay release of heat energy from the walls of the Tulous, thus providing thermal comfort that can be felt during both night and day temperatures. The Hakka Tulou structures have been found to resist destruction from natural disasters such as strong earthquakes even when more modern construction has not.

Through finite element modeling, this study has shown that the high volume of rammed earth used in the construction of the Hakka Tulous helps dissipate lateral force energy into much lower stresses for the rammed earth wall. This absorption of lateral force energy allows the rammed earth structures to survive even the strongest of earthquakes experienced in the region. The Hakka Tulou, if rated by the LEED green building certification program, would earn the highest certification as this rammed earth construction has offered efficient living for hundreds of years. As historic as these rammed earth structures are, they present an environmentally friendly option to structures of the future. 


\section{ACKNOWLEDGEMENTS}

I would like to thank my advisor, Dr. Hota GangaRao, for the support that he has provided not only during the duration of this project, however also throughout my time as a Masters student at West Virginia University.

I would also like to thank Dr. Ruifeng Liang for his direct guidance and assistance throughout this project. Without Dr. Liang's assistance in the project, which includes but is not limited to translating information from Chinese and overseeing project goals, it would have been much more difficult to complete the research.

Additionally, I am grateful to Dr. P. Vijay who I initially worked under when coming to WVU. His guidance during field testing assisted in my acquiring of valuable skills that proved necessary for this project.

I am also thankful to Mark Skidmore and Dave Dittenber for their advice and assistance during material testing as well as West Virginia University student, Matt Blandford, for his constructive feedback.

I would also like to acknowledge the Xiamen University of China as portions of my research reported in this document are based on a field study that was conducted in the summer of 2009 by WVU-CFC in collaborations with the Xiamen University.

Additionally, I would like to thank Minoru Ueda for providing his 7-day thermal data for this study as well as the National Science Foundation for its support. Without NSF support I would not have had the opportunity to study Hakka Tulous.

Lastly, I would like to thank my family and friends for their support during the duration of this research and during my stay at West Virginia University. 


\section{TABLE OF CONTENTS}

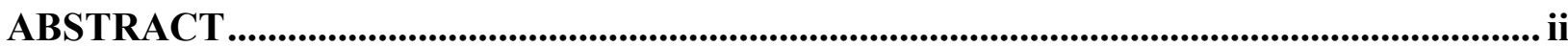

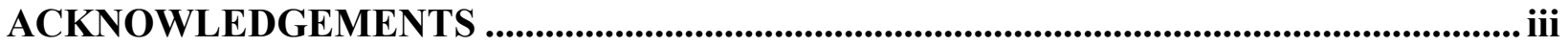

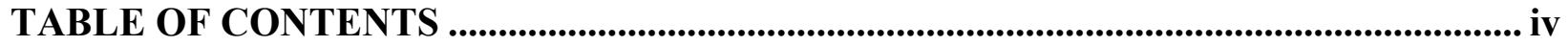

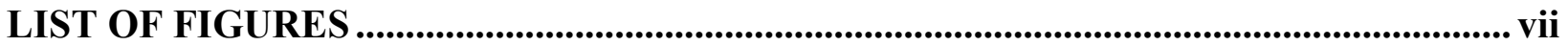

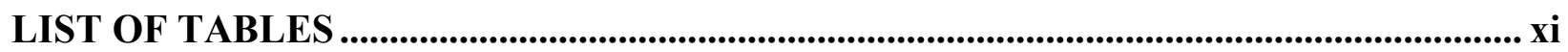

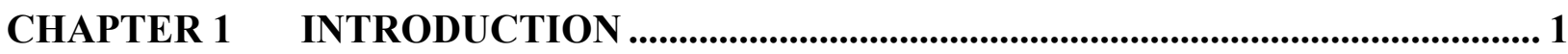

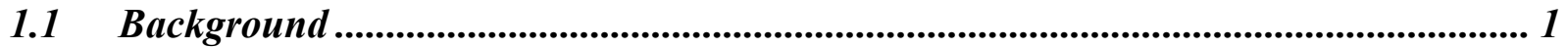

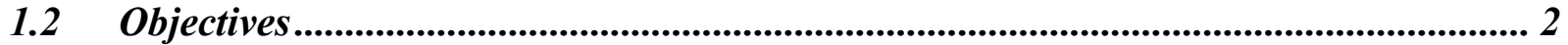

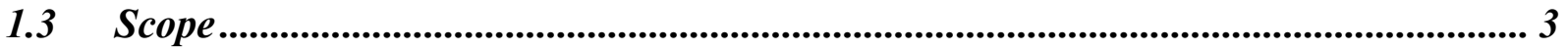

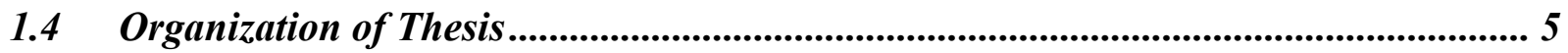

CHAPTER 2 LITERATURE REVIEW ..................................................................... 7

CHAPTER 3 MATERIAL CHARACTERIZATION AND STRUCTURAL

EVALUATION OF HISTORIC TULOU STRUCTURES................................................. 14

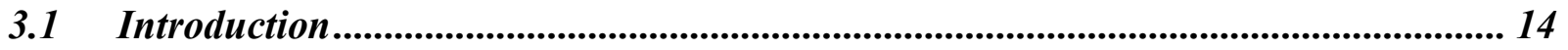

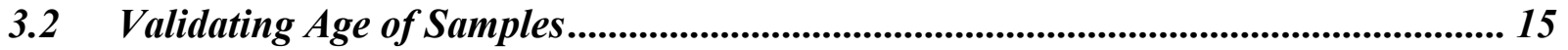

3.3 Scanning Electron Microscopy and Energy-dispersive X-ray Spectroscopy Analysis of Tulou Rammed Earth Samples....................................................................................... 16

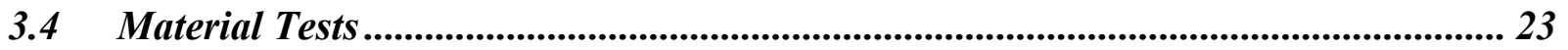




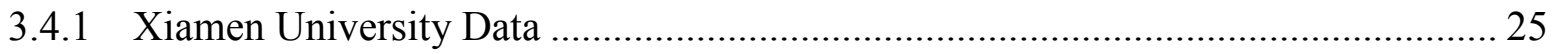

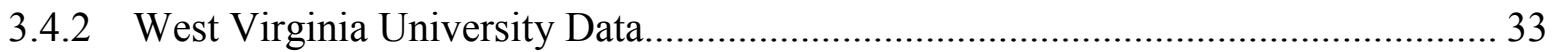

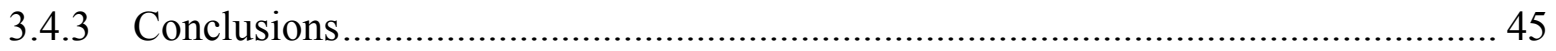

3.5 NDT, Ultrasonic and Rebound Hammer Tests............................................................... 50

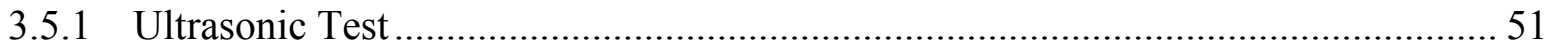

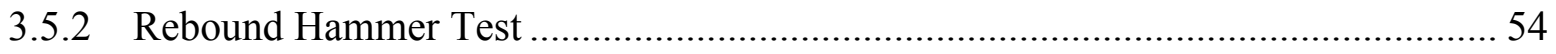

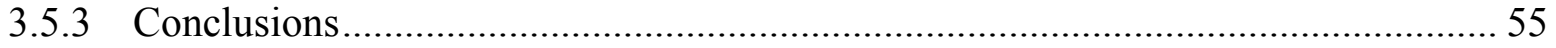

3.6 Load Testing on Floor and Roof Truss Systems............................................................. 56

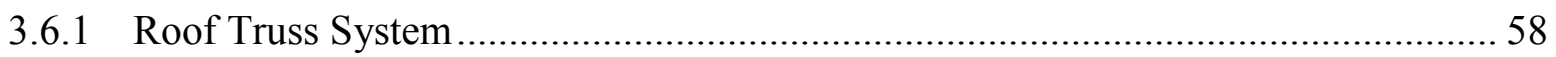

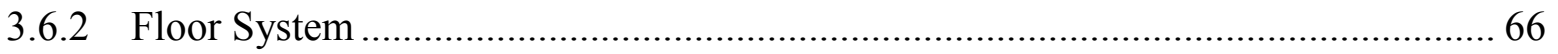

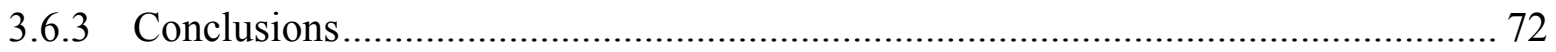

CHAPTER 4 FE MODELING EVALUATION ................................................................ 76

4.1 Introduction ....................................................................................................................... 76

$4.2 \quad$ Rule of Mixtures.................................................................................................................. 78

$4.3 \quad$ Self Healing Crack? ............................................................................................................. 83

4.3.1 Understanding Why the Crack Developed ................................................................ 83

4.3.2 Possible Mechanisms of Self Healing................................................................... 92

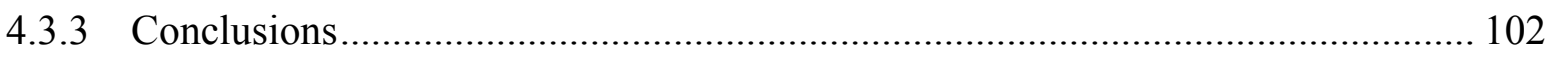

4.4 Earthquake Resistance of the Hakka Tulou ................................................................... 102

4.4.1 Simplified Lateral Force Analysis ..................................................................... 103 
4.4.2 Tulou Model Earthquake Response ............................................................... 107

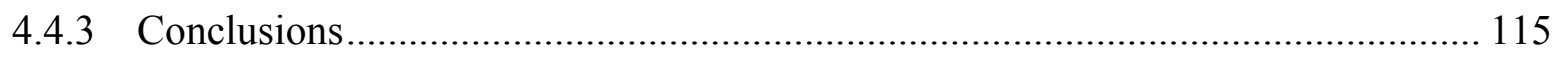

CHAPTER 5 THERMAL COMFORT ANALYSIS ...................................................... 117

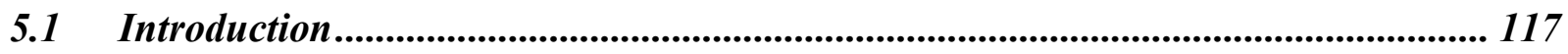

$5.2 \quad$ Thermal Resistivity ......................................................................................................... 118

$5.3 \quad$ Thermal Mass.............................................................................................................. 125

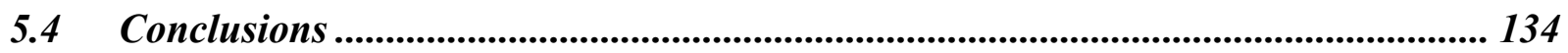

CHAPTER 6 DISCUSSION, CONCLUSIONS, AND RECOMMENDATIONS.......... 136

6.1 Discussion ................................................................................................................... 136

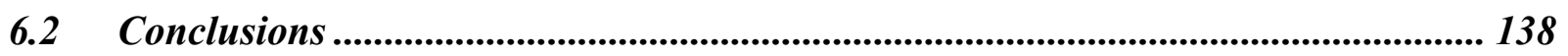

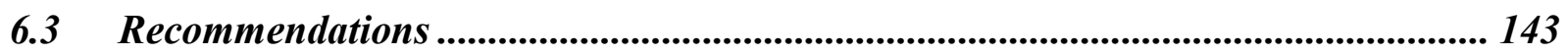

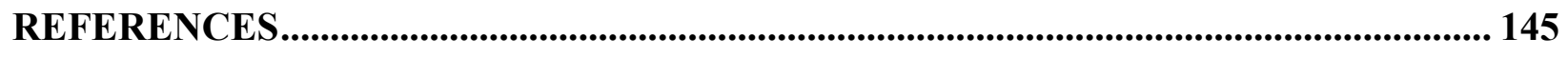

APPENDIX A- SAND FORK FLOOR JOIST LOAD TESTING ........................................... 152 


\section{LIST OF FIGURES}

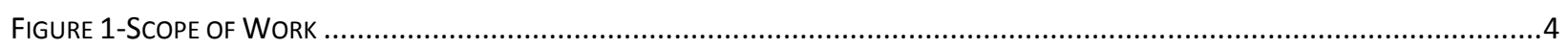

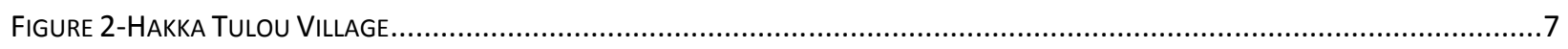

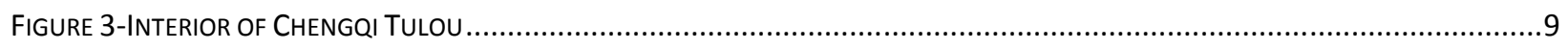

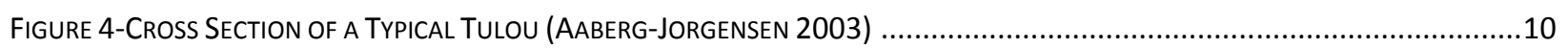

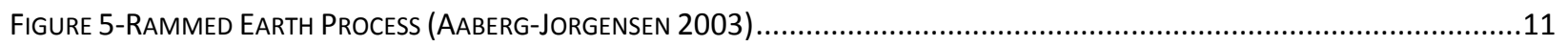

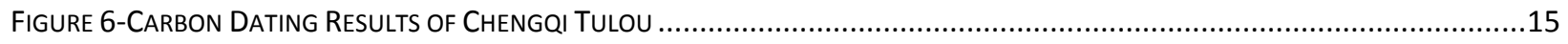

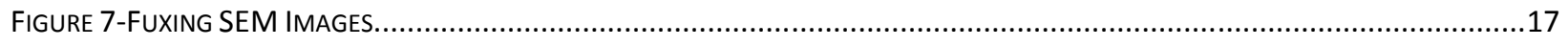

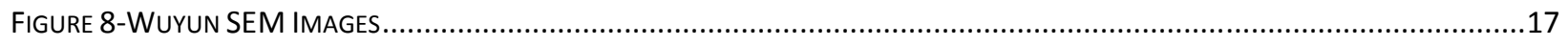

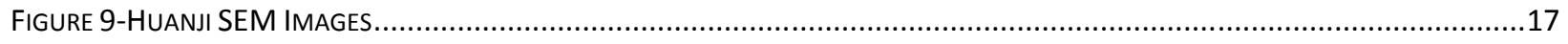

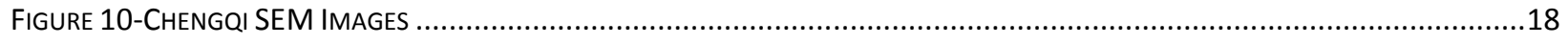

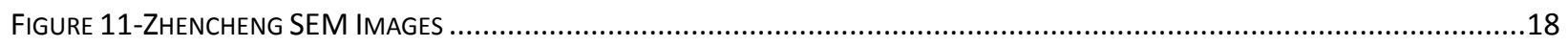

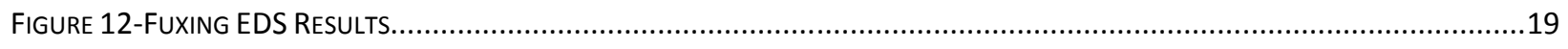

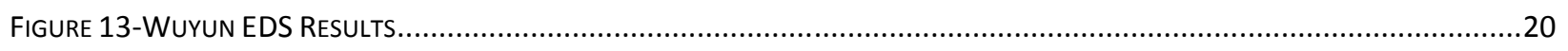

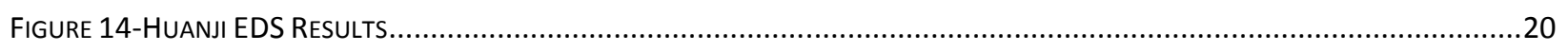

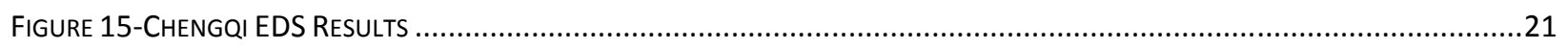

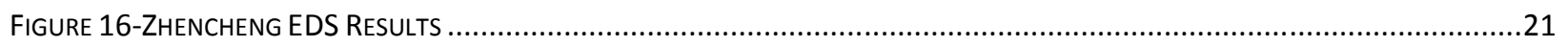

Figure 17-FaILURE Of CoRe EXTRACTION AND ColleCtION OF WALL SAMPLES ..................................................................24

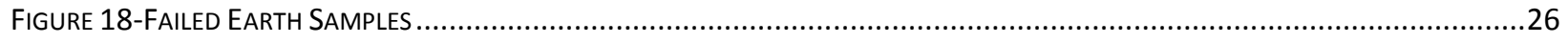

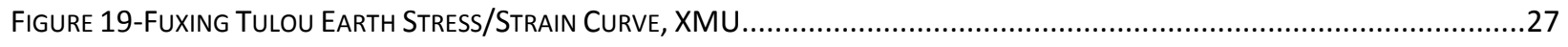

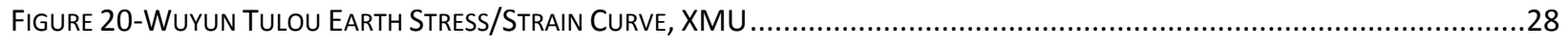

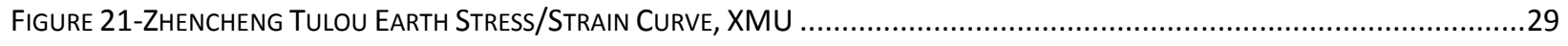

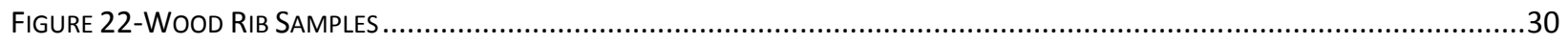

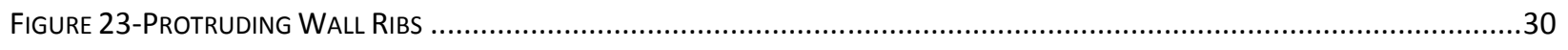

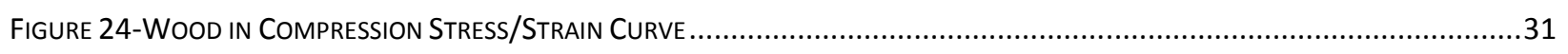

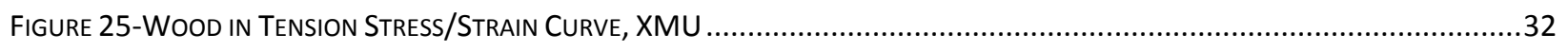


Figure 26-HongKeng Bamboo under Tension Stress/Strain CurVe, XMU

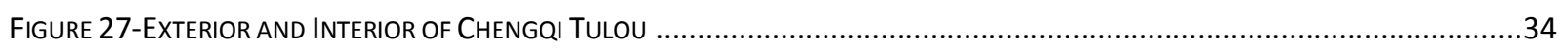

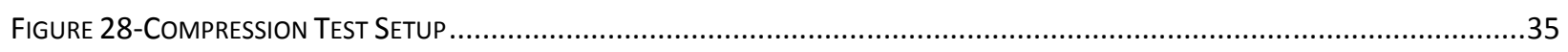

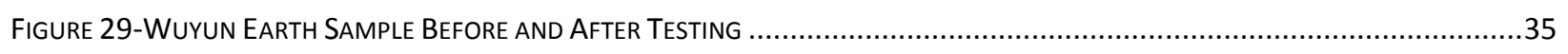

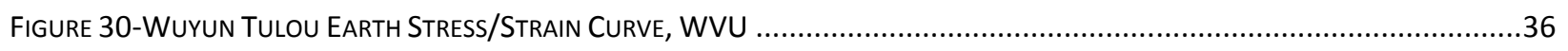

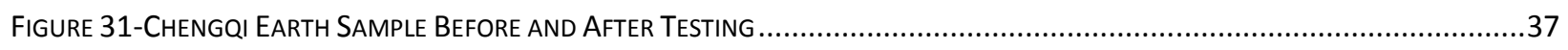

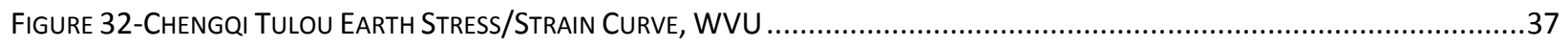

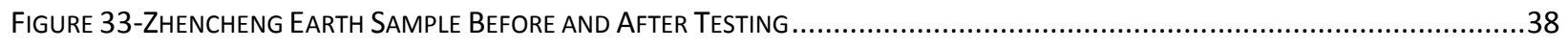

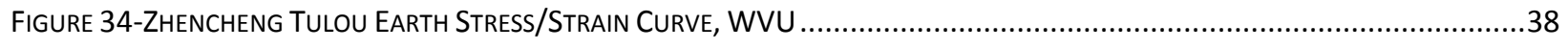

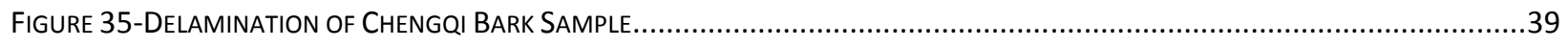

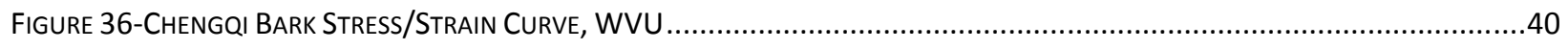

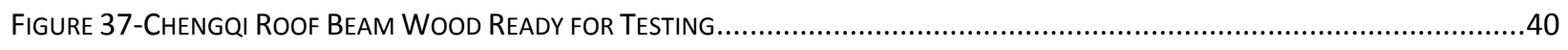

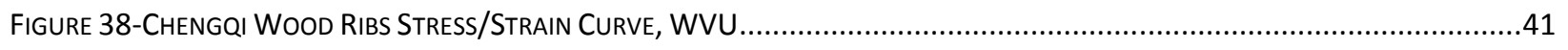

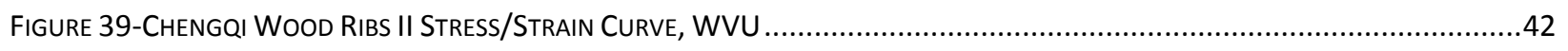

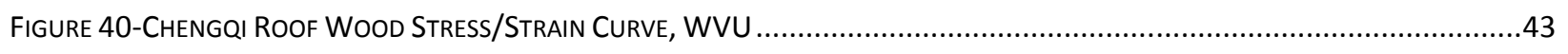

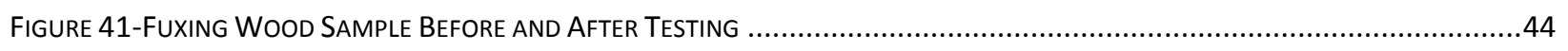

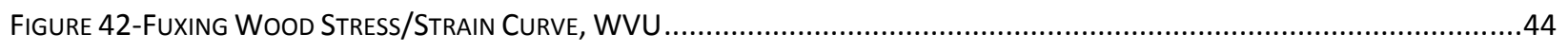

FIgURE 43-HongKeng BAMBoo In COMPRESSION StRESS/Strain CURVE, WVU .......................................................45

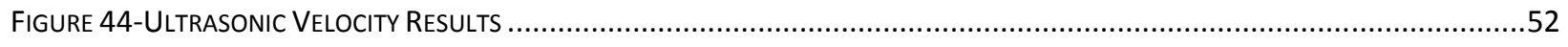

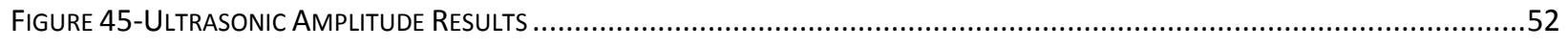

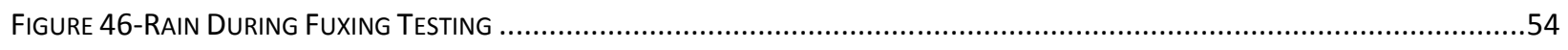

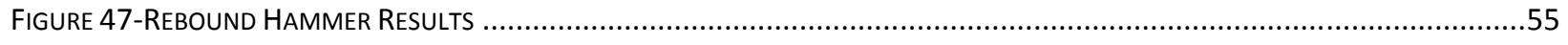

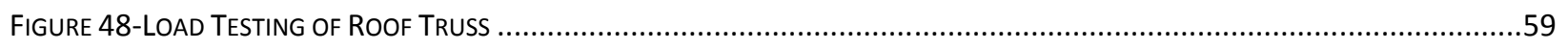

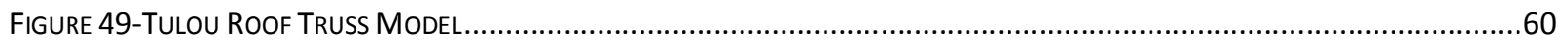

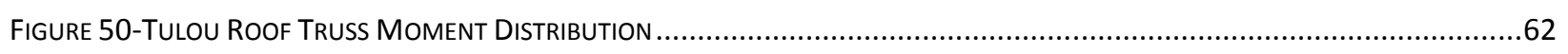

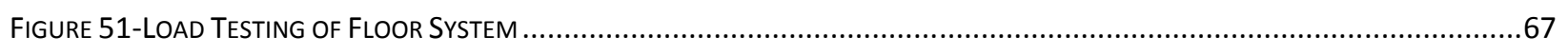

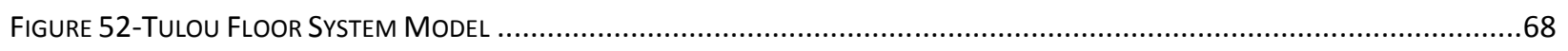


Figure 53-Tulou FloOR SYSTEM MOMENT DistRIBUTION.

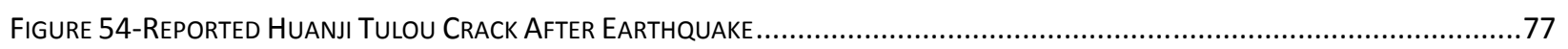

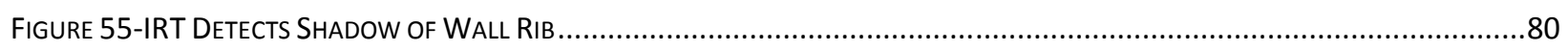

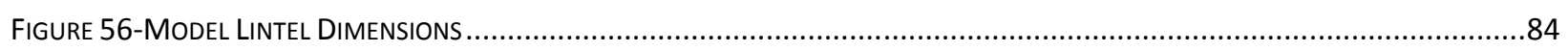

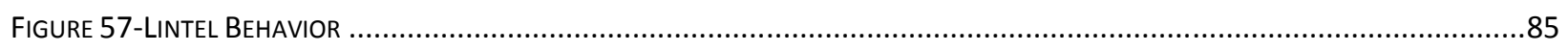

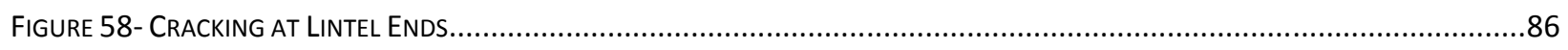

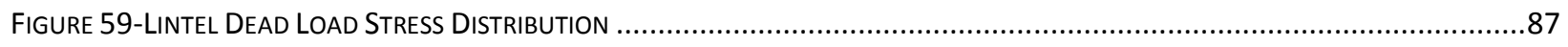

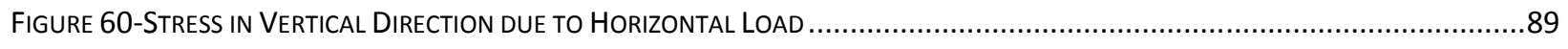

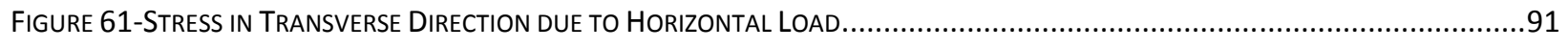

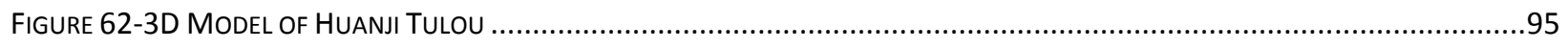

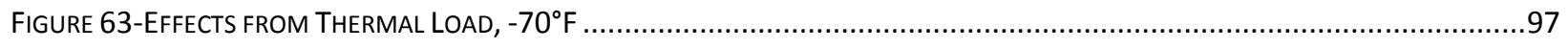

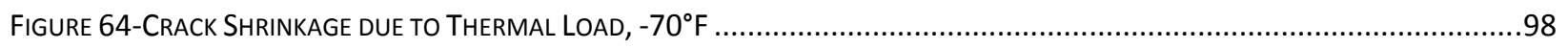

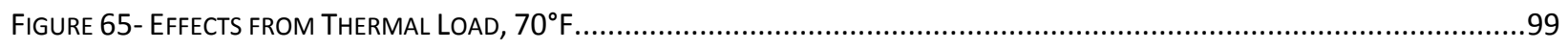

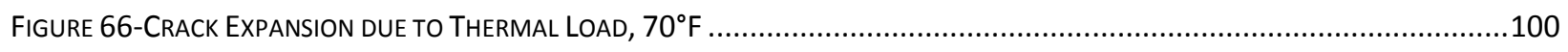

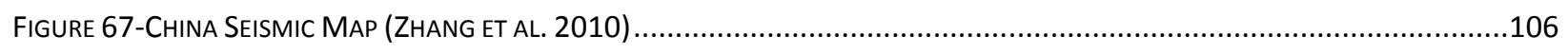

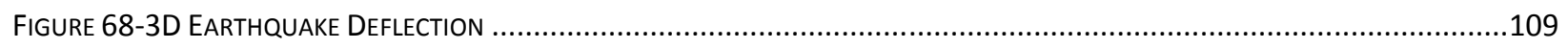

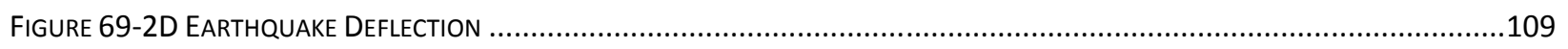

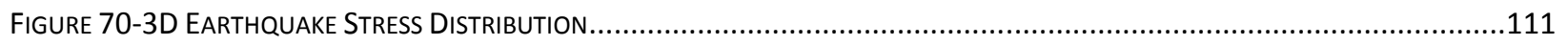

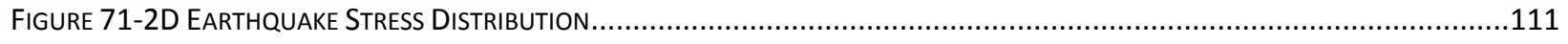

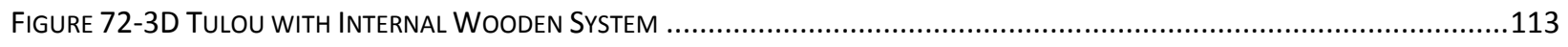

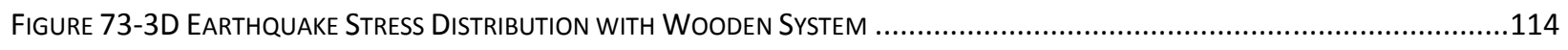

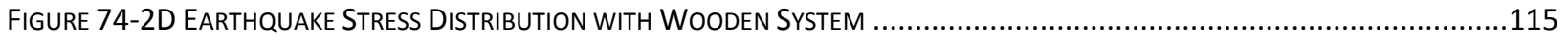

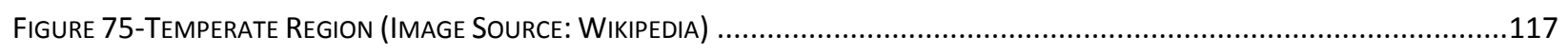

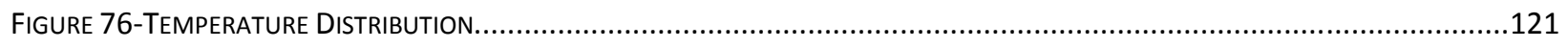

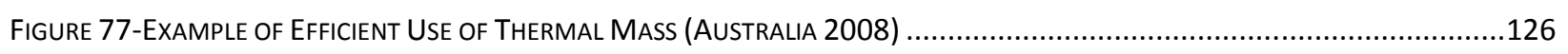

Figure 78-SeVEn Day TeMPerature DatA ChengQI TUlou (Ueda 2009).................................................................130

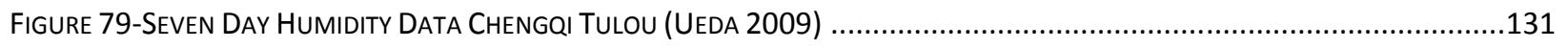


FIGURE 80-ROUGH RAMMEd EARTH WALLS OF CHENGQI TULOU ........................................................................

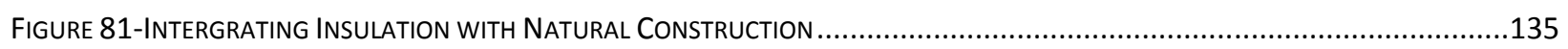




\section{LIST OF TABLES}

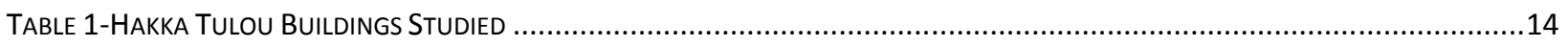

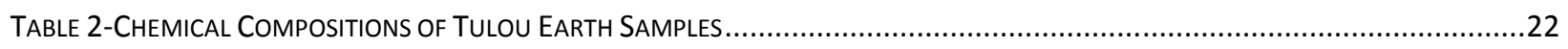

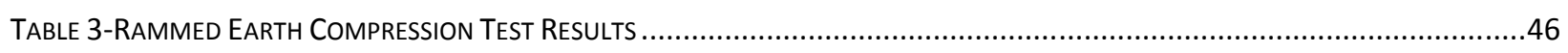

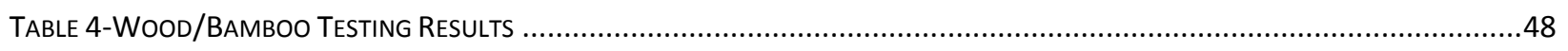

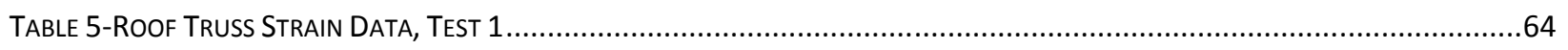

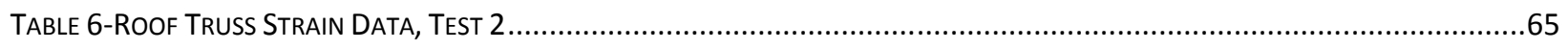

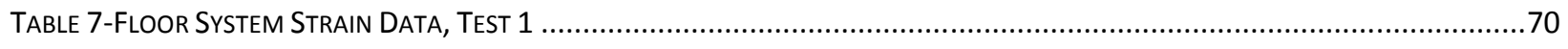

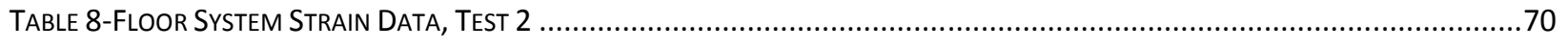

TABLE 9- LOAD SHARING EFFECTS Of FLOOR AND RoOf TRUSS SYSTEMS OF CHENGQI TULOU ...................................................73

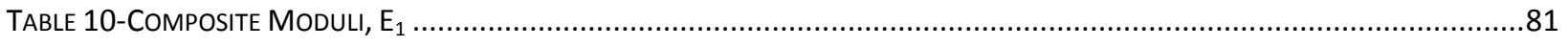

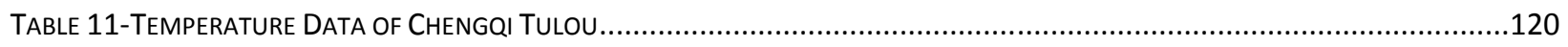




\section{CHAPTER 1 INTRODUCTION}

\subsection{Background}

Rammed earth is a sustainable construction material with many positive attributes to the environment compared to that of concrete and steel. The in-service World Heritage Hakka Tulous, from the Fujian Province of China, are historic and unique in design and performance. These buildings reflect the emergence of innovation, evolution, and advancement of the science and engineering of rammed earth structural construction from the 8th to 20th century. They can be considered the "greenest" in terms of their planning, design, construction, lifestyle, resource management, renewable energy, recycling of human and animal waste, low embodied energy and a modest ecological footprint. However, people, including those of the Hakka region, have underestimated the engineering value and historical significance of these buildings in terms of energy consumption for comfortable living, sustainability, and durability. In collaboration with engineers from the School of Architecture and Civil Engineering, Xiamen University, China and ASH-Autonomous \& Sustainable Housing Inc, Canada, engineers from West Virginia University Constructed Facilities Center traveled to Hakka Villages from June 15 - July 15, 2009 and performed field studies on the material and structural responses of the historic Hakka rammed earth buildings (Liang and Hota 2009a). A Forum of over 130 people on the Hakka Tulous was also conducted on June 24, 2009 at Xiamen University, China (Liang and Hota 2009b, Liang et al. 2009). This forum was to demonstrate the sustainability of Hakka village dwellings that were built hundreds of years ago and are still in use today. By conducting this study we can better understand how aging impacts both wood and rammed earth in a structural sense, the methods of 
construction used for natural building materials, and how such building materials/methods can be modified in order to be used in contemporary construction (Liang et al. 2010).

\subsection{Objectives}

The objectives of this study are:

- To better understand the thermo-mechanical and aging response of the Hakka Tulous, made from rammed earth, under thermal and earthquake loads through nondestructive field evaluation, laboratory testing, and finite element modeling.

- To perform and analyze material tests on samples acquired from Hakka Tulous as well as to perform nondestructive tests on Hakka Tulous in order analyze structural integrity of the rammed earth structures.

- To collect and analyze thermal data from Tulou sites in order to acquire a better understanding on how the rammed earth structures are able to maintain thermal comfort year round.

- To model and attempt to validate the claim that a crack in the rammed earth wall of the Huanji Tulou has self healed over time after a severe earthquake caused the crack.

- To model and analyze the Hakka Tulous' resistance to natural events such as 
earthquakes which produce large lateral forces on the structure.

\subsection{Scope}

The scope of work includes: 1) identification of constituent materials in rammed earth and investigation of durability of the constituents; 2) investigation of structural integrity of Hakka buildings for structural efficiency under extreme loads, including potential modes of failure and verification of the reported self-healing of cracks; 3) analysis of heat transfer process through rammed earth wall for thermal comfort and energy-efficiency; and 4) evaluation of potential benefits of material and structural performance for implementation in modern constructions.

All field studies were conducted in a nondestructive manner using techniques and equipment such as Infrared Thermography (IRT) Scanning Camera, Rebound Hammer, UltraSonic Testing Device, strain data acquisition for load tests on the wooden roof truss and floor components, and thermal data acquisition including humidity data from thermocouples. The data collected from the field study was then further processed at West Virginia University for their implications and material samples that were collected were further tested at laboratories for their mechanical properties. Computer modeling on the structural responses of Hakka Tulous was conducted using the material properties generated from the lab testing. The overall scope of work of the project is illustrated in Figure 1. 


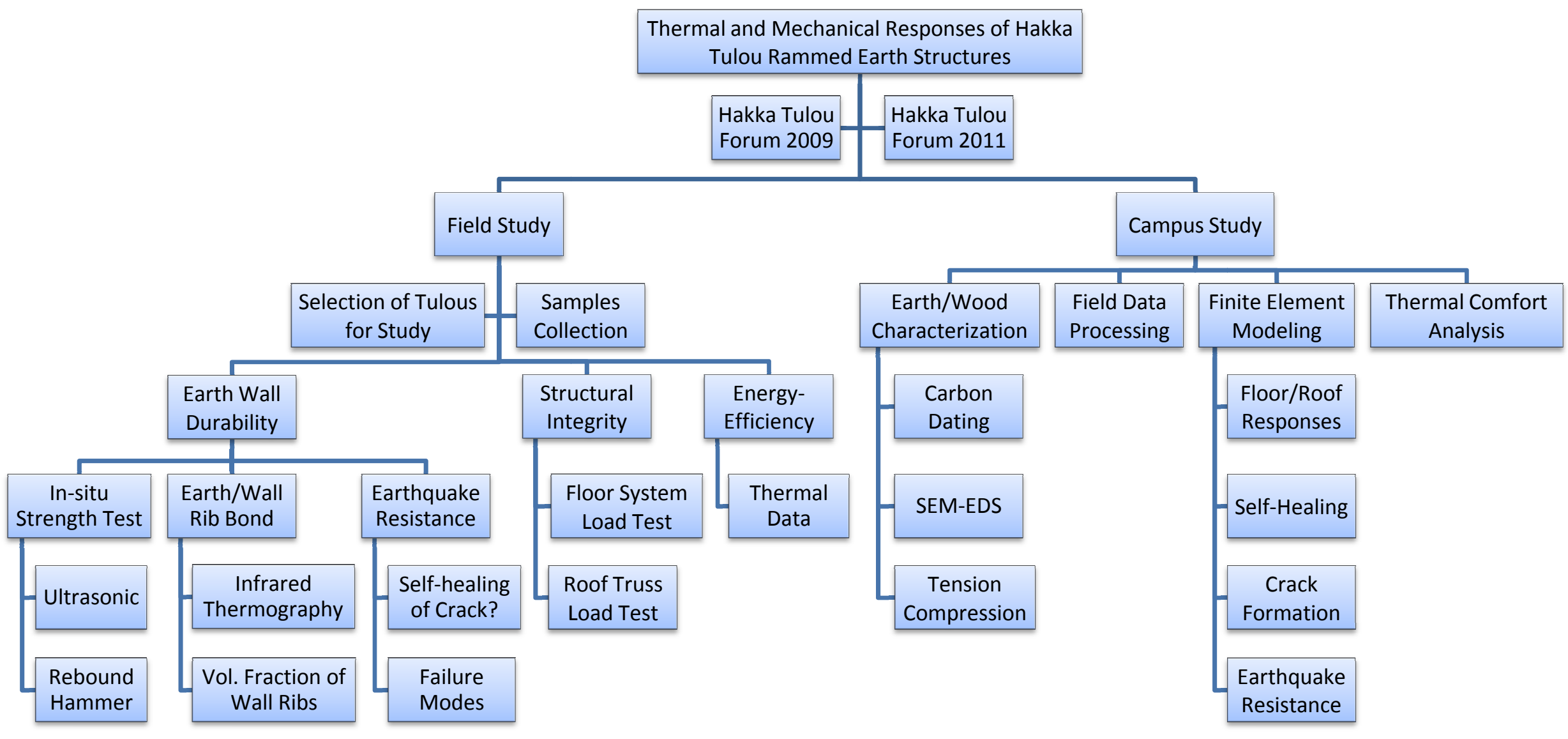

Figure 1-Scope of Work 


\subsection{Organization of Thesis}

After Chapter 1's introductory sections, Chapter 2 provides a literature review on published material pertaining to both Hakka Tulous and rammed earth. Subjects that will be covered in this section include, a general overview of Hakka Tulous, the construction process of rammed earth and the Hakka Tulous, as well as an overview on current guideline/design codes and analysis procedures for rammed earth.

Chapter 3 provides information on the analysis of Hakka Tulous using field testing and laboratory testing. This chapter is broken down into sections that cover carbon dating, SEM images, and EDS data, material testing on samples acquired from Tulou sites, load testing on both the wooden roof truss and floor system, and nondestructive testing that has been performed at several Tulou locations.

Chapter 4 focuses on computer modeling of Hakka Tulous, including review of the legitimacy of the self healing crack that has reportedly occurred at the Huanji Tulou following a strong earthquake. This chapter performs finite element modeling to create the crack as well as to show how a possible scenario of self healing would possibly look like. Also investigated are the Hakka Tulous' resistance to extreme lateral loads that have occurred from earthquakes. Finite element modeling is used to explain how the high material mass of rammed earth is able to successfully dampen the effects of such lateral loads. 
Chapter 5 covers thermal comfort that Hakka Tulous offer their residents. This chapter reviews thermal data as well as analyzes how the correct application of thermal mass has provided the Hakka Tulous with such thermal comfort, followed by Chapter 6 with discussions, conclusions, and recommendations. 


\section{CHAPTER 2 LITERATURE REVIEW}

Hakka Tulou structures are rammed earth dwellings that can be found in the southern and western parts of the Fujian Province in China. The name Hakka refers to the local people that have lived in these parts of the Fujian Province for hundreds of years. The buildings were constructed from the $10^{\text {th }}$ to even as late as the $20^{\text {th }}$ centuries and as of July $7^{\text {th }}, 2008$ have been listed as a UNESCO World Heritage Site (Wang 2008). The Tulous represent an independent culture within the Fujian Province of China. A single Tulou can be considered itself as a village due to the fact that a Tulou can have schools, housing, and shrines within its rammed earth walls. Typically, a village is made up of two or three Tulou structures, however larger villages are also typical as can be found like in Figure 2 below. Tulou structures are built in harmony with nature

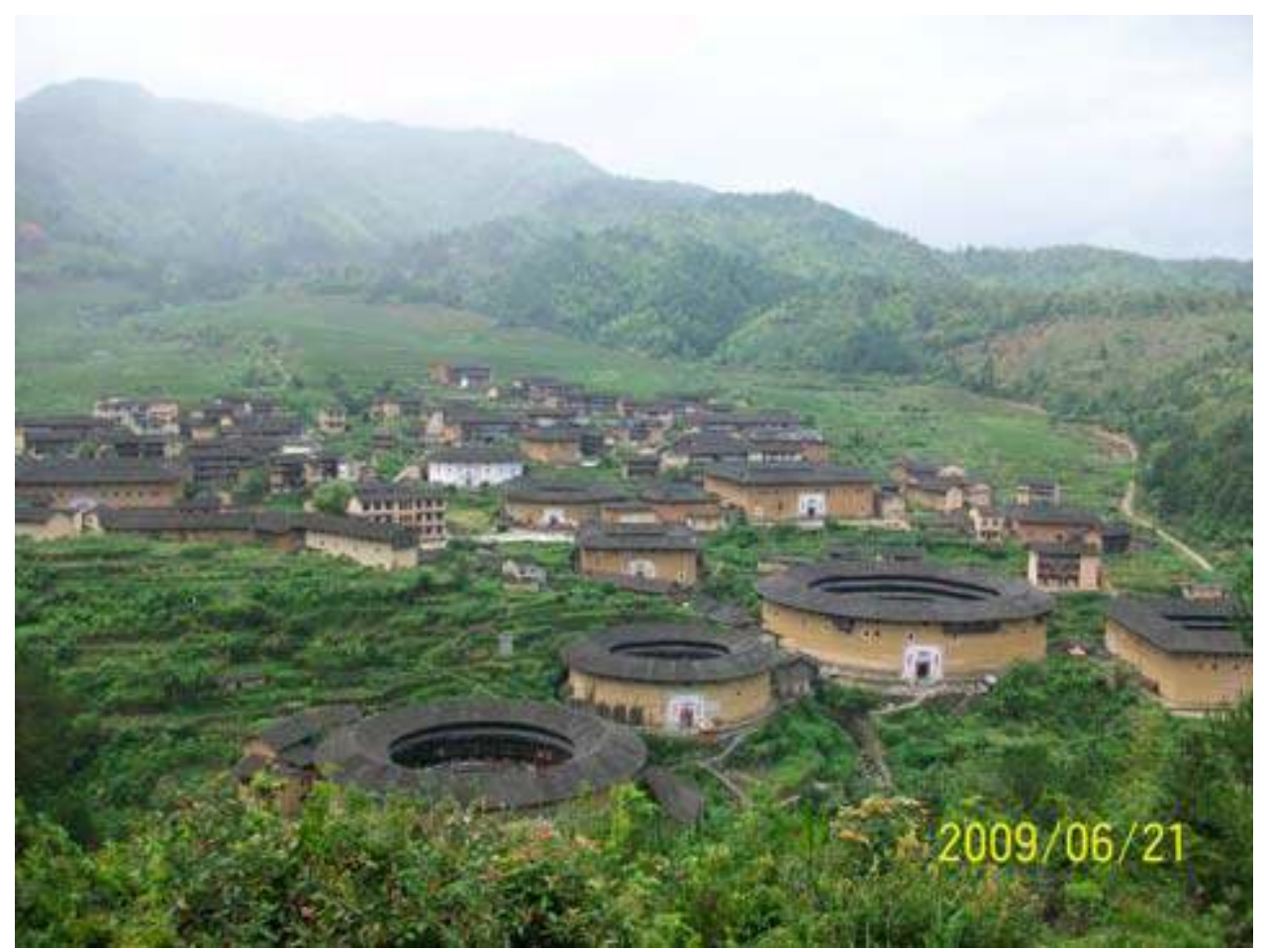

Figure 2-Hakka Tulou Village 
facing the south, as is common in Chinese tradition. The structures are always near roads or rivers and are commonly built against hills or mountains in order to create a natural scenic harmony along with providing resistance to strong winds (Encyclopedia 2008).

Hakka Tulous were constructed of varying materials that were almost always domestic to the respective region of that Tulou. Tulous were built from stones that would come from local river beds, clay, mud from rice fields, wood, and/or sanhetu (Zimmerman et al. 2005). Sanhetu is a composite material made up of earth, sand, and lime and is more commonly referred to as rammed earth. Some articles indicate that soupy glutinous rice and brown sugar are added in some wall systems (Yang 2010), however after talking with several Tulou owners it was found that they do not agree with these findings (Liang and Hota 2010). Our EDS spectrums were also not able to verify the existence of soupy glutinous rice and brown sugar. The larger scale Tulous were most typically built using this composite mix, however some smaller Tulous have been found to be constructed entirely of cut granite (Zimmerman et al. 2005). Most of the Tulous have at least 1,000 square meters in area whereas the bigger Tulous have over 5,000 square meters in useable area (UNESCO 2008). Hakka Tulous can be found in rectangular or circular shape with the latter being more common amongst the younger Tulou structures. The change from square to circular Tulous as well as larger foundations occurred simultaneously with the social and economical development of the Fujian Province (Wang 2008). The circular Tulous can range in size from 17 to 91 meters in outer diameter, with the largest Tulou having a wall thickness of 2.4 meters (Aaberg-Jorgensen 2003). Jens Aaberg-Jorgenson, a Danish architect who has studied the Chinese architecture since 1984, estimates that there are several thousand Tulous in existence, of these around one thousand are circular. Fuping Wang pins the number of Tulous in the two main counties in the Fujian Province, Yongding and Nanjing, at around 35,000 
(Wang 2008). The Tulous can house anywhere from 5 to 600 people, with the largest Tulou having over 250 residential rooms. The construction of the Hakka Tulous is very unique as can be seen by the interior picture of a circular Tulou in Figure 3.

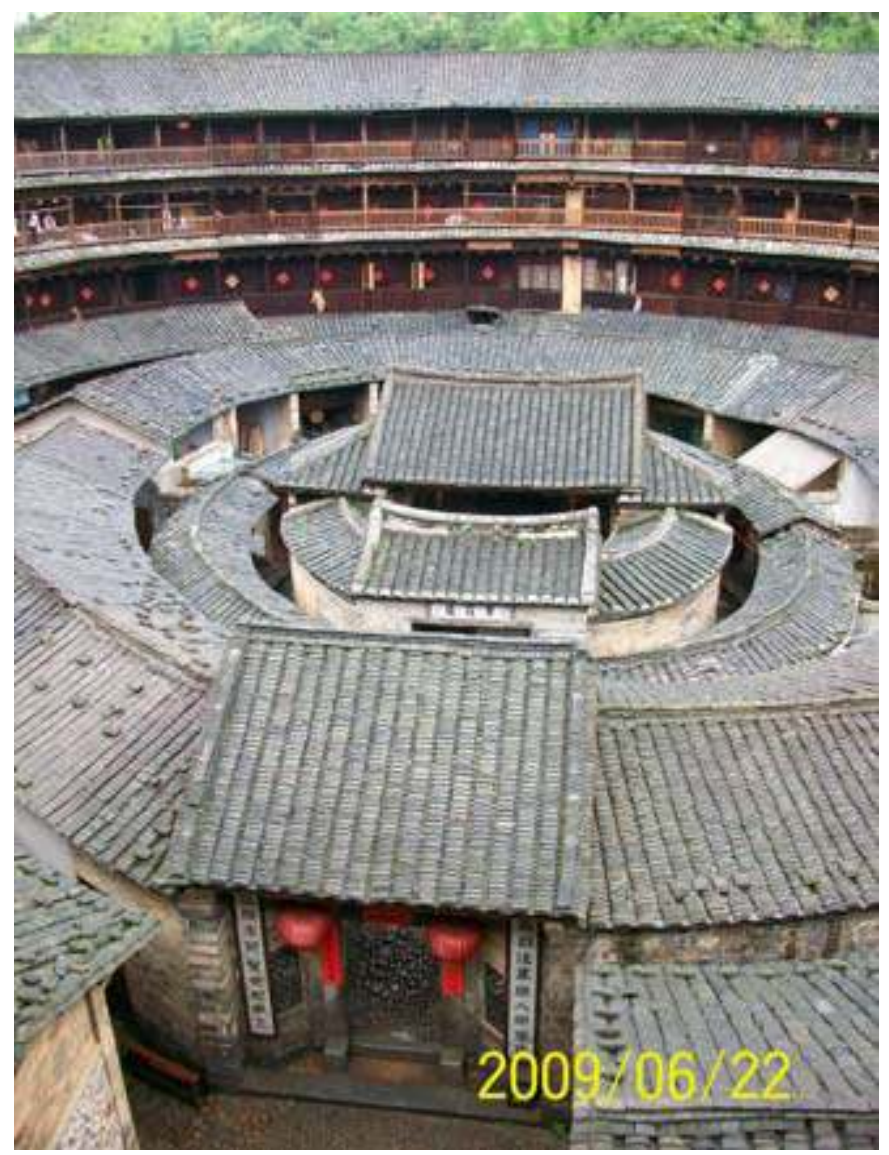

Figure 3-Interior of Chengqi Tulou

Every Tulou is built around an ancestral shrine that is home to Chinese superstitions. This ancestral shrine, which can be seen in the center of the courtyard in Figure 3, is of great importance to the local culture and tradition of the Hakka people. Each Tulou has one main entrance into the structure which leads directly into the courtyard of the building. From this courtyard, one is better able to see the wooden interior structure of the Tulou. Aaberg-Jorgenson (2003) has also created a cross section of a typical circular Tulou that can be seen in Figure 4. 


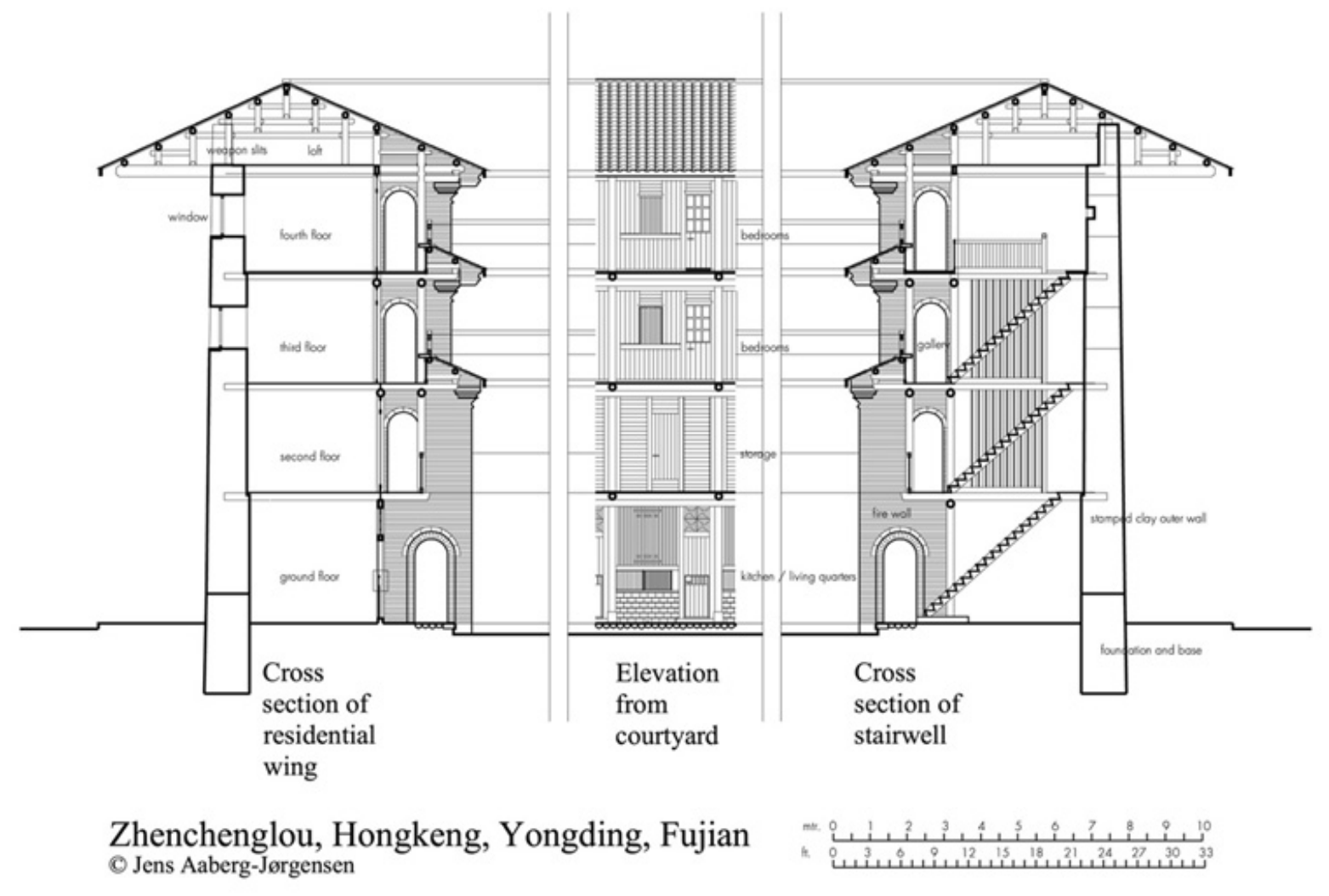

Figure 4-Cross Section of a Typical Tulou (Aaberg-Jorgensen 2003)

This cross section shows the heavy use of wood throughout the structure. Although the outside of the Tulou may be dominated by the thick rammed earth walls, the interior is solely wooden construction. As can be seen in Figure 4, the roof structure, floor system, as well as the columns that support half of the load experienced on the roof as well as the floor system, are all constructed of wood. The wooden system is a unique portion of Tulou construction as living quarters are created solely from this wood network, however it is the rammed earth portion of the Hakka Tulous that make the structure especially unique. As will be later analyzed during this report, it is known that the rammed earth walls provide structural stability along with thermal 
comfort to the inhabitants of the Tulou. The construction of the rammed earth walls is a laborious process that requires a mould in which the sanhetu will be placed. Bamboo and/or wooden sticks/chips are also added to the mix to act as reinforcement. From this step, the mixture is rammed together using either stones or other tools, as can be seen in Figure 5.

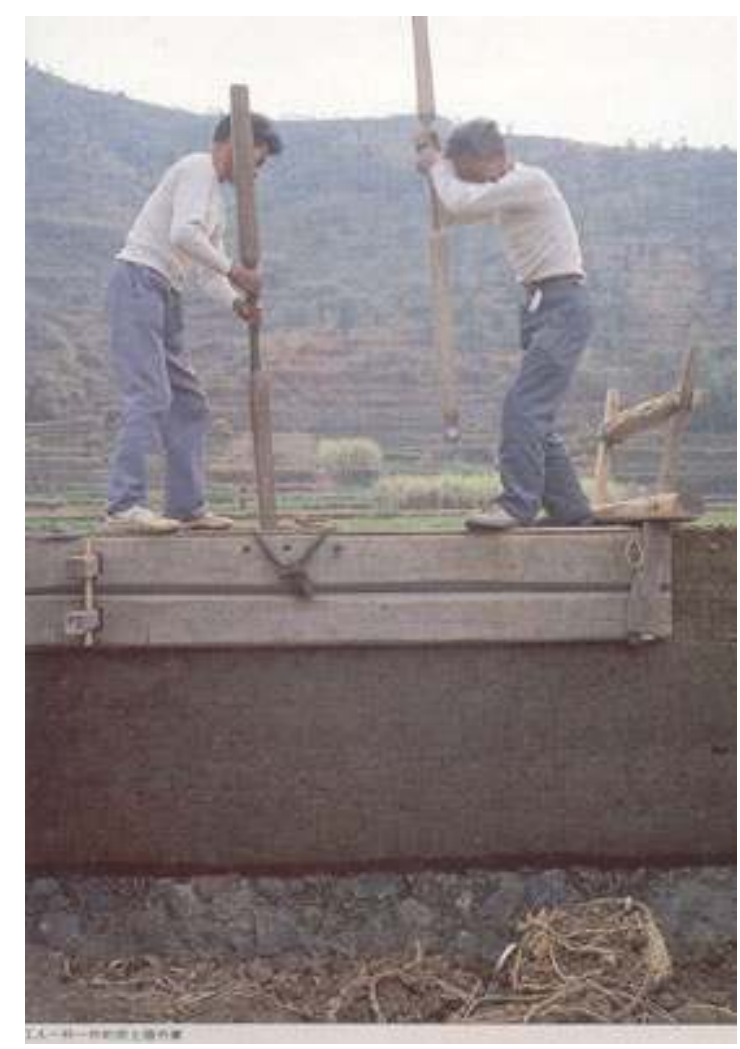

Figure 5-Rammed Earth Process (Aaberg-Jorgensen 2003)

The rammed earth layer is then allowed to fully dry to reach full strength before another layer is applied on top. This process is repeated numerous times for each level of the Tulou, with each level leaning slightly inward and the wall thickness slightly decreasing as one goes up (Aaberg-Jorgensen 2003). It is also important to note that before the rammed earth process begins, a foundation is created from stones found in local rivers. This foundation is followed by a base no higher than 1 meter which is also created of stones along with a mixture of clay. The 
foundation's only purpose is to distribute the weight of the Tulou, as this region does not experience frost (Aaberg-Jorgensen 2003).

The Hakka Tulous are only one historic example out of many, including the Great Wall of China, that displays the successful application of rammed earth as a core building material. Rammed earth has once again become more popular in recent years as it is an ecologically friendly and sustainable building material. There are currently only a few guidelines available in the construction of rammed earth structures. The Australian government is one of a few organizations that has pushed for national rammed earth building codes whereas in the United States effort for emphasis on such codes has stalled (Tibbets 1998). Currently the most well known rammed earth code in the US is the New Mexico Earthen Building Code. This code allows for basic rammed earth construction of buildings no taller than two stories tall and is basic at best (New Mexico 2003). ASTM has only recently released a guide for earthen wall building systems, ASTM E2392/E2392M - 10, in which ASTM confirms that earth construction is experiencing a revival in the industrial world. The publication however is strictly meant as a guide and thus is very general with recommendations such as: test methods of earth materials can be supplemented with other standard material tests for probable strength values, as well as, construction methods should follow traditional construction methods that are proven successful for at least three generations. As guidelines for rammed earth codes are difficult to find, guidelines for analysis of such structures is even rarer as interest for such structures has only recently spiked (ASTM 2010). One recent study performed by Jacquin et al. (2006) labeled, Analysis of Historic Rammed Earth Construction, has created rammed earth samples and tested them in compression order to compare failure modes to that of a finite element model. In the study P.A. Jacquin et al., have found that the Mohr-Coulomb failure criterion works fairly well 
in a finite element model when compared to actual conditions (Jacquin et al. 2006). Finite element modeling in this study however, has found that the Rankine Stress Theory has performed well when analyzing structures in a more global sense. More details of the finite element modeling performed in this study are provided in later chapters.

After reviewing literature on the topic of rammed earth structures such as the Hakka Tulous, it is found that there are limited construction guidelines available for rammed earth. These guidelines, which are not always in code form, are being further developed along with the analytical methods for rammed earth structures. Due to rammed earth experiencing recent interest and that studies are currently limited, this study hopes to provide a preliminary analysis into the rammed earth structure of the Hakka Tulou using both field testing and finite element modeling to further validate findings. 


\section{CHAPTER 3 MATERIAL CHARACTERIZATION AND STRUCTURAL EVALUATION OF HISTORIC TULOU STRUCTURES}

\subsection{Introduction}

It is known that the Hakka Tulous of the Fujian province have survived anywhere from a few hundred years to over one thousand years. To study the structural integrity of the rammed earth structures, SEM and EDS analysis was performed on rammed earth samples from several sites and material tests were performed on rammed earth, reinforcing wall ribs, and structural wood samples. Samples for these tests were collected from five different Tulous which can be seen below in Table 1.

Table 1-Hakka Tulou Buildings Studied

\begin{tabular}{|c|c|c|c|c|}
\hline Trite of Tulou & Slupe & Number of Stody & Agt & Scatus \\
\hline Faxing Tulou & Square & 2 stary. & ores 1200 years & partially in service \\
\hline Wogra Tulou & Sqgate & 4 stary & over 500 yexs: & partially in service \\
\hline Cbengei Tubu & Round & 4 stacy & over 300 years & in service \\
\hline Hosapi Tuloi & Flound & 4 stary & over 300 yeurs & in service \\
\hline Zhescheng Tulon & Ronand & 4 stary & about 100 peacs & in service \\
\hline
\end{tabular}

Data from these tests allow us to understand the strength of the materials as well as give us the correct parameters required for finite element modeling of the structures. Non destructive testing was also performed on the Hakka Tulous. NDT provides us with a quality control that can comparatively tell us which material is stronger or in better condition. Lastly, load testing 
was performed on the wooden roof truss and floor system in order to see how the system reacted to the loading and whether it is structurally sound.

\subsection{Validating Age of Samples}

To validate the ages of the Tulou buildings and material samples, initially provided to us by local records and locals of the respective Tulou regions, a material sample was sent for carbon dating. A wooden sample from a roof truss beam in the Chengqi Tulou, estimated by records to be built from 1662-1709, was sent to the NSF Arizona AMS Facility at the University of Arizona for carbon dating. The results of the carbon dating test can be seen below in Figure 6 .

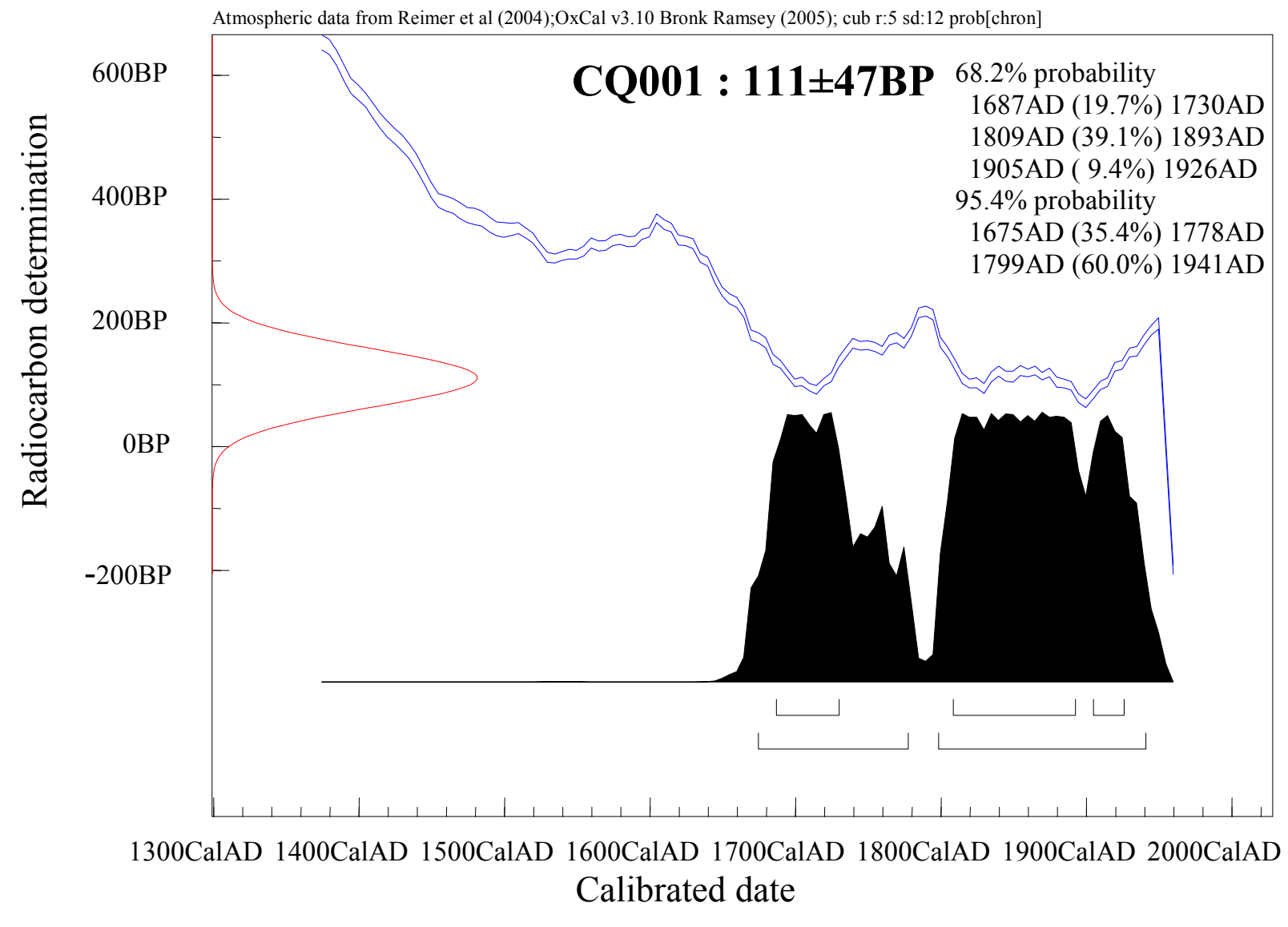

Figure 6-Carbon Dating Results of Chengqi Tulou 
As can be seen by the carbon dating results in Figure 6, there is a $95.4 \%$ probability that the sample is aged between the two calendar age ranges 1675AD-1778AD and 1799AD1941AD. These results are consistent with the completion date of 1709 that is associated with the Chengqi Tulou. It is reasonable to assume that because the age of the sample from the Chengqi Tulou has been correctly dated and verified, the records for other Tulou building ages are also correct and thus used in this study.

\subsection{Scanning Electron Microscopy and Energy-dispersive X-ray Spectroscopy Analysis of Tulou Rammed Earth Samples}

In order to examine the composition of the rammed earth samples from various Hakka Tulous both scanning electron microscopy, SEM, and Energy-dispersive X-ray Spectroscopy, EDS, were used. The scanning electron microscopy provides images of the earth samples at a micro scale allowing one to compare surface images of rammed earth samples from different Tulous. In the figures below one can see a set of two images for each Tulou in a scale of both $10.0 \mathrm{um}$ and $1.00 \mathrm{~mm}$. The SEM images are shown in Figures 7-11 in order of oldest to youngest Tulou with the Fuxing Tulou being 1,240 years old, Wuyun Tulou 500 years old, Huanji and Chengqi 300 years old, and the Zhencheng Tulou 100 years old. 


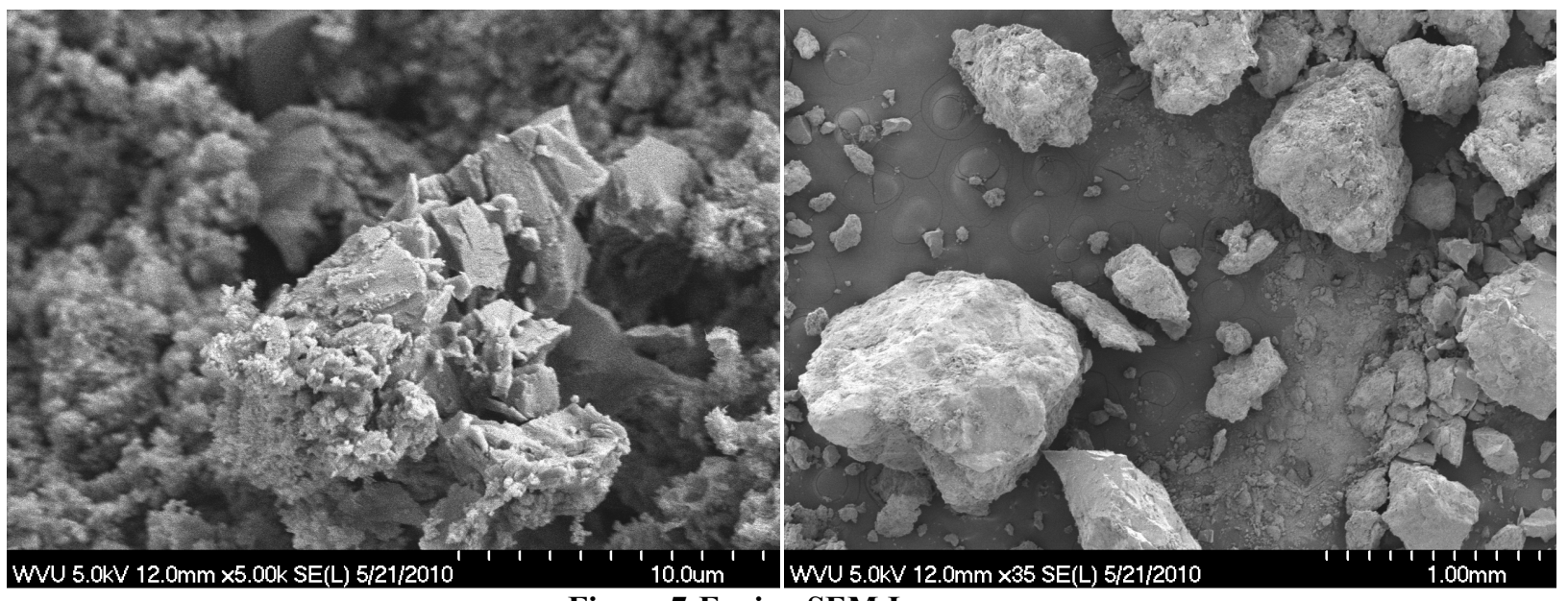

Figure 7-Fuxing SEM Images

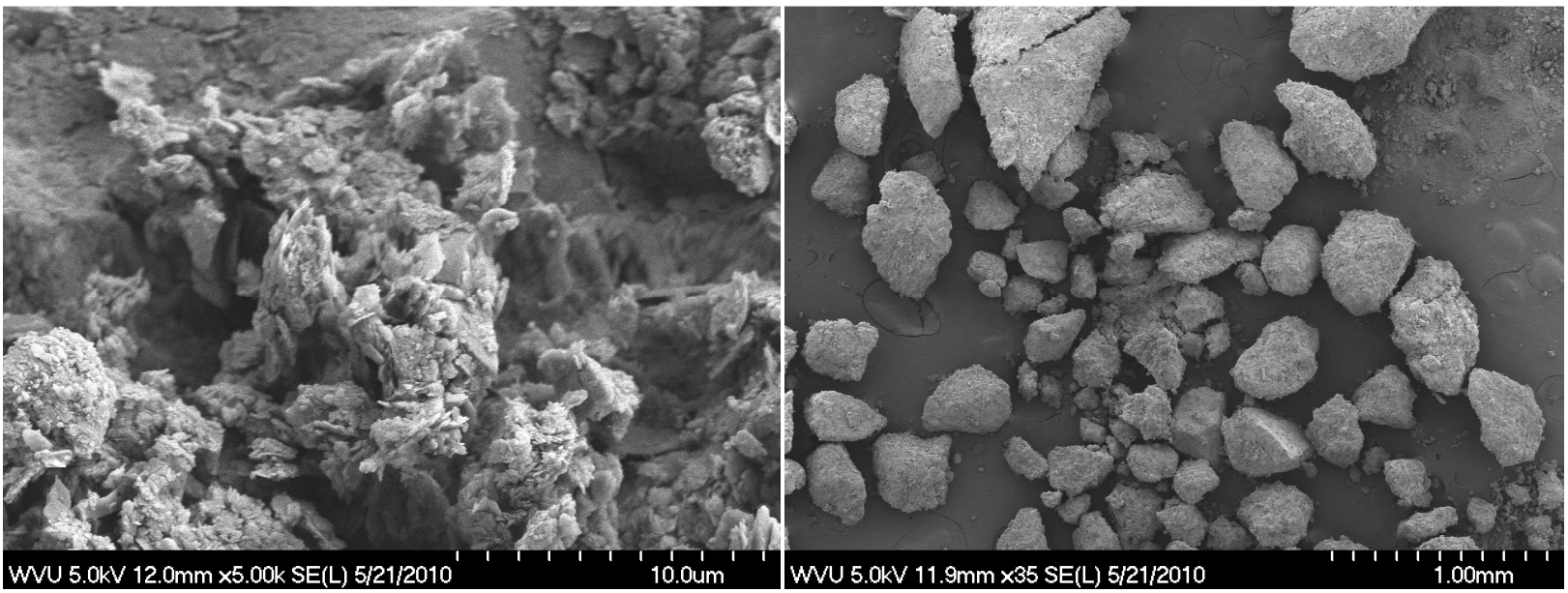

Figure 8-Wuyun SEM Images

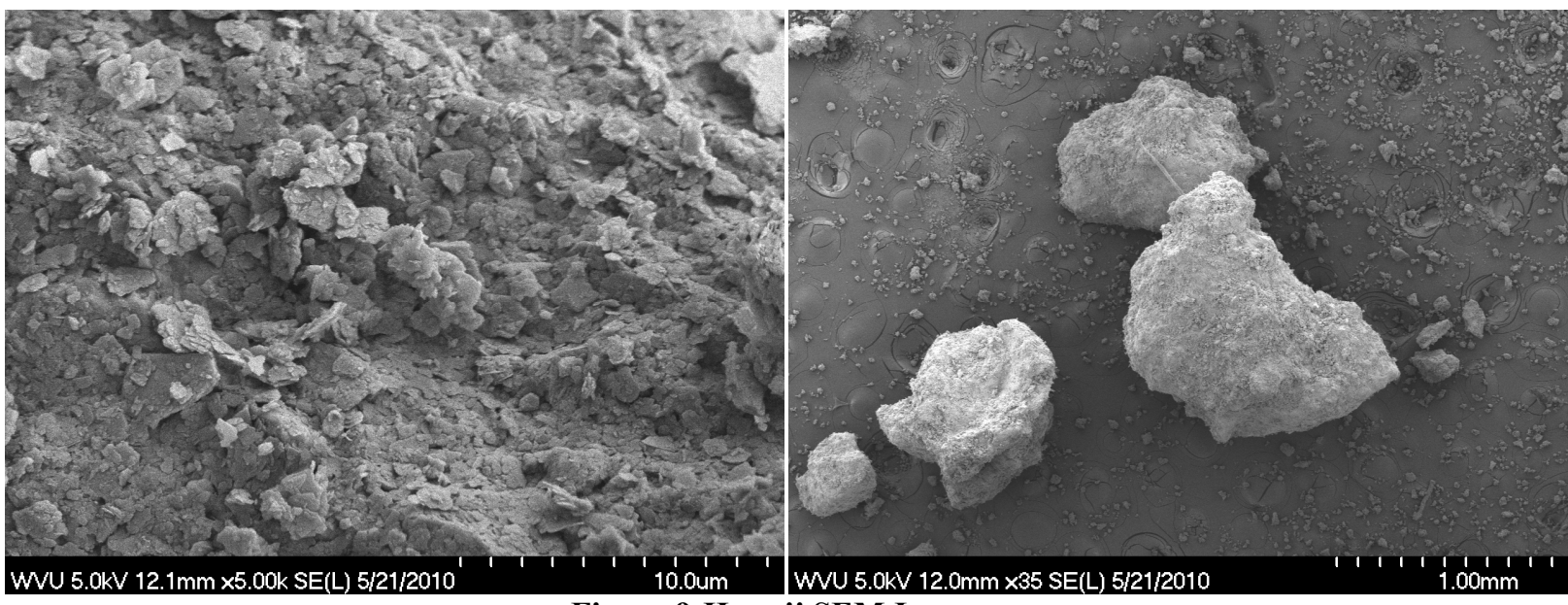

Figure 9-Huanji SEM Images 


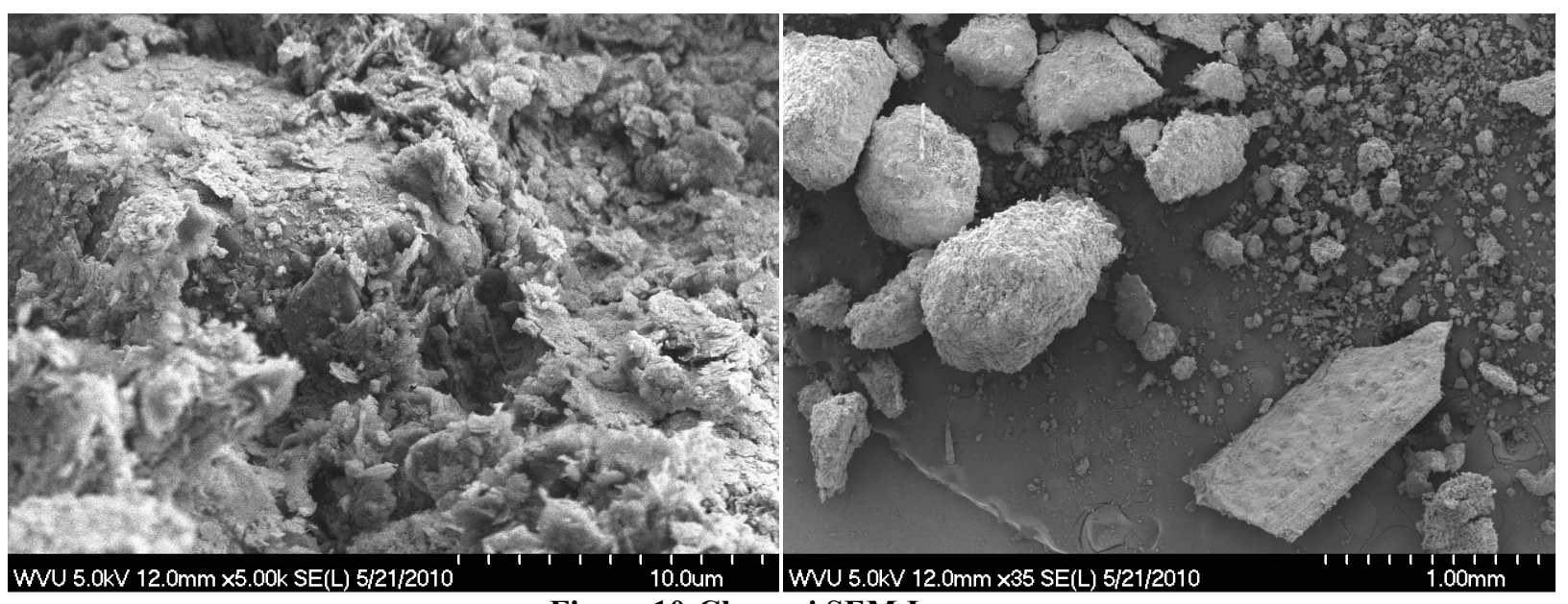

Figure 10-Chengqi SEM Images

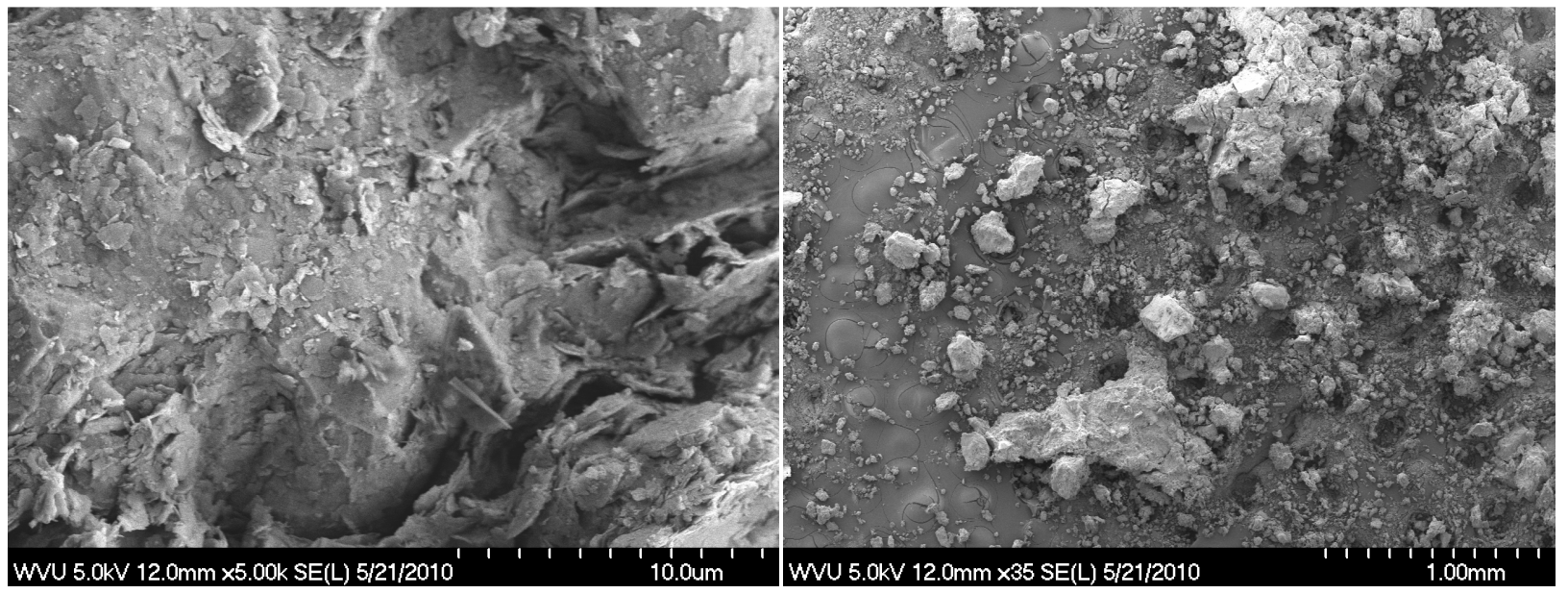

Figure 11-Zhencheng SEM Images

After reviewing the SEM images of the five Tulous it can be seen that the samples all look similar to each other. One detail that can be seen different from other samples is that of the Zhencheng sample at $1 \mathrm{~mm}$. The Zhencheng sample at $1 \mathrm{~mm}$ shows more consistency of the material as there are smaller 'blocks' extruding from the sample. This could be attributed to the fact that the Zhencheng Tulou, the youngest among the buildings at 100 years of age, performs well in nondestructive testing as shown in Section 3.5, NDT, Ultrasonic and Rebound Hammer Tests.

The next analysis performed involved using Energy-dispersive X-ray Spectroscopy or EDS. EDS analysis can explain the chemical composition of a sample by showing the amount of 
existing elements relatively to each other. Figures $12-16$ below show the chemical composition from samples of five Tulous organized from the oldest to youngest Tulou.

C:\{EDS\}Liang\}Fuxing pic 08 spec.spc

Label A: Fuxing pic 08 spec

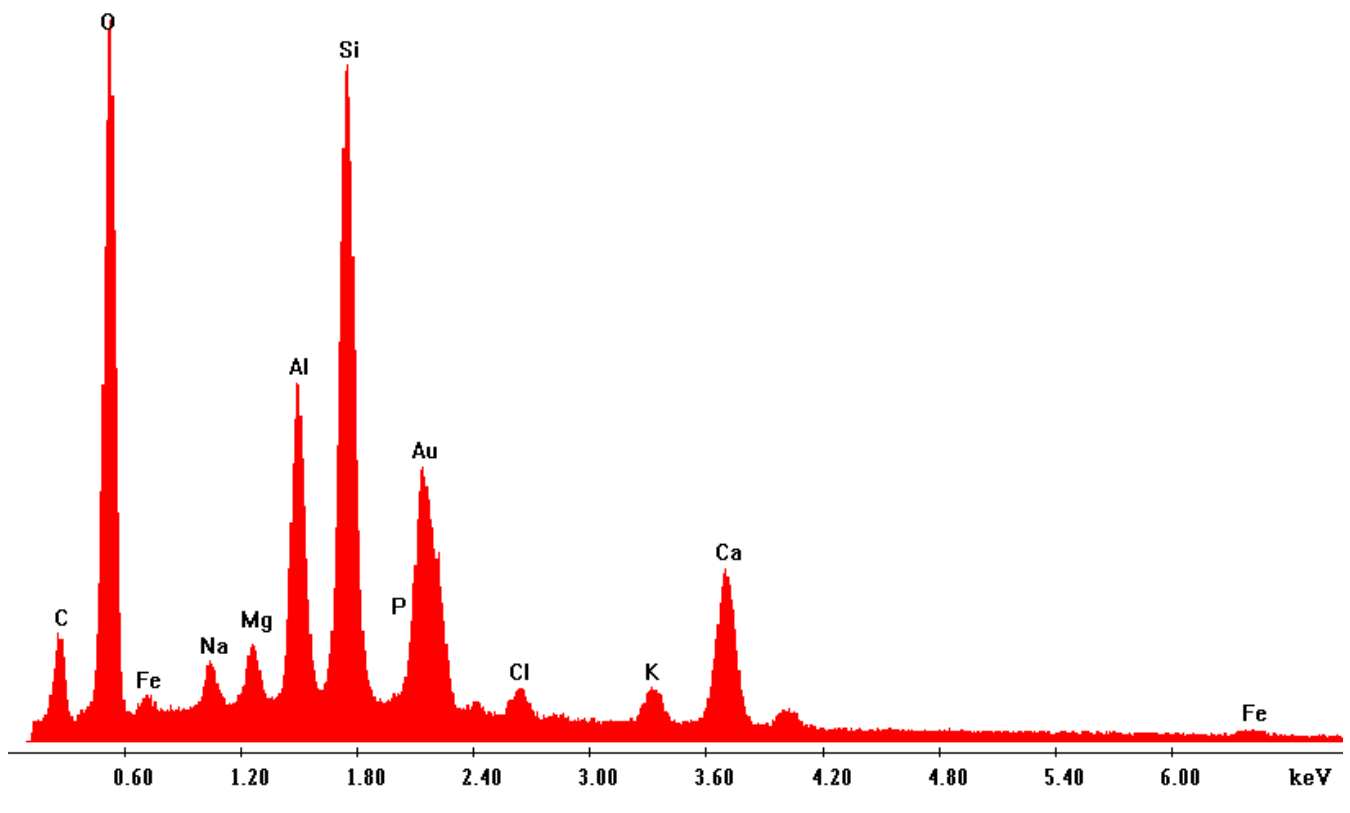

Figure 12-Fuxing EDS Results 


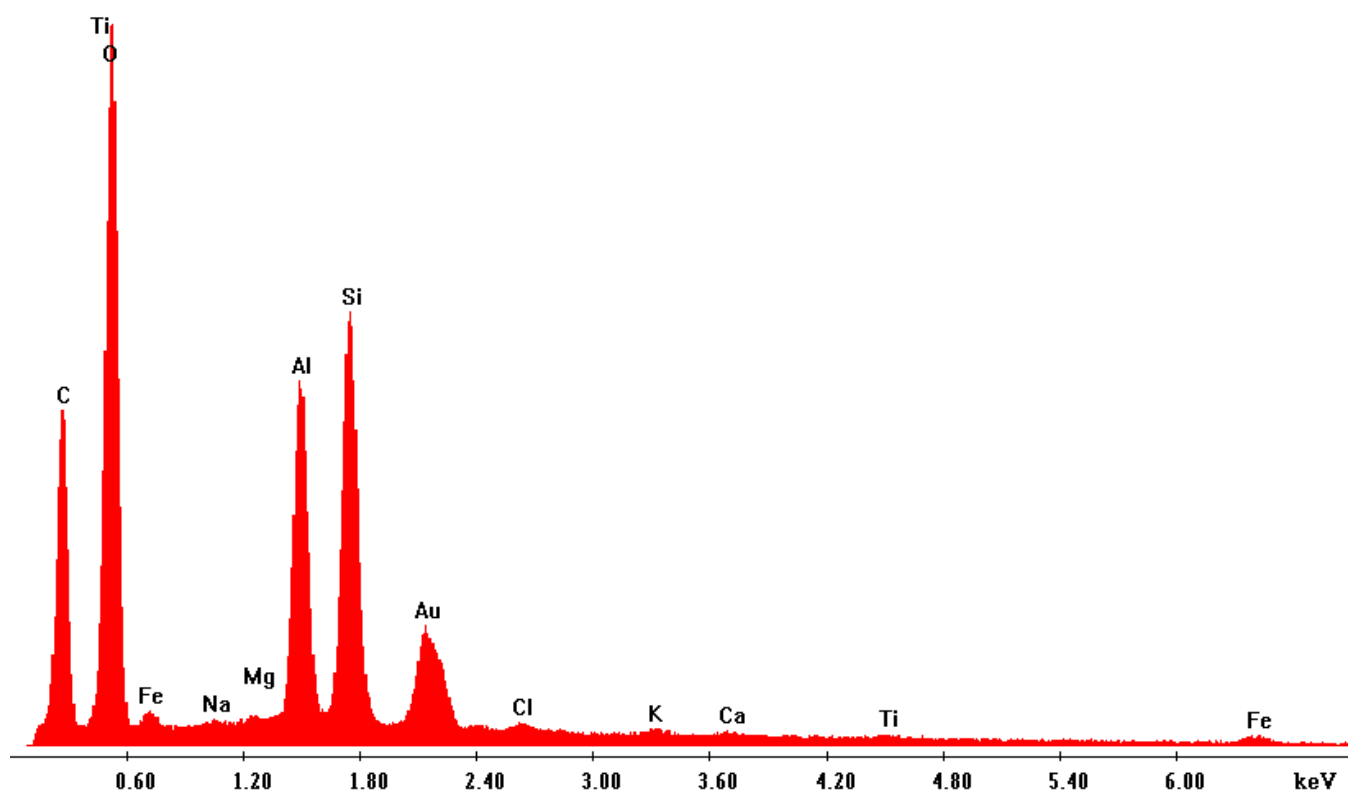

Figure 13-Wuyun EDS Results

C:łEDS|LiangłHuanji pic 05 spec.spc

Label A: Huanji pic 05 spec

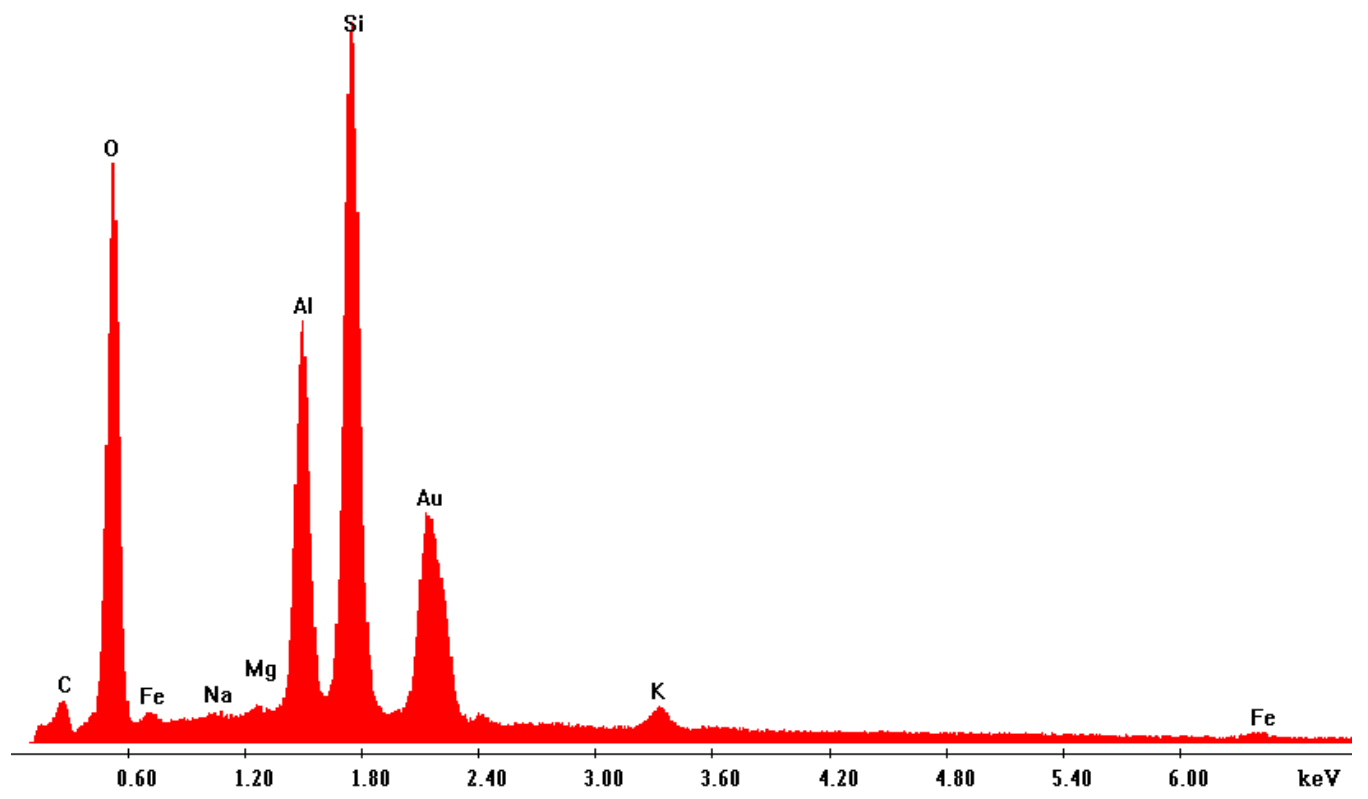

Figure 14-Huanji EDS Results 


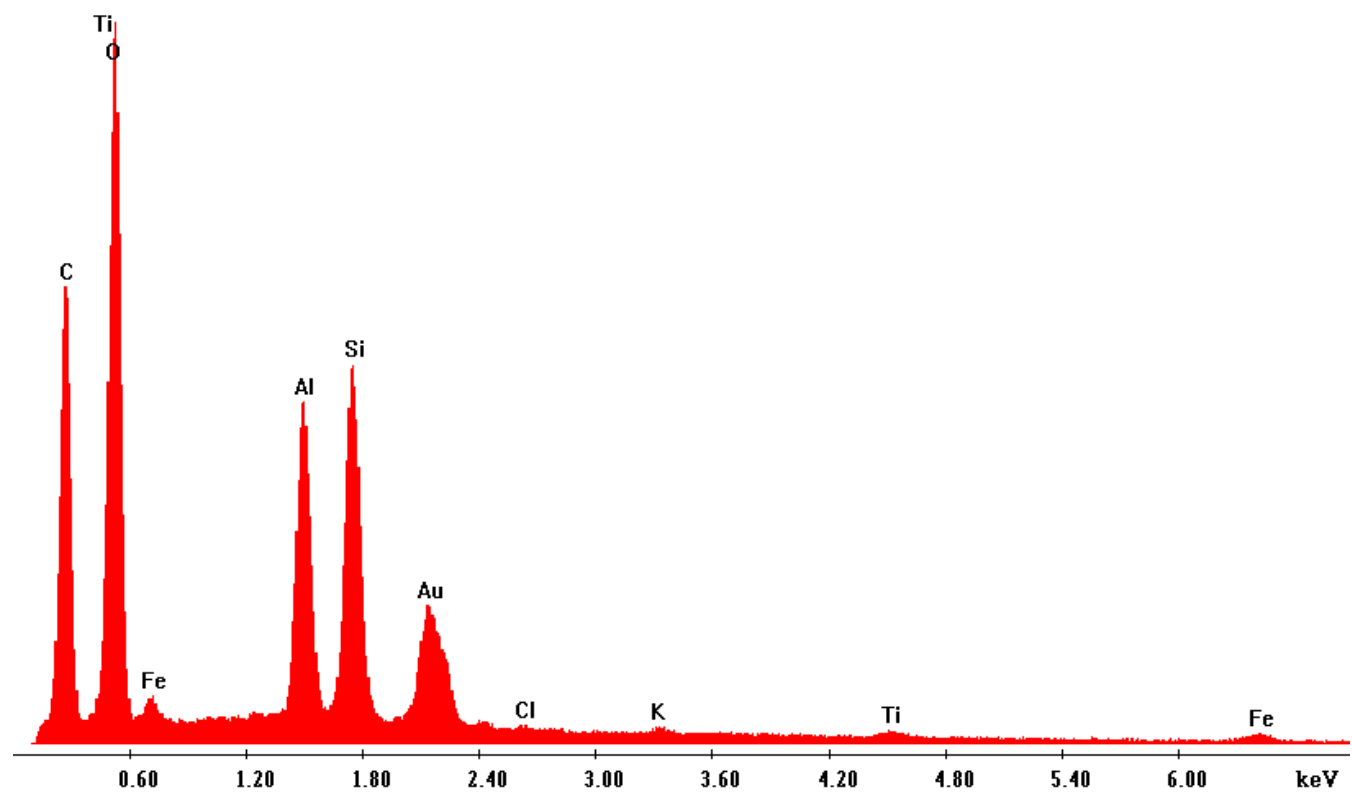

Figure 15-Chengqi EDS Results

C:\{EDSłLLiangZZhen Cheng pic 05 spec.spc

Label A: Zhen Cheng pic 05 spec

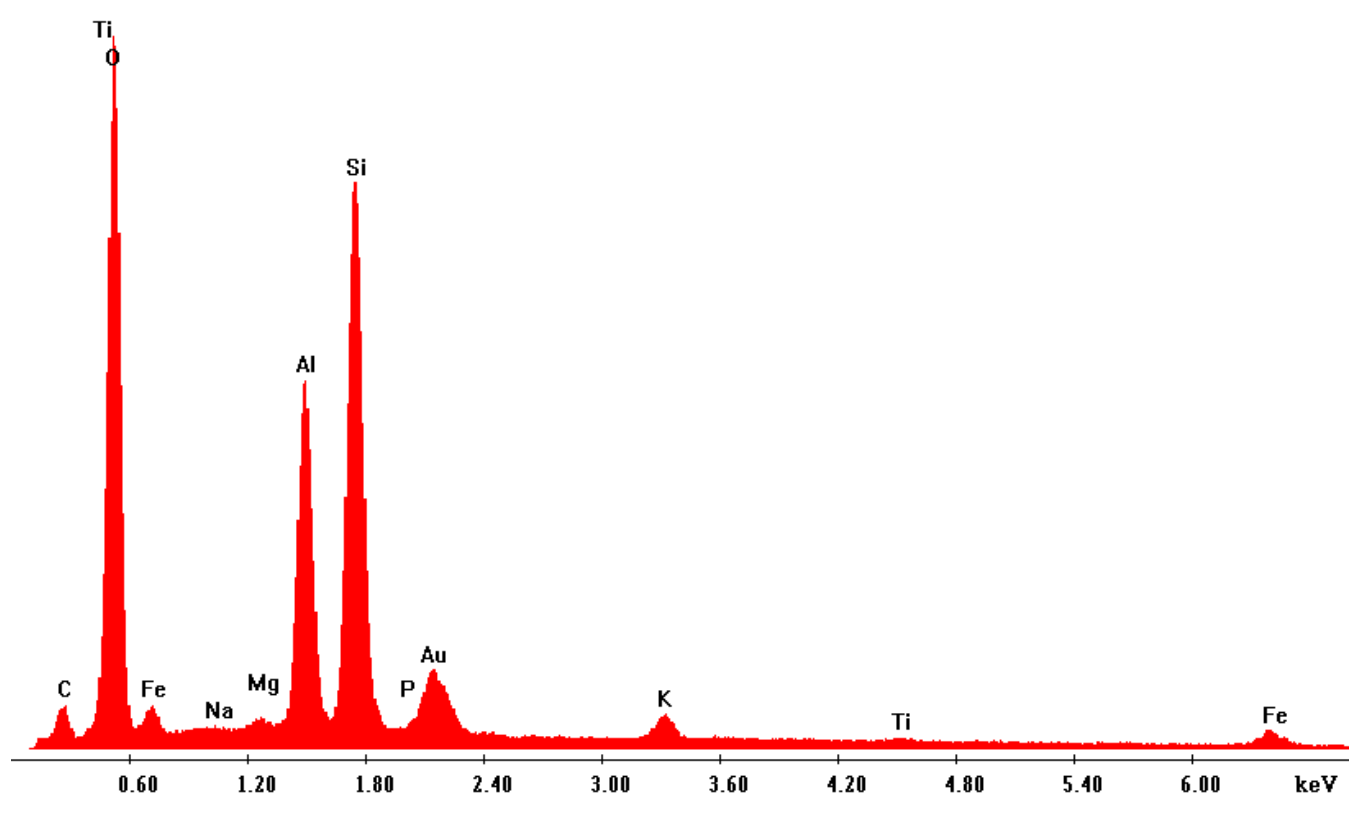

Figure 16-Zhencheng EDS Results 
A summary of the chemical composition of the five Tulou earth samples can be seen below in Table 2.

Table 2-Chemical Compositions of Tulou Earth Samples

\begin{tabular}{|c|c|c|}
\hline Title of Tulou & Dominant Elements & Less Dominant Elements \\
\hline Fuxing Tulou & $\mathrm{O}, \mathrm{Al}, \mathrm{Si}, \mathrm{Ca}$ & $\mathrm{C}, \mathrm{Fe}, \mathrm{Na}, \mathrm{Mg}, \mathrm{P}, \mathrm{Cl}, \mathrm{K}$ \\
\hline Wuryun Tulou & $\mathrm{C}, \mathrm{Ti}, \mathrm{O}, \mathrm{Al}, \mathrm{Si}$ & $\mathrm{Fe}, \mathrm{Na}, \mathrm{Mg}, \mathrm{Cl}, \mathrm{K}, \mathrm{Ca}$ \\
\hline Chengqi Tulou & $\mathrm{C}, \mathrm{Ti}, \mathrm{O}, \mathrm{Al}, \mathrm{Si}$ & $\mathrm{Fe}, \mathrm{Mg}, \mathrm{K}, \mathrm{Cl}$ \\
\hline Huraji Tulou & $\mathrm{O}, \mathrm{Al}, \mathrm{Si}$ & $\mathrm{C}, \mathrm{Fe}, \mathrm{Na}, \mathrm{Mg}, \mathrm{K}$ \\
\hline Zhencheng Tulou & $\mathrm{Ti}, \mathrm{O}, \mathrm{Al}, \mathrm{Si}$ & $\mathrm{C}, \mathrm{Fe}, \mathrm{Na}, \mathrm{Mg}, \mathrm{P}, \mathrm{K}$ \\
\hline
\end{tabular}

From the EDS data one can see that all of the samples from the five different Tulous show an abundance in oxygen, silicon, and aluminum as well as gold. It was noted by the test administrator that gold should be neglected from the results as it is from the sample preparation coating, not from earth samples themselves. Three of the five Tulous, Zhencheng, Chengqi, and Wuyun, show an abundance in titanium and the Chengqi and Wuyun Tulous also show significant amounts of carbon, due to the presence of wood peices. As can be seen from the varying results above, the composition of these samples is unique to what is locally available on site for each of the respective Tulous. For the autogenous healing process discussed later in section 4.3.2, the key ingredient that one is to look for is calcium. Calcium is the key element in lime which is what causes self healing as explained later. The initial theory was that lime must be existent in the rammed earth of the Huanji Tulou in order for the crack of $20 \mathrm{~cm}$ to self heal. Based on the EDS data, no calcium was found in the sample of the Huanji Tulou and so this theory is thrown into question. One variable that could explain the lack of calcium is simply that the sample tested was a small sample with respect to the rest of the structure. There is a possibility that other areas of the rammed earth wall do contain calcium and simply the sample tested did not. Overall, out of the samples tested, only the oldest Tulou, the Fuxing Tulou, displays an abundant amount of calcium. This large amount of calcium in the Fuxing Tulou has 
most likely played a structural role for the Tulou as this Tulou has survived now for over 1,240 years.

\subsection{Material Tests}

In order to analyze and accurately model the Hakka Tulous, an understanding of the strength of materials must be acquired. Samples of materials, such as rammed earth and wooden and bamboo reinforcement that were used in some Tulous rammed earth walls for increased strength, were taken from several of the Tulous that were visited during June 15-July 15, 2009. Samples of the materials are not of ASTM standards in size due to the destructive nature of collecting the samples from the existing historic structures. ASTM suggests that for wood compression tests parallel to the grain samples be $2 \times 2 \times 8$ in in size and that rammed earth tests follow standard construction material tests (ASTM 2010). Cores of the rammed earth walls from the Tulous were not able to be successfully extracted due to the rammed earth becoming brittle under the vibrations caused by the extracting equipment. Instead samples had to be chiseled out of the wall as can be seen in Figure 17 below. 

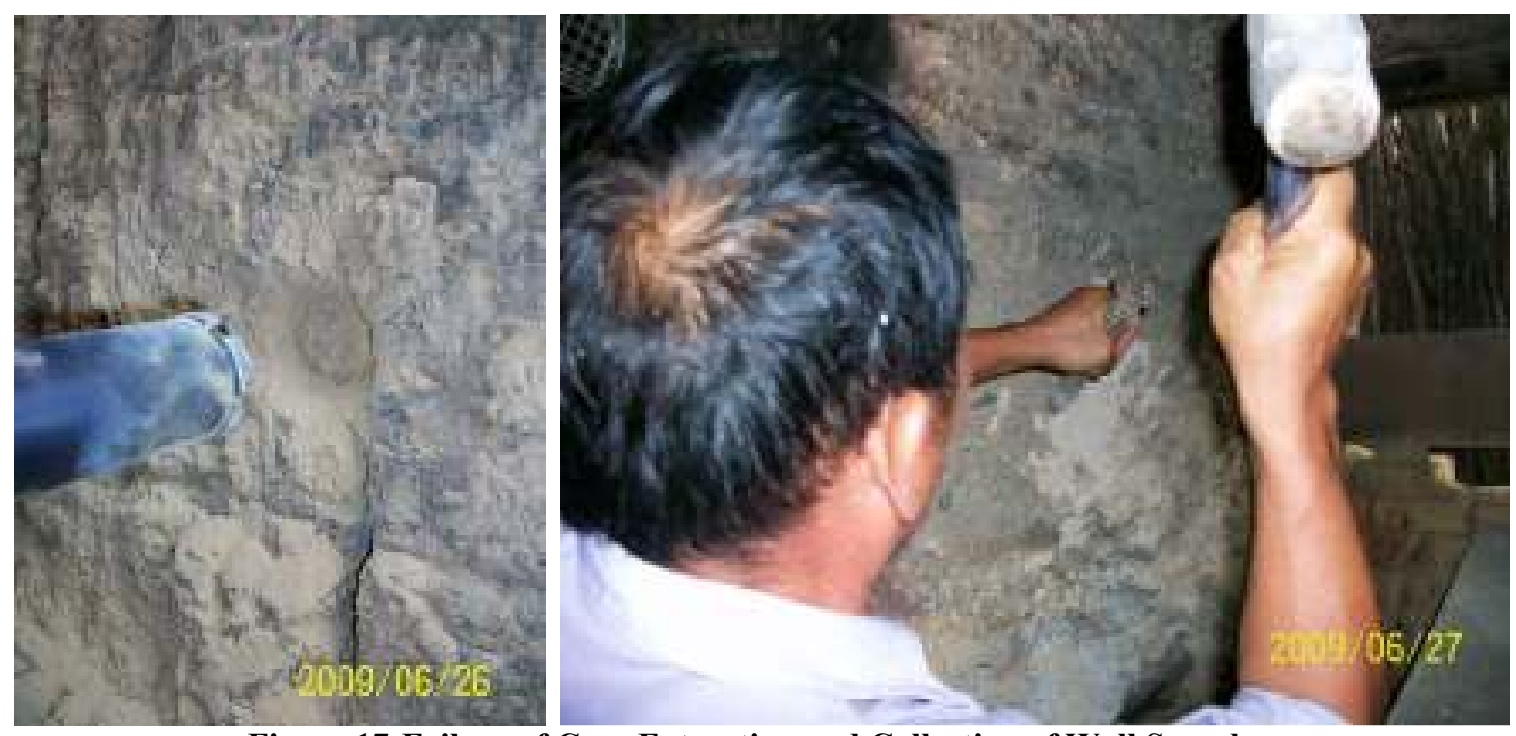

Figure 17-Failure of Core Extraction and Collection of Wall Samples

Strength tests such as tension and compression tests were performed on the acquired samples keeping in mind that the sizes of the samples were not to ASTM standards. Some material tests were performed by the Xiamen University in China and data from the tests were then sent to West Virginia University for further analysis. Other materials tests and data were performed entirely at the Constructed Facilities Center at West Virginia University. From these tests a stress-strain curve was created from which the modulus of elasticity could be determined and used for future modeling purposes. Experimental Error was accounted for in the data that showed such a trend when calculating for the modulus of elasticity. Due to the small size of the samples and defects of materials, such as cracks, and irregular shapes of materials, some data did not represent a typical stress-strain curve of the material and subsequently that data was disregarded. 


\subsubsection{Xiamen University Data}

Material testing and subsequent data from the tests in the following sections were performed and provided by Mr. Li Yanhao from the School of Architecture and Civil Engineering at the Xiamen University (XMU) in China.

\subsubsection{Earth Compression Test}

Rammed earth samples that came from the main wall structure of the Tulous were extracted and tested from three locations, Fuxing Tulou, Wuyun Tulou, and Zhencheng Tulou. The Fuxing Tulou is the oldest of the Tulous that were visited at an approximate age of 1,240 years. The structure is rectangular in shape which is typical of the older Tulous in the region. The Wuyun Tulou is also a square Tulou with an approximate age of 500 years and the Zhencheng Tulou is circular in shape and the youngest of the all the Tulous visited at 100 years old. A failed earth sample from a compression test can be seen in Figure 18 below. 


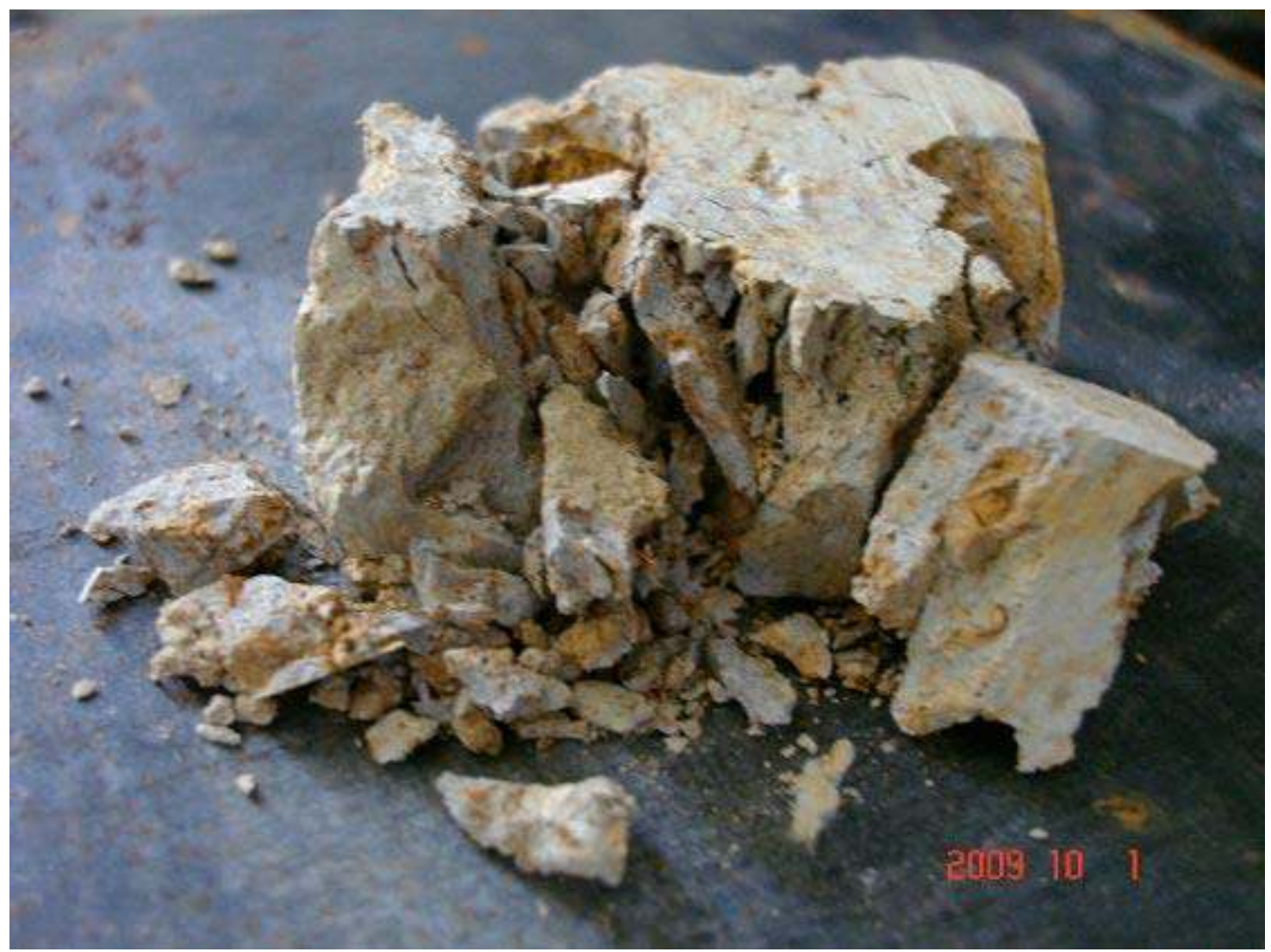

Figure 18-Failed Earth Samples

\subsection{Fuxing Tulou}

As seen in Figure 19 below, only one sample yielded good results from testing which means that a modulus of elasticity value could only be extrapolated from this single data set. From Figure 19, the modulus of elasticity for this rammed earth sample is calculated as being $6,318 \mathrm{psi}$ and the ultimate strength for this sample is found to be $282 \mathrm{psi}$. 


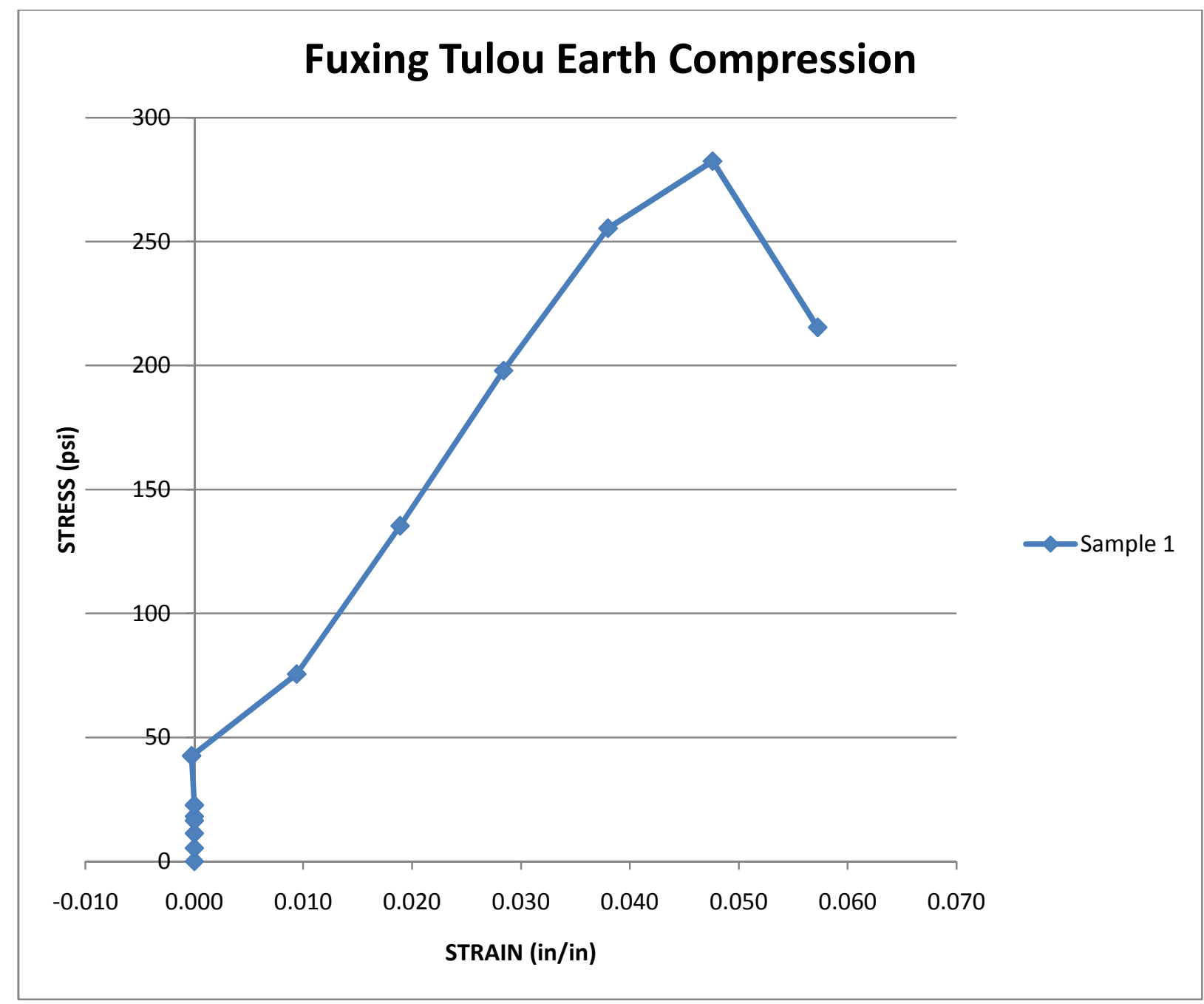

Figure 19-Fuxing Tulou Earth Stress/Strain Curve, XMU

\subsection{Wuyun Tulou}

As seen in Figure 20 below, two test samples gave valid results which means that a modulus of elasticity value was averaged from two data sets. From Figure 20, the average modulus of elasticity, for the rammed earth samples, is calculated as being 1,706 psi and the average ultimate strength is found to be $133 \mathrm{psi}$. The modulus of elasticity for each sample was calculated from the initial point of loading to the first perceived failure, for example, in sample one only the first four points were considered for the modulus of elasticity. 


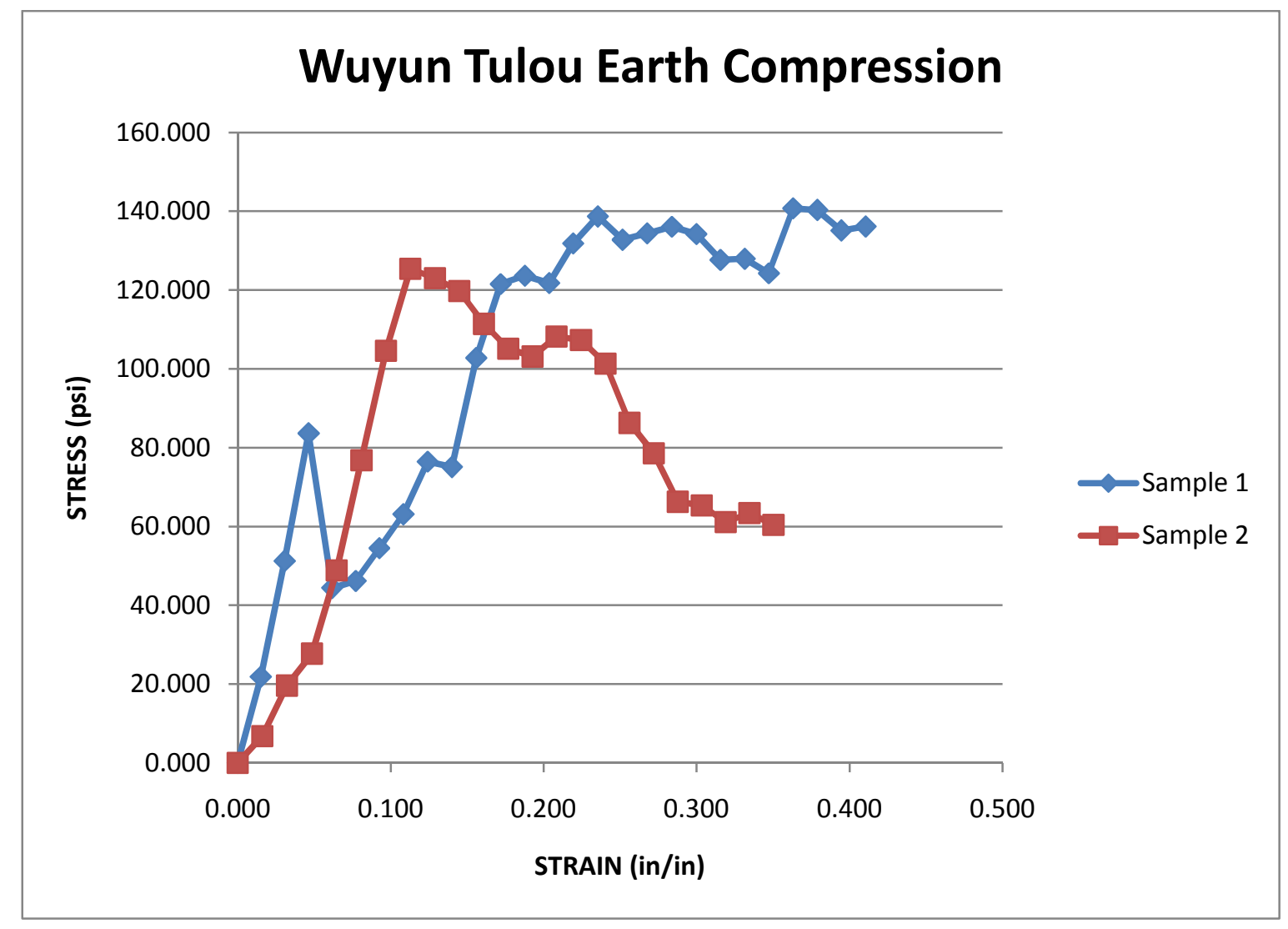

Figure 20-Wuyun Tulou Earth Stress/Strain Curve, XMU

\subsection{Zhencheng Tulou}

As seen in Figure 21 below, three samples gave valid results. The average modulus of elasticity for this rammed earth is calculated as being 3,598 psi and the average ultimate strength is found to be $196 \mathrm{psi}$. 


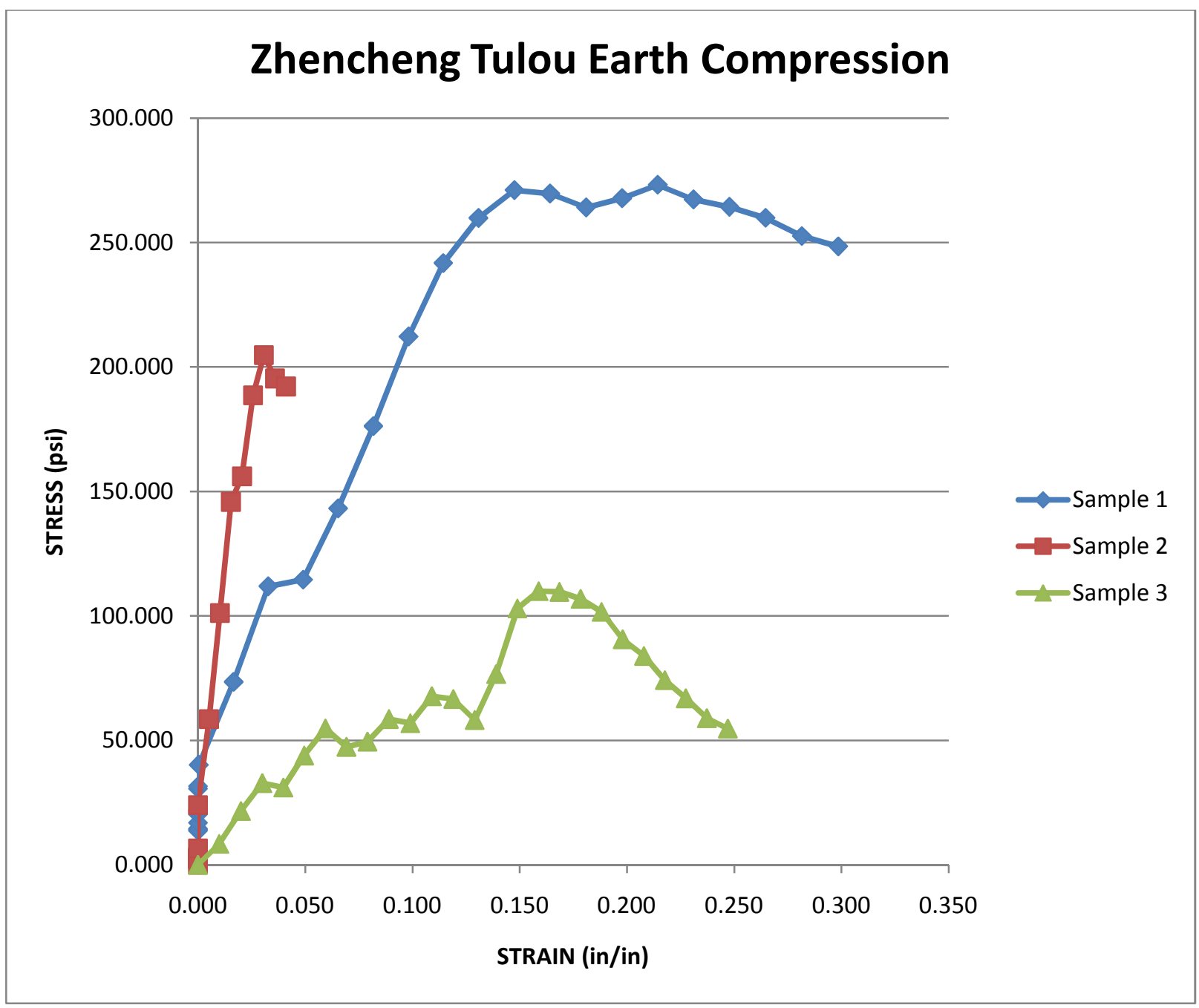

Figure 21-Zhencheng Tulou Earth Stress/Strain Curve, XMU

\subsubsection{Wood Compression Test}

Wood samples that can be seen in Figure 22 below, were acquired from protruding 'ribs' as seen in Figure 23, and were tested under compression. The wooden wall ribs tested by the Xiamen University came from the Chengqi Tulou. The wooden ribs act as reinforcement for the rammed earth walls and increase strength of the structure in order to better withstand loads from high winds and earthquakes. 


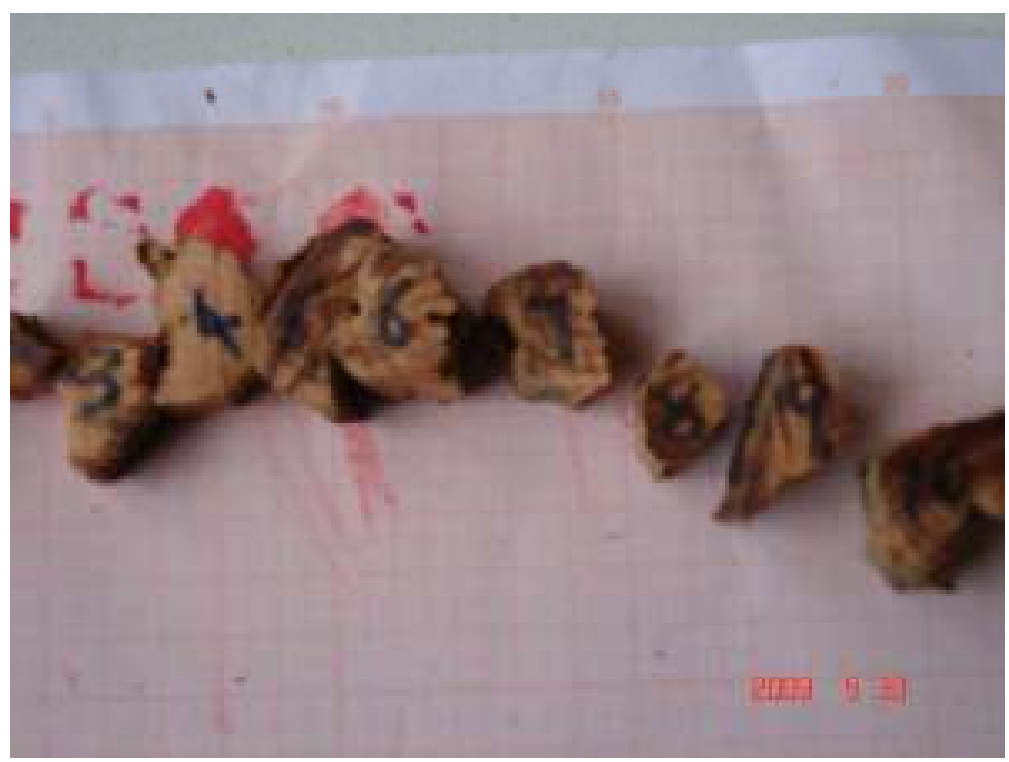

Figure 22-Wood Rib Samples

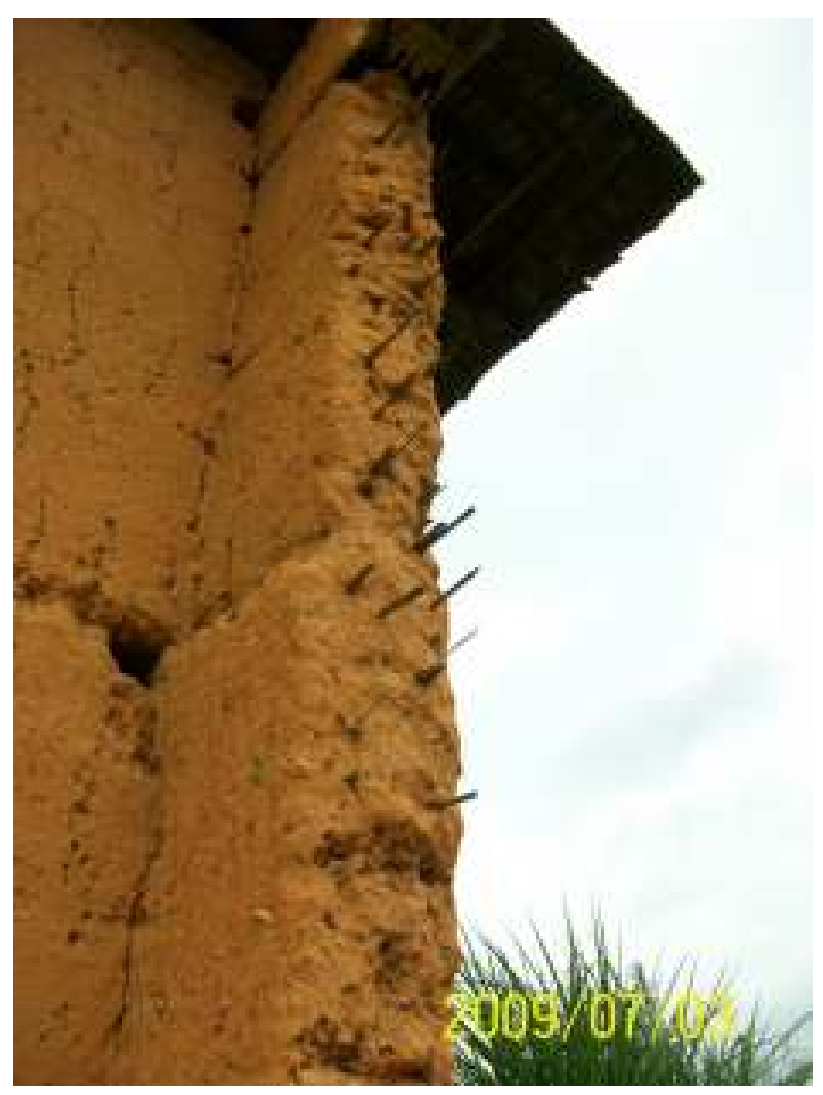

Figure 23-Protruding Wall Ribs 
As seen in Figure 24 below, six samples displayed good results from testing which means that a modulus of elasticity value was extrapolated from six data sets. From Figure 24, the average modulus of elasticity for this piece of wood rib sample in compression is calculated to be 46,799 psi and the average ultimate strength is found to be 3,382 psi.

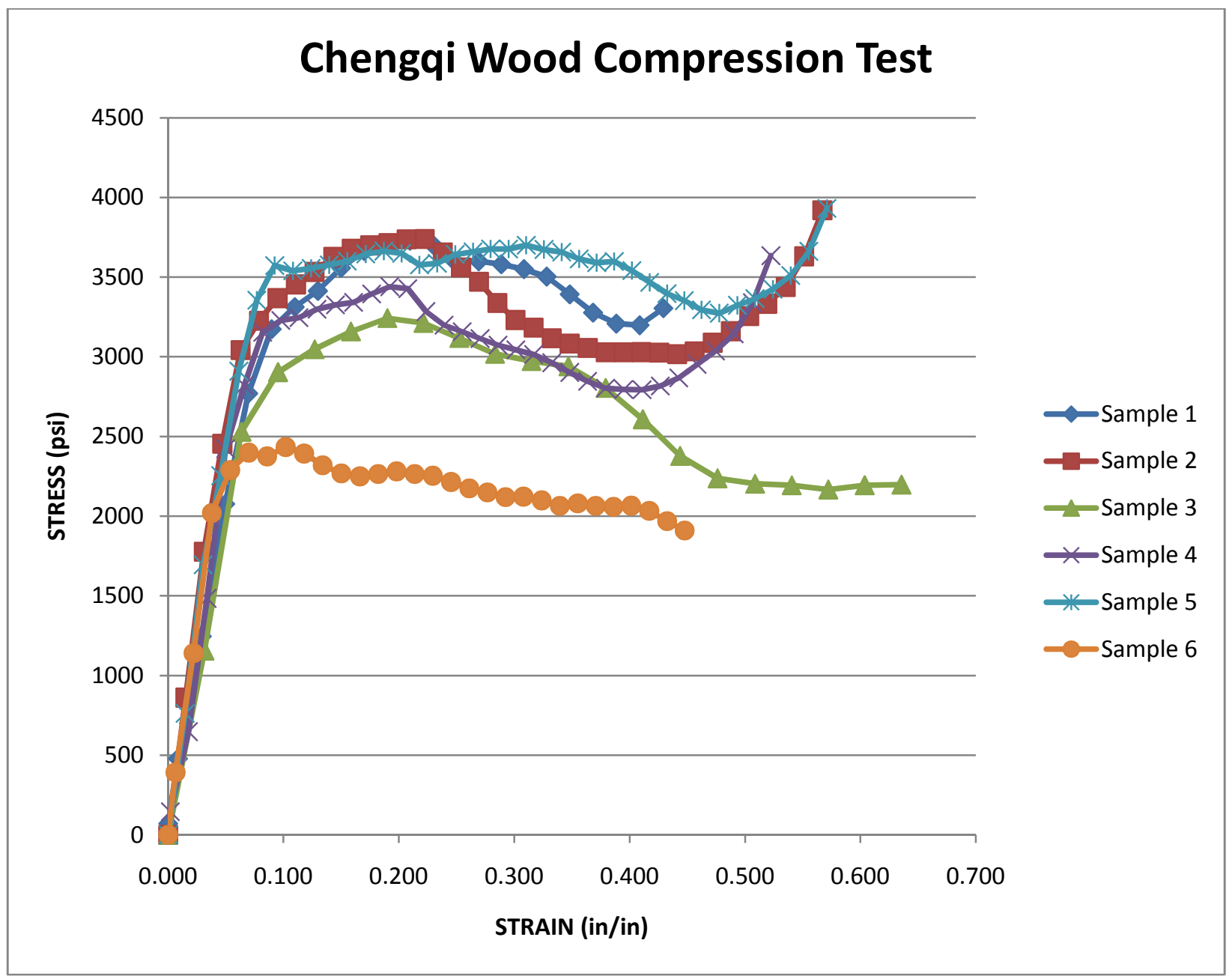

Figure 24-Wood in Compression Stress/Strain Curve

\subsubsection{Wood Tension Test}

Other wooden samples that were acquired from the protruding ribs, also from the Chengqi Tulou, were tested in a tension strength test. As seen in Figure 25 below, three samples 
gave valid results. The average modulus of elasticity for the wood rib sample under tension is calculated to be 34,737 psi and the average ultimate strength is found to be 1,707 psi.

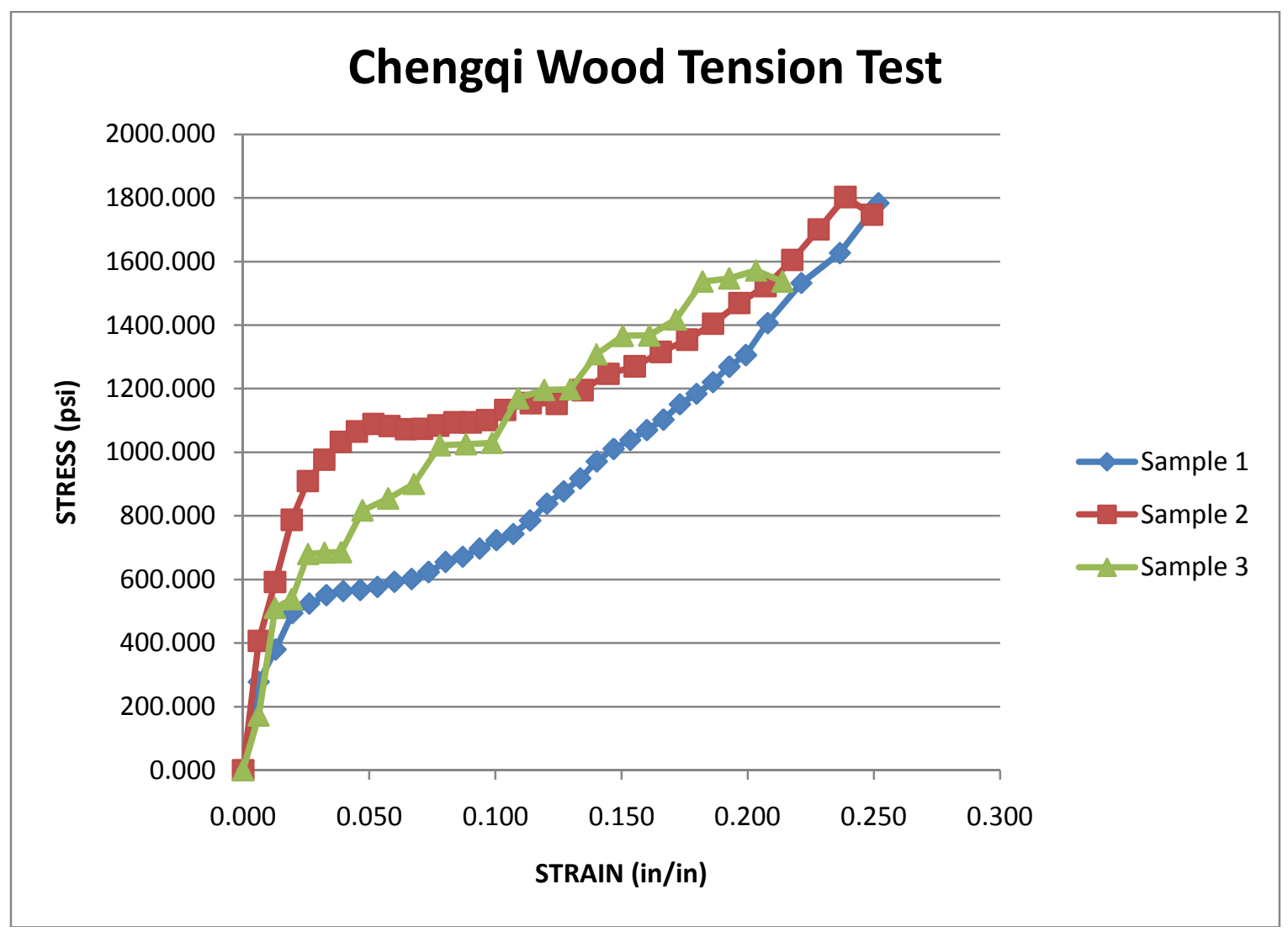

Figure 25-Wood in Tension Stress/Strain Curve, XMU

\subsubsection{Bamboo Tension Test}

One of the Tulous, located in the HongKeng village, was found to have bamboo reinforcing its rammed earth walls. The bamboo samples were acquired from protruding ribs and were tested in a tension strength test just like their wooden counterparts. As seen in Figure 26 below, two samples displayed good results from testing. The average modulus of elasticity for the bamboo rib samples under tension is calculated to be 463,178 psi and the average ultimate strength is found to be 4,452 psi. 


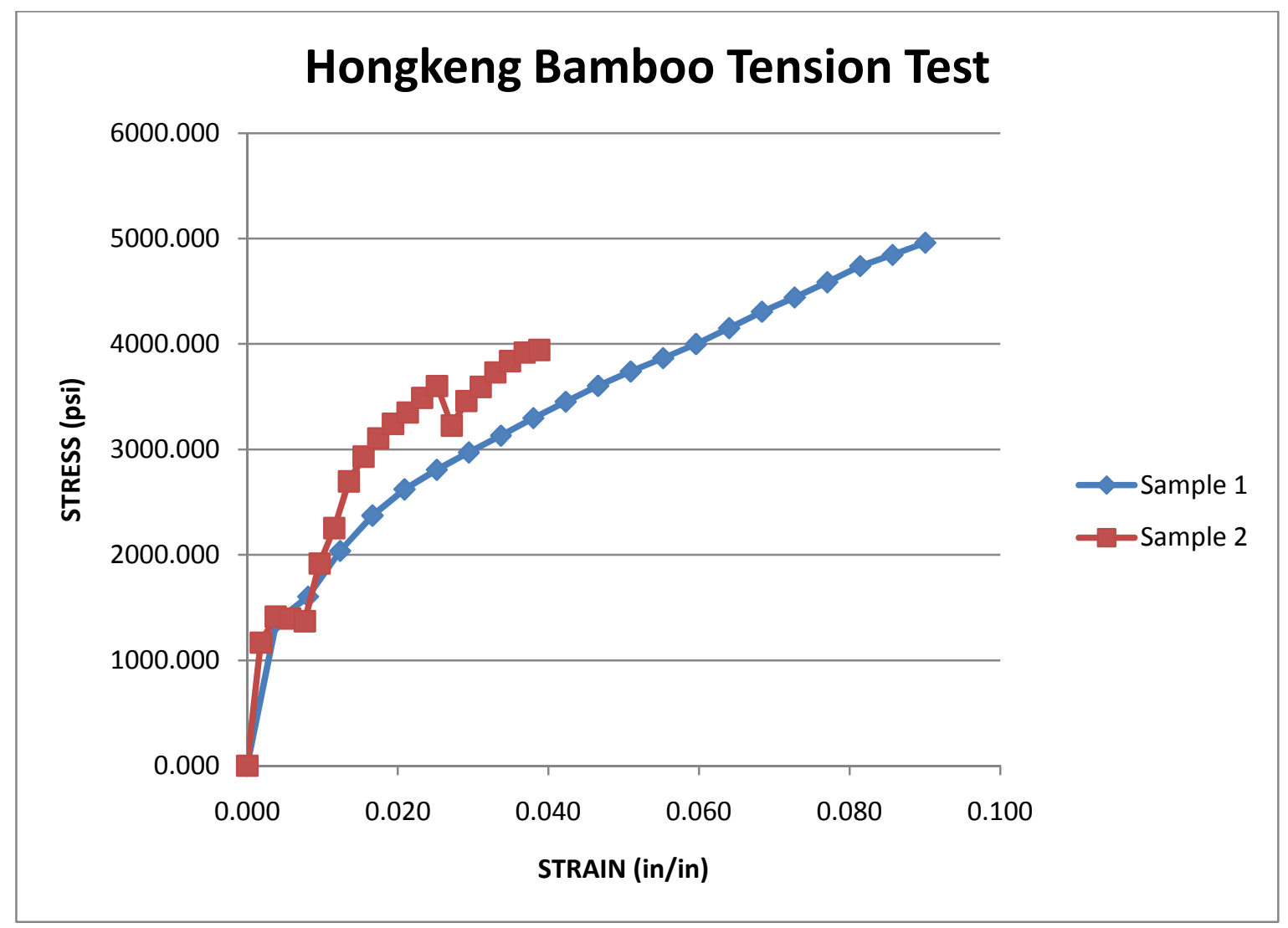

Figure 26-HongKeng Bamboo under Tension Stress/Strain Curve, XMU

\subsubsection{West Virginia University Data}

Material testing and subsequent data from the tests in the following sections were performed by the Constructed Facilities Center at West Virginia University.

\subsubsection{Earth Compression Test}

Similarly as was performed previously by the Xiamen University, rammed earth samples from the main wall structure of the Tulous were extracted and tested from three locations, Wuyun Tulou, Chengqi Tulou, and Zhencheng Tulou. The Wuyun Tulou is a square Tulou with an approximate age of 500 years and the Zhencheng Tulou is circular in shape and the youngest of the all the Tulous visited at 100 years old. The Chengqi Tulou is known as the King of Tulous as it boasts over 400 rooms and has a circular outer diameter of 73 meters. The Tulou is 
approximately 300 years old and took about 50 years to build in its entirety; Figure 27 below effectively shows the mass of the structure.
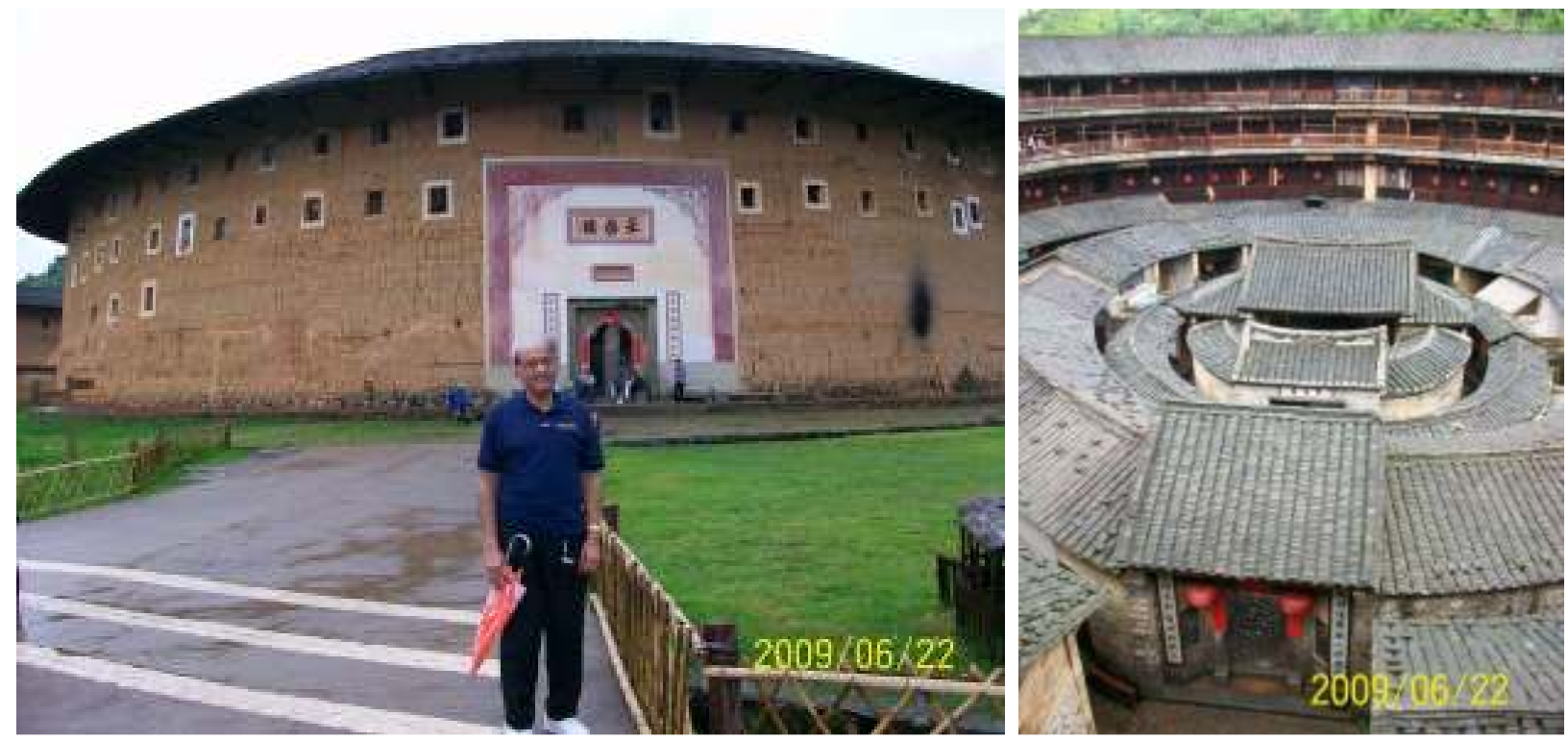

Figure 27-Exterior and Interior of Chengqi Tulou

It is important to note that there was difficulty in extracting rammed earth samples from the walls as discussed earlier, thus this has limited the amount of samples available to be tested. The samples that were successfully extracted were cut to represent a rectangular shape however this was not always possible, consequently the sample sizes are not to ASTM standard. Compression tests were performed on an Instron testing instrument at a loading rate of 120 $\mathrm{lbs} / \mathrm{min}$ in order to stay within ASTM loading rates of 10-30 psi/s. A compression fixture was not used during testing which led to local crushing of at least the Chengqi wood and bark ribs, resulting in smaller than expected values. Figure 28 below shows the testing setup that was used for all samples. 


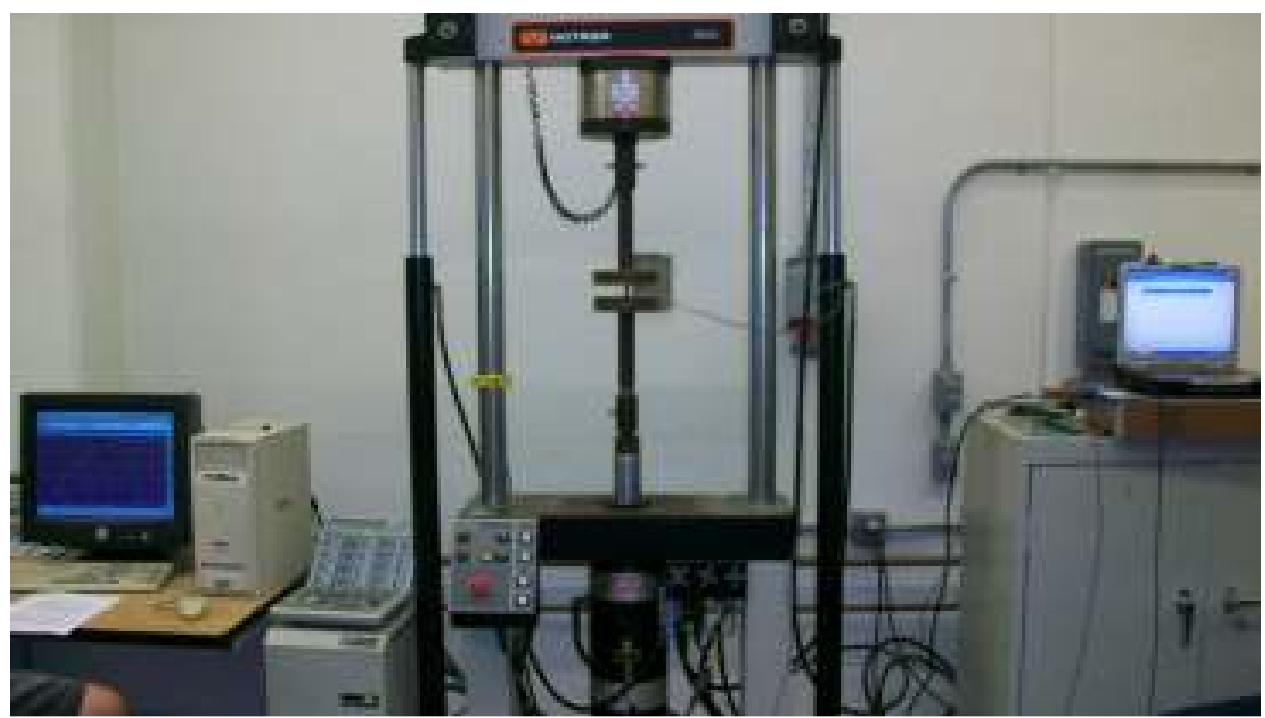

Figure 28-Compression Test Setup

\subsection{Wuyun Tulou}

In Figure 29, one can see the rammed earth sample from the Wuyun Tulou before and after compression testing. Only one sample was made available from the rammed earth wall of the Wuyun Tulou. From Figure 30, the modulus of elasticity for this rammed earth sample is calculated to be $2129 \mathrm{psi}$ and the ultimate strength for this sample is found to be 279 psi.

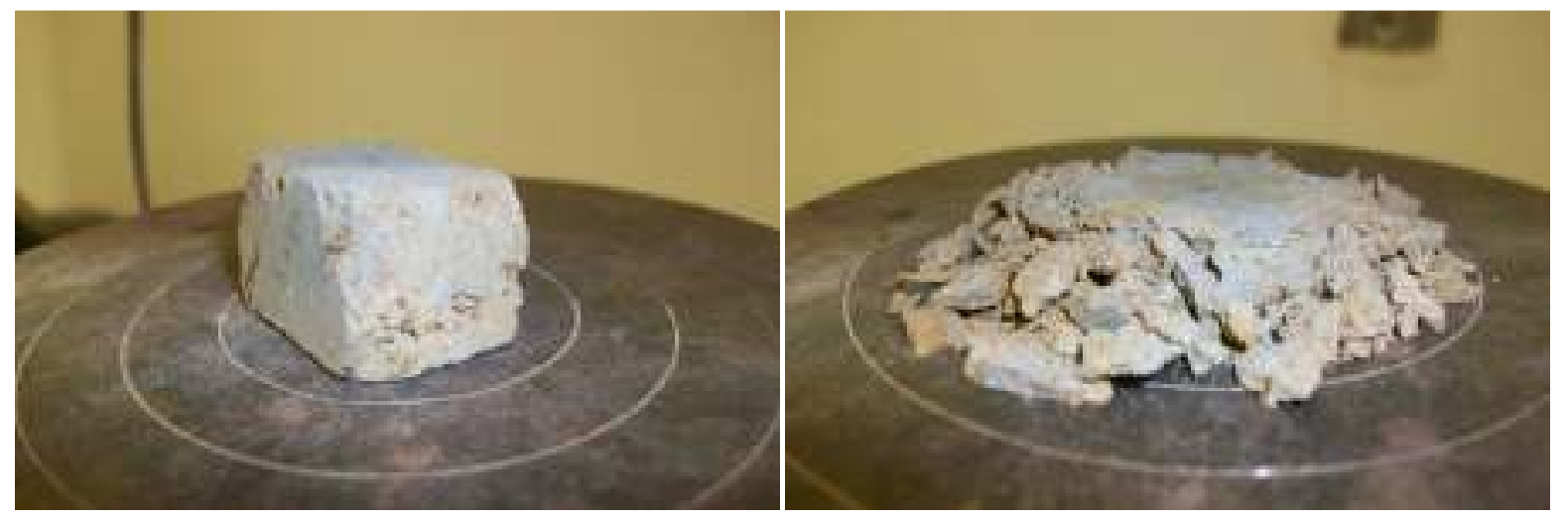

Figure 29-Wuyun Earth Sample Before and After Testing 


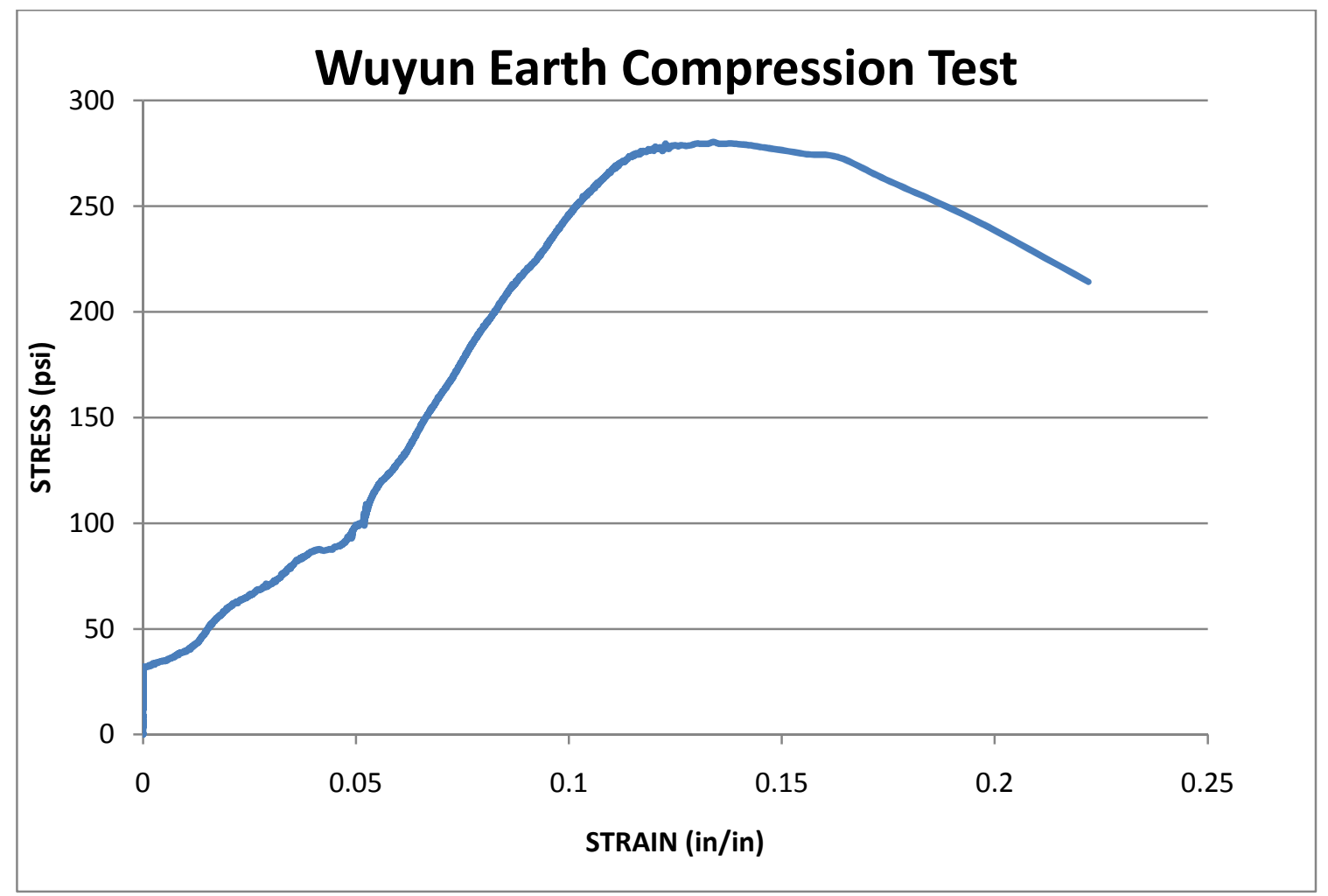

Figure 30-Wuyun Tulou Earth Stress/Strain Curve, WVU

\subsection{Chengqi Tulou}

In Figure 31, one can see the rammed earth sample from the Chengqi Tulou before and after compression testing. From Figure 32, the modulus of elasticity for this rammed earth sample is calculated to be 8,147 psi and the ultimate strength for this sample is found to be 411 psi. 

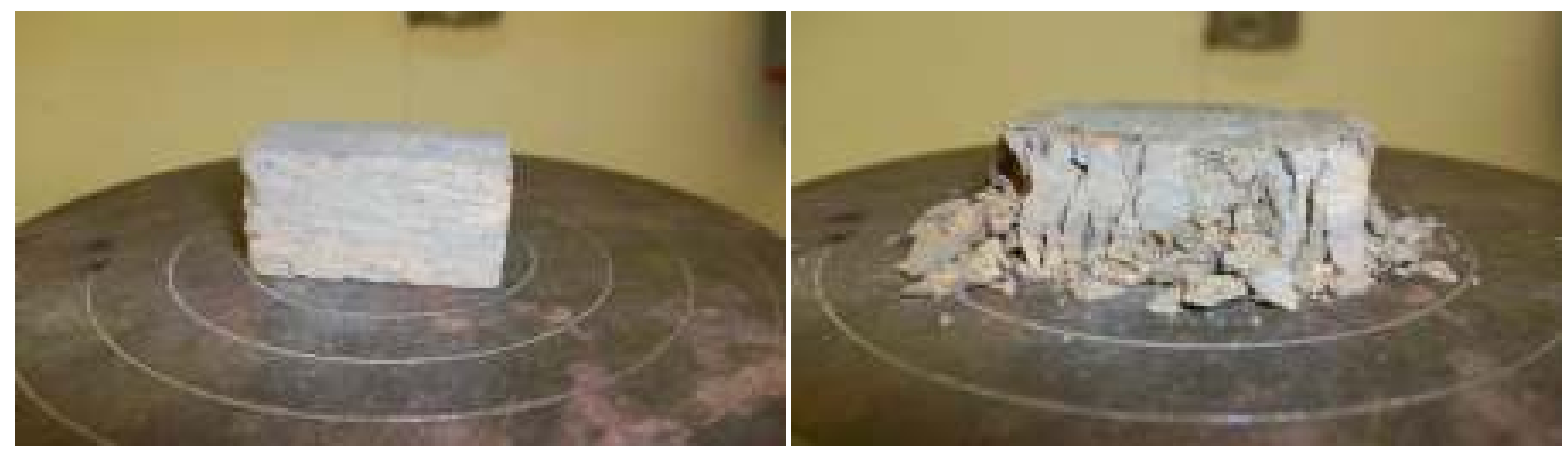

Figure 31-Chengqi Earth Sample Before and After Testing

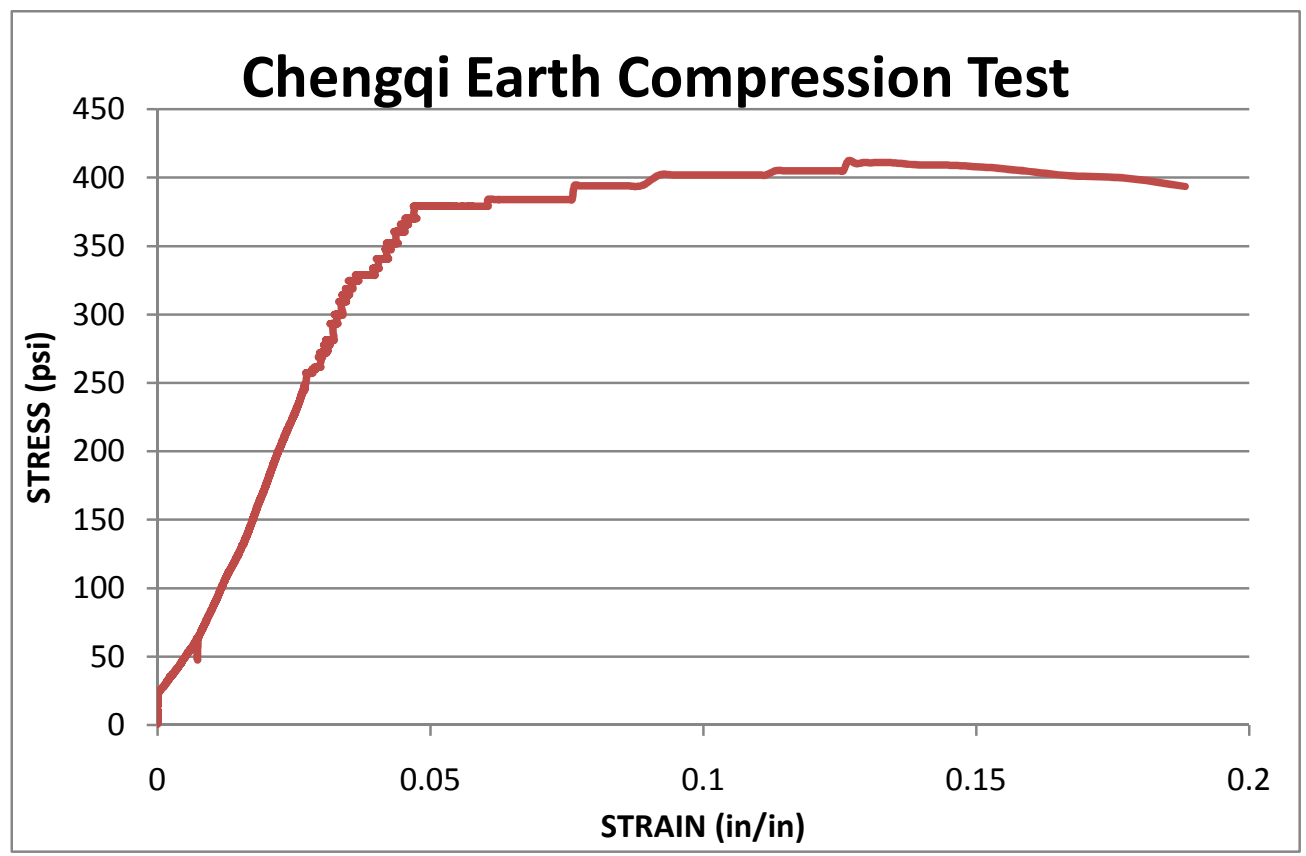

Figure 32-Chengqi Tulou Earth Stress/Strain Curve, WVU

\subsection{Zhencheng Tulou}

In Figure 33, one can see the rammed earth sample from the Zhencheng Tulou before and after compression testing. From Figure 34, the modulus of elasticity for this rammed earth sample is calculated to be 4,291 psi and the ultimate strength for this sample is found to be 126 psi. 

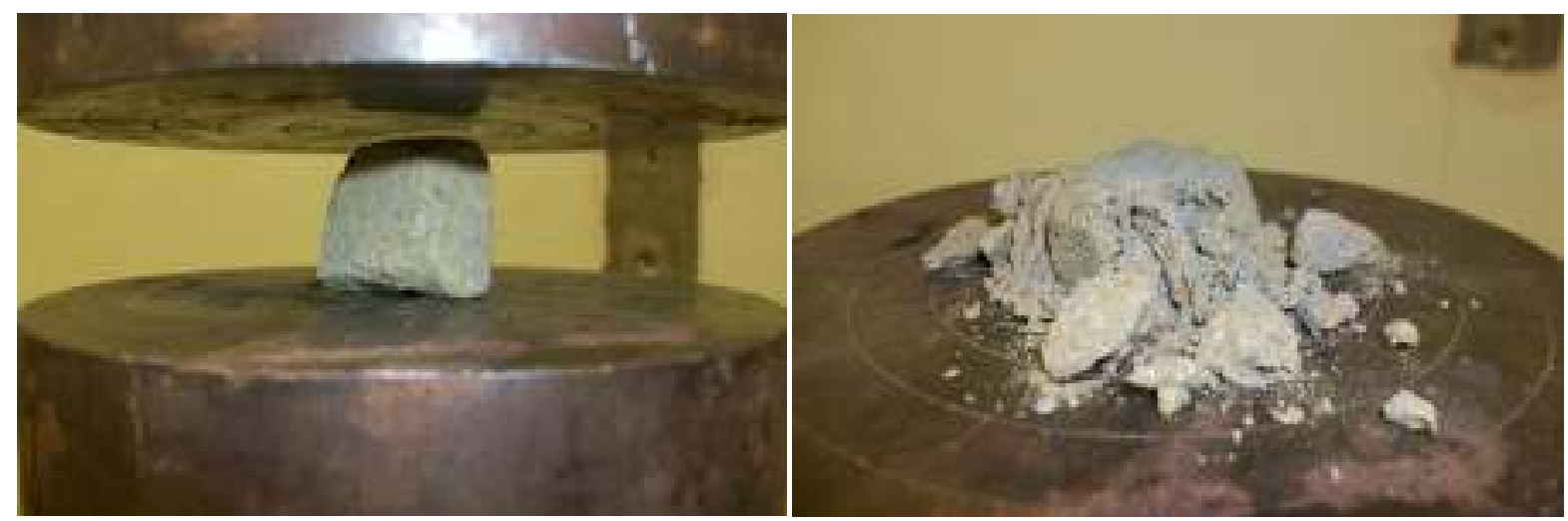

Figure 33-Zhencheng Earth Sample Before and After Testing

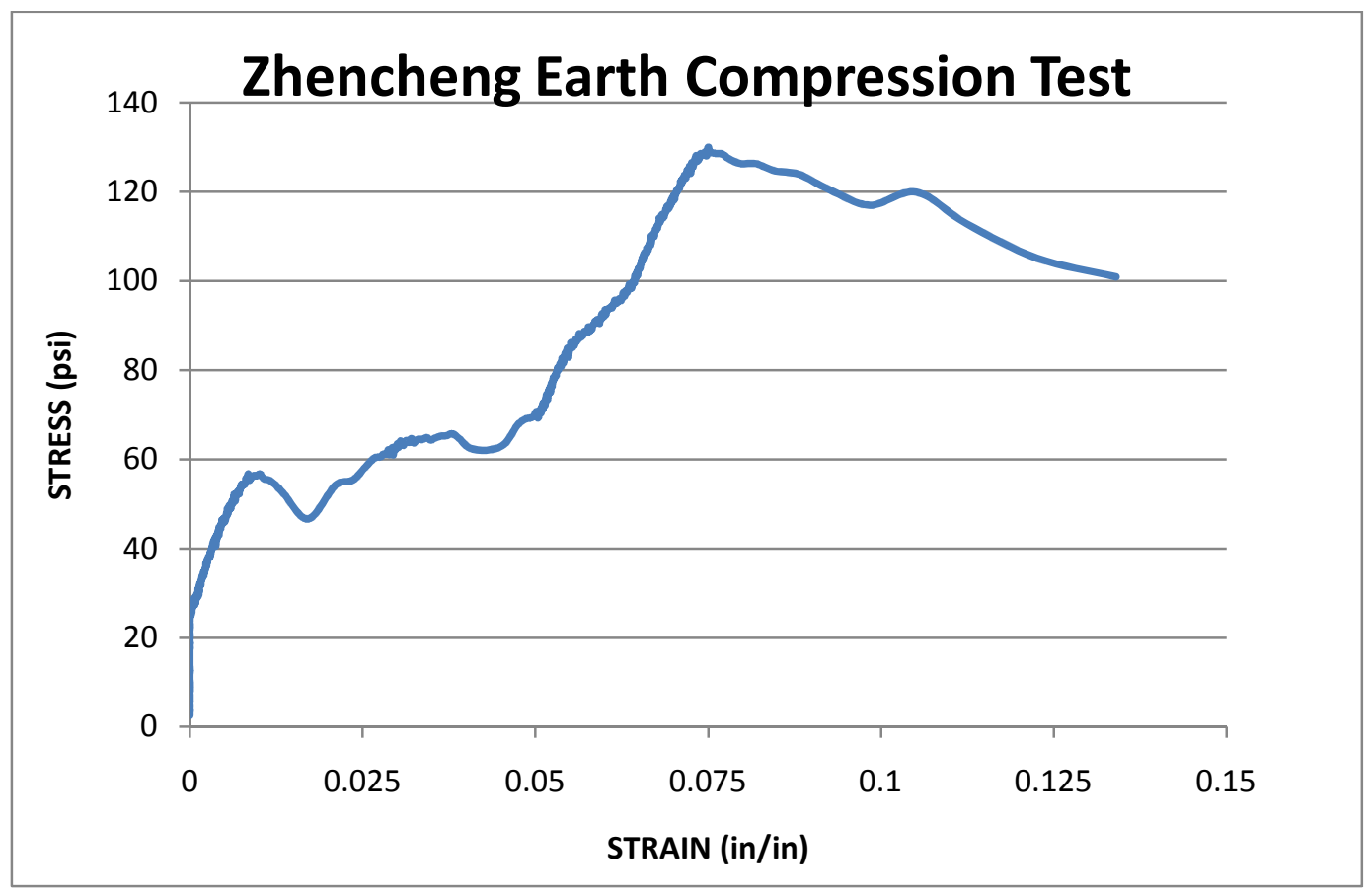

Figure 34-Zhencheng Tulou Earth Stress/Strain Curve, WVU

\subsubsection{Wood Compression Test}

Wooden Samples from the Chengqi and Fuxing Tulou were extracted and tested in compression at a rate of $120 \mathrm{lb} / \mathrm{min}$ on an Instron testing instrument. From the Chengqi Tulou, we were able to successfully extract both bark and wooden wall ribs that are used as reinforcement inside the rammed earth walls. Also, from the Chengqi Tulou we were able to extract wood from the beam of the wooden roof truss as well as wood from another portion of 
the wood roof truss. From the Fuxing Tulou, several samples of wooden wall ribs were also able to be extracted from the rammed earth walls.

\subsection{Chengqi Bark Wall Ribs}

Bark samples were acquired from protruding 'ribs' at the Chengqi Tulou. The bark ribs act as reinforcement for the rammed earth walls and increase strength of the structure in order to better withstand loads from high winds and earthquakes. Figure 35 below shows a bark sample delaminating before failure; this was the primary mode of failure for both samples tested. Such failure is known as local crushing and is a direct result of not using compression fixtures during testing, thus lowering strength values.

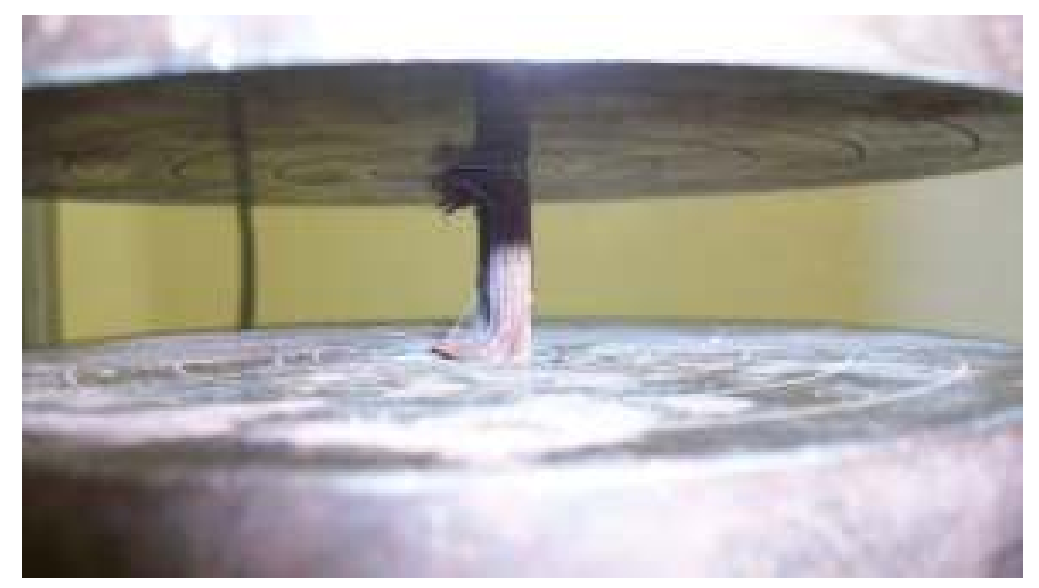

Figure 35-Delamination of Chengqi Bark Sample

From Figure 36, the average modulus of elasticity for the bark wall rib samples in compression is calculated to be $52,583 \mathrm{psi}$ and the average ultimate strength is found to be 2,484 psi. 


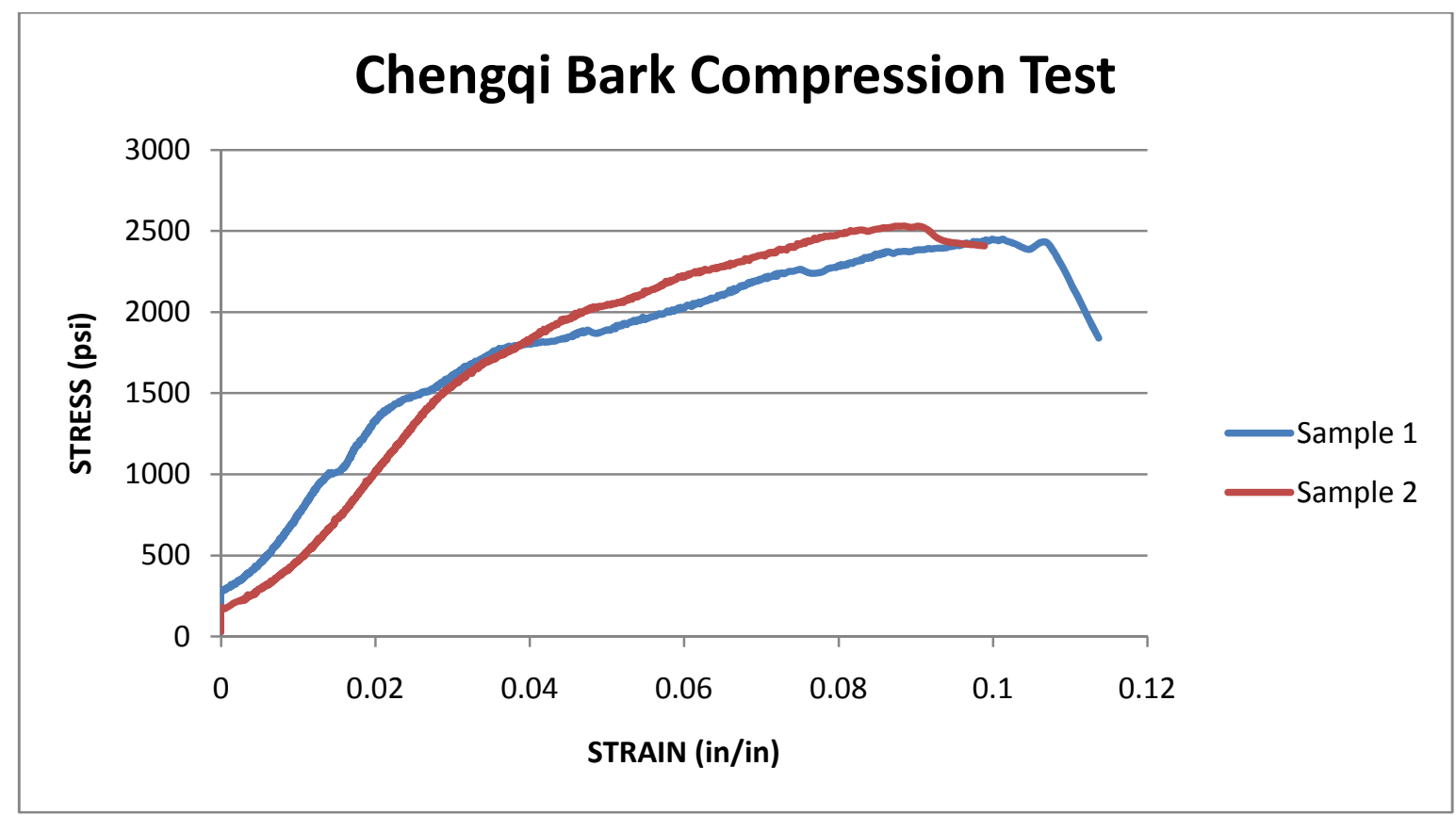

Figure 36-Chengqi Bark Stress/Strain Curve, WVU

\subsection{Chengqi Wood Ribs}

Wooden wall rib samples were acquired from protruding 'ribs' at the Chengqi Tulou. The wood ribs act as reinforcement for the rammed earth walls similarly as does the bark reinforcement. Figure 37 shows one of the wooden wall rib samples seated in the Instron machine readied for compression testing.

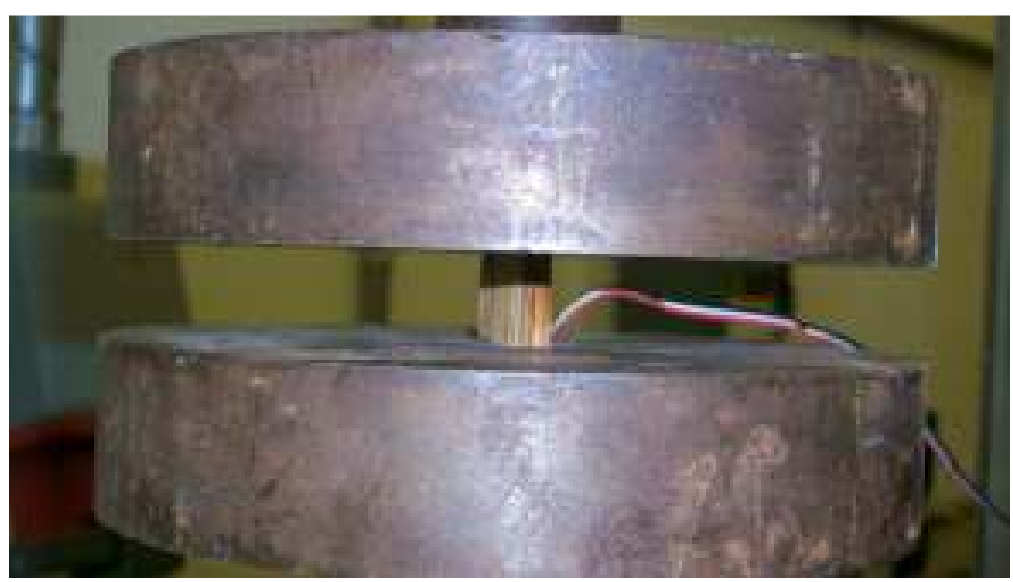

Figure 37-Chengqi Roof Beam Wood Ready for Testing 
From Figure 38, the average modulus of elasticity for the wood samples is calculated to be 57,308 psi and the average ultimate strength for these samples is found to be 4,717 psi

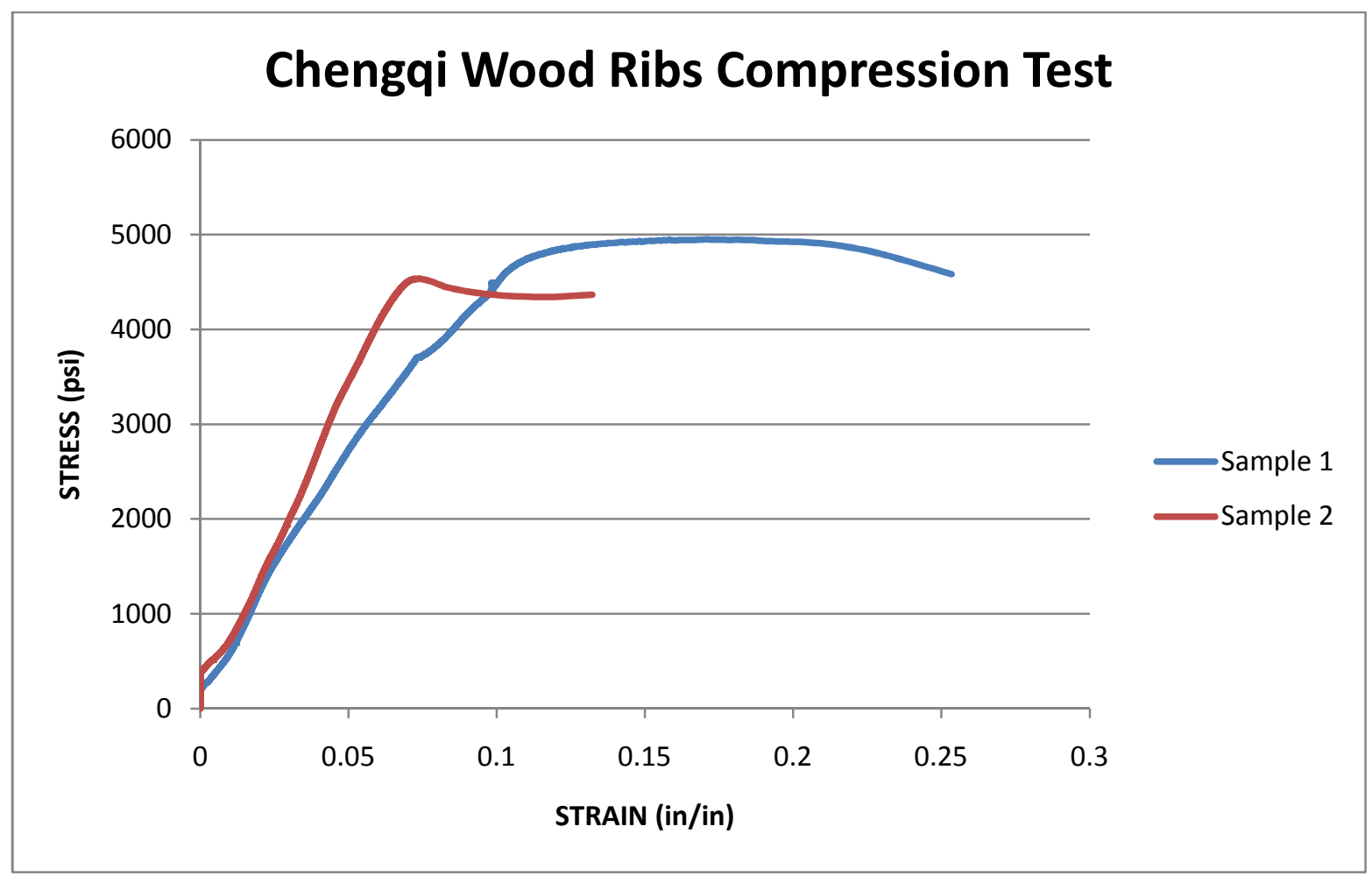

Figure 38-Chengqi Wood Ribs Stress/Strain Curve, WVU

\subsection{Chengqi Wooden Wall Ribs II}

Two more samples of wall ribs were taken from a different location from the Chengqi Tulou. From Figure 39, the average modulus of elasticity for the wooden wall rib samples in compression is calculated to be 303,364 psi and the average ultimate strength is found to be 4,870 psi. 


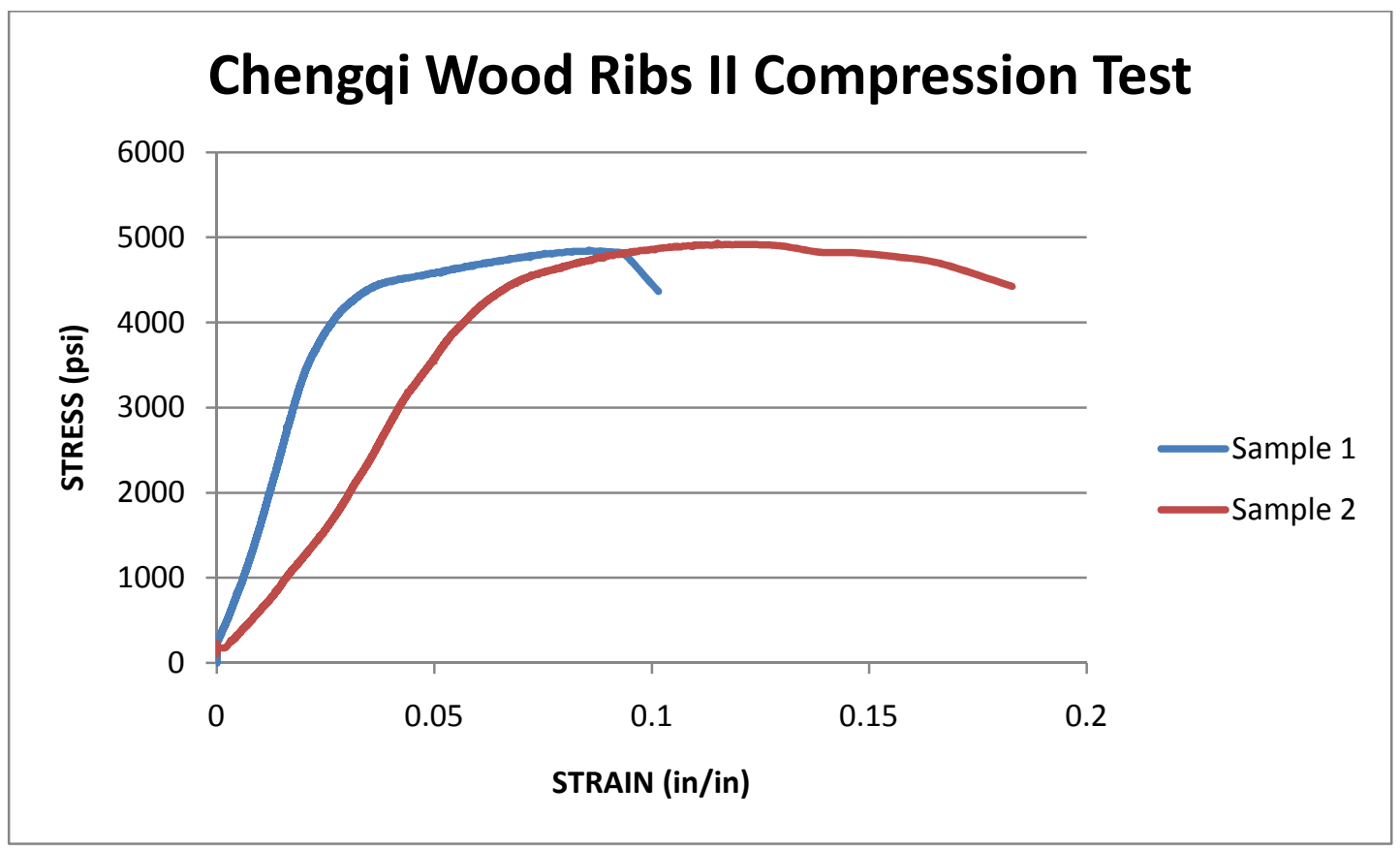

Figure 39-Chengqi Wood Ribs II Stress/Strain Curve, WVU

\subsection{Chengqi Roof Wood}

A sample of wood was acquired from the wooden roof truss of the Chengqi Tulou. The wood plays a key role in the structural integrity of the roof truss as it directly supports roof loads. From Figure 40, the modulus of elasticity for this wood sample is calculated to be 175,461 psi and the ultimate strength for this sample is found to be $3,990 \mathrm{psi}$ 


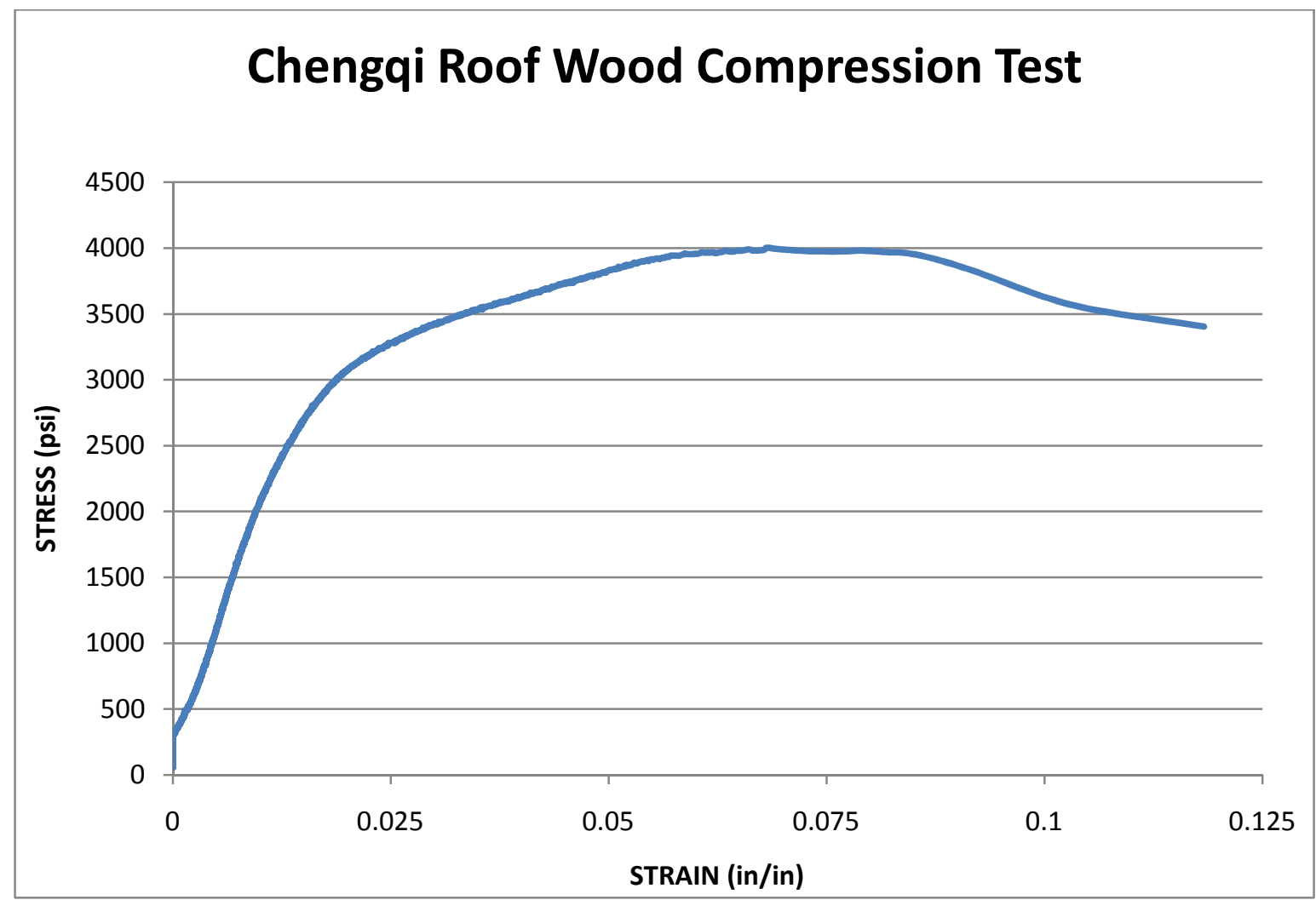

Figure 40-Chengqi Roof Wood Stress/Strain Curve, WVU

\subsection{Fuxing Wooden Wall Ribs}

A larger amount of wooden wall ribs were successfully extracted from the Fuxing Tulou. The wooden ribs perform as reinforcement for the rammed earth walls just as they do at the Chengqi Tulou. Figure 41 below shows a Fuxing wood sample before and after compression testing, it is interesting to note that all 8 samples failed in a similar buckling manner. 


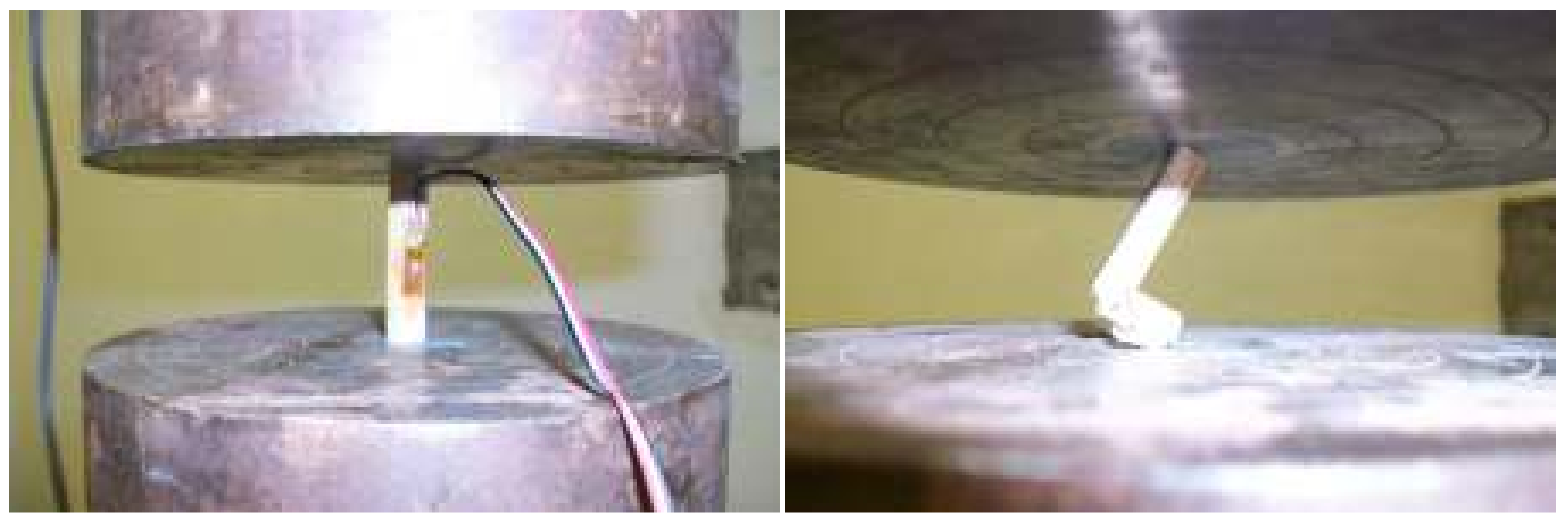

Figure 41-Fuxing Wood Sample Before and After Testing

From Figure 42, the average modulus of elasticity for the wooden wall rib samples in compression is calculated to be 227,944 psi and the average ultimate strength is found to be 4,376 psi.

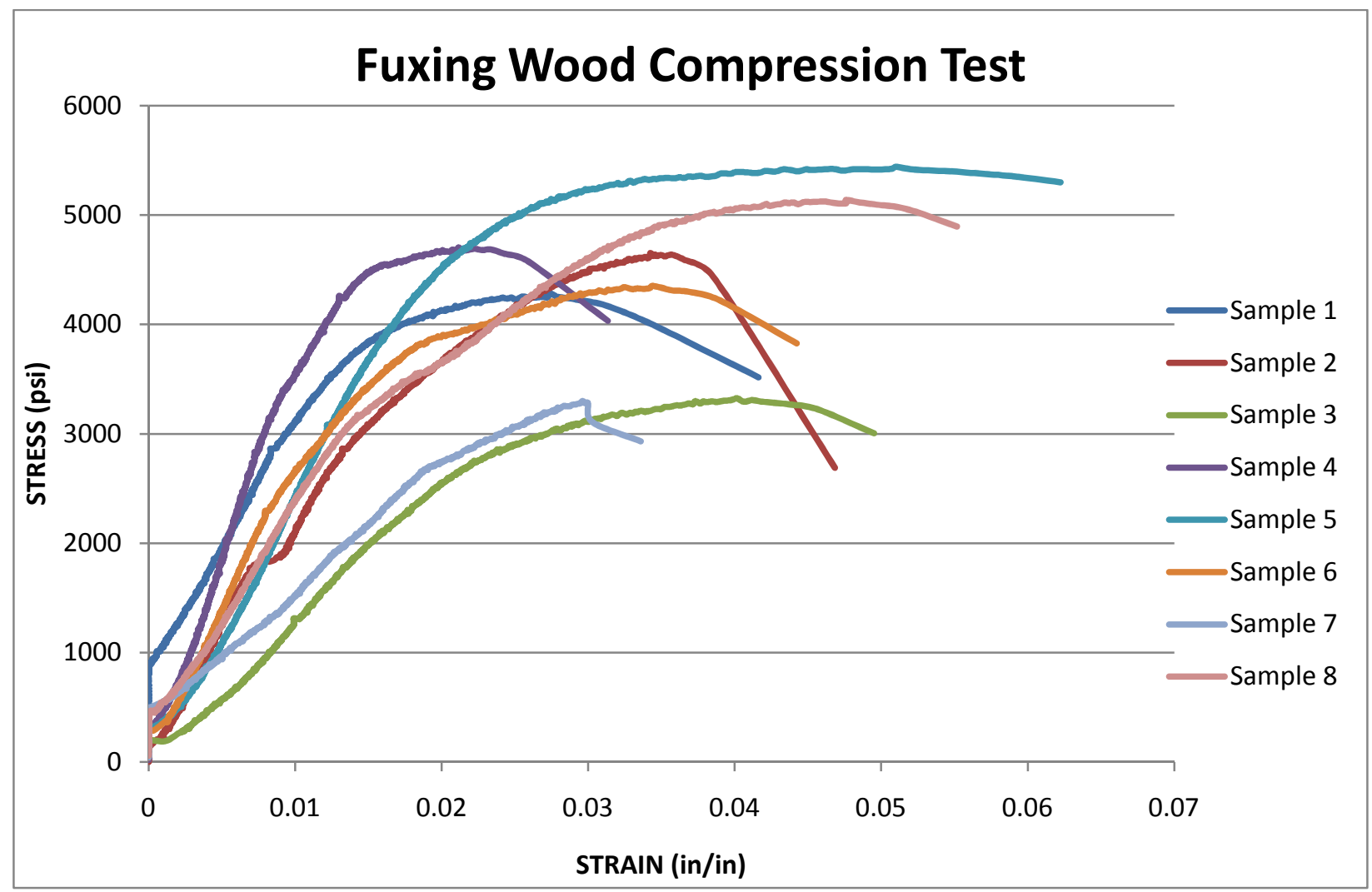

Figure 42-Fuxing Wood Stress/Strain Curve, WVU 


\subsubsection{Bamboo Compression Test}

Bamboo samples acquired from a Tulou in the Hongkeng village were also tested in a compression strength test just like their wooden counterparts. As seen in Figure 43 below, two samples gave valid results. The average modulus of elasticity for the bamboo rib samples in compression is calculated to be 300,023 psi and the average ultimate strength is found to be 11,039 psi.

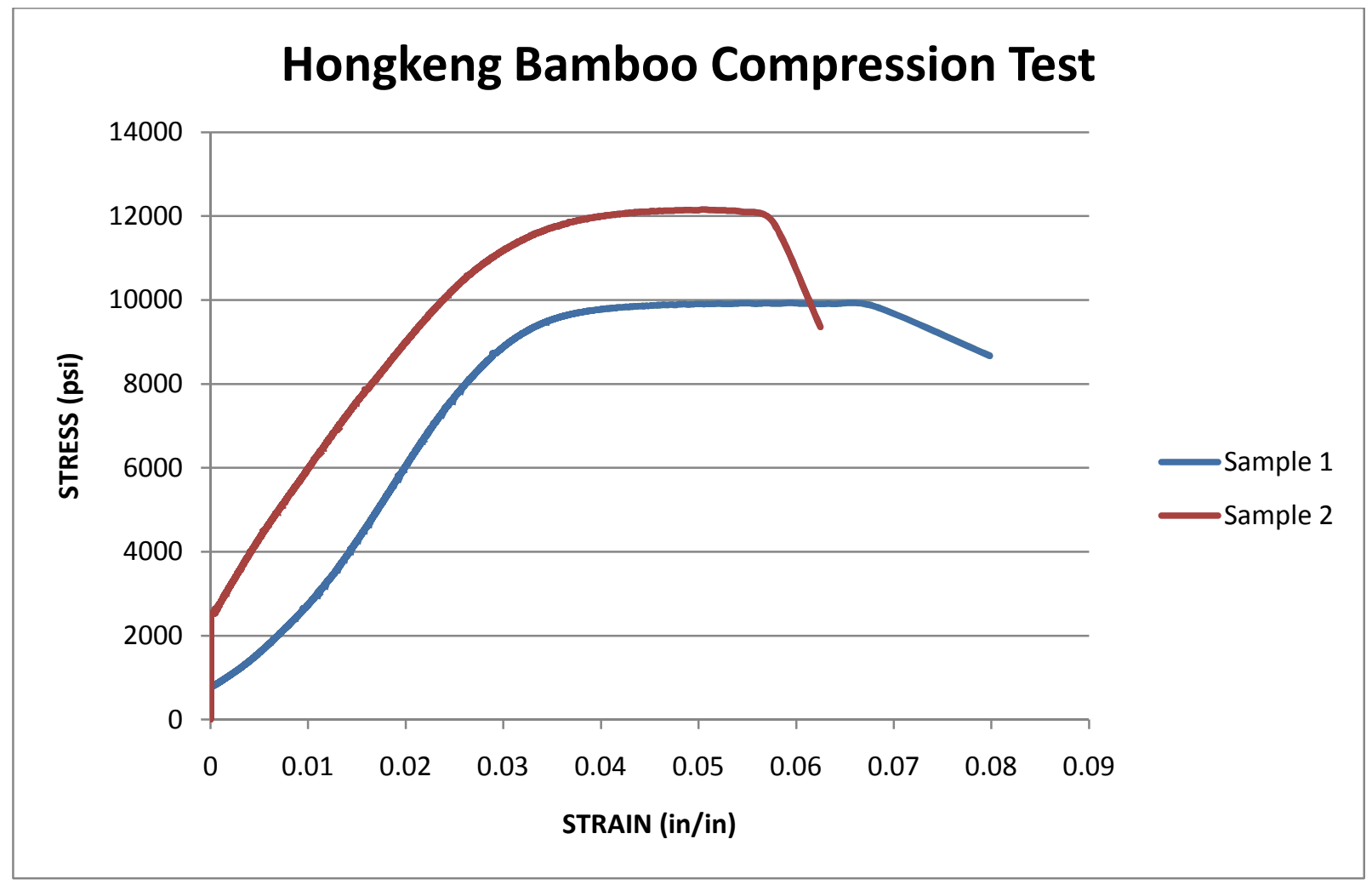

Figure 43-HongKeng Bamboo in Compression Stress/Strain Curve, WVU

\subsubsection{Conclusions}

After analysis of the earth samples from the Fuxing Tulou, Wuyun Tulou, Chengqi Tulou and Zhencheng Tulou, one can see that there is no correlation with the strength of the rammed earth and the age of the structure; this leads one to believe that the composition of the material 
dictates its strength. Table 3 below is a summary and comparison of both the Xiamen University data and the data from testing at West Virginia University.

Table 3-Rammed Earth Compression Test Results

\begin{tabular}{|c|c|c|c|c|c|}
\hline \multicolumn{6}{|c|}{ Rammed Earth Compression Test Results } \\
\hline & & \multicolumn{2}{|c|}{ Xiamen University } & \multicolumn{2}{c|}{ WVU } \\
\hline Tulou & Age (years) & $E(p s i)$ & $\begin{array}{c}f^{\prime} c \\
(p s i)\end{array}$ & $E(p s i)$ & $\begin{array}{c}f^{\prime} c \\
(p s i)\end{array}$ \\
\hline Fuxing & 1240 & 6318.1 & 282.4 & $X$ & $X$ \\
\hline Wuyun & 500 & 1705.5 & 133.1 & 2129.3 & 278.8 \\
\hline Chengqi & 300 & $X$ & $X$ & 8147.1 & 411.1 \\
\hline Zhencheng & 100 & 3597.9 & 196.0 & 4291.4 & 125.9 \\
\hline
\end{tabular}

The Fuxing Tulou earth sample, the oldest at 1,240 years old, is the second strongest of the samples tested with a modulus of elasticity of $6,318 \mathrm{psi}$ and an ultimate compressive strength of 282 psi as presented by the Xiamen University. The PI (Liang) talked to the owner of the Fuxing Tulou while performing field studies on location. As per the owner, in the 1970's it took two people 16 days to make an opening for a window and 40 days for a side door, showing the high strength of the rammed earth walls. The Fuxing Tulou rammed earth wall is built of a composite mixture known as "Sanhetu" that includes red soil, lime, and pebbles. One article indicates that soupy glutinous rice and brown sugar are added in some wall systems for added strength (Yang 2010), however when the PI talked to Tulou owners, they did not agree with this statement. Our EDS spectrums were also not able to verify this statement. On the other hand, it is the high amount of lime/calcium that explains why the Fuxing earth wall has been able to retain such high strength for such a long time.

Data from testing at West Virginia University on the Wuyun earth samples correlate closely to the Xiamen University's findings with regard to the modulus of elasticity, however not as closely in terms of ultimate strength. A modulus of elasticity of 2,129 psi and ultimate 
strength of 279 psi were found for the Wuyun earth sample at WVU, making this the weakest of the samples tested. It is important to note that these rammed earth property values are consistent with the values of a soft clay which has a modulus of elasticity range of 700 psi to 2,800 psi (Geotechnical 2010).

The newer Chengqi Tulou with an age 300 years is the strongest of the samples tested with a modulus of elasticity of 8,147 psi and ultimate compressive strength of 411 psi as per WVU testing. The youngest of the samples tested, from the Zhencheng Tulou, was found to have a modulus of elasticity of 4,291 psi and an ultimate strength of 126 psi. The Xiamen University's data was in agreement with WVU's data, finding that the Zhencheng earth samples yielded a modulus of elasticity of 3,598 psi and an ultimate strength of $196 \mathrm{psi}$. The data show that although the modulus of elasticity is higher in the Zhencheng Tulou than the Wuyun Tulou, the ultimate strength is actually less, which could be due to the limited amount of samples tested as well as differences in the samples' sizes and shapes. The high strength in the Chengqi Tulou can most likely be attributed to the large carbon percentage in the sample as shown by our EDS data, meaning that there is a large mixture of rammed earth and wood chips within the sample. Such a mixture in composition of the rammed earth samples explains their higher stiffness than the above referred regular soft clays, instead, approaching the values for sandy clays clay shales, and silty sands (Geotechnical 2010).

Again, as shown in Table 3, it is remarkable that the rammed earth sample from the oldest Tulou, Fuxing Tulou, has maintained such high strength and stiffness, higher than the younger Tulous tested besides the Chengqi Tulou. On contrast, the rammed earth sample from Wuyun Tulou at 500 years in-service, has the lowest strength and stiffness, possibly due to prolonged weathering effects as well as the composition of the material. This, among many other 
factors, helps explain why part of Wuyun Tulou's front rammed earth wall is leaning inward and currently needs structural rehabilitation. Looking at the overall data for the earth compression tests it can be seen that the composition of the samples clearly plays a role in their mechanical properties.

Table 4-Wood/Bamboo Testing Results

\begin{tabular}{|c|c|c|c|c|c|c|}
\hline & \multicolumn{6}{|c|}{ Wood/Bamboo Testing Results } \\
\hline & & & \multicolumn{2}{|c|}{ Xiamen University } & \multicolumn{2}{|c|}{ WVU } \\
\hline & Tulou & $\begin{array}{c}\text { Age } \\
\text { (years) }\end{array}$ & $E(p s i)$ & $f^{\prime} c(p s i)$ & $E(p s i)$ & $f^{\prime} c(p s i)$ \\
\hline \multirow{6}{*}{ 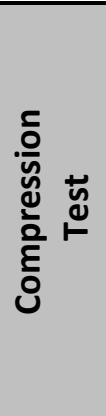 } & Chengqi Roof Wood & 300 & $\bar{x}$ & $\bar{x}$ & 175460.5 & 3990.3 \\
\hline & Chengqi Wood Ribs & 300 & 46799.3 & 3382.3 & 57308.3 & 4717.4 \\
\hline & $\begin{array}{c}\text { Chengqi Wood Ribs } \\
\text { II }\end{array}$ & 300 & $x$ & $x$ & 303363.6 & 4870.3 \\
\hline & Chengqi Bark Ribs & 300 & $x$ & $x$ & 52582.8 & 2483.6 \\
\hline & Fuxing Wood Ribs & 1240 & $x$ & $x$ & 227943.7 & 4376.3 \\
\hline & HongKeng Bamboo & $?$ & $\mathrm{x}$ & $x$ & 300023.1 & 11039.3 \\
\hline \multirow{2}{*}{ 亮 } & Chengqi Wood Ribs & 300 & 34736.7 & 1707.3 & $x$ & $x$ \\
\hline & HongKeng Bamboo & $?$ & 463178.1 & 4452.4 & $x$ & $x$ \\
\hline
\end{tabular}

Table 4 summarizes the mechanical property data of wood/bamboo samples tested. Wooden wall rib samples from the Chengqi Tulou, tested by the Xiamen University in China, behaved fairly similarly in both compression and tension tests. In compression, the average modulus of elasticity for the wooden samples was 46,799 psi and ultimate strength was 3,382 psi whereas in tension, the average modulus of elasticity for the wooden samples was $34,737 \mathrm{psi}$ and ultimate strength 1,707 psi. The compression data from XMU for the Chengqi Wood ribs closely matches WVU data which exhibit a modulus of elasticity of 57,308 psi and ultimate compressive strength of $4,717 \mathrm{psi}$. These values are much lower than that of any typical wood whose modulus of elasticity is usually in the magnitudes of the hundred thousand's and higher (Green et al. 1999). The lower modulus of elasticity for the samples tested could be due to the 
age of the samples, representing degradation of the wooden samples through aging, as well as the wooden samples being damaged as they had been protruding from an existing rammed earth wall. Also, the size of the samples tested may have altered the results as well. It is important to note that without using the compression fixture, local crushing was experienced in the Chengqi Wood and Bark Rib samples, thus lowering actual strength values. Other samples did not exhibit this mode of failure and thus more accurately represent actual strength values. Wooden wall ribs from another location at the Chengqi Tulou (Ribs II) as well as from the Fuxing Tulou, tested by WVU, showed much more strength in compression as well as more consistent results with an average modulus of elasticity of 303,364 and 227,944 psi and an average ultimate strength of 4,870 and 4,376 psi. Wood samples from the Chengi Tulou roof truss was also tested in compression, resulted in an average modulus of elasticity of 175,461 psi and an ultimate strength of 3,990 psi. Lastly, bark samples that act as wall rib reinforcement at the Chengqi Tulou was also tested and resulted in an average modulus of elasticity of 52,582 psi and an average ultimate strength of 2,484 psi. It is interesting to note that the strength of all the samples tested at West Virginia University, including the bark, were higher than the wooden samples tested at the Xiamen University in China.

Bamboo samples were tested both in tension by the Xiamen University and in compression by West Virginia University. In tension, bamboo showed an average modulus of elasticity of 463,178 psi and an ultimate strength of 4,452 psi. In compression, bamboo showed an average modulus of elasticity of 300,023 psi and an ultimate strength of 11,039 psi. Even though this modulus is much higher than wood it is still much lower than that of the typical average modulus of elasticity of tension for bamboo which is $2.76^{*} 10^{6}$ psi (Bambus 2010). Similar to the wood samples, the lower modulus of elasticity for the samples tested could be due 
to the age of the samples, representing degradation of the bamboo through aging. The size of the samples tested may have also altered the results.

Having the modulus of elasticity for these materials allows one to more accurately model a Hakka Tulou in a Finite Element program as well as compare the current strength of the material to that of typical values of the material. Using the values from the rammed earth, wood, and bamboo, one can use the rule of mixtures and find the actual modulus of elasticity of the reinforced rammed earth wall for modeling purposes.

\subsection{NDT, Ultrasonic and Rebound Hammer Tests}

The definition of nondestructive testing is as follows, "nondestructive testing (NDT) techniques refer to those techniques or methods that enable the testing of materials/structural components without impairing their future usefulness. These are the only class of techniques that can be used for testing and long-term monitoring of in-situ structures" (Halabe 2009). For the purpose of this study, nondestructive testing was necessary as to be able to understand the condition of the material and the rammed earth walls, without destroying the historic structures. Both an ultrasonic test and rebound hammer test were performed on several Tulous in order to analyze the strength of the material. The Tulous being tested were, Zhencheng, Huanji, Wuyun, and Fuxing Tulous with varying ages of 100, 320, 500, and 1,240 years of age.

Ultrasonic testing is a NDT test which can tell us the strength of the material as well as if defects are present in the material. A wave, in this case produced by an ultrasonic transducer, through a material such as the rammed earth walls of the Tulou structures, can give valuable information with respect to the structural integrity of the structure being tested. The velocity of the wave is a function of the material's properties such as stiffness, density, and Poisson's ratio 
as well as the presence of defects. A combination of velocity and amplitude measurements provides more useful information by increasing the sensitivity of the ultrasonic technique to defects. In most cases a decrease in wave amplitude represents a defect. One can compare the velocity of a wave to the amplitude to see if there are inconsistencies, if inconsistencies exist then there is a possibility that a defect may be present.

The rebound hammer test is typically used for measuring the hardness of concrete samples. The rebound hammer measures the hardness by striking a mass on a surface and measuring its rebound value (Halabe et al. 1995). In this application the rebound hammer was used to measure the level of deterioration in the rammed earth walls amongst different aged Tulous. Theoretically, one would expect for the readings on the younger Tulous to be higher than that of the older Tulous if strength was solely based on age of the material.

\subsubsection{Ultrasonic Test}

One would expect the most recently built Tulou to have the highest strength due to deterioration effects that occur over the years. The velocity of the wave created by an ultrasonic transducer is directly proportional to that of the modulus of elasticity of the material meaning the higher the modulus of elasticity, the higher the expected velocity. In Figure 44 seen below, the average values of multiple velocity readings are shown for the Tulous tested. As can be seen in this figure there is somewhat of a correlation between the age of a Tulou and the velocity of the ultrasonic wave, meaning that there is possibly a correlation between the strength of the rammed earth walls and the age of the structure. 


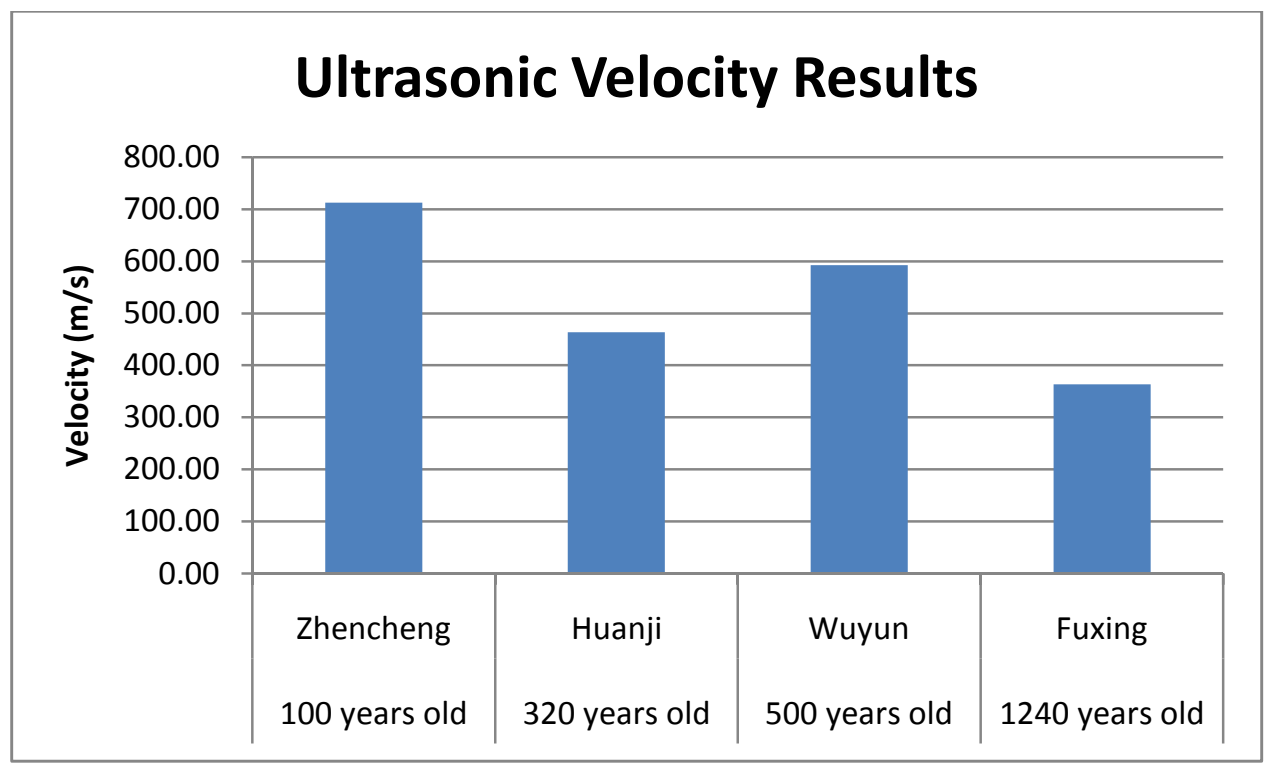

Figure 44-Ultrasonic Velocity Results

The amplitude of the wave sent through a material is also expected to be higher through a more "sound" material or a material that shows fewer defects. As can be seen in Figure 45, the average amplitude reading is highest for the youngest Tulou and lowest for the oldest Tulou. This data shows that there also is somewhat of a correlation between age of the Tulou and the average amplitude reading of the wave.

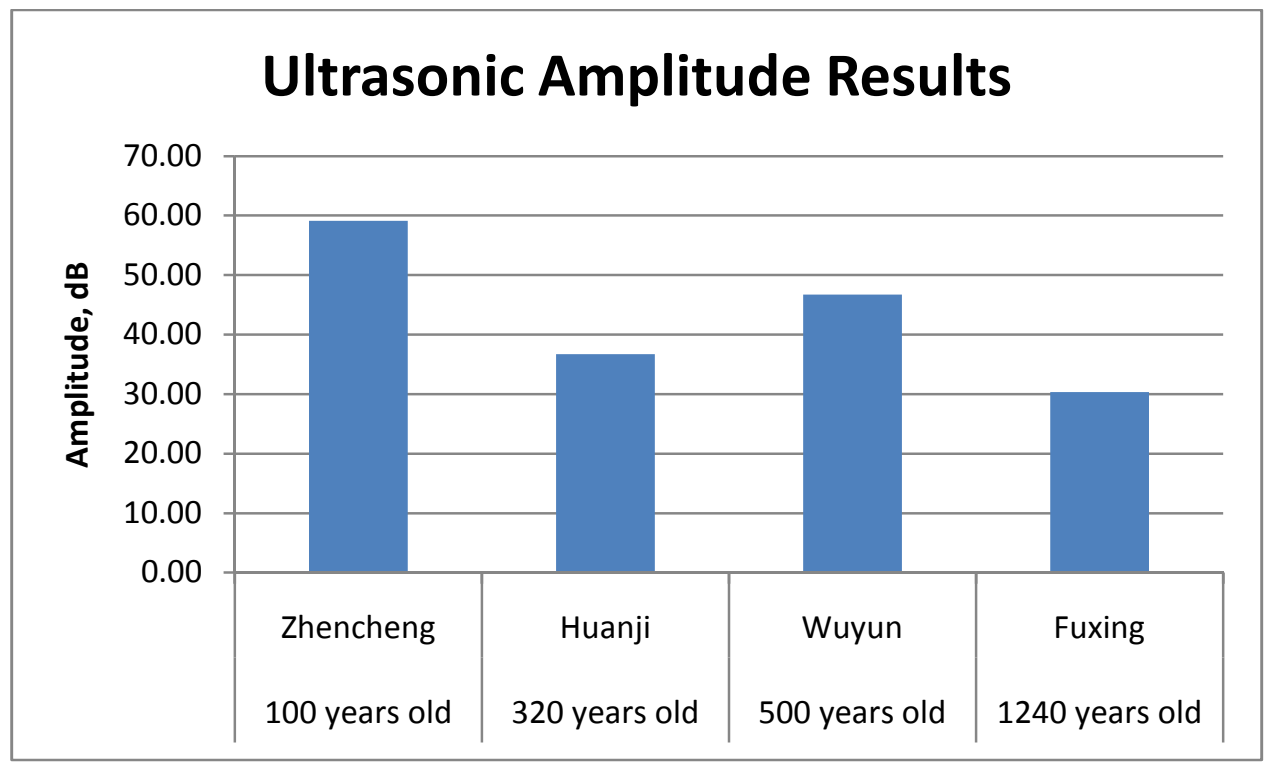

Figure 45-Ultrasonic Amplitude Results 
Combining the data from both the velocity and amplitude results, yields data that is consistent with each other. This most likely means that no large defect exists in the areas of the material that were tested and that reduction in the readings can be correlated to both the deterioration of the rammed earth through increased age and/or the composition of the rammed earth. Theoretically, the velocity values should also match up with the modulus of elasticity values of the rammed earth that was analyzed in section 3.4.1.1. The velocity data unfortunately does not match up proportionally to the modulus of elasticity values of the Tulous, as the highest modulus of elasticity was found to be in the Fuxing Tulou which also happens to have the lowest wave velocity and wave amplitude. Such discrepancies could have occurred due to the non uniform sample sizes being tested in the earth compression test as well as differences in the composition of the rammed earth samples. It is also important to note that during testing of the Fuxing Tulou it was raining as seen in Figure 46 and as a result the rammed earth walls were wet which could have affected the results. 


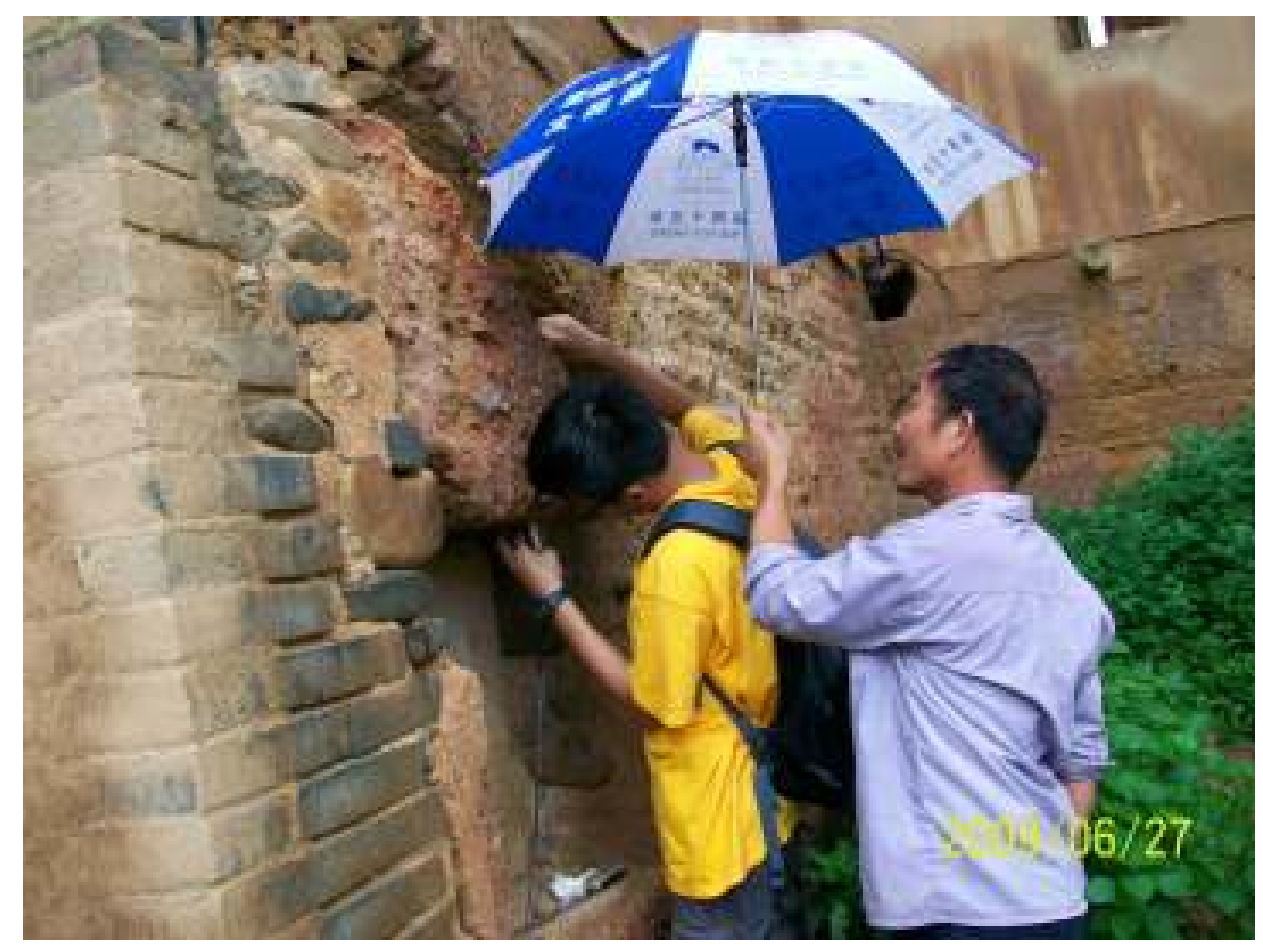

Figure 46-Rain During Fuxing Testing

Regardless of the discrepancies and differences in correlating the NDT data to material test data, ultrasonic data shows a slight correlation between the age of the structure and strength of the material.

\subsubsection{Rebound Hammer Test}

The rebound hammer test consisted of using two different rebound hammers, one specifically for brick and another specifically for mortar. As shown in Figure 47, the average rebound hammer readings do not show as good of a correlation between age of the Tulou and hardness of the sample as did the ultrasonic data. If anything can be extrapolated from this set of data it could be that the mortar rebound hammer represents the conditions of the rammed earth wall more accurately than the brick rebound hammer by showing results that are more consistent to that of material testing. If this proves to be true, then according to the mortar rebound hammer results, strength of the rammed earth walls does not correlate to the age of the structure, rather to 
the composition of the rammed earth. To further explain, from the material testing the Fuxing Tulou had the strongest modulus of the elasticity, the Wuyun Tulou had the weakest, and the Zhencheng was in between the two, this is consistent with what the mortar rebound hammer shows as the Fuxing Tulou had the hardest material, Wuyun the weakest, and the Zhencheng in between the two. Such correlations show that the oldest Tulou is the strongest and the youngest Tulou is in the middle of the two in terms of strength. Since this set of data match material testing results where age is not correlated to strength, it is believed that the rebound hammer results are more accurate than the ultrasonic results.

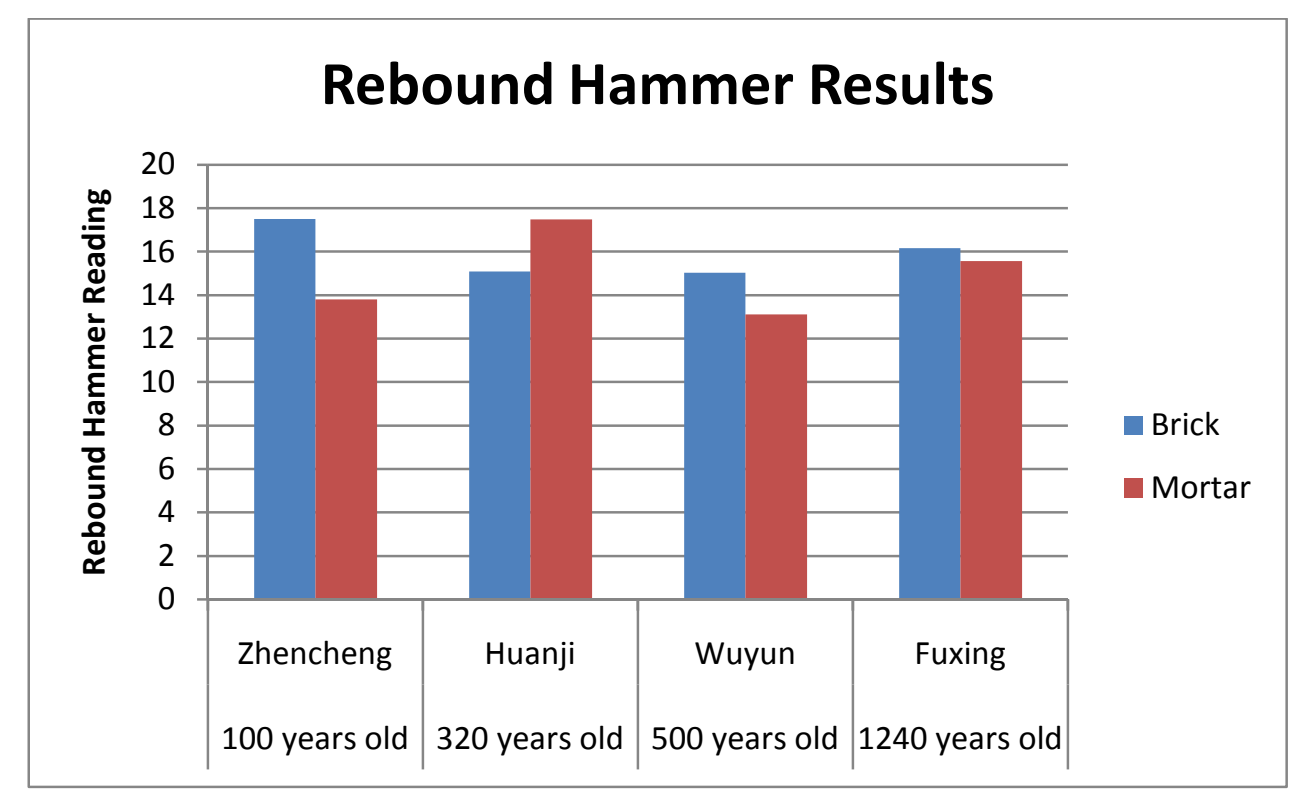

Figure 47-Rebound Hammer Results

\subsubsection{Conclusions}

For the purpose of this project, nondestructive testing provides a comparison of the structural integrity between the different Tulous tested. Ultrasonic testing was not able to yield material strength values that were similar to those values calculated from material tests in the lab. The data from the mortar rebound hammer tests did however resemble the data from earth 
compression tests on rammed earth samples. The fact that both the mortar rebound hammer test and material tests coincide with each other lead one to believe that the ultrasonic test data is inaccurate. Such discrepancies in the ultrasonic test could have occurred simply from not testing enough sample areas as the results are only a statistical representation of the actual values of the

entire structure. If one is to interpret the results from the material and mortar rebound hammer tests as correct, then age does not have the main role in determining the strength of structure, rather the composition of the rammed earth walls themselves dictate the materials' strength. The mortar rebound hammer test results confirm to us that rammed earth can maintain a high strength even at the age of 1240 years as shown by the Fuxing Tulou. Such results are truly remarkable especially when one is to consider that rammed earth, which maintains its strength for so many centuries, is created solely from locally available natural materials.

\subsection{Load Testing on Floor and Roof Truss Systems}

When discussing the structural integrity of Hakka Tulous, attention must be turned to the inner wooden structure of the Tulou. The inner wooden structure of the Tulou carries the loads that are experienced within the Tulou and distribute these loads to both the rammed earth wall and the interior wooden columns. As can be seen in Figure 48, the wooden roof truss is tied into the rammed earth wall as well as wooden columns that extend down into the ground surface. Through the understanding of how the wooden structure works with loads one can further understand the structural integrity of the Tulou structure. The structural efficiency of the Chengqi Tulou building was first evaluated through load tests during field study and then later compared with FE modeling results. It is important to note that load testing of such structures is a good form of nondestructive testing that allows us to predict or estimate the material properties of a 
structure without damage to the structure itself. Also, load testing of such structures shows how structurally sound a structure may or may not be. In order to predict material properties of a structure, one must compare the strain gage results from the load test to the stress values from an FE model. One may back calculate and predict the modulus of elasticity of a material in the FE model by matching the strain from the FE model to the strain values from the load tests. This back calculation can be done using the relationship between stress and strain as seen in Equation 1 below.

$$
\sigma=E \epsilon
$$

By knowing the modulus of elasticity of the wood, this allows us to see what type of wood was used in the Tulou structure as well as what types of wood with equivalent strength can be used for other similar structures. Two types of load tests i.e. roof truss and floor beam were conducted in Chengqi Lou. First, representative structures were identified for the test; second, a number of strain gages were mounted at appropriate locations; third, strain gages were connected to the multi-channel strain gage indicator; fourth, load was gradually applied up to a value of 250 $\mathrm{kg}$ and a reading from each channel was taken. The geometric dimensions of the building such as column and beam positions, wall thickness, OD/ID etc were also measured.

Typical types of woods that can be found in the Fujian Province of China where Hakka Tulous exist are fir, pine, and rosewood (Encyclopedia 2008). More specifically, the domestic species of these woods are most likely, China-fir, or cunninghamia lanceolata, whose modulus of elasticity can be compared to that of Douglas-fir at $1.97 \times 10^{6}$ psi, Indian Rosewood with a modulus of elasticity of $1.78 \times 10^{6} \mathrm{psi}$, and Radiata Pine with a modulus of elasticity of $1.48 \times 10^{6}$ psi. (Green et al. 1999). It is reasonable to assume that China-fir may have been used in the construction of most Tulous due to its abundance in the region and its strong resistance to decay, 
which would explain how the structure has been able to maintain its strength over such a long period of many years (Morell 2001). In order to confirm the possibility of China-fir being used in the structure, a FE model was created and tested to match the results of field data.

A common difficulty in modeling is portraying support conditions of a structure accurately in a model. Theoretically speaking, there is an obvious difference between a fixed, pinned, or roller support. A fixed support allows for no rotation and no translation in both the horizontal and vertical directions, a pinned support allows rotation however no translation in both directions, and finally a roller support allows for translation in one direction as well as rotation. Support conditions in the real world are practically never fully any of the three conditions, rather actual support conditions are a mixture of multiple conditions. For example, a support is rarely ever fully fixed, rather a support behaves in a matter that is partially fixed and partially pinned, with the partial fixidity of the support partially resisting rotation and the partial pinned behavior allowing for partial rotation. Due to such conditions, it is impossible to exactly predict actual conditions in a FE model analysis; rather we must make reasonable assumptions in order to most accurately simulate realistic conditions.

\subsubsection{Roof Truss System}

The wooden roof truss that supports the massive roof structure of the Tulou can be seen below in Figure 48. In the left hand portion of this photo, one can observe the top of the rammed earth wall to which the roof truss distributes a portion of its load. In the right hand portion of the photo, one can see where the roof truss distributes the remainder of its load into columns that extend all the way down into the ground surface. 


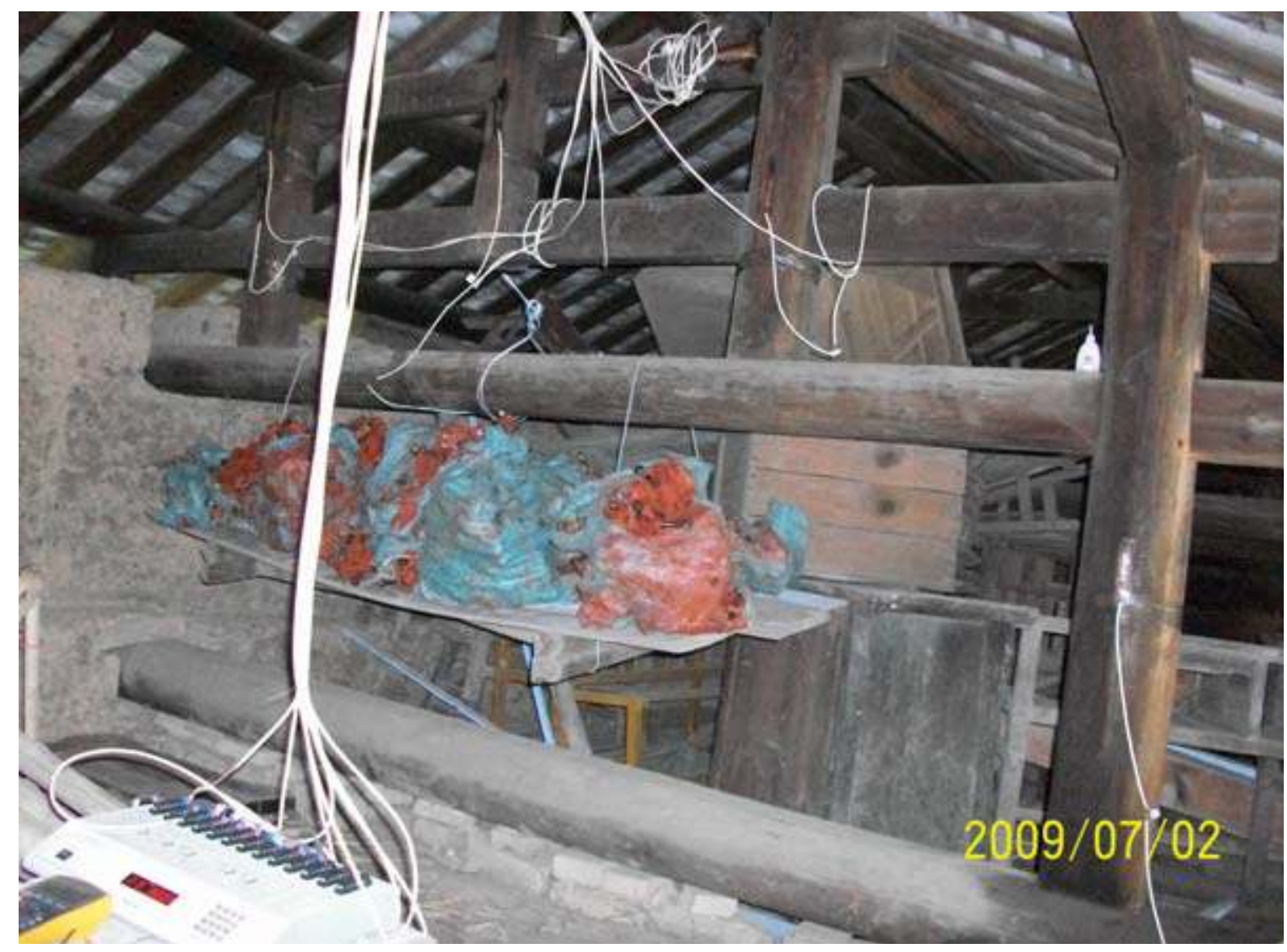

Figure 48-Load Testing of Roof Truss

A two point load test was performed in increment weights up to $250 \mathrm{~kg}(550 \mathrm{lbs})$ on the main beam of the truss that directly tied into both the rammed earth wall and main columns of the structure. The two point load was centered on this main beam which is labeled as member M10b in Figure 49 and is where strain gage number 4 is centered on the bottom side of the beam. In Figure 49, strain gage markers are boxed and members are labeled in order to be able to compare strain gage results with results from the FE model. 


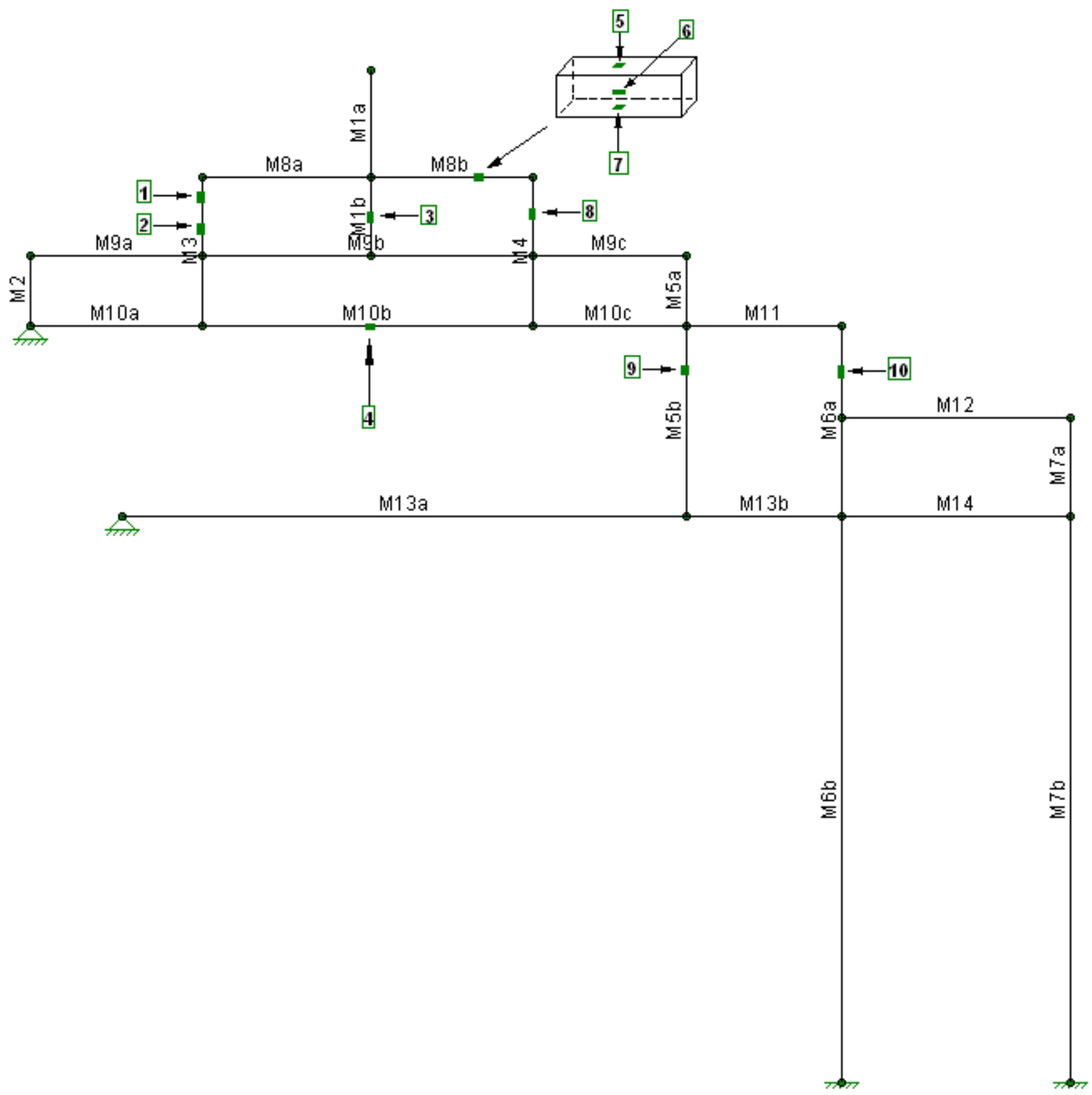

Figure 49-Tulou Roof Truss Model

In Figure 49, one can see that at the location where the roof truss ties into the rammed earth wall the support condition is assumed as pinned. This assumption was made because although the beam is not connected directly to the wall, rather it is laying in a groove made in the 
rammed earth wall, the frictional resistance as well as the mass of the structure will prevent it from translating and acting like a roller. The wooden columns are assumed to be fixed due to the fact that they continue down several floors and directly tie into the ground. Although they are not fully fixed, there is a limitation in rotation from the connection and thus the reason for not assuming a pinned connection here. In reality, the roof truss is a flexible wooden structure at each connection, however it does not fully behave in a way a truss normally would in the manner of pinned connections and members having the full freedom to rotate. The frictional resistance and the connection system of the members prevents the freedom to rotate in a full manner and thus is why connections were assumed to behave more closely to fixed connection preventing rotation. All of these assumptions were made in order create a FE model that most accurately represents actual conditions of the roof truss.

Before comparing strain results of specific members from the model to that of field tests, an interesting observation can be made from Figure 50 . 


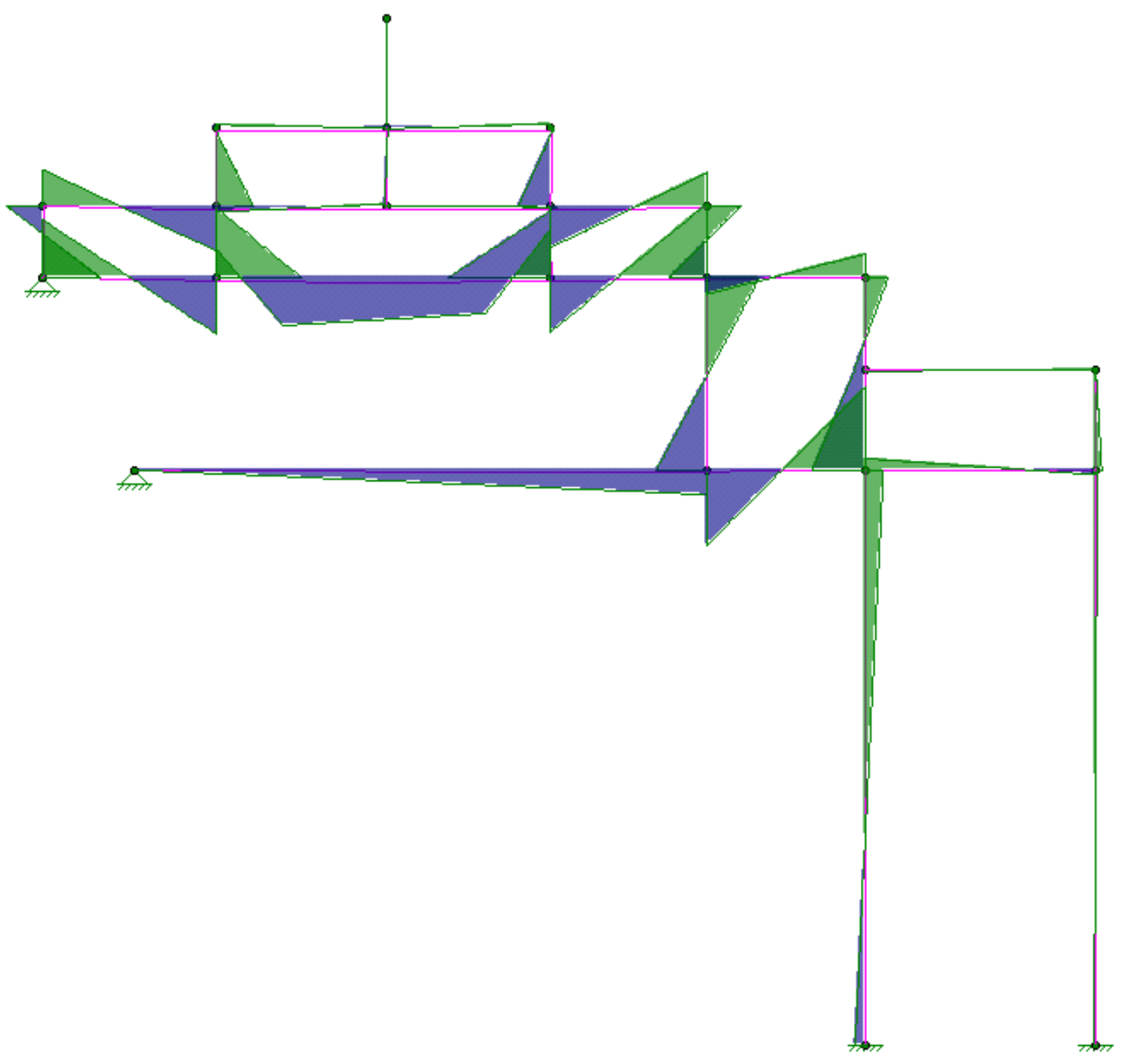

Figure 50-Tulou Roof Truss Moment Distribution

This figure above shows that the Hakka people from over one thousand years ago had some kind of understanding about bending stresses. The roof truss, typically loaded from roof loads at the top and side nodes of the truss, experiences bending and shears stresses due to the connections not acting fully pinned. This differs from modern day trusses as trusses only experience axial forces and no shear or moment forces. Knowing that their trusses experience these forces the Hakka people designed their truss with several intermittent vertical members, specifically members M3 and M4, that intercept the longer horizontal members, specifically 
members M10a, M10b, and M10c which actually contribute to a single member but for the purpose of analysis have been broken into three segments. By doing this the maximum bending moment has been dramatically reduced by turning a simple beam action into a continuous beam action with opposite sides of the beam resisting moment from each other. This reduction in bending moment in turn reduces bending stresses as can be seen in Equation 2 below.

$$
\sigma=\frac{M y}{I}+\frac{P}{A}
$$

Below in Table 5 and Table 6, the strain values of each member has been matched up from the field test data to the modeling data from RISA structural analysis, using several possible modulus' of elasticity. Please refer to Figure 49, in order to identify where each member and strain gage is located. When analyzing this set of data several underlying assumptions have to be made. Firstly, it is difficult to predict in which way a circular column with no weak axis will deflect or bend when under an applied load and where on a circular column to apply a strain gage to see such bending effects. Instead, due to the sheer size of the beams, ranging from $7 "-8.5 "$ in diameter, and relatively small load applied, bending effects will be ignored and columns will only be analyzing for the axial effects experienced. Also, due to previous assumptions concerning support conditions and member connection flexibility, it is assumed that the most accurate modeling results will be from the members closest to the loading. This is due to the fact that as we get farther away from the loading and analyze more distant members there are more connections and thus more opportunities for the errors to propagate due to assumptions taken. The loading analyzed throughout the modeling process was at max load applied, $250 \mathrm{~kg}$, due to the fact that this is where we get our highest readings and many of the smaller loads gave little to no effects. It is also important to note that some of the field test data may not be accurate as wood has many defects and sometimes strain gages may be applied over 
a defect, thus altering the results. The load test was performed twice on the roof truss as to make sure strain gage results read relatively the same in both tests. One can tell a strain gage is malfunctioning or over a defect in the wood if for example, during test one a member may be in compression whereas in test two the member may randomly change behavior and act in tension.

Table 5-Roof Truss Strain Data, Test 1

\begin{tabular}{|c|c|c|c|c|c|c|c|c|c|c|c|}
\hline & Test 1 & & & & & & & & & & \\
\hline & Gauge \#: & 1 & 2 & 3 & 4 & 5 & 6 & 7 & 8 & 9 & 10 \\
\hline & Member & M3 & M3 & M1b & M10b & $\begin{array}{l}\text { M8b } \\
\text { (top) }\end{array}$ & $\begin{array}{l}\text { M8b } \\
\text { (mid) }\end{array}$ & $\begin{array}{l}\text { M8b } \\
\text { (bot) }\end{array}$ & M4 & M5b & M6a \\
\hline & Load (kg) & $\mu \varepsilon$ & $\mu \varepsilon$ & $\mu \varepsilon$ & $\mu \varepsilon$ & $\mu \varepsilon$ & $\mu \varepsilon$ & $\mu \varepsilon$ & $\mu \varepsilon$ & $\mu \varepsilon$ & $\mu \varepsilon$ \\
\hline \multirow{10}{*}{ 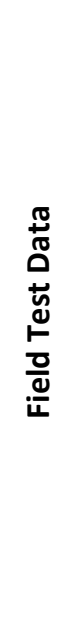 } & 25 & 1 & 1 & -1 & 5 & -1 & 2 & -1 & -1 & 1 & 7 \\
\hline & 50 & 1 & 0 & 1 & 12 & 2 & 8 & -7 & 5 & 0 & 5 \\
\hline & 75 & -1 & 0 & 12 & 21 & 3 & 9 & -11 & 6 & 0 & 8 \\
\hline & 100 & -2 & -21 & 10 & 29 & 5 & 10 & -15 & 14 & -21 & 8 \\
\hline & 125 & -2 & -24 & 10 & 34 & 4 & 13 & -17 & 17 & -24 & 10 \\
\hline & 150 & -4 & -28 & 7 & 42 & 7 & 15 & -25 & 22 & -28 & 6 \\
\hline & 175 & -4 & -28 & 6 & 48 & 7 & 17 & -26 & 24 & -28 & 7 \\
\hline & 200 & -3 & -32 & 5 & 56 & 7 & 19 & -28 & 24 & -32 & 4 \\
\hline & 225 & 2 & -32 & 6 & 64 & 5 & 21 & -29 & 22 & -32 & 6 \\
\hline & 250 & 3 & -32 & 5 & 72 & 7 & 29 & -29 & 19 & -32 & 6 \\
\hline $\begin{array}{c}\text { Risa, } \\
\mathrm{E}=1 \\
\mathrm{msi}\end{array}$ & 250 & -0.12 & -0.12 & 0.48 & 59.53 & -6.82 & -11.02 & -15.22 & -0.18 & -1.05 & -6.02 \\
\hline $\begin{array}{l}\text { Risa, } \\
E=.7 \\
5 \mathrm{msi}\end{array}$ & 250 & -0.16 & -0.16 & 0.65 & 79.37 & -9.09 & -14.69 & -20.29 & -0.24 & -1.40 & -8.03 \\
\hline $\begin{array}{c}\text { Risa, } \\
E=.5 \\
\text { msi }\end{array}$ & 250 & -0.24 & -0.24 & 0.97 & 105.8 & -12.12 & -19.59 & -27.06 & -0.36 & -2.10 & -12.04 \\
\hline
\end{tabular}


Table 6-Roof Truss Strain Data, Test 2

\begin{tabular}{|c|c|c|c|c|c|c|c|c|c|c|c|}
\hline & Test 2 & & & & & & & & & & \\
\hline & Gauge \#: & 1 & 2 & 3 & 4 & 5 & 6 & 7 & 8 & 9 & 10 \\
\hline & Member & M3 & M3 & M1b & M10b & $\begin{array}{l}\text { M8b } \\
\text { (top) }\end{array}$ & $\begin{array}{l}\text { M8b } \\
\text { (mid) }\end{array}$ & $\begin{array}{l}\text { M8b } \\
\text { (bot) }\end{array}$ & M4 & M5b & M6a \\
\hline & Load (kg) & $\mu \varepsilon$ & $\mu \varepsilon$ & $\mu \varepsilon$ & $\mu \varepsilon$ & $\mu \varepsilon$ & $\mu \varepsilon$ & $\mu \varepsilon$ & $\mu \varepsilon$ & $\mu \varepsilon$ & $\mu \varepsilon$ \\
\hline \multirow{5}{*}{ 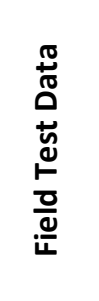 } & 50 & 1 & 1 & 8 & 12 & -6 & 5 & 3 & -4 & -1 & 1 \\
\hline & 100 & 1 & -1 & 6 & 26 & -14 & 6 & 5 & -8 & 0 & 6 \\
\hline & 150 & -1 & -2 & 7 & 37 & -21 & 8 & 6 & 1 & -2 & 4 \\
\hline & 200 & 1 & -2 & 6 & 50 & -27 & 10 & 12 & -7 & -3 & 6 \\
\hline & 250 & -1 & -2 & 6 & 69 & -30 & 13 & 17 & -22 & -4 & 5 \\
\hline $\begin{array}{c}\text { Risa, } \\
E=1 \\
\text { msi }\end{array}$ & 250 & -0.12 & -0.12 & 0.48 & 59.53 & -6.82 & -11.02 & -15.22 & -0.18 & -1.05 & -6.02 \\
\hline $\begin{array}{c}\text { Risa, } \\
E=.75 \\
\text { msi }\end{array}$ & 250 & -0.16 & -0.16 & 0.65 & 79.37 & -9.09 & -14.69 & -20.29 & -0.24 & -1.40 & -8.03 \\
\hline $\begin{array}{c}\text { Risa, } \\
\mathrm{E}=.5 \\
\mathrm{msi}\end{array}$ & 250 & -0.24 & -0.24 & 0.97 & 105.83 & -12.12 & -19.59 & -27.06 & -0.36 & -2.10 & -12.04 \\
\hline
\end{tabular}

The first point that can be observed from the above two tables is how structurally sound the roof truss is. The magnitudes of all the members in both the field test and FE model are very low and show very little strain put onto the system when under a load of even $250 \mathrm{~kg}$. This loading is equivalent to about 3.5 " of snow applied to the each roof truss assuming the roof truss is approximately spaced at $7.25^{\prime}$ intervals.

Assumably the most accurate data will occur at member M10b and strain gage number 4 due to its proximity to the loading as this is the member being loaded with the two point load. As can be seen in both tests this is where the maximum strain occurred with 72 and $69 \mu \varepsilon$ and that the bottom of the beam is in tension. This is to be expected as this is where the two point load is applied, also the bottom of the member is expected to be in tension due to positive 
bending moment occurring. Since both tests are consistent with each other and the member is behaving as expected, member M10b's strain will be directly compared to the FE model results.

In order to get model results close to the values experienced in field testing, a modulus of elasticity of around $.75^{*} 10^{6} \mathrm{psi}$ was found to be most accurate having produced a strain of $68 \mu \varepsilon$ in member M10b. This modulus of elasticity is below that of the three types of woods found in the region, pine, fir, and rosewood. This could be due to fatigue, weathering, and other factors associated with aging of the materials, as well as errors in the modeling process due to support conditions and many other factors previously mentioned. With a modulus of elasticity value lower than that of the domestic wood species producing such structurally sound results, it can be inferred that any of the domestic woods with modulus' of elasticity from $1.48 \times 10^{6} \mathrm{psi}$ and up could have been used for the roof truss.

\subsubsection{Floor System}

The wooden floor system in the Tulou structure is a continuation of the wooden roof truss as the columns that tied into the ground surface from the roof truss also maintain the weight of lateral beams holding the weight of floor loads as well as the loads experienced from the roof truss. This floor system can be seen below in Figure 51. 


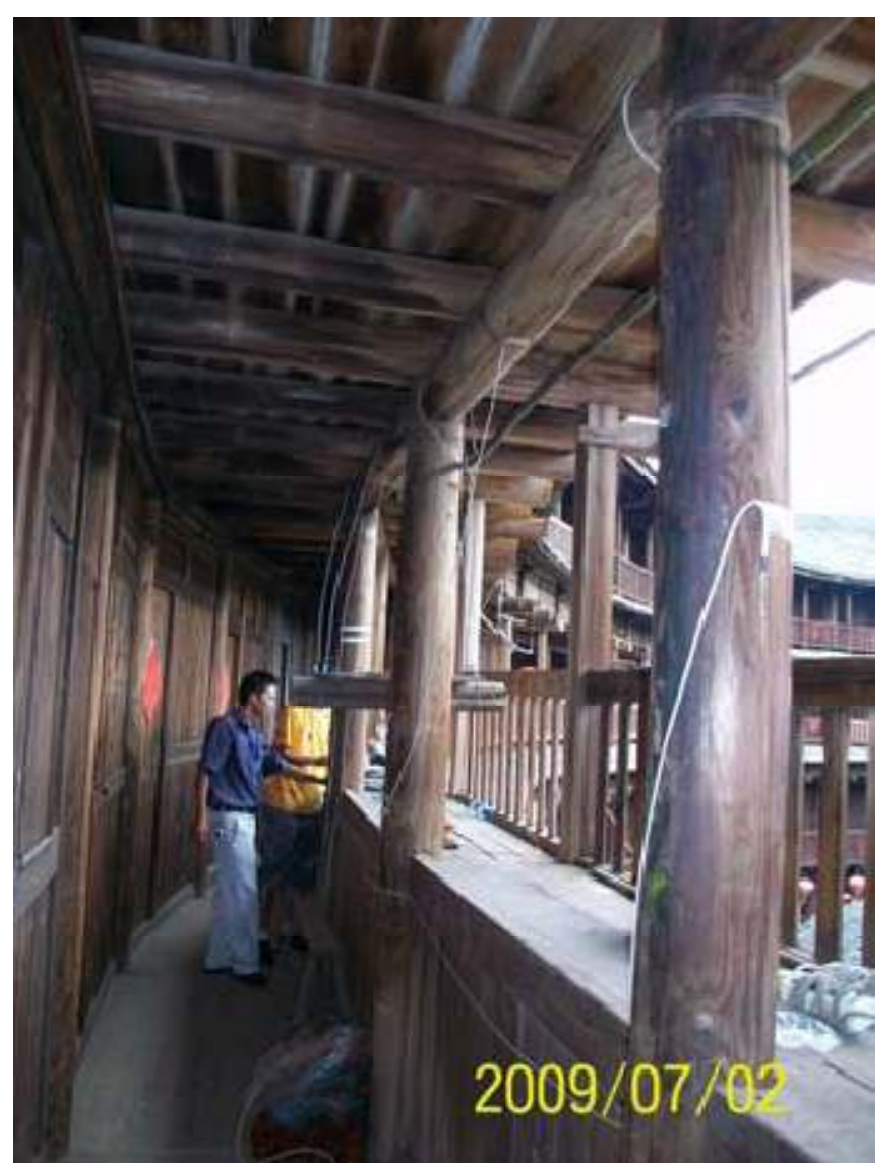

Figure 51-Load Testing of Floor System

In this figure one may observe the large columns that extend from the roof truss down into the ground surface, holding a portion of each floor's load. The lateral beams can also be seen at the top end of the columns, these beams take on the load from the floor and then distribute the load to the columns which then distribute the load into the ground surface.

A FE model of the floor system can be seen below in Figure 52. The same assumptions were taken as during modeling of the wooden roof truss. Strain gage locations and numbers can be seen boxed in green as well as member labels along each member. 


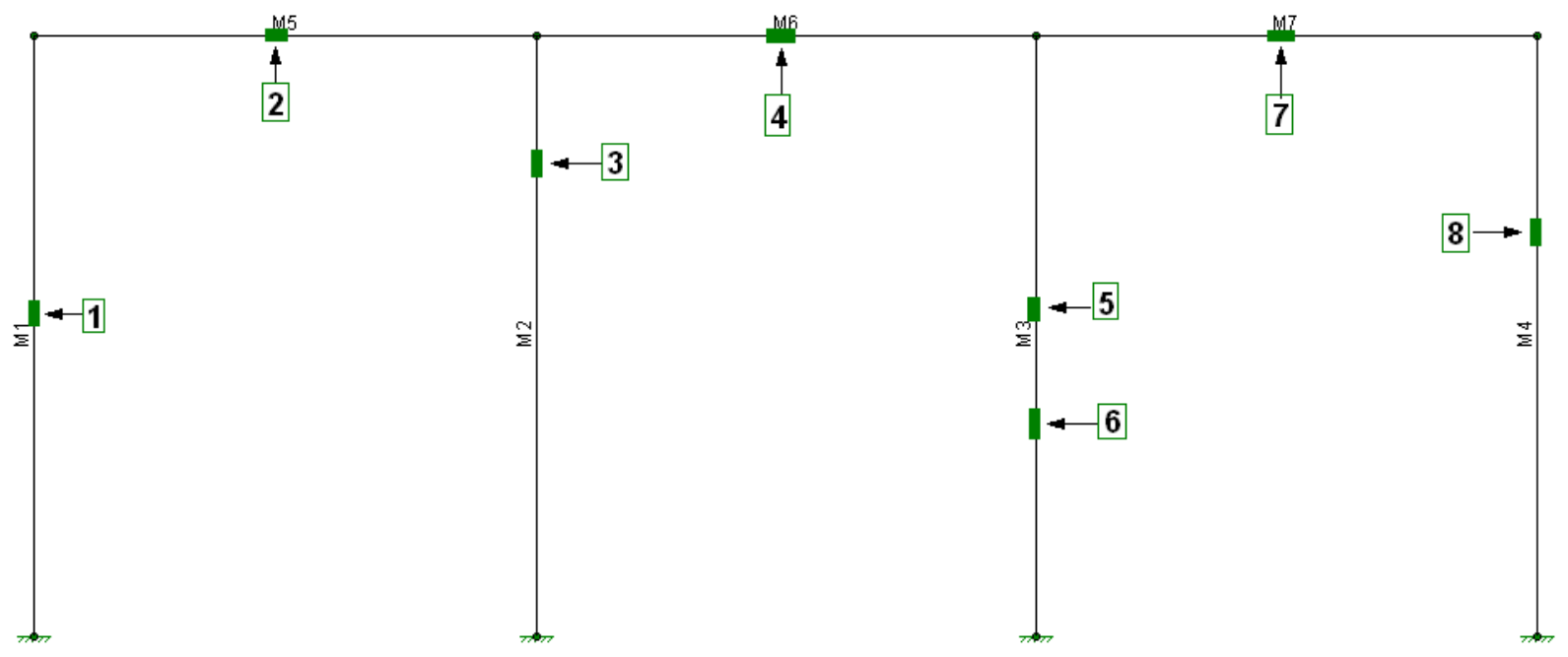

Figure 52-Tulou Floor System Model

A two point load was applied at the middle third of member M6 and strain gage number four was placed at the center and on the bottom of member M6 to experience maximum strain due to the two point load. The test was done in the same manner as with the roof truss test with weight being incrementally added up to a final load of $250 \mathrm{~kg}$. 


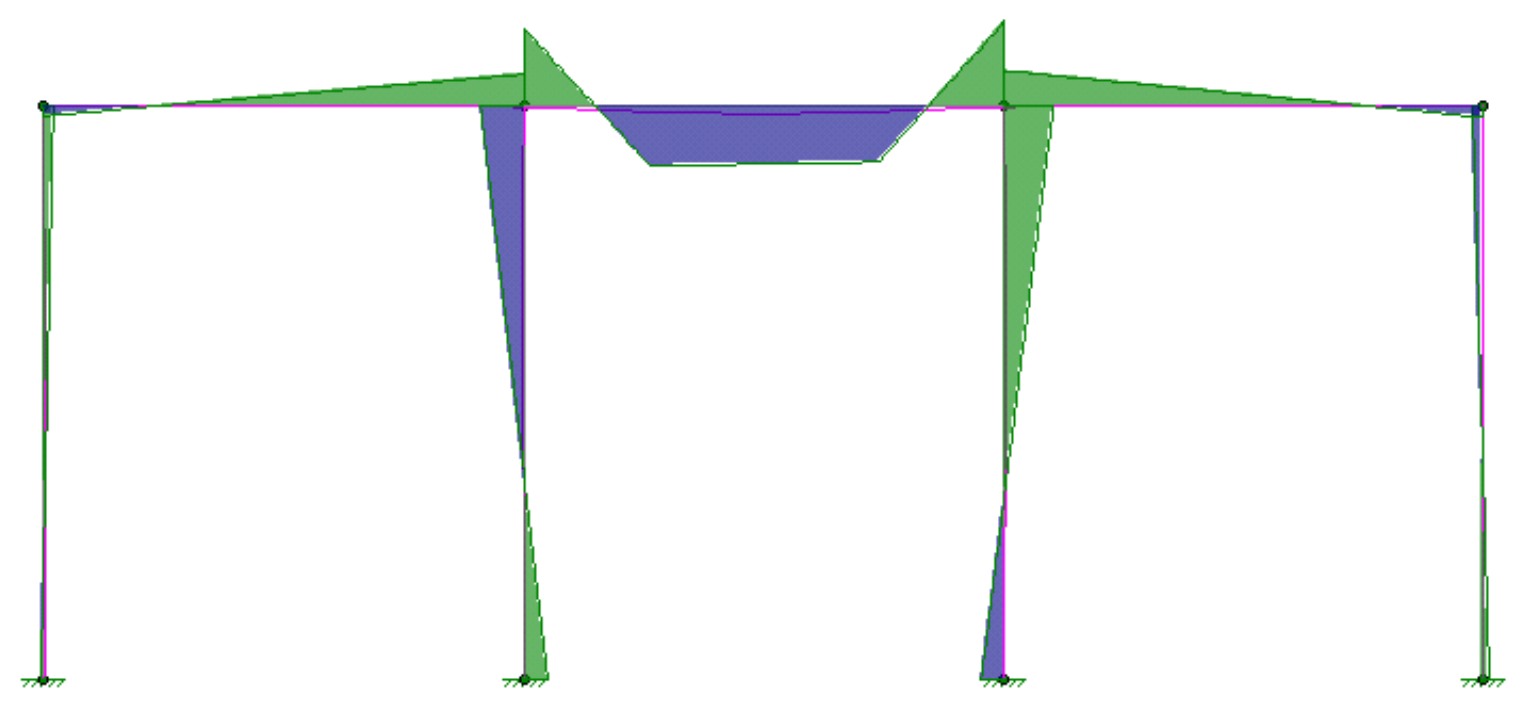

Figure 53-Tulou Floor System Moment Distribution

The moment bending diagram due to a two point load of $250 \mathrm{~kg}$ can be seen above in Figure 53. The moment distribution effect due to a two point load applied to the center beam is minimal beyond the two other sections to the left and right of the beam being loaded. For this reason a section of 3 beams is sufficient for analysis of the floor system when applying a maximum load of $250 \mathrm{~kg}$. Figure 53-Tulou Floor System Moment Distribution, also shows that the maximum moment occurs at the beam being loaded, thus maximum strain also exists at this point, which is to be expected. 
Table 7-Floor System Strain Data, Test 1

\begin{tabular}{|c|c|c|c|c|c|c|c|c|c|}
\hline & Test 1 & & & & & & & & \\
\hline & Gauge \#: & 1 & 3 & 5 & 6 & 8 & 2 & 4 & 7 \\
\hline & Member & M1 & M2 & M3 & M3 & M4 & M5 & M6 & M7 \\
\hline & Load (kg) & $\mu \varepsilon$ & $\mu \varepsilon$ & $\mu \varepsilon$ & $\mu \varepsilon$ & $\mu \varepsilon$ & $\mu \varepsilon$ & $\mu \varepsilon$ & $\mu \varepsilon$ \\
\hline \multirow{5}{*}{ 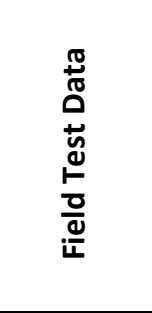 } & 50 & 0 & -1 & 10 & 1 & -2 & 2 & 5 & -2 \\
\hline & 100 & -2 & -4 & 21 & -6 & 3 & 1 & 12 & -2 \\
\hline & 150 & -1 & -6 & 33 & 0 & 6 & 0 & 18 & -1 \\
\hline & 200 & -4 & -11 & 46 & 15 & 3 & -1 & 25 & -2 \\
\hline & 250 & -5 & -11 & 69 & 34 & 16 & -4 & 27 & -1 \\
\hline $\begin{array}{l}\text { Risa, } \\
\text { E=2 msi }\end{array}$ & 250 & 0.20 & -2.99 & -2.63 & -2.63 & 0.24 & -6.73 & 29.43 & -6.18 \\
\hline $\begin{array}{c}\text { Risa, } \\
\text { E=1.5 msi }\end{array}$ & 250 & 0.27 & -3.99 & -3.50 & -3.50 & 0.32 & -8.97 & 39.23 & -8.24 \\
\hline $\begin{array}{l}\text { Risa, } \\
\text { E=1 msi }\end{array}$ & 250 & 0.40 & -5.99 & -5.25 & -5.25 & 0.48 & -13.45 & 58.85 & -12.36 \\
\hline $\begin{array}{c}\text { Risa, } \\
\text { E=.5 msi }\end{array}$ & 250 & 0.80 & $\begin{array}{c}- \\
11.97\end{array}$ & -10.50 & -10.50 & 0.97 & -26.90 & 117.70 & -24.72 \\
\hline
\end{tabular}

Table 8-Floor System Strain Data, Test 2

\begin{tabular}{|c|c|c|c|c|c|c|c|c|c|}
\hline & Test 2 & & & & & & & & \\
\hline & Gauge \#: & 1 & 3 & 5 & 6 & 8 & 2 & 4 & 7 \\
\hline & Member & M1 & M2 & M3 & M3 & M4 & M5 & M6 & M7 \\
\hline & Load (kg) & $\mu \varepsilon$ & $\mu \varepsilon$ & $\mu \varepsilon$ & $\mu \varepsilon$ & $\mu \varepsilon$ & $\mu \varepsilon$ & $\mu \varepsilon$ & $\mu \varepsilon$ \\
\hline \multirow{5}{*}{ 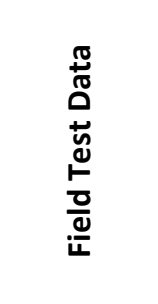 } & 50 & -1 & -5 & 4 & -7 & -2 & -5 & 4 & -6 \\
\hline & 100 & -3 & -7 & 12 & -14 & -4 & -7 & 9 & -8 \\
\hline & 150 & -7 & -13 & 19 & -19 & -5 & -13 & 22 & -9 \\
\hline & 200 & -6 & -14 & 31 & -24 & -4 & -14 & 30 & 17 \\
\hline & 250 & -9 & -16 & 48 & -38 & -2 & -16 & 37 & 23 \\
\hline $\begin{array}{c}\text { Risa, } \\
\mathrm{E}=1.5 \mathrm{msi}\end{array}$ & 250 & 0.27 & -2.99 & -2.63 & -2.63 & 0.24 & -6.73 & 29.43 & -6.18 \\
\hline $\begin{array}{l}\text { Risa, } \\
\text { E=1 msi }\end{array}$ & 250 & 0.40 & -3.99 & -3.50 & -3.50 & 0.32 & -8.97 & 39.23 & -8.24 \\
\hline $\begin{array}{c}\text { Risa, } \\
E=.5 \mathrm{msi}\end{array}$ & 250 & 0.80 & -5.99 & -5.25 & -5.25 & 0.48 & -13.45 & 58.85 & -12.36 \\
\hline $\begin{array}{c}\text { Risa, } \\
\mathrm{E}=.35 \mathrm{msi}\end{array}$ & 250 & 1.14 & -11.97 & -10.50 & -10.50 & 0.97 & -26.90 & 117.70 & -24.72 \\
\hline
\end{tabular}


Table 7 and Table 8 above show the results of the two tests that were run at the same location. The first observation that can be made is that the magnitudes of all the strains are once again very low, showing that the floor system is structurally sound just as was the wooden roof truss. The second observation that can be seen is that a maximum strain of 69 and $48 \mu \varepsilon$ is found on member 3, a column, which is not to be expected. Member 3 had two strain gages applied to it, numbers 5 and 6 , in test one both show that the column is in tension and in test two, one gage is in tension and another gage is in compression. Under our initial assumption bending effects were to be ignored for the columns due to the small load applied and relative large size of the columns. Due to bending effects being ignored it is to be expected that the columns would be in compression. If any of the gages were in tension in the column this would show that there is a bending effect, however the fact that the two load tests are not consistent with each other, as well as not knowing the exact orientation of the gages on the column, complicates the analysis of the behavior of the columns. Ignoring the column data, the maximum strain does occur at member 6 and strain gage 4 with a strain of 27 and $37 \mu \varepsilon$ from the two load tests at $250 \mathrm{~kg}$. By once again back calculating and trying to simulate this strain at this location in the model, one can see that a modulus of elasticity between $2 * 10^{6}$ to $1.5^{*} 10^{6}$ psi appears to match fairly closely with modeled strains of 30 and $40 \mu \varepsilon$. With such a high modulus of elasticity it can be inferred that the most likely wood species used here is China-fir with the highest modulus of elasticity of all the local species at close to $2 * 10^{6}$ psi.

It is of interest to note that such load testing on floor systems has been performed previously by WVU on domestic historic structures. One example of such load testing was on the building floor system of Sand Fork elementary school, West Virginia, which was built in 1921. Wooden floor joists which were 2"x12" and spanned from $20 \mathrm{ft}$ to $23 \mathrm{ft}$ were loaded with 
distributed loads of 40 and 80 psf. There too, magnitudes of maximum strain were similar to that of the Hakka Tulou with most strains being under $100 \mu \varepsilon$. During one test, an 1,000 lb concentrated load was applied to a floor joist resulting in only a strain of $234 \mu \varepsilon$. Complete data from this floor joist load test can be seen in Appendix A. This example of load testing proves that such low strain values is not uncommon in historic structures with wooden systems and further validates the strain values found during load testing at the Hakka Tulous.

\subsubsection{Conclusions}

The strain gage results show that both the wooden roof truss and floor system are structurally sound even with such a high age of the structure. A load of $250 \mathrm{~kg}$ had a very minimal impact on the structures tested. From FE modeling analysis and analysis of data, one can see that for the roof truss a modulus of elasticity of $.75^{*} 10^{6}$ psi matched the field test results closely and for the floor system a modulus of elasticity from $2 * 10^{6}$ to $1.5^{*} 10^{6}$ psi matched the field test results closely. This means that for the roof truss any of the local wood species would have sufficed since all have a modulus of elasticity above $.75^{*} 10^{6} \mathrm{psi}$, whereas for the floor system China Fir was the only species of wood with such a high modulus of elasticity. The difference in strength between the roof truss and floor system could be due to any number of factors. Although the roof system and floor system could be made out of different types of wood, it is more likely that they were created from the same source, in this case China-Fir. China-Fir exemplifies excellent structural strength as well as high decay resistance which also explains how the Tulous are able to maintain their structural strength over such a long period of years. This assumption is also confirmed by Fuping Wang, in his text, A History of the Tulou Buildings, in which he states that China fir timber is used in the construction of the Hakka 
Tulous (Wang 2008). It has been found that China-Fir's high decay resistance comes from oils within the wood which gives it a natural resistance to both fungi and termites (Lu et al. 1987).

Table 9- Load Sharing Effects of Floor and Roof Truss Systems of Chengqi Tulou

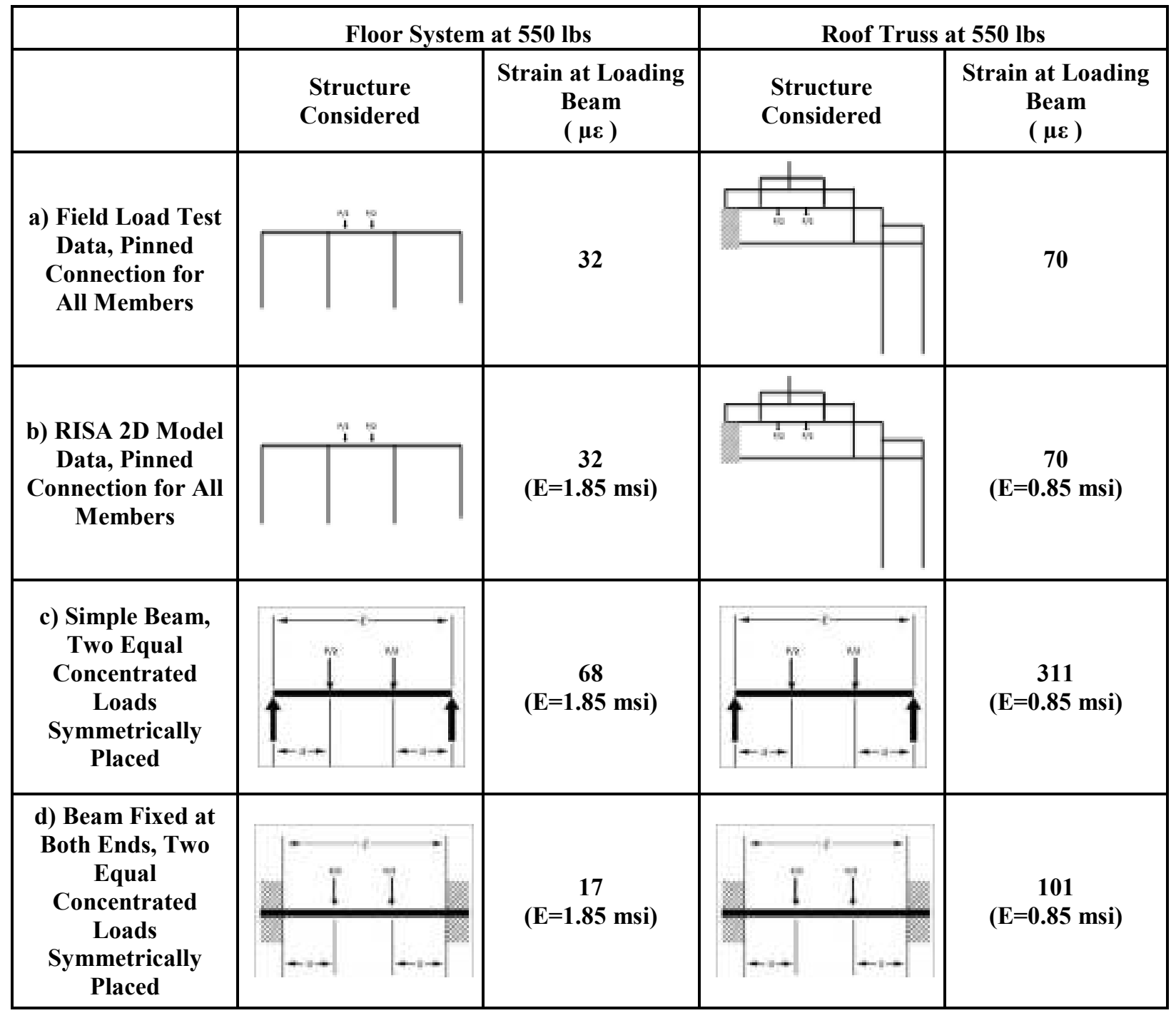

One can observe that for the floor system and roof truss under the loading scenario presented in Table 9, a simple beam analysis with boundary conditions of fixed-fixed or pinnedpinned is adequate. As mentioned previously, all realistic connections typically fall in between a fixed or pinned boundary. In a simple beam, or one that exemplifies pinned boundary conditions, moment transfer is zero and rotation is allowed, whereas for $100 \%$ fixed boundary 
conditions, rotation is restrained and thus $100 \%$ of the moment is transferred. For the floor system if one is to look at a theoretical simple beam, the maximum strain is found to be 68 microstrain whereas using fixed boundary conditions results in the maximum strain to be 17 microstrain. From actual testing we find that the maximum strain is 32 microstrain which reveals that the actual boundary conditions represent a $71 \%$ fixed end condition which means that $71 \%$ of the moment will be redistributed to the remainder of the structural system. This result demonstrates that the jointed neighboring members have a high load-sharing effect in a manner similar to a fixed beam. Similarly, for the roof truss load test, for the simple beam case a maximum strain of 311 microstrain was found and for the fixed beam end support case a maximum strain of 101 microstrain was found. Field measurements resulted in a maximum strain of 70 microstrain which show that this system behaves very similarly to fixed end conditions. Also because the actual beam tested in the field is continuous it is expected that the results would be lower than for a non-continuous fixed end condition beam. The continuity of the beam allows for the rotation to be resisted by the rest of the member and thus actual strain results are lower than a non-continuous fully fixed beam.

It is interesting to note that if one is to model both the wooden roof truss and floor system using the conservative parameters found for the Chengqi roof wood in section 3.4.2.2.2, the system is still found to be structurally sound. By using the modulus of elasticity of 57,308 psi found by material testing of the roof beam, we find that a maximum stress of $89 \mathrm{psi}$ is induced in the floor system and a maximum stress of $128 \mathrm{psi}$ is induced in the roof system. These values are not near the ultimate strength of the material and so it can be said that even though material testing and load testing results did not concur with each other, both show that the system is structurally sound. For analysis purposes, the most accurate data most likely comes from load 
testing as the whole system is considered during testing and in the data, whereas for material testing only small cut out samples of larger beams were able to be used for analysis, most likely altering actually strengths of the system as a whole. 


\section{CHAPTER 4 FE MODELING EVALUATION}

\subsection{Introduction}

Rammed earth structures have existed on this earth for thousands of years in regions that exhibit both hurricane force winds, typhoons, and earthquakes. In these regions, civilization has seen modern construction fall victim to nature's power whereas the older rammed earth structures have been able to withstand these conditions through the test of time. Nowhere else is this situation more prevalent than in the Fujian Province of China which is prone to earthquakes. Here the Hakka Tulous have lasted for hundreds of years, outlasting newer, more modern construction. Since the $11^{\text {th }}$ century, seven earthquakes of magnitude 5 or higher on the Richter scale have been recorded in the region. Some Tulou buildings have displayed cracks in their walls and broken roof tiles because of the earthquakes, however there has been no structural damage to any of the Tulous in the region. One specific example of a Tulou's resistance to an earthquake can be seen from the 1918 earthquake that registered at 7.0 on the Richter scale near the Huanji Tulou which was built in 1693. After the earthquake, it was reported that a crack had formed on the rammed earth wall measuring $20 \mathrm{~cm}$ in width and 3 meters in length. The locals claim that this crack has self healed since the earthquake and after measuring the width of the crack in the summer of 2009 , it has been found that the crack is now only $5 \mathrm{~cm}$ in width. A picture of the crack in the Huanji Tulou can be seen in Figure 54. If in fact the crack was originally $20 \mathrm{~cm}$ in width as initially reported, there could be some kind of self healing process that can possibly be explained scientifically. In order to further analyze the structural behavior of the Hakka Tulou buildings, finite element modeling using RISA structural engineering 
software created by RISA technologies will be used to duplicate the structural behavior experienced in real world conditions.

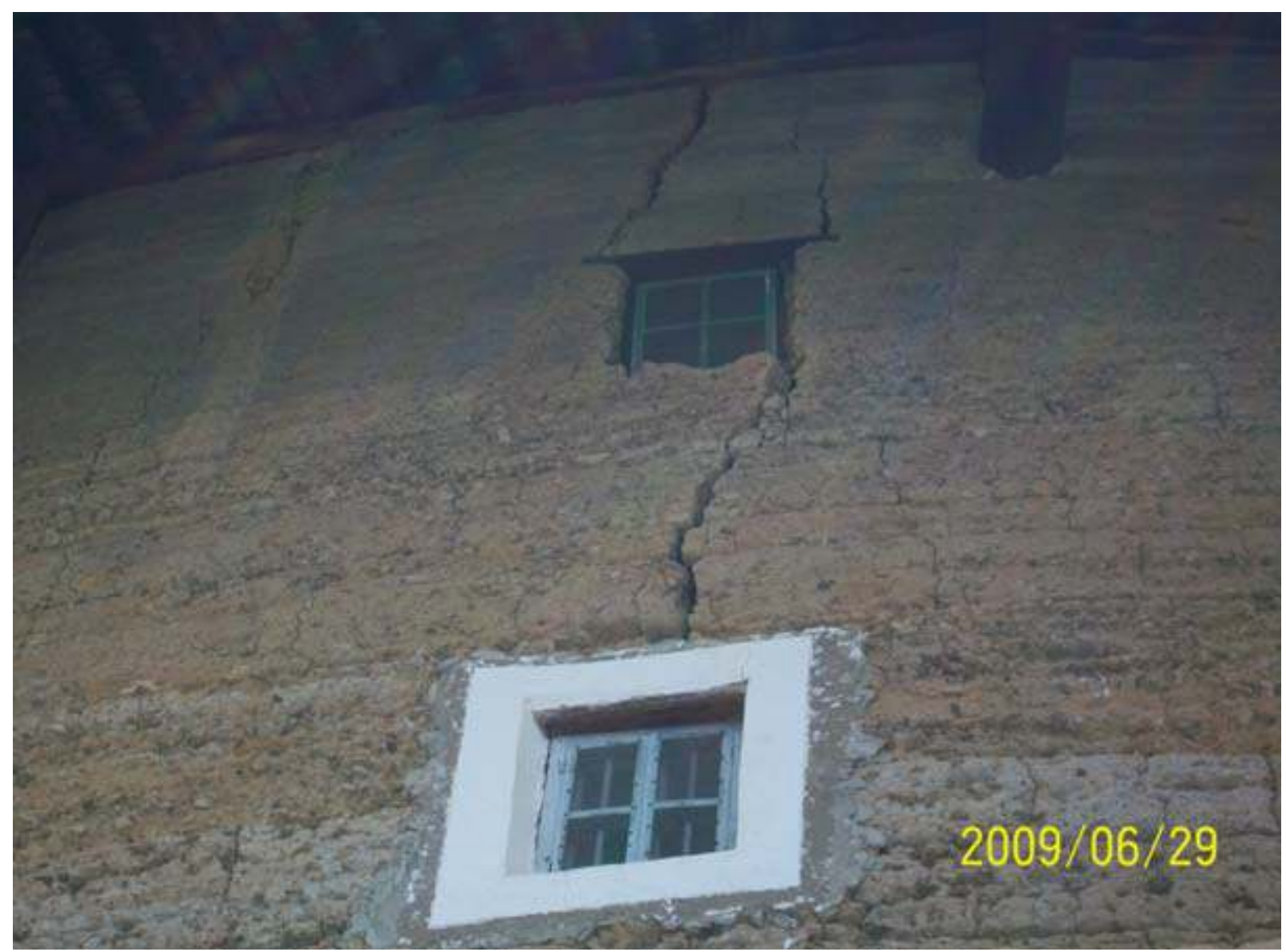

Figure 54-Reported Huanji Tulou Crack After Earthquake

Many of the Hakka Tulous' rammed earth walls were created with wood or bamboo strips within them acting as reinforcement to strengthen the rammed earth walls. The Huanji Tulou, where the crack appeared after the earthquake, coincidentally did not have any reinforcement within the rammed earth walls as proven by the Infrared Thermography Camera (IRT). If the wall were truly self healing, a section of the surrounding rammed earth wall would have debonded from the wall rib, be it either wood or bamboo. The cavity that would have been left in the place of the debonded wall rib and surrounding earth wall could have been captured by 
the IRT camera to prove that such healing has occurred. Unfortunately since there is no reinforcement, we cannot immediately justify the self-healing story and instead must attempt to validate the story by recreating a possible scenario.

\subsection{Rule of Mixtures}

By reinforcing the rammed earth walls with either wood or bamboo, the overall strength of the wall increases. In this section, the rammed earth from the weakest Tulou, Wuyun Tulou, will be analyzed with and without reinforcement in order to quantify the strength increase provided by reinforcement. To see the effect that wood and bamboo reinforcement have on the strength of a rammed earth wall, one must use the rule of mixtures Equation for the longitudinal modulus, $\mathrm{E}_{1}$, which can be seen in Equation 3 below.

$$
\mathrm{E}_{1}=\mathrm{E}_{\mathrm{f}} \mathrm{V}_{\mathrm{f}}+\mathrm{E}_{\mathrm{m}}\left(1-\mathrm{V}_{\mathrm{f}}\right)
$$

Where " $E_{1}$ " is the longitudinal modulus of elasticity, " $E_{f}$ " is the modulus of elasticity of the fiber, or in this case the reinforcing wood or bamboo strips, " $E_{m}$ " is the modulus of elasticity of the matrix, or in this case the rammed earth, and " $\mathrm{V}_{\mathrm{f}}$ " is the volume fraction of fiber or reinforcing strips. According to Barbero (1999) this Equation implies that the fiber-matrix bond is perfect and that " $\mathrm{E}_{1}$ " is mainly a fiber dominated property. Knowing that the bond between rammed earth and wood or bamboo will never be perfect, this Equation is likely to result in a liberal value when compared to the actual longitudinal strength. The transverse modulus of elasticity, " $\mathrm{E}_{2}$ ", can also be found for a given composite using the inverse rule of mixtures as seen in Equation 4 below.

$$
\frac{1}{E_{2}}=\frac{V_{m}}{E_{m}}+\frac{V_{f}}{E_{f}}
$$


Where " $\mathrm{E}_{2}$ " is the transverse modulus of elasticity that is perpendicular to the direction of the fibers and " $\mathrm{V}_{\mathrm{m}}$ " is the volume fraction of the matrix, or in this case the rammed earth. All other variables are the same as described under Equation 3. Barbero (1999) notes that for the inverse rule of mixtures, the fibers do not have a significant impact to the stiffness in the transverse direction unless the volume of fibers is high, otherwise this is a property dominated by the matrix, or rammed earth in this case. Barbero (1999) also mentions that this Equation is typically not accurate and that it typically underestimates the transverse Modulus and thus should only be used for qualitative evaluation rather than for design. Since earth is a monolithic material, and the volume of reinforcement is generally low, it is a conservative assumption to take " $E_{2}$ " as simply the modulus of elasticity of the rammed earth.

IRT technology was initially used in order to find the volume of wood or bamboo used as reinforcement within the rammed earth walls. However, it was found that the IRT was not sensitive enough to detect the difference in the heat transfer rate between the walls with or without wall ribs, this can be seen below in Figure 55. 


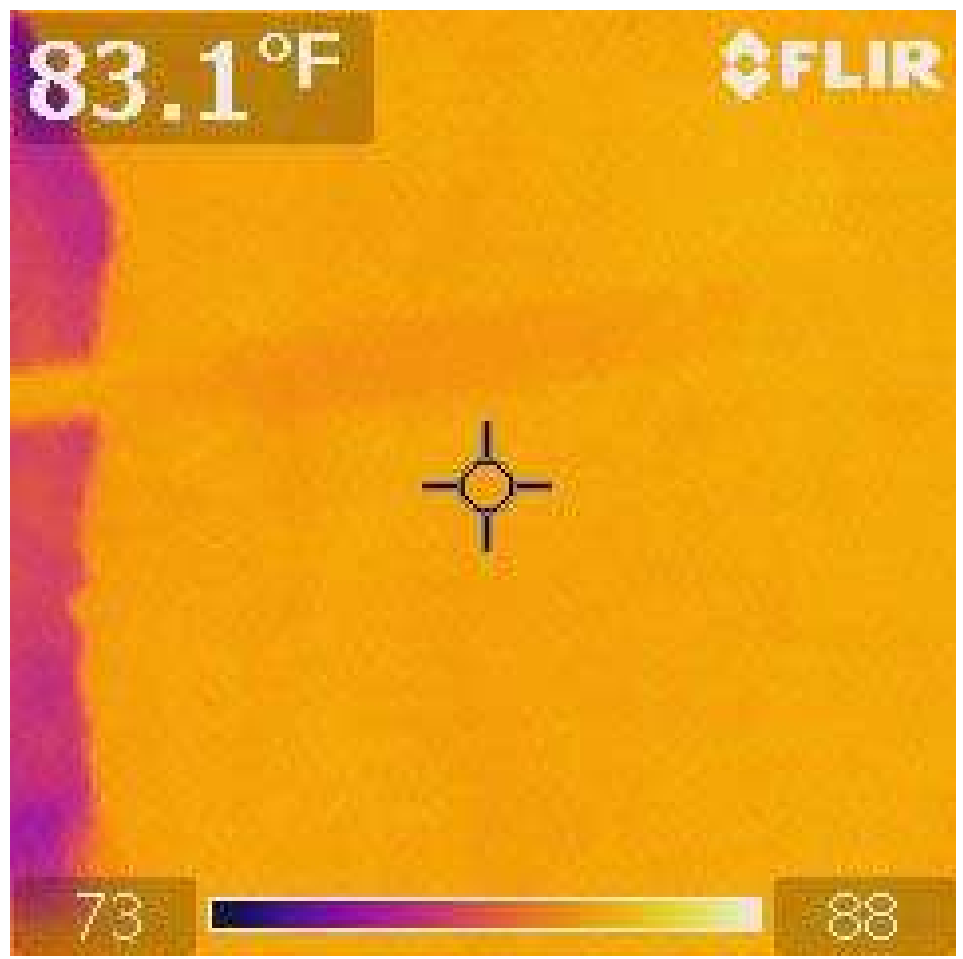

Figure 55-IRT Detects Shadow of Wall Rib

IRT cameras were not able to identify whether the bond between the earth and the wall ribs is good or not. This is because the temperature gradient is not large enough between them, and because IRT is only able to identify defects at a limited depth. Instead of using IRT cameras to estimate the volume of reinforcement, a visual estimate has to be taken from Figure 23 which can be seen in section 3.4.1.2. Dimensions were taken of the protruding wooden wall ribs, the wall, as well as spacing of the wall ribs. With such dimensions, a rough estimate can be calculated of the volume of reinforcement used for the sample cross section, also known as the fiber volume fraction, and apply it to the entire structure. Based on the samples collected, it can be seen that the wooden samples were typically round and varying at around 1.5 inches in diameter, which results in a fiber cross section area of $1.767 \mathrm{in}^{2}$. Bamboo samples were broken up into rectangular shapes with dimensions typically around 0.5 inch $x 1$ inch, which results in a fiber cross section area of $0.5 \mathrm{in}^{2}$. If one is to assume that the same spacing is used for both 
wood reinforcement and bamboo reinforcement as exhibited by the exposed wall ribs in Figure 23 , then the volume fraction for wood reinforcement comes out to 0.067 or $6.7 \%$ and the volume fraction for bamboo reinforcement comes out to 0.018 or $1.8 \%$. From the earlier section Material Tests, one can see that the most conservative modulus of elasticity for wooden wall ribs is in tension and is found to be $34,737 \mathrm{psi}$ and that the modulus of elasticity of bamboo in tension is found to be 463,178 psi. For modeling purposes and in order to be conservative, the modulus of elasticity used to represent the rammed earth due to it being the weakest of all samples tested, is 1,706 psi from the Wuyun Tulou. From the data collected, fiber volume fraction, modulus of elasticity of the fiber, and modulus of elasticity of the matrix, the values were then plugged into Equation 3 in order to find the longitudinal modulus of elasticity, " $\mathrm{E}_{1}$ ". A summary of the results can be seen in Table 10 .

Table 10-Composite Moduli, $\mathbf{E}_{1}$

\begin{tabular}{|c|c|c|c|}
\hline Type of & Volume & Fiber Modulus & Composite Longitudinal \\
\hline Reinforcement & Fraction (\%) & of Elasticity (psi) & Modulus, $\mathrm{E}_{1}$ (psi) \\
\hline None & $\mathrm{n} / \mathrm{a}$ & $\mathrm{n} / \mathrm{a}$ & 1705.5 \\
\hline Wood & $6.70 \%$ & 34736.67 & 3918.6 \\
\hline Bamboo & $1.80 \%$ & 463178.1 & 10012 \\
\hline
\end{tabular}

As can be seen in the table above, reinforcing the rammed earth with wood made the wall over two times stronger than without reinforcement, with a composite longitudinal modulus of 3,919 psi. Reinforcing the wall with bamboo made the rammed earth wall nearly six times stronger, with a composite longitudinal modulus of 10,012 psi.

It is important to note that these findings are based on the assumptions that the spacing throughout the entire rammed earth wall of the Tulou is similar to that of the cross section seen in Figure 23 and that both wood and bamboo are spaced equally center to center as seen in the cross section, meaning that the same number of samples were used for both materials with wood 
consuming a larger area with its larger cross section area. With these assumptions in mind it is still obvious to see that with a volume fraction $5 \%$ less than that of wood, bamboo, if properly bonded with the rammed earth, has a much larger impact on the composite longitudinal modulus with less volume than the wood. The material used for reinforcement of the rammed earth walls was most likely chosen by what was locally available in the region of the Tulou. Regardless of what material was used for reinforcement, both wood and bamboo have a significant impact on increasing the longitudinal modulus of the rammed earth wall. This increase in longitudinal modulus of elasticity also has a correlation with the increase of ultimate strength of the material as has been exhibited in other materials such as concrete, although further research would need to be performed in order to discover the actual correlation for reinforcement of rammed earth construction.

Rammed earth has a similar density to that of concrete with a density of $100 \mathrm{lb} / \mathrm{ft}^{3}$ where as concrete's density can range from $90-155 \mathrm{lb} / \mathrm{ft}^{3}$ (Engineering Toolbox 2005). To find the ultimate strength of concrete, knowing the density and modulus of elasticity, an empirical Equation has been provided by ACI 318 as can be seen in Equation 5 below.

$$
\mathrm{E}=33 \rho^{1.5} \sqrt{f c^{\prime}}
$$

In this Equation the density is input as $\mathrm{lb} / \mathrm{ft}^{3}$ and the ultimate compressive strength, $\mathrm{fc}$ ' is input as psi with the output, E, in psi. Such a relation currently does not exist for rammed earth and most likely cannot due to the complexities of the material's composition, thus the ultimate strengths must be assumed correct from the material tests in section 3.4.1.1. Ultimate compressive strengths for rammed earth typically range from 450-800 psi (Earth Materials 2010). From the material tests, according to Xiamen University data, the older square Fuxing and Wuyun Tulou of 1,240 and 500 years of age have an ultimate compressive strength of 282 
and 133 psi, whereas the younger, round Zhencheng Tulou of 100 years has an ultimate compressive strength ranging of 196 psi. According to West Virginia University Data, the 300 year old Chengqi Tulou displayed the highest ultimate strength of 411 psi while the Zhencheng Tulou displayed an ultimate strength of only 126 psi. Aging may have played a role in degrading the ultimate strength of the materials as only the Chengqi Tulou data show typical ultimate strength values for that of rammed earth. Future research must be done in order to further explore how reinforcement of the rammed earth impacts the material's strength.

\subsection{Self Healing Crack?}

\subsubsection{Understanding Why the Crack Developed}

As mentioned earlier in section 4.1 Introduction, a strong earthquake measuring 7.0 on the Richter scale reportedly created a large crack in the rammed earth wall of the Huanji Tulou. This crack can be seen earlier in Figure 54, forming around the wooden lintel. The wooden lintel is the frame located around the window, its purpose is to direct the structural load coming from the weight of the walls, as well as other forces, away from the window. With a properly installed lintel, the window should experience little to no force coming from the rammed earth walls. In order to further understand whether this crack has self healed from $20 \mathrm{~cm}$ thick to $5 \mathrm{~cm}$ thick, one must analyze why the crack occurred here in the first place. A model of the lintel as well as the rammed earth wall was created in RISA Structural Analysis with dimensions similar to that of the Huanji Tulou as can be seen below in Figure 56. 


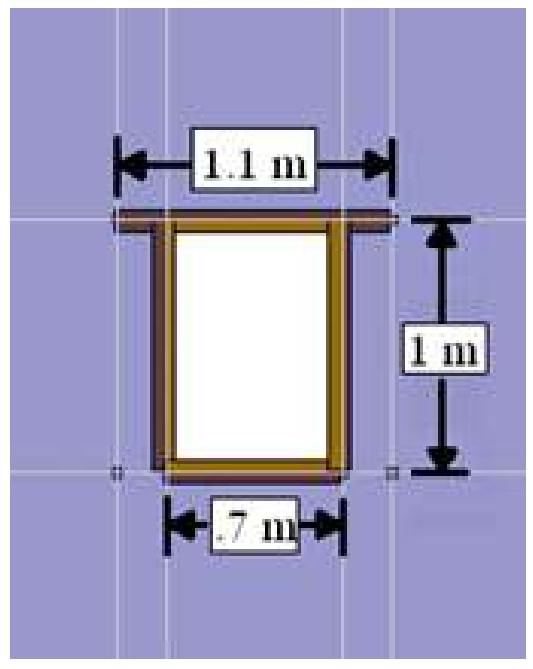

Figure 56-Model Lintel Dimensions

In the model of the lintel and window a wall thickness of 1.8 meters was used, as measured at the base of the Huanji Tulou. The wall thickness in Tulous decreases minimally as the height increases however this difference is small and so for the model a uniform wall thickness of 1.8 meters was used. For the lintel, $2 \times 4$ larch was used for analysis since the primary interest is simply the behavior of the lintel structure. Also, a modulus of elasticity of 1,706 psi was used for the rammed earth in the model as no rammed earth samples were tested from the Huanji Tulou and this value is the most conservative found through material testing of other Tulous. Knowing that rammed earth has a density of $1,600 \mathrm{~kg} / \mathrm{m}^{3}$, one can calculate the dead load experienced due to the weight of the rammed earth wall on top of the lintel (Engineering Toolbox 2005). The rammed earth wall extends 2.75 meters from the top of the lintel to the top of the wall, this height multiplied with the wall thickness results in a distributed dead lead of $7,920 \mathrm{~kg} / \mathrm{m}$ that acts on the top of the lintel. In reality, the lintel also supports a portion of the roof loads that are distributed throughout the wooden frame system and the rammed earth walls, however it will be assumed that most of the force comes from the weight of the rammed earth walls. A step by step pictorial reference of how the lintel acts when under this 
dead load force can be seen below in Figure 57.

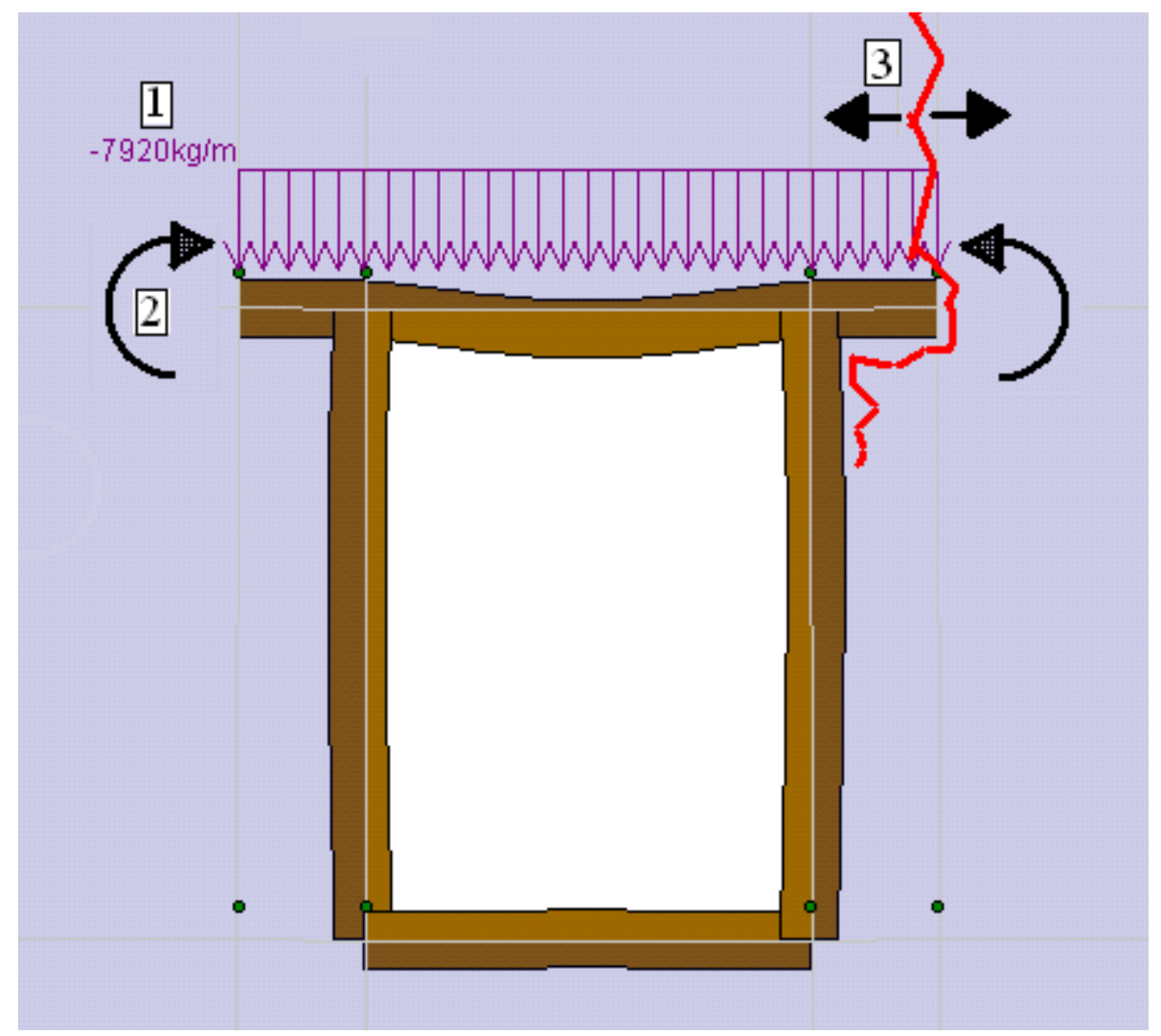

Figure 57-Lintel Behavior

Figure 57 shows a deflection image of the lintel resulting from the dead load of the rammed earth walls. The deflections of the lintel are magnified by a factor of ten in order to effectively display the behavior of the lintel. Step one shows the dead load of the rammed earth acting on the top portion of the lintel. From here a positive bending moment is created as can be seen in step two. This positive bending moment allows the lintel to bend downwards in the center and slightly upwards at the ends. The upward deflection that is experienced at the ends of the lintel creates a compression action in the vertical direction of the rammed earth wall. The rammed earth wall will most likely not be in pure compression and will tend to buckle either inwards or outwards. This buckling will then create a tension action in the horizontal direction of the rammed earth. Step three shows the tension action that is experienced within the rammed 
earth walls and then shows the predicted crack pattern due to tension failure of the material. A close up image of the crack at the Huanji Tulou forming directly at the ends of the lintel due to tensile splitting can be seen below in Figure 58.

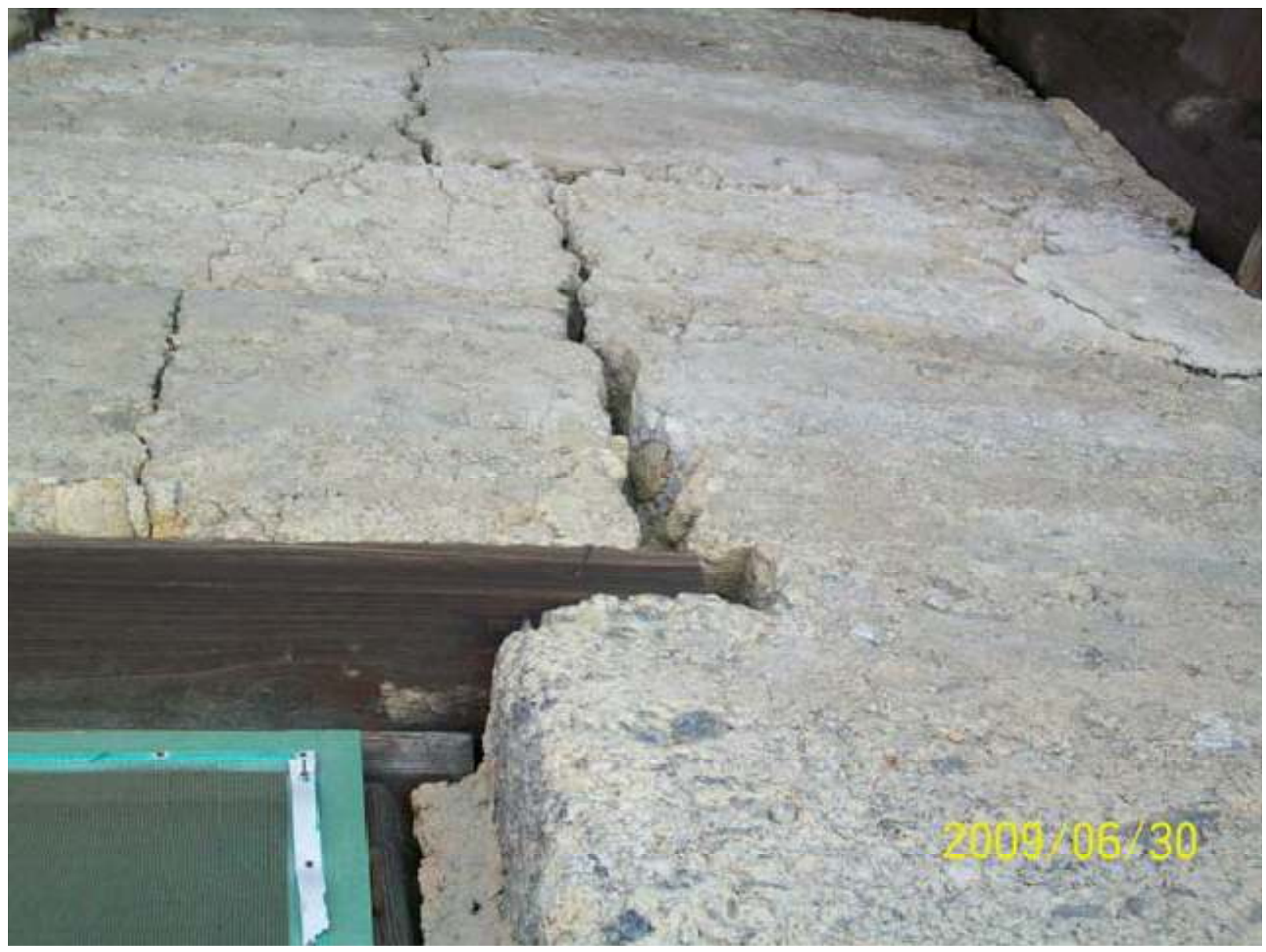

Figure 58- Cracking at Lintel Ends

Since rammed earth, similar to concrete, is weaker in tension than compression, tensile splitting will be the primary failure mode. For a crack to occur, the crack must find the easiest path of travel, or in this case the areas of greatest stress concentration. A stress distribution due to dead load experienced on the lintel can be seen below in Figure 59. 


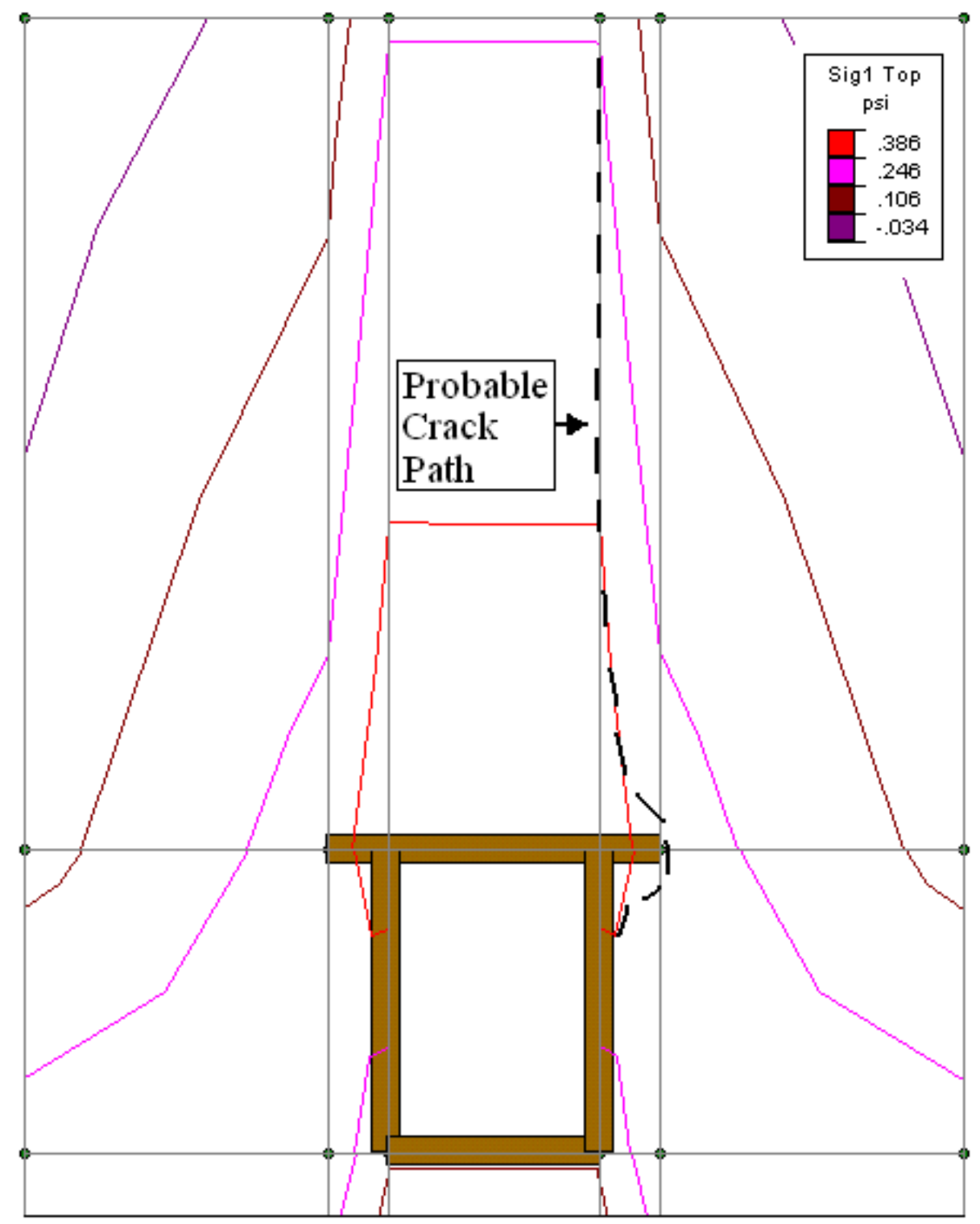

Figure 59-Lintel Dead Load Stress Distribution

Failure analysis will be performed using the maximum principle stress theory also known as the Rankine stress theory. This theory states that the material will yield when any of the principle stresses reaches the yielding stress (Benham 1973). As mentioned earlier, for rammed earth the material will yield first in the transverse direction $\left(\sigma_{2}\right)$ due to the material being much weaker in tension. RISA structural analysis provides principle stresses as well as von Mises stresses for the model. The von Mises stress theory uses the difference between all the principle 
stresses to define a yielding value that is known as distortion strain energy. The von Mises theory is found to most accurately model ductile materials (Benham 1973). Through numerous testing it has been found that the maximum stress theory works best for predicting failure in brittle materials such as concrete, cast-iron, and ceramics. (Benham 1973). As rammed earth is a brittle material, analysis of the material will be performed using the Rankine stress theory.

It is important to note that in the RISA structural analysis software, tension is labeled as a negative value and compression is labeled as a positive value. The stress distribution above shows the stress, $\sigma_{1}$, which is the stress in the vertical direction of the wall. The model proves that the lintel does create a compression action on the rammed earth walls in the vertical direction. Figure 59 also shows where the maximum compressive stress is located and thus where most buckling action is likely to occur. By knowing where the greatest stress occurs one can map a probable crack path started from the lintel and continue in areas of greatest stress. The dead load alone is not enough to create cracking in the rammed earth walls as the greatest stress shown in the model is $.386 \mathrm{psi}$. In material tests the oldest Tulous' rammed earth had ultimate compressive strengths of at least $126 \mathrm{psi}$ and the newer Tulous had strengths much higher than that. Even if one is to be conservative and take the earth's ultimate compressive strength at $126 \mathrm{psi}$, the system is still not close to cracking under self weight, which is to be expected. Failure in the rammed earth walls represented by cracking will occur due to stresses in the $\sigma_{2}$ or horizontal direction. Stresses in the horizontal direction are in tension due to buckling which means that the material will fail earlier than the ultimate compressive strength, knowing that it is stronger in compression than in tension. Since we only know that rammed earth is weak in tension, one must assume that the material will fail in the transverse direction $\left(\sigma_{2}\right)$ at a stress much lower than the ultimate compressive strength of the material. There is a direct correlation 
between $\sigma_{1}$ and $\sigma_{2}$ as the more the material is in compression, the more buckling will occur and thus more tension force applied in the horizontal direction. Still the stresses due to self weight are far too low to create cracking, instead one must analyze the system when external loads are applied, thus multiplying the effect of the dead load and increasing the existing stresses.

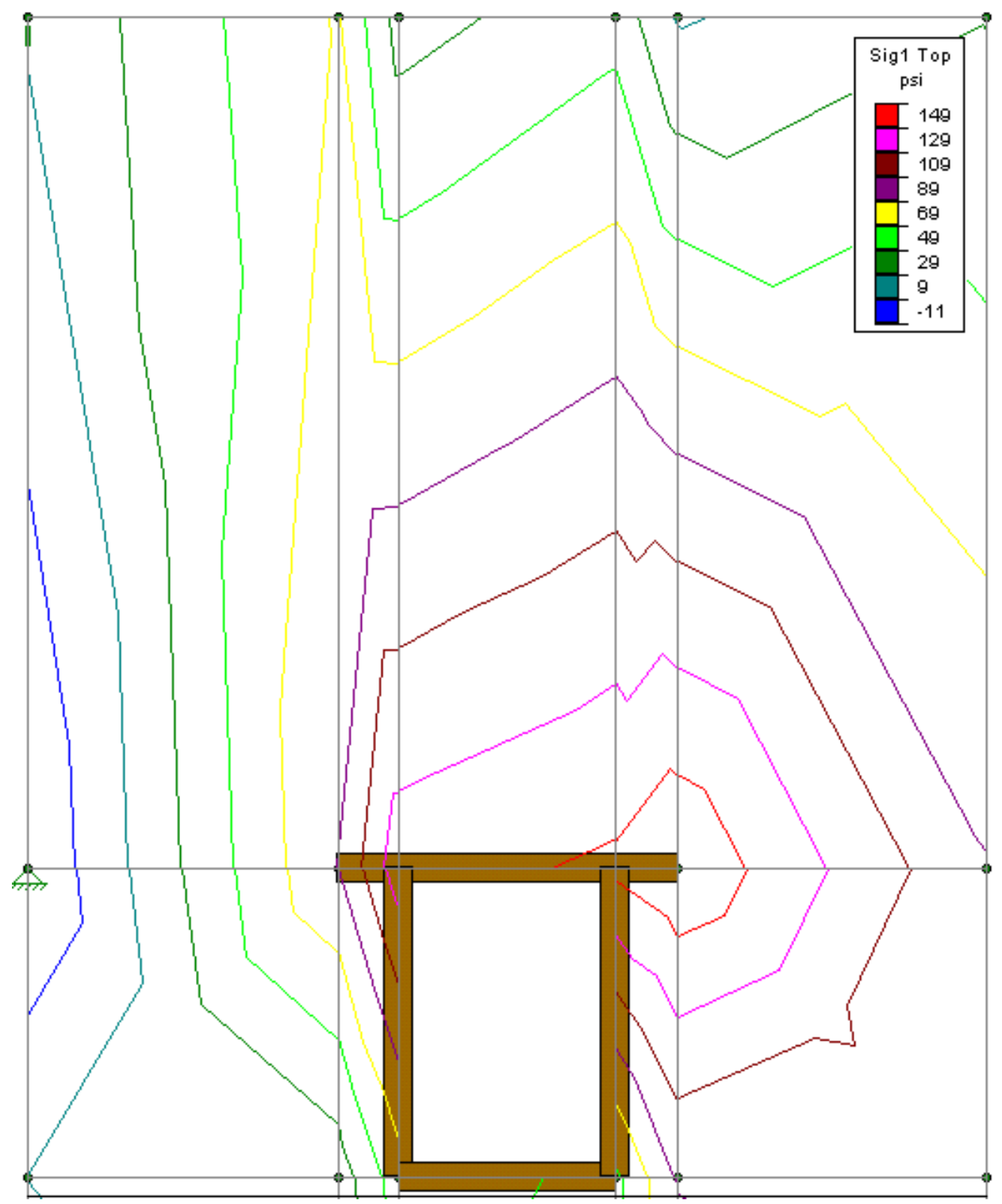

Figure 60-Stress in Vertical Direction due to Horizontal Load

External loads that can increase the stresses experienced around the lintel and in the rammed earth wall can come from both strong winds and seismic activity. Figure 60 shows the 
stress distribution in the vertical direction $\left(\sigma_{1}\right)$ due to a horizontal load. The horizontal load added to the model is to act as an equivalent shear load that is experienced by an earthquake. For the purpose of analysis, a 1,000 KN (225 kips) horizontal load was added $4 \mathrm{~m}$ below the lintel (coincides with the maximum considered earthquake for the region). To allow the model to move as desired the bottom restraints were released to mimic the base of the structure moving together with the ground. One support was added at the top of the base to mimic the top of the structures wanting to resist motion. For stability purposes another support was added horizontal to the lintel, doing so also created stresses that accurately modeled where the crack began in real life. By implemented the supports in the way previously explained, this model of the lintel and rammed earth wall is being forced into a second mode shape, meaning that there will be two different curvatures in the deflection shape. The support conditions were implemented in this way in order to accurately portray how the crack occurred at the end of the lintel as it did in the Huanji Tulou. Also, during an earthquake structures will experience more than one mode of deflection and thus multiple mode analysis is an accurate simulation of what could occur to the Tulou during seismic activity. As can be seen above in Figure 60, a 1,000 KN horizontal load creates a compressive stress that is $149 \mathrm{psi}$ in the vertical direction $\left(\sigma_{1}\right)$ at the ends of the lintel. This is a large jump from the .386 psi experienced by the weight of the rammed earth wall alone and if we are to consider the lowest ultimate compressive strength of rammed earth tested, this stress surpasses the ultimate strength value of $126 \mathrm{psi}$ and thus represents failure. However, realistically the rammed earth would have failed much before the $\sigma_{1}$ stress would have ever reached the ultimate compressive strength of the rammed earth. The vertical stress component does create the potential for more buckling and thus a higher stress in the transverse direction $\left(\sigma_{2}\right)$ as can be seen in the figure below. 


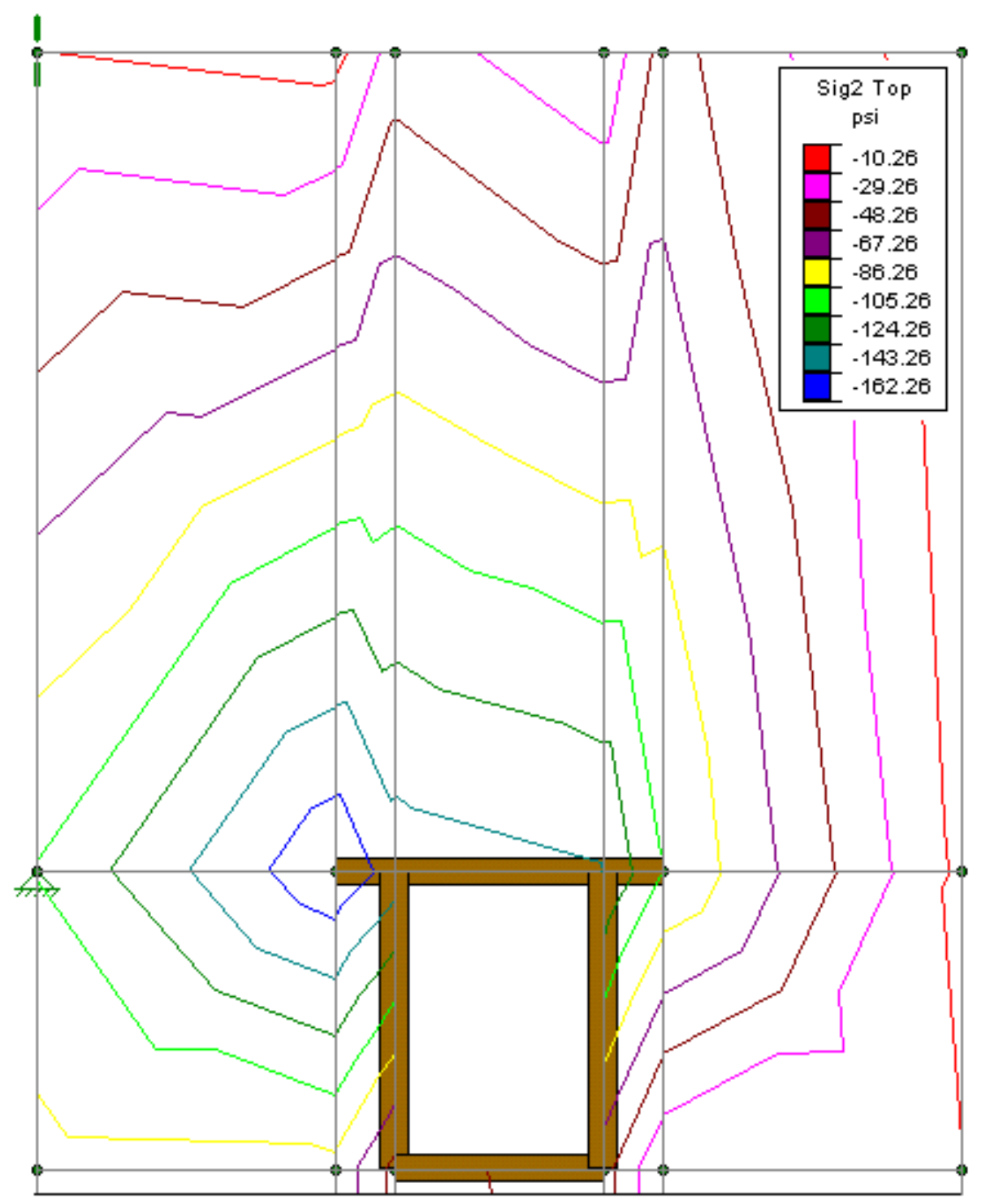

Figure 61-Stress in Transverse Direction due to Horizontal Load

In the above Figure 61, the max tensile stresses in the transverse direction due to the same 1,000 KN horizontal load can be found at the end of the lintel. Due to the 1,000 KN load, a max tensile stress of 162 psi has developed which is higher than the ultimate compressive strength which means that the stress is much higher than the low ultimate tensile strength of the material. This relation shows that the horizontal load has clearly caused cracking in the rammed 
earth wall beginning at the end of the lintel and continuing the path of greatest stress. The load applied is also well beyond the load required to create such cracking in the rammed earth wall.

Through the modeling performed in RISA structural analysis software we can see exactly how an earthquake can cause increased loading in the Tulou and in return cause higher stresses leading to potential cracking. Finite element modeling has accurately predicted and modeled exactly where the highest stress developments begin and thus where tensile cracking is likely to occur. It is interested to note that the one such crack found in the Tulous occurred in the Huanji Tulou which has no wall reinforcement through the use of either wood or bamboo. The rammed earth wall's strength could have been increased as explained in the section 4.2, and thus in turn could have possibly prevented the cracking that occurred in the Huanji Tulou due to the earthquake experienced. Cracking could have also been avoided or minimized by making the lintel stiffer by adding more wood to the lintel, in particular to the top most portion. By increasing the stiffness of the lintel, the stresses due to dead load will also be minimized and thus the effects of an earthquake or wind load are more likely to have less dramatic increase on the existing local stresses of the structure.

\subsubsection{Possible Mechanisms of Self Healing}

Self healing of cracks is a phenomenon that is known as autogenous healing in the scientific community. Autogenous healing has been researched for several decades in common building materials such as concrete. Current research regarding autogenous healing of concrete has mostly portrayed the healing of small cracks or micro cracks experienced in concrete systems. Most research has also focused on self healing systems that only work with the addition of water which makes above ground healing systems quite limited (Termkhajornkit et al. 2009). Further investigating research on autogenous healing, Stefan Jocabsen and Erik J. 
Sellevold (1996) found that concrete deteriorated by rapid freeze/thaw gained much of its original strength back after absorbing water. Hans-Wolf Reinhardt and Martin Jooss (2003) research in autogenous healing of concrete, concentrated on the how the crack width and water temperature affects the healing process. In their research, it was found that cracks smaller than $.10 \mathrm{~mm}$ can self heal and close when under ideal conditions involving the flow of water. There has also been research focusing on the use of fly ash in concrete systems as a mean of autogenous healing without the need of additional hydration. So far preliminary research is promising, showing concrete systems using fly ash have less micro cracks and higher strength after 28 days of pouring than regular concrete systems (Termkhajornkit et al. 2009). Fly ash is able to self heal without the use of additional hydration because the process is activated by the hydration reaction of cement (Termkhajornkit et al. 2009). As mentioned previously, most research on autogenous healing has focused on the self healing of micro cracks in concrete, little to no research has focused on the autogenous healing of rammed earth or other natural materials. Even with limited research on the self healing powers of rammed earth one may take some important knowledge of how the autogenous process works in concrete and use it towards making an educated hypothesis on how rammed earth structures, in particular the Huanji Tulou have displayed autogenous healing.

To begin comparing the autogenous healing of concrete systems to that of rammed earth, one must first understand how these concrete systems are healing. The key ingredient to the autogenous healing process is lime. As cracks appear in concrete systems, water infiltrates the cracks and dissolves any lime that it may come in contact with. The dissolved lime is then taken to the surface of the crack where it carbonates and begins to heal the crack (Rhydwen 2007). This re-cementing of concrete systems depends on several factors including age, degree of 
contact of the crack, curing conditions, moisture conditions, and most importantly the availability of lime or fly ash (Angelbeck 1978). Another key point to be taken from previous research is that autogenous healing of concrete systems was found to occur without the need of supplementary water when systems included fly ash. Autogenous healing without the use of supplementary water is more similar to the conditions experienced by the reported self healing at the Huanji Tulou. The difference still remains that autogenously healed cracks in concrete are smaller than one millimeter whereas at the Huanji Tulou the crack was reported to originally be $20 \mathrm{~cm}$ in width.

The Hakka Tulous are well known to be built with numerous domestic materials including but not limited to, clay, sand, water, and most importantly for the self healing process, lime (Hong 2006). If there was in fact self healing that took place at the Huanji Tulou as reported, then lime surely has played an important role in the process. After using finite element modeling to replicate the behavior of the Huanji Tulou it is my belief that there is a possibility that the Huanji Tulou's crack did autogenously heal from its original $20 \mathrm{~cm}$ in width. In order for autogenous healing to take place in the rammed earth walls of the Tulou structure there must be an ideal temperature and humidity situation as well as the presence of lime. Further research must be done to further understand the impact that temperature, humidity, and lime have on the autogenous healing process in rammed earth. Finite element modeling however, has been able to show how temperature directly impacts the healing process. A three dimensional model of the Huanji Tulou can be seen below in Figure 62. 


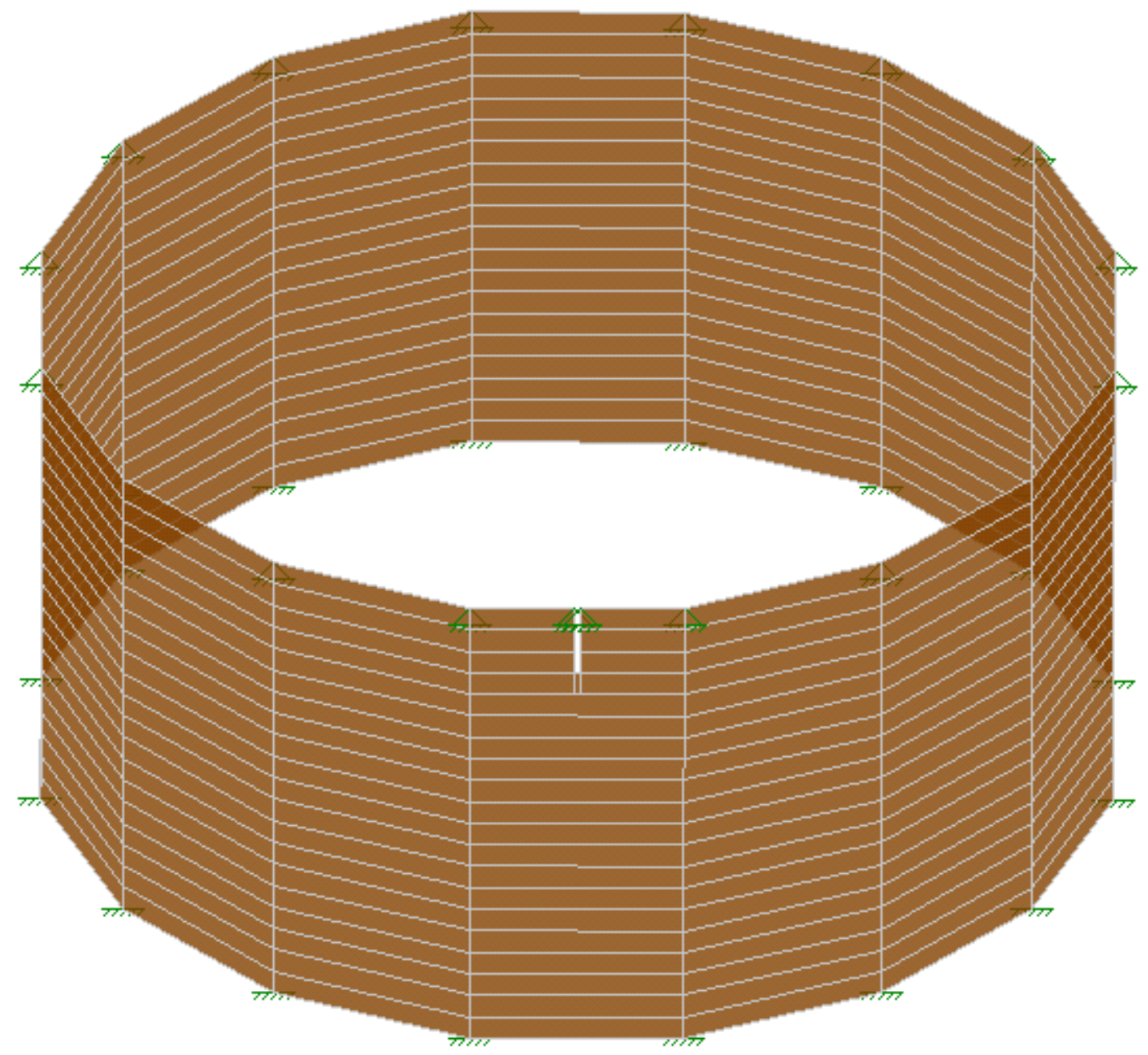

Figure 62-3D Model of Huanji Tulou

In this three dimensional model of the Huanji Tulou, the dimensions are the same as the actual Huanji Tulou with a wall height of 20 meters, outside diameter of 43.2 meters, and a wall thickness of 1.8 meters. A modulus of elasticity of 1,706 psi was used for the rammed earth in the model as no rammed earth samples were tested from the Huanji Tulou and this value is the most conservative found through material testing of other Tulous. The crack found at the Huanji Tulou is also modeled into the structure as can be seen in the figure above with a crack length of 3 meters and a crack width of 20 centimeters. The round rammed earth walls were 
created in the finite element modeling program in order to see how thermal effects, such as thermal expansion, impact the autogenous healing process. The internal wooden structure of the Tulou is not shown nor was modeled and instead can be assumed to restrain, to a certain extent, the thermal effects experienced on the rammed earth walls. For the model, boundary conditions were assumed accordingly: at the base of the rammed earth walls the conditions most closely follow a fixed connection as the rammed earth walls tie in directly to either earth or stone foundations that are common amongst Hakka Tulous. The top of the rammed earth wall was assumed to act as a pinned connection as the wooden roof structure ties into and lies on the top of the rammed earth wall. The roof connection is flexible and allows rotation which is the reason for the pinned connection rather than a fixed connection at this location. It is important to understand that these are theoretical boundary conditions whereas in reality boundary conditions are a balance between the restrained and free conditions. The model is made up of 14 flat sides with each side having 20 plates that are 1.8 meters thick and 1 meter tall, making a total height of 20 meters. A temperature load was applied across the entire model in order to see the thermal effects of the structure knowing the thermal expansion coefficient as well as using the assumed boundary conditions. A thermal expansion coefficient of a clay brick of $.0000033 \mathrm{in} / \mathrm{in} /{ }^{\circ} \mathrm{F}$ was assumed satisfactory for the analysis of the rammed earth walls (Friedman 2006).

For the first test, a temperature load of $-70^{\circ} \mathrm{F}$ was applied to the entire structure. The effects of this temperature load can be seen below in Figure 63 . 


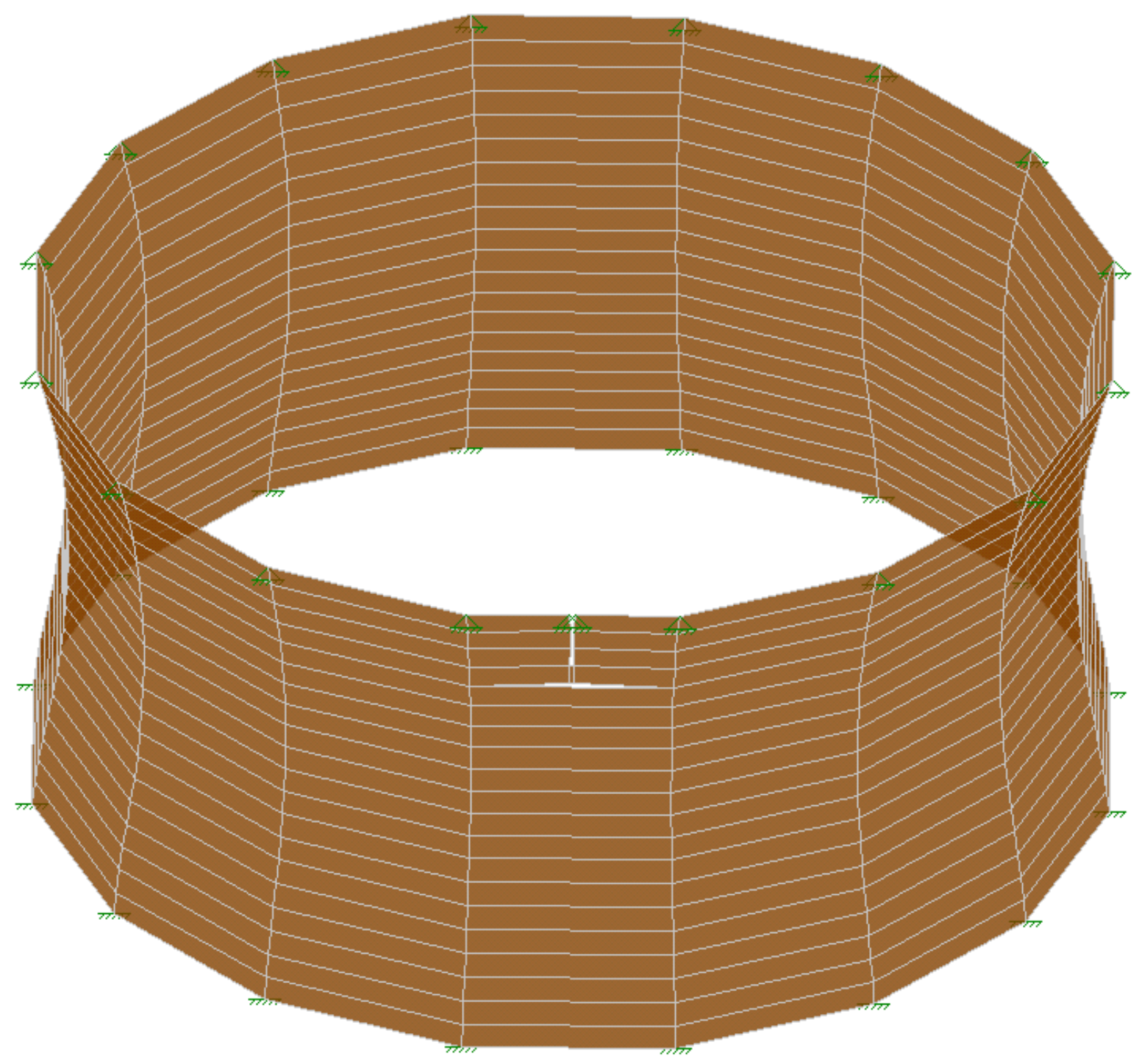

Figure 63-Effects from Thermal Load, $-7^{\circ} \mathrm{F}$

In Figure 63 it can be seen that the model of the Huanji Tulou is attempting to decrease in size due to the decrease in temperature. The restraints at both the top and bottom of the Tulou are limiting the temperature effects. Also, it is important to note that the interior wooden structure, not modeled here, would restrain to a certain extent, the temperature effects experienced on the rammed earth walls. To better see what the thermal load did to the crack see Figure 64. 


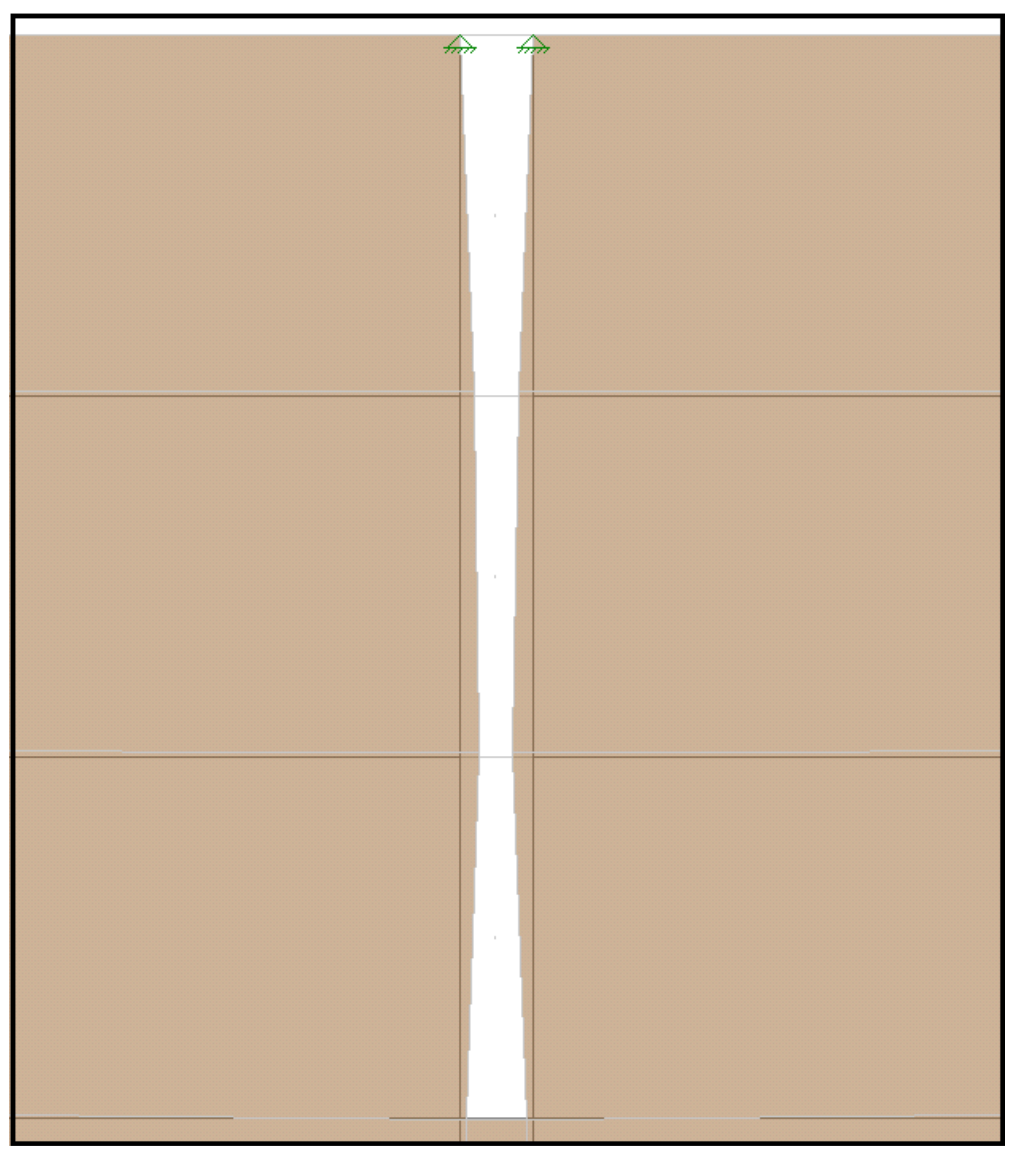

Figure 64-Crack Shrinkage due to Thermal Load, $-\mathbf{7 0}^{\circ} \mathrm{F}$

In Figure 64 one may see the deflected shape of the crack along with the outline of the original crack width of 20 centimeters. With the cooler thermal load, it can be seen that the crack is actually shrinking in width. The $-70^{\circ} \mathrm{F}$ load that is applied to the entire Tulou closes the crack by over half at the most extreme point. At the extreme point the crack closes by 10.8 centimeters leaving a crack width of 9.2 centimeters. When a thermal load of $70^{\circ} \mathrm{F}$ is applied to entire structure, the exact opposite can be seen as the crack actually widens, this can be seen below both Figure 65 and Figure 66. 


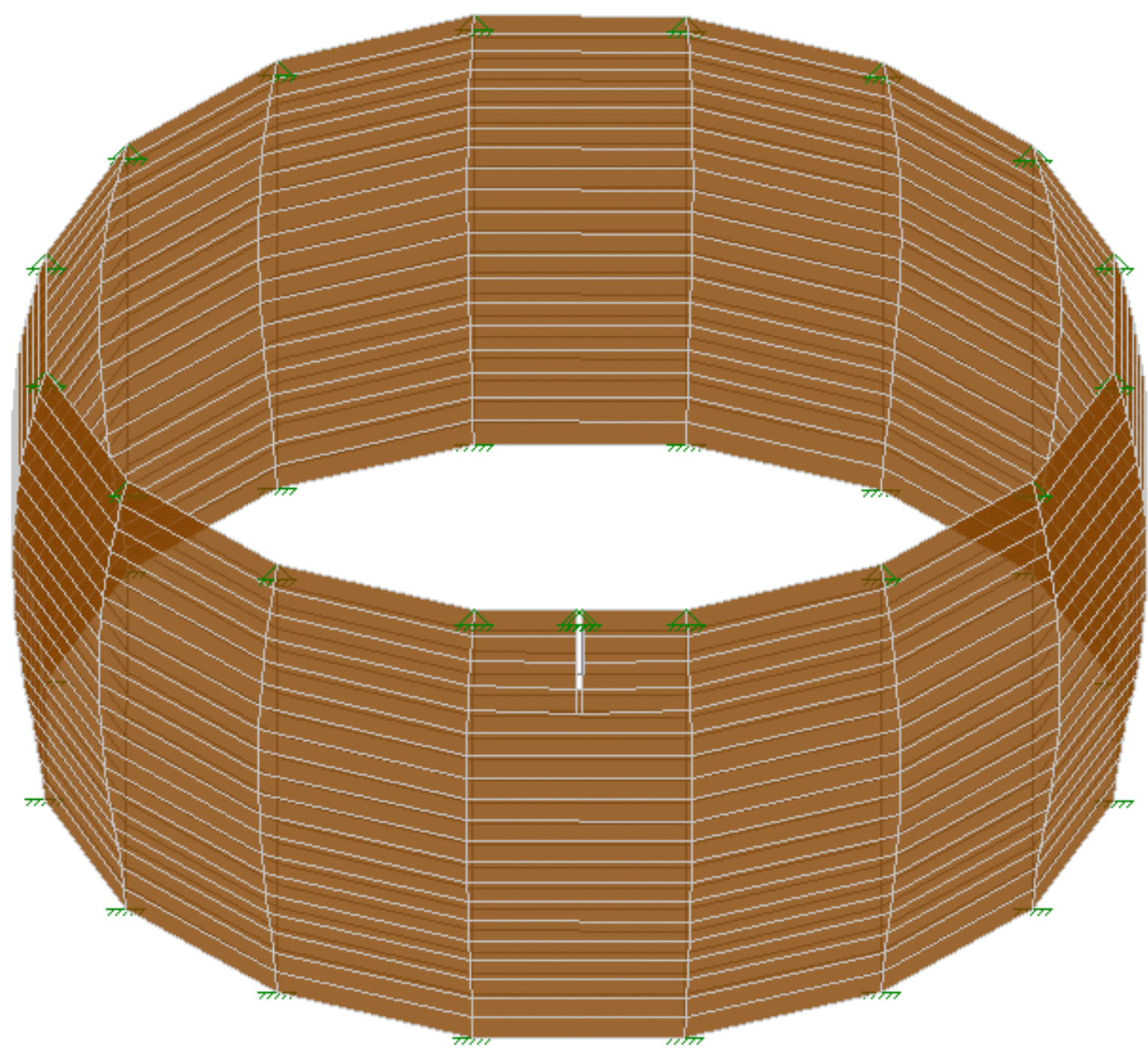

Figure 65- Effects from Thermal Load, $7^{\circ} \mathrm{F}$ 


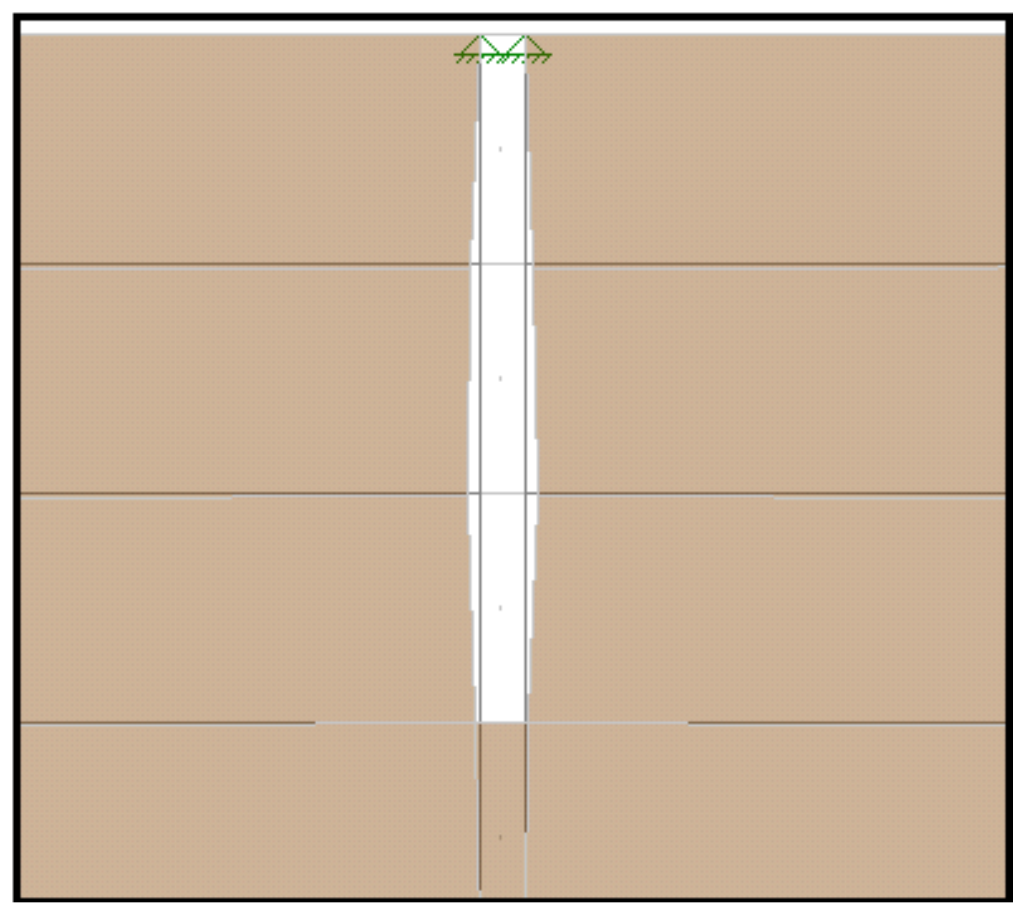

Figure 66-Crack Expansion due to Thermal Load, $70^{\circ} \mathrm{F}$

Both figures above show that a temperature increase of $70^{\circ} \mathrm{F}$ experienced along the whole Tulou causes significant thermal expansion with restraints limiting the effects at both the top and bottom. It is once again important to note that the internal wooden structure will limit the effects experienced by the $70^{\circ} \mathrm{F}$ on the rammed earth walls. In Figure 66 , the crack actually widens by 10.8 centimeters at the most extreme point making the total crack width at the extreme point 30.8 centimeters.

From the finite element modeling one can see that smaller temperatures cause the crack to decrease in width and that larger temperatures increase the width of the crack. These temperature effects however do not explain the autogenous healing of the rammed earth as healing of the crack is simply reversed when the temperature goes back up. Temperature is thus found to not be the sole factor in the autogenous healing process rather an important part of the process. 
As explored later in Chapter 5, the Fujian Province has mild winters due to its proximity to the equator and a temperature difference of $70^{\circ} \mathrm{F}$ between summer and winter seasons is very unlikely. A $70^{\circ} \mathrm{F}$ thermal load was merely used as to show what temperature flux was required to close the crack about $50 \%$. Regardless of the thermal load used for modeling, a single temperature flux is not an important factor to be taken from this modeling as such drastic temperature changes are unlikely and the effects are reversed when the temperatures increases. Rather, the model shows that there is the possibility for the crack to decrease in size with decreases in temperature. Combining the temperature effects with other factors such as humidity and the existence of lime may create an ideal scenario for autogenous healing to take place. A possible scenario of autogenous healing could look like the following, as the winter season comes the average temperatures drop causing the Huanji Tulou's rammed earth walls to slightly shrink. With the crack width now decreased due to lower temperatures and prime moisture conditions the lime could be activated during this time. The lime, mixed with the rammed earth, could fill in the crack and re-harden itself much like it does in concrete structures. This process could occur slowly over a period of several winters and in the end could produce the self healing phenomena that has been reported at the Huanji Tulou. If one was to look at the issue locally, than the crack width from 20 centimeters to 5 centimeters is a drastic change as the crack has healed $75 \%$, however, if one is to look at the situation globally, as in the entire circumference of the rammed earth walls, than the rammed earth has only experienced an elongation of $.113 \%$ in length. This theory has however been proven inconclusive as in section 3.3 we find that the Huanji Tulou does not in fact show any signs of lime. 


\subsubsection{Conclusions}

The crack that has reportedly autogenously healed at the Huanji Tulou from 20 centimeters in width to 5 centimeters in width occurred due to a strong earthquake that hit the region. The crack began at the end of a window lintel due to high stress concentrations occurring from bending of the upper portion of the lintel. Through modeling it is understood where and why exactly the crack formed where it did. The main issue however, is whether this crack has autogenously healed as reported by the locals. Finite element modeling shows the potential of the crack to close up due to thermal loads however this alone cannot verify the existence of autogenous healing. Instead one must look at well researched phenomena of autogenous healing in concrete and compare it to rammed earth. Autogenous healing has occurred in concrete at a micro level and usually only with the presence of additional water. Lime is the key ingredient in the healing process of concrete and this ingredient also is found in the rammed earth walls of many Hakka Tulous. EDS data has shown that in the sample tested, the Huanji Tulou did not contain lime, however it is important to note that this one small sample is not a good representation of the entire rammed earth wall. Other areas of the rammed earth wall of the Huanji Tulou could contain calcium, however due to the fact that our EDS data shows no calcium in our Huanji rammed earth sample, we cannot confirm the story of autogenous healing. Further research must be done on the autogenous properties of natural materials such as rammed earth in order to completely understand if such phenomena can actually occur.

\subsection{Earthquake Resistance of the Hakka Tulou}

Hakka Tulou structures have been subjected to extreme stresses induced by typhoons, floods, and earthquakes. Since the $11^{\text {th }}$ century seven earthquakes of above magnitude 5 on the 
Richter scale have been recorded in the region. Some Tulou buildings have had cracks in their walls and broken roof tiles because of the earthquakes, however there has been no structural damage to any of the Tulou buildings. Even though both square and round Tulous have been found to perform well in these natural conditions, it is well known that a circle design is advantageous as there are no corners meaning that there are no stress concentrations in the rammed earth walls. It would seem that the Hakka people have learned the advantages of having a circular structure over a square one as the newer Tulous have been built in circular form. The circular shape of the Tulous, as well as the high mass of the Tulou structures, have helped disperse the dynamic loads experienced by earthquakes. With the rammed earth walls being so thick and tall there is very high mass to distribute the earthquake loads through and in return material stresses are kept low and away from failure zones. To further understand this behavior in Hakka Tulous, a model of the Huanji Tulou was used for earthquake analysis. In order to model the behavior of the Tulou during an earthquake, the simplified lateral force analysis procedure provided by ASCE-7 was used.

\subsubsection{Simplified Lateral Force Analysis}

The simplified lateral force procedure is typically used for frame type structures no taller than three stories as this method focuses on base shear rather than the dynamic response from an earthquake. The base shear that results from an earthquake is of primary concern for short structures as dynamic effects control for taller structures. The Huanji Tulou being modeled is four stories tall with a height of 20 meters. Due to the thickness of the walls and resulting high mass of the rammed earth, it can be assumed that a simplified lateral force analysis will be sufficient for the structure as dynamic effects will be minimized. The resulting calculations shown are thus the effects of base shear being distributed throughout the four floors of the 
structure. By distributing this base shear throughout the structure one can then analyze the stress induced into the rammed earth walls by a design earthquake for the region. It is important to note that only the rammed earth walls and their self weight are considered for the purposes of this analysis. The internal wooden structure and live loads are minimal with respect to the actual weight of the thick rammed earth walls and since the modulus of elasticity of the modeled rammed earth is being taken as 1,706 psi the study is still being taken as conservative. The modulus of elasticity of 1,706 psi was used for the rammed earth in the model as no rammed earth samples were tested from the Huanji Tulou and this value is the most conservative found through material testing of other Tulous. It is important to note that the model displays the applied stresses and that the modulus of elasticity only impacts the deflections of the structure. Varying material strength will change when the material would enter the inelastic zone as well as when the material would ultimately fail. With a lower modulus of elasticity the building would deflect more and enter the inelastic zone much sooner than a stronger material. It is supposed that for design purposes one should not use the equivalent lateral force analysis as the Tulou structure has an occupancy category of III, meaning that more than 300 people congregate in one area and failure of the structure would represent a substantial hazard to human life. Due to the fact that this study is intended as a basic analysis on the reaction of the Tulou structures to earthquake loads and that the study is already being conservative with material properties of the model, the simplified lateral force analysis method was deemed appropriate.

There are two important Equations that are used in the simplified lateral force analysis and both can be seen below in Equations 6 and 7 (ASCE 7-05).

$$
\begin{gathered}
V=\frac{F S_{D S}}{R} W \\
S_{D S}=\frac{2}{3} F_{a} S_{S}
\end{gathered}
$$


Equation 6 calculates the base shear for a maximum considered earthquake by incorporated several factors including ' $\mathrm{W}$ ' which is the effective seismic weight of the structure. ' $R$ ' is simply the response modification coefficient which will be taken as 1.5 for a bearing wall system made of ordinary plain masonry walls, this factor was chosen as it most resembled the conditions of a rammed earth wall. ' $F$ ' is a factor that depends on the structure height, since this method is used for a maximum of three stories, the upper value of 1.2 for three stories was used for analysis purposes. ' $\mathrm{S}_{\mathrm{DS}}$ ' is a design spectral response acceleration at short periods, $5 \%$ damped, which can be calculated using Equation 7. ' $F_{a}$ ' is the short period site coefficient at 2 seconds which can be found in a table knowing both ' $\mathrm{S}_{\mathrm{s}}$ ' and site class of the area of interest. Since the site class is unknown, ASCE-7 states that one can classify the site as class D unless geotechnical data determines that class $\mathrm{E}$ or $\mathrm{F}$ are present. ' $\mathrm{S}$ ' ' is the mapped spectral response acceleration, 5\% damped, at a period of 1 second (ASCE 7-05).

The Global Seismic Hazard Assessment Program (GSHAP) has compiled seismic maps from all around the world. The seismic map for China, which can be seen in Figure 67 below, was created by the Chinese government in 1992 and shows peak ground acceleration which has a $10 \%$ chance of exceeding marked intensities in 50 years (Zhang et al. 2010). 


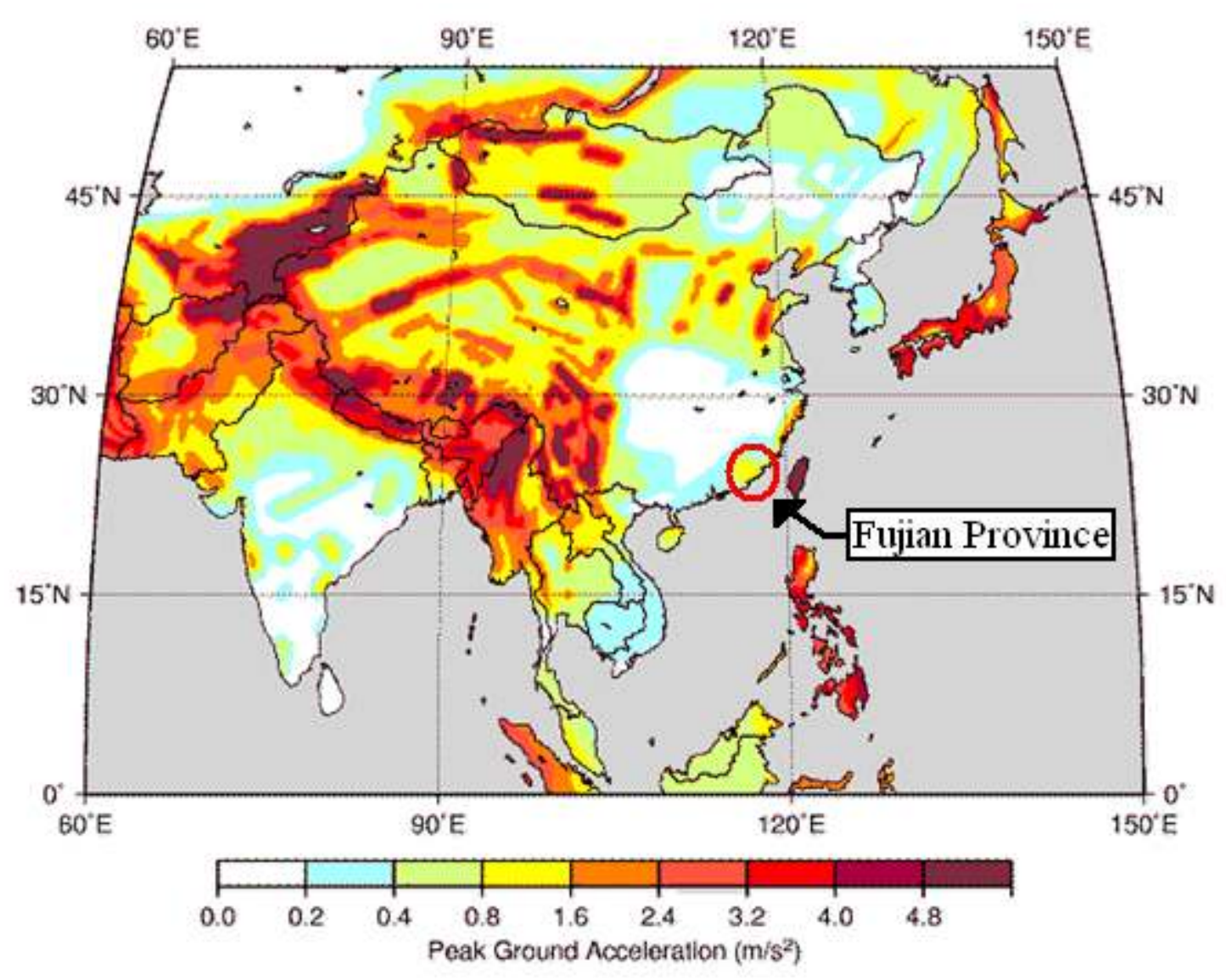

Figure 67-China Seismic Map (Zhang et al. 2010)

From Figure 67 it can be seen that the peak ground acceleration for the Fujian Province varies from $.8-1.6 \mathrm{~m} / \mathrm{s}^{2}$. This map also coincides with an earthquake report on China performed by Lanbo Liu, in which he states no major post Paleozoic tectonic activity has been found in the region and thus seismicity for the Fujian province is low (Liu 2001). No maps of spectral response acceleration for the China region were found. ASCE-7 allows one to convert peak ground acceleration, PGA, to the mapped spectral response acceleration, ' $\mathrm{S}_{\mathrm{s}}$ ', by simply multiplying the PGA by a factor of 2.5. To be conservative, a PGA of $1.6 \mathrm{~m} / \mathrm{s}^{2}$ was multiplied by 2.5 to get an ' $\mathrm{S}_{\mathrm{s}}$ ' value of 4 . ASCE-7 states that ' $\mathrm{S}_{\mathrm{s}}$ ' need not be taken higher than a value of 1.5 which results in a short period site coefficient, ' $F_{a}$ ', of 1.0. By plugging in the ' $\mathrm{S}_{\mathrm{s}}$ ' and ' $\mathrm{F}$ ' 
values of 1.5 and 1.0 into Equation 7, one gets a ' $\mathrm{S}_{\mathrm{DS}}$ ' value of 1.0. One can then plug this ' $\mathrm{S}_{\mathrm{DS}}$ ' value back into Equation 6, which simplifies into what can be seen in Equation 8.

$$
V=.8 W
$$

Equation 8 above calculates the base shear force for the entire structure. A density of $1,600 \mathrm{~kg} / \mathrm{m}^{3}$ was used for rammed earth as with previous modeling. Knowing the density, height of 20 meters, as well as the area of the Huanji Tulou (1.8 m thick wall, outer diameter $43.2 \mathrm{~m})$ results in a total weight of the structure of $7.49^{*} 10^{6} \mathrm{~kg}\left(16.5^{*} 10^{6} \mathrm{lbs}\right)$ which results in a total base shear of $5.99 * 10^{6} \mathrm{~kg}\left(13.2 * 10^{6} \mathrm{lbs}\right)$. To find the vertical distribution of the force that must be applied to each floor of the structure, we must use the total base shear and input it into the Equation below.

$$
\mathrm{F}_{\mathrm{x}}=\frac{w_{x}}{W} V
$$

In Equation 9 above, ' $\mathrm{w}_{\mathrm{x}}$ ' represents the portion of the effective seismic weight of the structure. Since our structure has 4 evenly spaced floors, the force per floor is equal to $1 / 4$ of the total base shear which is equal to around $1.5^{*} 10^{6} \mathrm{~kg}\left(3.3^{*} 10^{6} \mathrm{lbs}\right)$ per floor. Divivided by 16 , which is the amount of nodes used to create the circular model, the resulted per node lateral load for each of the four floors turns out to be $93,645 \mathrm{~kg}(206,452 \mathrm{lbs})$. These loads were applied in a simaltaneous direction on all 16 nodes for each floor in order to represent the effects of a maximum considered earthquake that can be expected in the Fujian Province.

\subsubsection{Tulou Model Earthquake Response}

As mentioned previously, the same model of the Huanji Tulou that was used during crack analysis, was similarly used for earthquake analysis using the RISA 3D structural analysis software. The Huanji Tulou in situ and in the modeling environment, has a height of 20 meters 
and an outer diameter of 43.2 meters with a wall thickness of 1.8 meters. Both Figure 68 and Figure 69 show the maximum deflected shape of the Tulou model after imputing the lateral loads calculated in the previous section. These lateral loads represent the maximum considered earthquake for the region and thus this model shows the most extreme deflected shape of the Tulou model with a modulus of elasticity of 1,706 psi. In the model, a maximum horizontal deflection of 2.5 meters is found 20 meters from the ground surface as a result of the lateral load induced by the maximum considered earthquake. It is important to note that this large deflection only occurs when modeling without the internal wooden structure and when using the lowest modulus of elasticity of 1,706 psi. The deflection is reduced to 1 meter and 0.4 meters when one is to consider the same model with wooden or bamboo reinforcement as found previously in section 4.2 ( $E=3,919$ psi and 10,012 psi respectively). If one is to only consider the strongest of the rammed earth tested, coming from the Chengqi Tulou with E=8,147 psi, then the resulting deflection is only 0.5 meters, showing that rammed earth alone can be stiff enough to avoid massive deflections experienced by the maximum considered earthquake. It must be understood that when modeling earthquake behaviors in such a program, the program performs only a linearly elastic analysis. In the modern world it is not feasible for all buildings to be designed 'elastically' for a maximum considered earthquake and so buildings must be ductile and most likely reach their inelastic zone in order to prevent failure. 


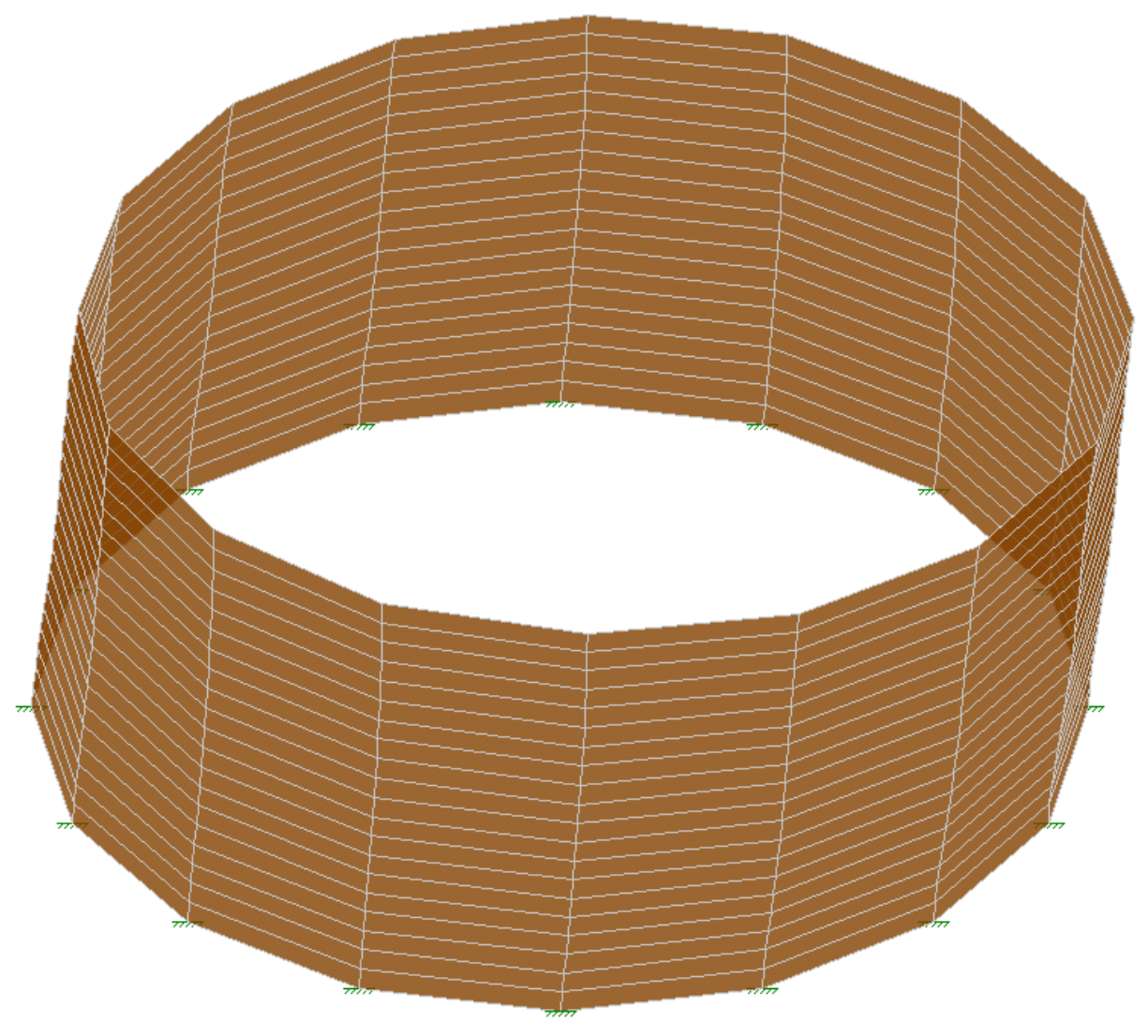

Figure 68-3D Earthquake Deflection

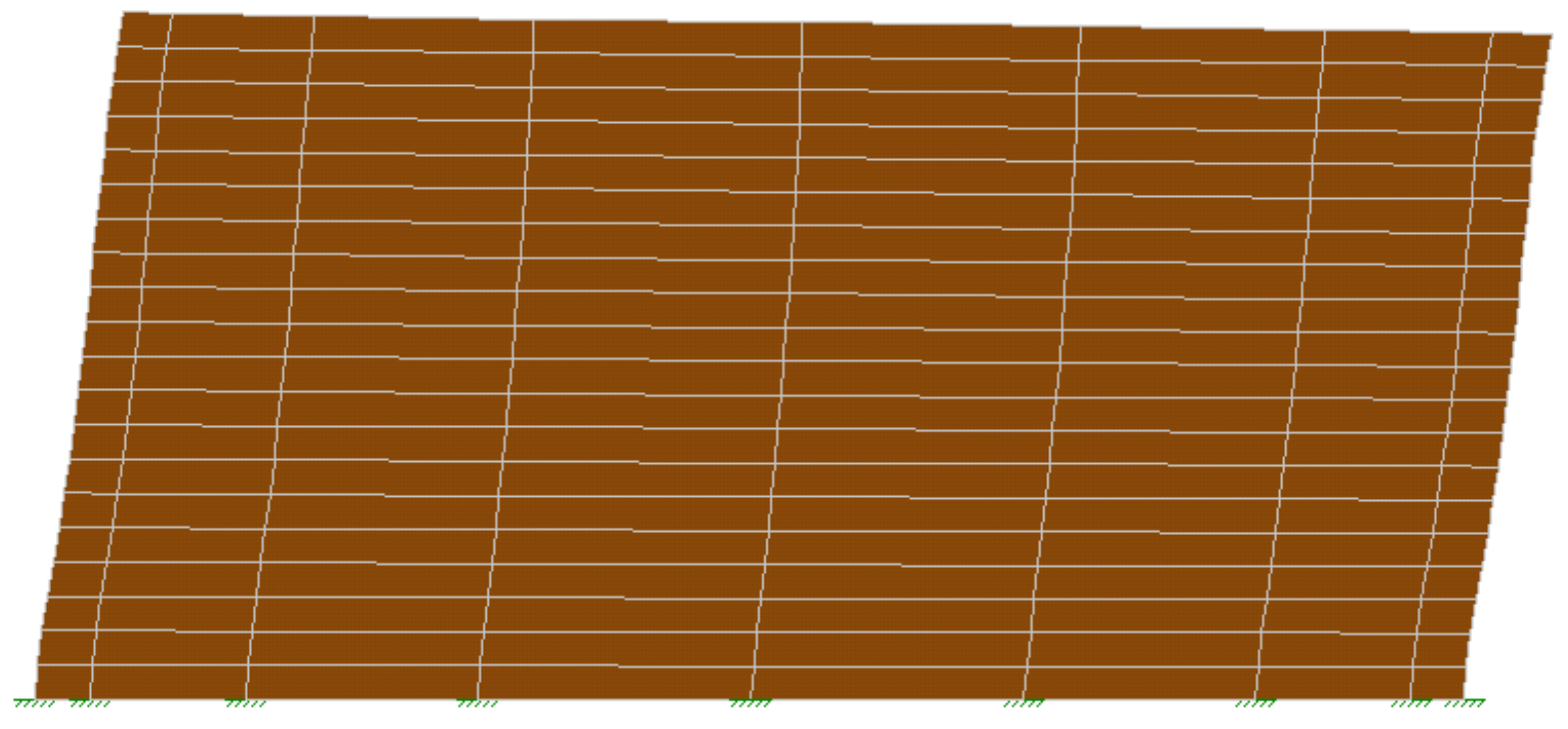

Figure 69-2D Earthquake Deflection 
Both Figure 70 and Figure 71 show the stress distribution of the rammed earth walls due to a maximum design earthquake for the region. Stress analysis will once again be performed using the maximum principle stress theory. This theory states that the material will yield when any of the principle stresses reaches the yielding stress (Benham 1973). Through numerous testing it has been found that the maximum stress theory works best for predicting failure in brittle materials such as concrete, cast-iron, and ceramics. (Benham 1973). As rammed earth is a brittle material, analysis of the material will be performed using this maximum stress theory. It is important to note that in the RISA structural analysis software, tension is labeled as a negative value and compression is labeled as a positive value. The stress distribution below shows the stress, $\sigma_{1}$, which is the stress in the vertical direction of the wall. ' $\sigma_{2}$ ' is not shown because the values are simply the transverse of $\sigma_{1}$, with the same magnitudes of stress appearing in the opposite direction meaning that 141 is also the maximum tensile stress experienced in the rammed earth wall. 


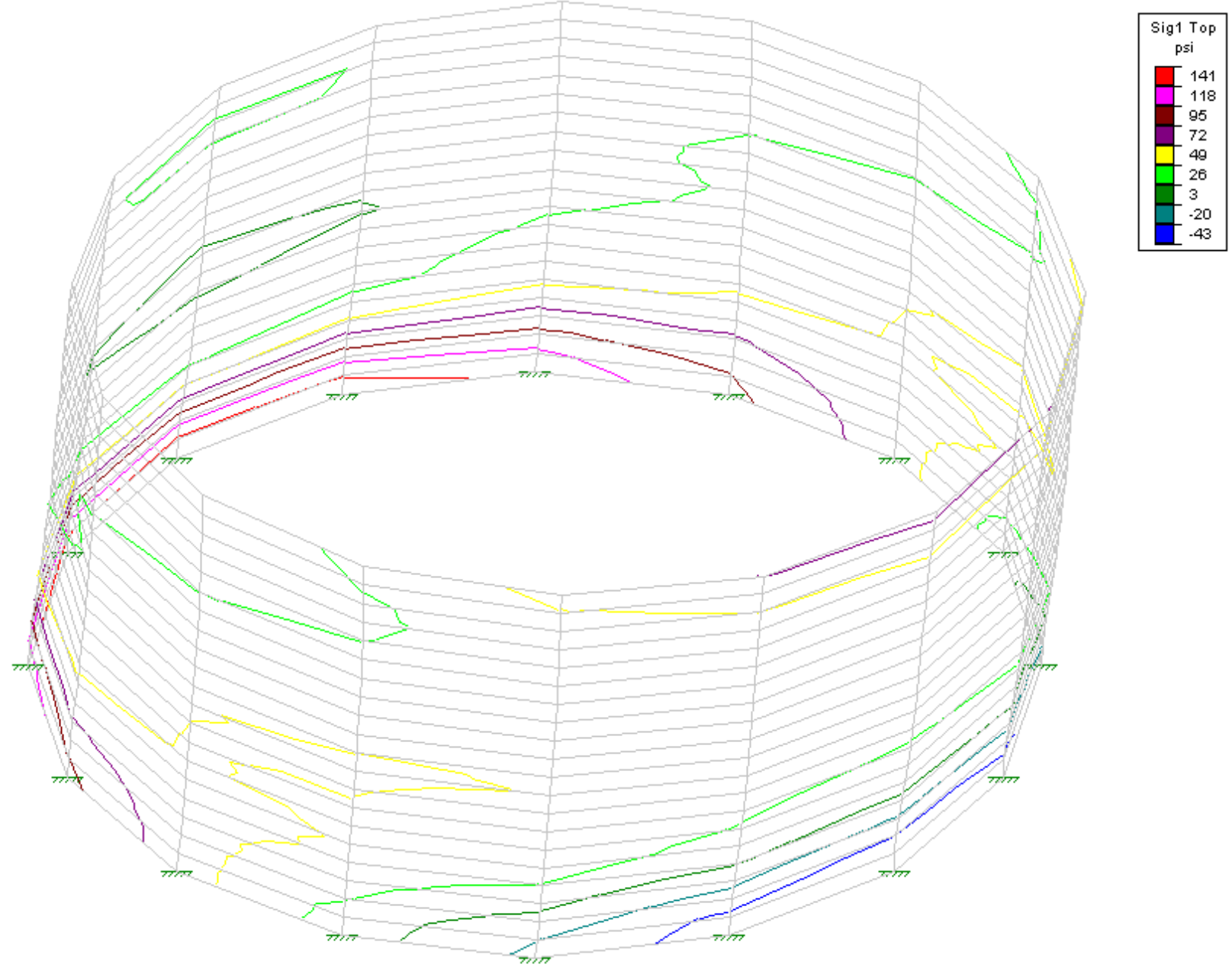

Figure 70-3D Earthquake Stress Distribution

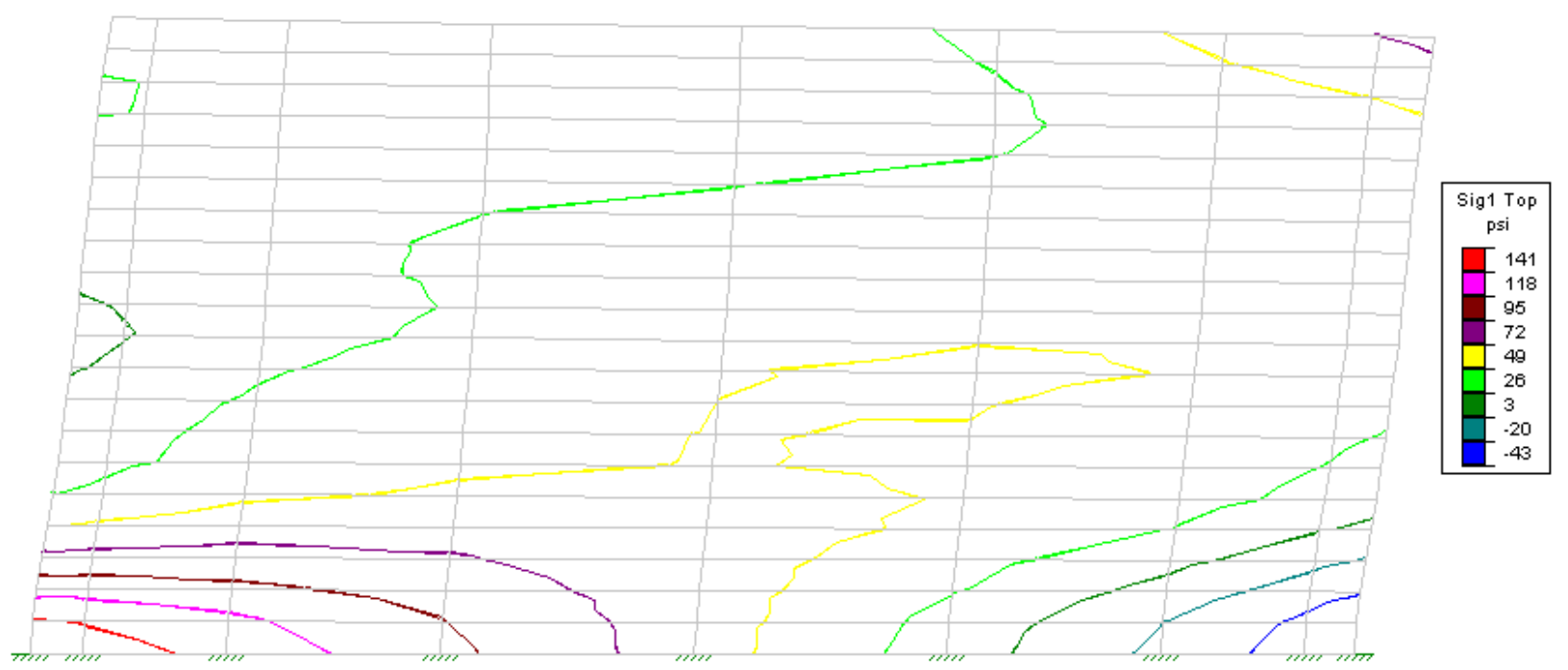

Figure 71-2D Earthquake Stress Distribution 
As can be seen in the stress analysis above, a maximum compressive stress of $141 \mathrm{psi}$ occurs near the base of the Tulou in the $\sigma_{1}$ direction which coincidently means that a maximum tensile stress of 141 psi occurs near the base at the opposite end of the Tulou in the $\sigma_{2}$ direction. The model is conservative as it only considers the rammed earth walls and not the internal wooden structure and since rammed earth was not tested from the Huanji Tulou, the lowest modulus of elasticity, directly affecting deflection, of 1,706 psi was chosen from all rammed earth samples tested. Realistically however, since the Huanji Tulou is one of the younger Tulou structures at 300 years of age the modulus of elasticity of the rammed earth is most likely to be higher and thus ultimate strength is most likely to be higher as well. If one is to analyze the stress data above and compare the data to ultimate strength values that range from 126 psi to 411 psi as found in compression testing, one would see that a possible failure would occur near the base of the structure, which considers only rammed earth, as a maximum stresses of 141 psi in tension and compression occurred in the model. It is important to note that only ultimate compressive strengths are known for the rammed earth and that tensile strength of such materials is lower than its compressive strength, for this reason the structure would fail in tension at the base, sooner than it would in compression. The rammed earth walls as an individual unit resist the design earthquake very well with only the base showing high stresses that could possibly result in cracking at the base depending on the ultimate strength of the material. Seeing as how the model used the maximum considered earthquake for the region and the wooden internal structure was neglected during modeling, it can be said that the high mass and volume of the Hakka Tulous does a very efficient job of dissipating energy experienced from earthquakes. Also if one is to consider that typical ultimate compressive strengths for rammed earth range from 450-800 psi, then these stresses experienced from the maximum considered earthquake are 
not enough to cause failure (Earth Materials 2010). By modeling the rammed earth walls without the internal wooden structure, one can better see how well the rammed earth contributes to the overall strength of the structure. The material by itself has however shown that it can be too ductile with such high lateral forces, to combat this the Hakka Tulous use an internal wooden system to stiffen the overall structure. To understand how well the entire structure responds to a maximum considered earthquake for the region, a model with the internal wooden system has been created as shown in Figure 72.

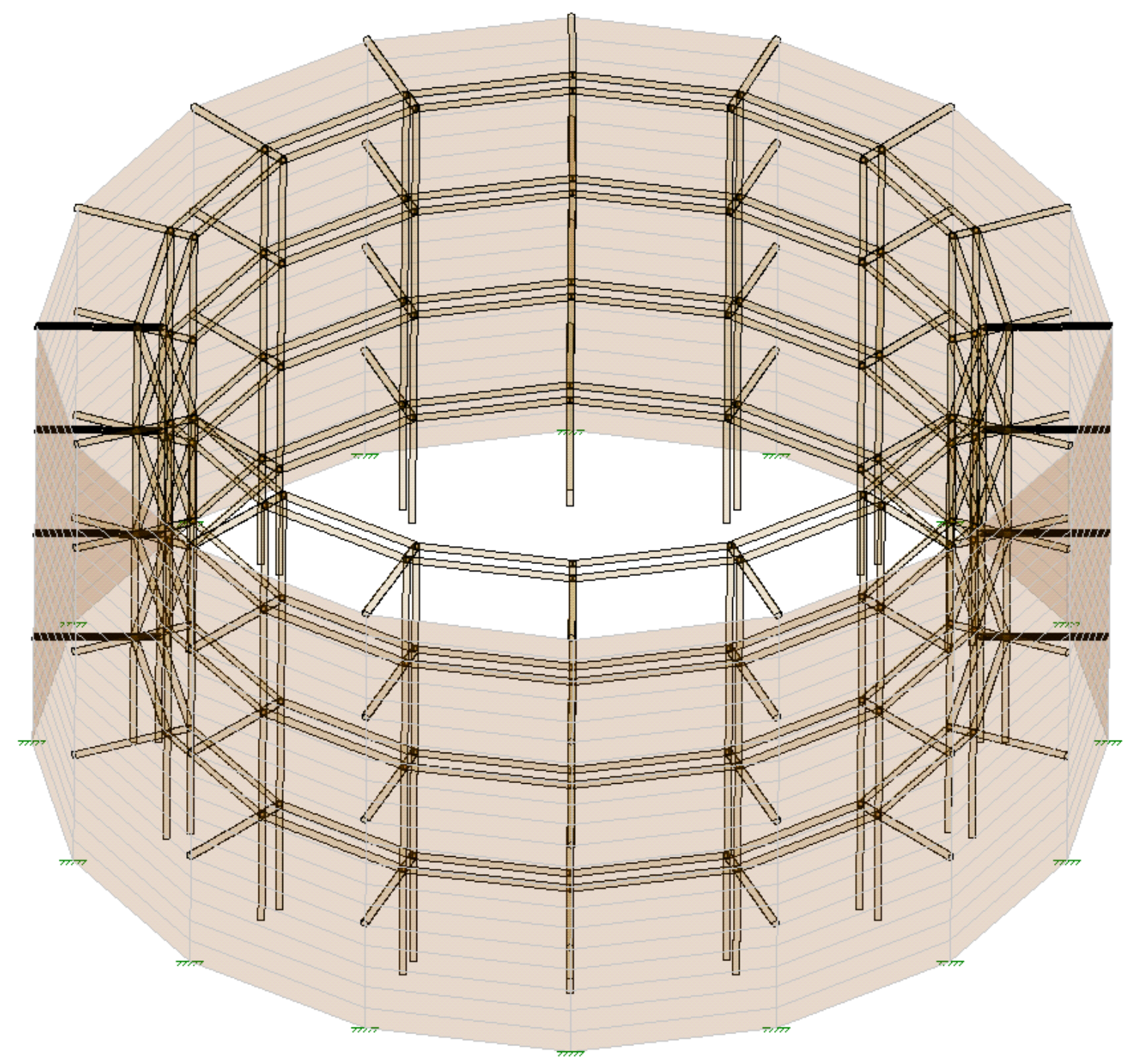

Figure 72-3D Tulou with Internal Wooden System 
The model above has been created using the dimensions found in Figure 4. In the model the wooden beams and columns are round with a diameter of 8 " which is typical of the internal wooden system as found out during load testing. The material used in the model is Douglas Fir which also has properties very similar to that of China Fir. The images below show the stress distribution of a maximum considered earthquake when the model considers the weakest rammed earth ( $\mathrm{E}=1706 \mathrm{psi})$ and internal wooden system.

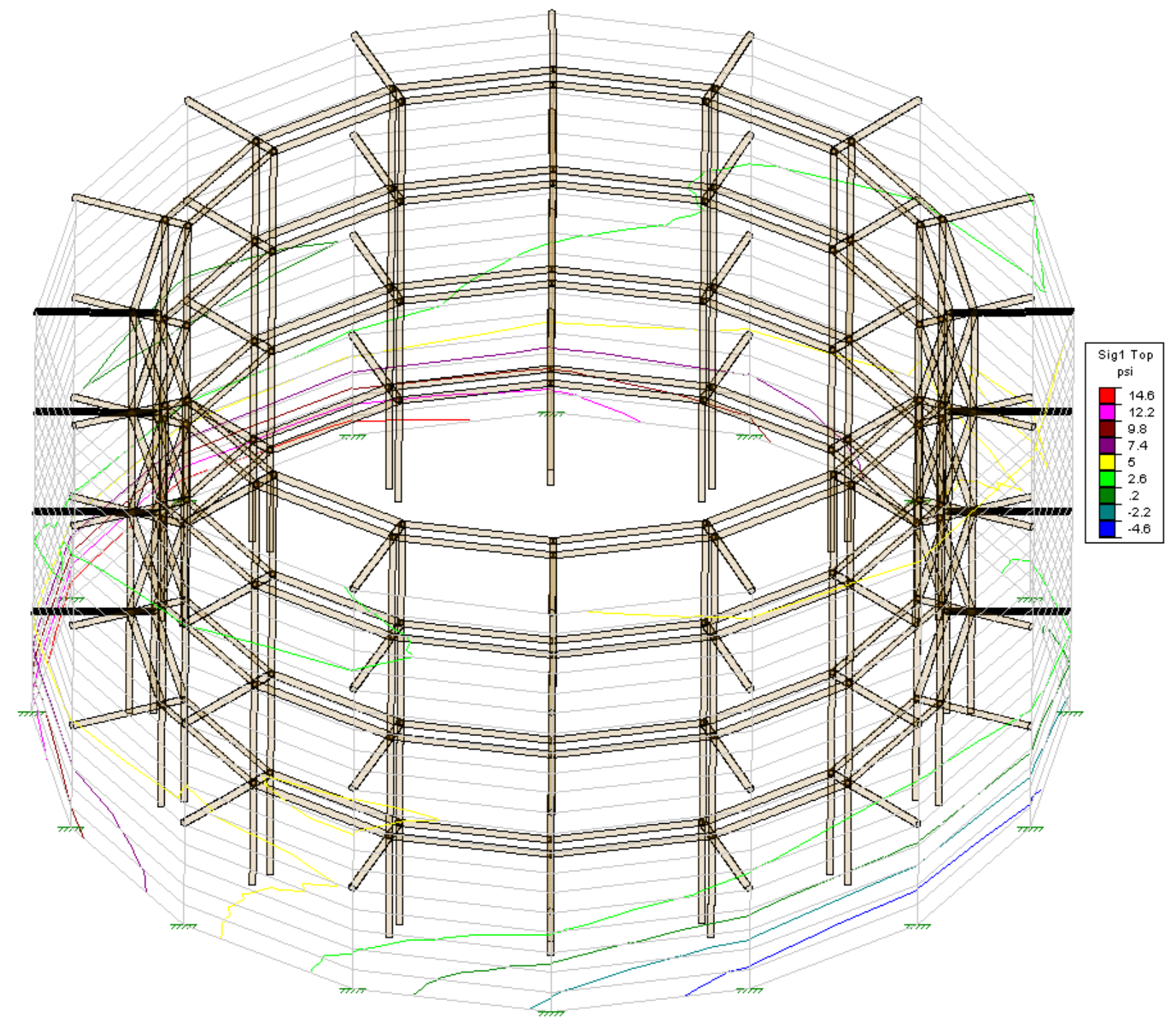

Figure 73-3D Earthquake Stress Distribution with Wooden System 


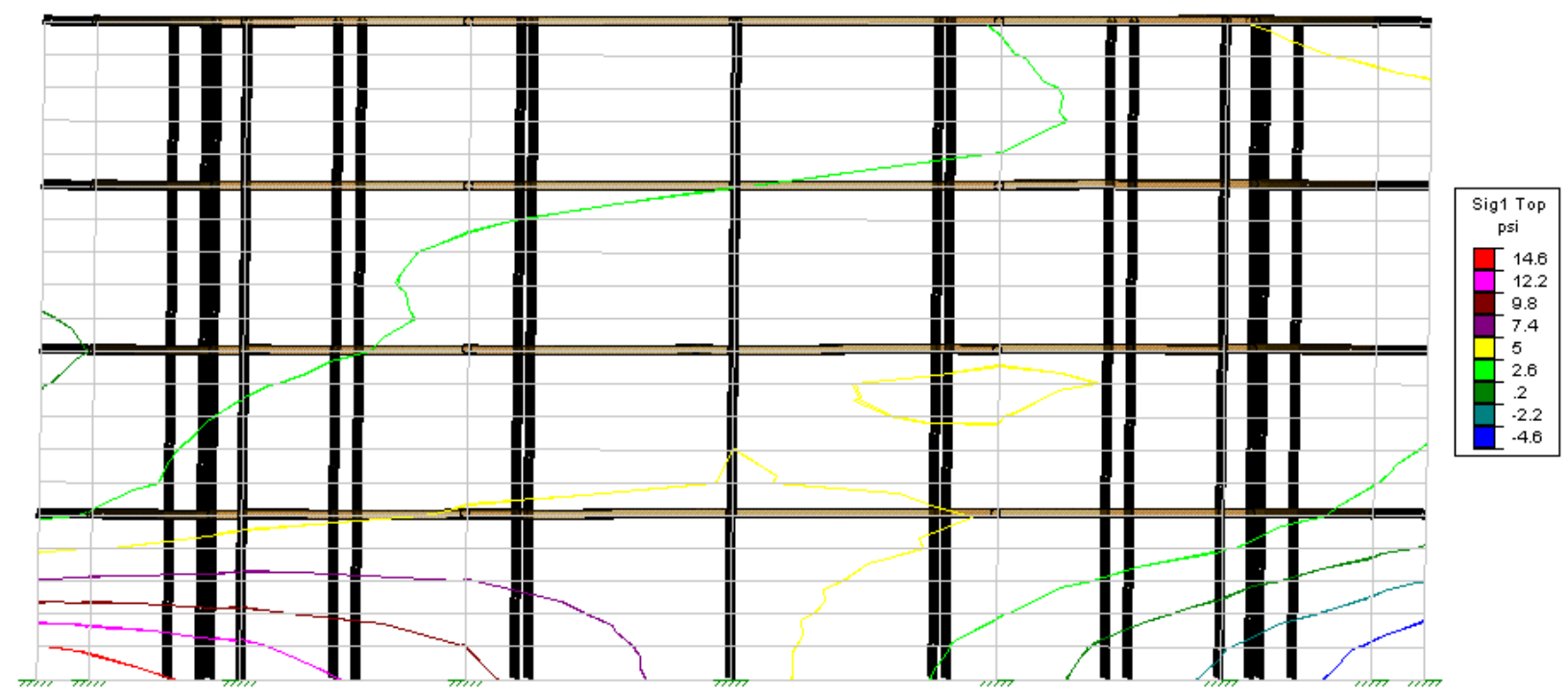

Figure 74-2D Earthquake Stress Distribution with Wooden System

As seen in Figure 73 and Figure 74, maximum stresses in compression in the ' $\sigma_{1}$ ' direction, as well as in tension in the ' $\sigma_{2}$ ' (not shown) are only 14.6 psi. Such low stresses show that although when rammed earth acts alone it is strong, together with a stiffer structural component it is further strengthened and better resists lateral loads. Not only is the stress far from the critical stress of any of the rammed earth samples tested, noting that reinforcement was not considered in this model, however deflections were also limited with a maximum deflection of only 0.2 meters being found.

\subsubsection{Conclusions}

The Hakka Tulous have shown their resilience to natural disasters such as earthquakes for hundreds of years. Where modern construction has failed in many regions of the world from earthquakes, rammed earth structures have been found to prevail and are still standing today. The Hakka Tulous exemplify an optimal seismic configuration as per FEMA with a low height to base ratio, equal floor heights, symmetrical plan shape, identical resistance on all axis, and uniform cross section (FEMA 2006). The goal for this analysis was to see how the optimal 
seismic configuration in Hakka Tulous aided in resistance to earthquake forces. Finite element modeling was used to better understand the Tulous' high resistance to lateral loading from earthquakes. After modeling it has been found that the high mass of rammed earth structures, in particular the Hakka Tulous, help dissipate the lateral loads experienced from earthquakes and thus the structure as a whole experiences much lower stresses than would a more modern light frame structure. In actual conditions, the Hakka Tulous are possibly even more effective than modeling results as conservative parameters were used throughout the model. By modeling the rammed earth walls alone one can see how strong this material is without any other structural support. Adding the internal wooden structures only further shows how the Hakka Tulou does an excellent job at resisting the effects of a maximum considered earthquake. With such modeling it can be further shown that rammed earth is an effective building material. 


\section{CHAPTER 5 THERMAL COMFORT ANALYSIS}

\subsection{Introduction}

Within the walls of the Hakka Tulous, many families live in comfort during both summer and winter at the climate within the Fujian Province of China. The Fujian Province lies at the end of the temperate zone closest to the equator as can be seen in Figure 75 below, meaning that the region has four seasons throughout the year of spring, summer, autumn, and winter. Due to the close proximity of the Fujian Province to the equator the winters tend to be very mild and the summers are usually fairly hot.

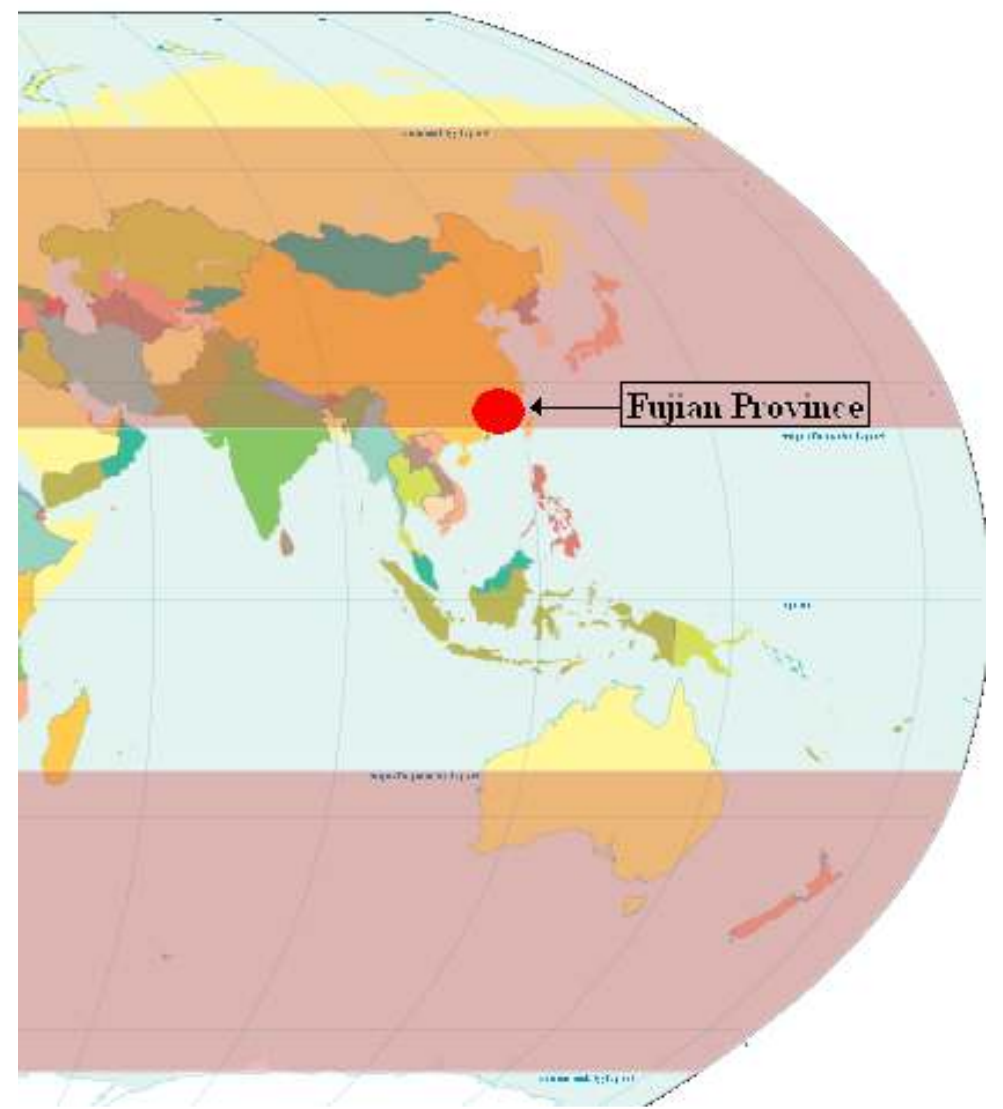

Figure 75-Temperate Region (Image Source: Wikipedia)

In the case of this thermal analysis the heat transfer is by form of conduction, which means that heat energy is transferred from molecule to molecule until temperature equilibrium is 
reached (Wilson 1998). There are two particularly important properties of a material that can control the process of conduction and in turn control the thermal comfort of any structure, including the Hakka Tulous. These properties are known as the thermal resistivity and thermal mass of a material. Both thermal resistivity and thermal mass play a key role in determining the thermal comfort of an area. The thermal resistance of a material is the ability of a material to resist heat flow, meaning that the higher the thermal resistance of a material, the more the material will resist temperature change with respect to its surrounding temperature (Plastics New Zealand 2003). Thermal mass meanwhile is the ability of a material to absorb and release heat in an attempt to reach a thermal equilibrium with its surrounding area (Australia 2008). It is well known that materials with high thermal mass have relatively low thermal resistivity and thus are not good insulators. Materials that typically have high thermal mass and thus absorb a lot of heat energy in order to change temperature are high density materials such as concrete, brick, and in this case rammed earth (Australia 2008). An analysis must be performed on the material properties of the rammed earth wall in order to fully understand the thermal comfort that is experienced in the Tulous year round.

\subsection{Thermal Resistivity}

As mentioned previously, materials with high thermal mass typically have low thermal resistance. Knowing this, one can expect that the rammed earth walls of the Tulou structure having high thermal mass while having low thermal resistance. Thermal resistivity is typically denoted as the ' $r$ ' value and represents how well a material acts as an insulator with respect to unit thickness. This ' $r$ ' value is simply the reciprocal of the ' $k$ ' value, thermal conductivity, which is the rate of heat transfer between a homogeneous material (Plastics New Zealand 2003). 
The unit for thermal resistivity is, $\frac{m-k}{w}$. The thermal resistivity of a material can be found using Equation 10 below.

$$
r=\frac{1}{k}
$$

Where ' $k$ ' is the thermal conductivity of a material. Since the thermal conductivity of the rammed earth walls varies with respect to the composition of the rammed earth, which is different at each site, and because the thermal conductivity for the rammed earth wall is unknown we will use the assumption that the thermal conductivity of the rammed earth is similar to that of a clay brick which is $.91 \frac{w}{m-k}$ (Tierrafino 2010). Using the assumed value of thermal conductivity for the rammed earth, the thermal resistivity of the rammed earth is calculated as being, $1.0986 \frac{m-k}{w}$. Another method for calculating the thermal resistivity has been recently been examined by Sargentis et al. In this method one can actually determine the thermal resistivity of a material in situ using temperature data recorded at the site (Sargentis et al. 2009). Table 11 shows the temperature that was recorded at several periods of time throughout the day at several locations of the Tulou. This set of data from the Chengqi Tulou was chosen as a representation for this method because the data showed the greatest temperature difference between outside air temperature and inside room temperature and the greatest difference of temperature would best display the effectiveness of this method. 
Table 11-Temperature Data of Chengqi Tulou

\begin{tabular}{|c|c|c|c|c|}
\hline \multirow{2}{*}{$\begin{array}{l}\text { Chengqi Tulou } \\
\text { Test Date July } 12009 \\
\text { temperature data (F) }\end{array}$} & \multicolumn{4}{|c|}{ Location of thermocouple } \\
\hline & inside room & $\begin{array}{c}\text { inner wall } \\
\text { surface }\end{array}$ & $\begin{array}{c}\text { outer wall } \\
\text { surface }\end{array}$ & $\begin{array}{l}\text { outer } \\
\text { yard }\end{array}$ \\
\hline Time & $t_{L i}$ & $t_{1}$ & $t_{2}$ & $t_{L a}$ \\
\hline $10: 50$ & 80.2 & 81 & 88 & 82.9 \\
\hline $12: 00$ & 79.7 & 81 & 89 & 84 \\
\hline $13: 30$ & 79.5 & 83 & 95 & 89.6 \\
\hline $15: 20$ & 79.5 & 81 & 112 & 96.1 \\
\hline $18: 00$ & 79.7 & 80 & 101 & 96.6 \\
\hline
\end{tabular}

As can be seen from Table 11, the greatest temperature difference between the outside temperature and inside temperature of a room can be seen at the time of 15:20 with an outside temperature of $112^{\circ} \mathrm{F}$ and an inside room temperature of $79.5^{\circ} \mathrm{F}$. The subscripts that can be seen in the table as well as in Sargentis et al.'s method and Equations are, $\mathrm{t}_{\mathrm{La}}$ which represents the outside temperature, $t_{\mathrm{Li}}$ the inside temperature, $\mathrm{t}_{1}$ the interior surface temperature, and $\mathrm{t}_{2}$ the exterior surface temperature. To further illustrate the scenario, Figure 76 shows a cross section of the Tulou and shows how the temperature fluctuates through the Tulou when being heated by the sun from the outside. 


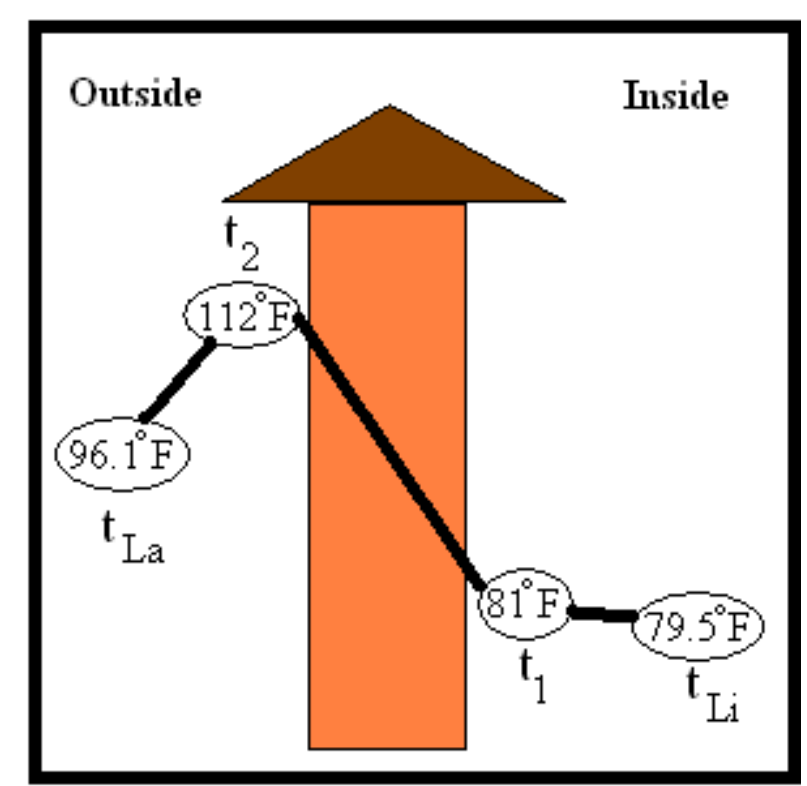

Figure 76-Temperature Distribution

Equations 11, 12, 13, and 14 below are the Equations from Sargentis et al.'s method in which an in situ "R" value can be calculated from temperature data recorded through a thickness of a material.

$$
\mathrm{a}_{\mathrm{i}}=\frac{K^{\prime}\left(t_{L i}-t_{l a}\right)}{t_{L i}-t_{1}}
$$

In Equation 11, $\mathrm{a}_{\mathrm{i}}$ represents the interior surface conductivity which can be found with both the temperature data seen in Figure 76, as well as our assumed thermal conductivity value of .91 $\frac{w}{m-k}$. Plugging in these values into Equation 11 results in an $\mathrm{a}_{\mathrm{i}}$ value of $10.075 \frac{\mathrm{w}}{\mathrm{m}-\mathrm{k}}$.

$$
\mathrm{a}_{\mathrm{FAN}}=\frac{a_{i}\left(t_{L i}-t_{1}\right)}{t_{2}-t_{L a}}
$$

Using the $\mathrm{a}_{\mathrm{i}}$ value calculated in Equation 11, one can plug in this value into Equation 12 to calculate the outdoor surface conductivity. The outdoor surface conductivity, $\mathrm{a}_{\mathrm{FAN}}$, is found to be $-.975 \frac{w}{m-k}$ after all values are substituted in.

$$
\frac{1}{\Lambda}=\frac{1}{K^{\prime}}-\frac{1}{a_{F A N}}-\frac{1}{a_{i}}
$$


In Equation 13 above, we will use all the variables previously calculated in Equations 11 and 12 as well as the assumed thermal conductivity value of $.91 \frac{w}{m-k}$ in order to find the thermal resistance of the rammed earth wall, $\frac{1}{\Lambda}$, which is found to be $2.025 \frac{m-k}{w}$.

$$
\mathrm{R}_{\mathrm{IN} \mathrm{SITU}}=\frac{1}{a_{F A N}}+\frac{1}{\Lambda}+\frac{1}{a_{i}}
$$

Equation 14 uses all of the variables calculated in Equations 11, 12, and 13 in order to find an in situ " $R$ " value. This " $R$ " value is in fact the thermal resistivity of the material, "r", as the Equation's units are $\frac{m-k}{w}$. After substituting in the appropriate values, the " $r$ " value that is found in Equation 14 comes out to be the exact same as simply the inverse of the thermal conductivity, $1.0986 \frac{m-k}{w}$. With similar results it can be determined that with an assumed thermal conductivity value of $.91 \frac{w}{m-k}$, the actual thermal resistivity of the rammed earth wall is $1.0986 \frac{m-k}{w}$.

More commonly, materials are rated on their thermal resistance, which is denoted as the ' $R$ ' value. The ' $R$ ' value represents the ability of a given material to resist heat flow. The higher the ' $R$ ' value the more the material is resistant to heat per unit thickness. If you were to double a given thickness of a material, the ' $R$ ' value of this material would also double. The thermal resistance is simply the reciprocal of the ' $\mathrm{C}$ ' value, thermal conductance, which represents the amount of heat transmitted through a unit area of a given material per unit temperature difference (Plastics New Zealand 2003). The unit for thermal resistance is, $\frac{m^{2}-k}{w}$. The thermal resistance of a material can be found using Equation 15 (Plastics New Zealand 2003). 


$$
\mathrm{R}=\frac{d(m)}{k\left(\frac{w}{m K}\right)}
$$

Where ' $d$ ' is the thickness of the material being tested and ' $k$ ' is the thermal conductivity of the material. In the United States materials are rated on their thermal resistance by showing the $\mathrm{R}$ value in such a way, R-30, which means that the thermal resistance of that given material is $30 \frac{\mathrm{ft}^{2}-F^{\circ}-h r}{B T U}$ per given inch of material. So if you had 1 foot of the given material rated at R-30, the thermal resistance would actually be $360 \frac{\mathrm{ft}^{2}-F^{\circ}-h r}{B T U}$.

To calculate the ' $R$ ' value of the entire rammed earth we use the thickness of the rammed earth wall at the Chengqi Tulou of 1.8 meters, and divide it by the assumed value for thermal conductivity of $.91 \frac{w}{m-k}$. This method is the same as multiplying the thickness of the rammed earth wall to the "r" value of $1.0986 \frac{m-k}{w}$. Performing such operations results in a ' $\mathrm{R}$ ' value of $1.98 \frac{m^{2}-k}{w}$ in SI units or $11.24 \frac{\mathrm{ft}^{2}-F^{\circ}-h r}{B T U}$ in American units. To get this ' $\mathrm{R}$ ' value into the standard 'R-\#' format that you see materials rated by in the United States, one must divide this ' $R$ ' value by the thickness of the rammed earth wall in inches, while keeping the units in the current ' $R$ ' value the same. By following this operation the rating for thermal resistivity of the rammed earth wall is found to be R-.16 per inch which means that the thermal resistance is .16 $\frac{\mathrm{ft}^{2}-F^{\circ}-h r}{B T U}$ for every inch of rammed earth wall.

With a thermal resistance rating of R-.16 per inch of material, the rammed earth walls of the Tulou structure proves what was initially assumed, the dense material is not a good thermal resistor. It is interesting to note that the rammed earth wall's thermal resistance is similar to that of concrete which is rated at R-.10 per inch (Step Warmfloor 2010). To compare, a material that has high thermal resistance is polyurethane foam which has an ' $R$ ' rating between $R-5.80$ per 
inch and R-7.70 per inch (Step Warmfloor 2010). In order to create the equivalent thermal resistance experienced by one inch of R-7.70 per inch polyurethane foam, one would need to use over four feet of rammed earth. It can thus be concluded that the thermal comfort experienced is not a result of the thermal resistance of the rammed earth, rather it is due to the thermal mass of the structure.

The predicted ' $R$ ' value for the rammed earth walls may actually be higher than originally calculated according to Environmental Building News. According to Alex Wilson of Environmental Building News, materials with a high thermal mass experience a mass-enhanced ' $R$ ' value (Wilson 1998). This is due to real-life scenarios in which the outside and inside temperatures are not constant. During the day, the rammed earth wall may experience heat flow going from the outside to the inside in order to reach a temperature equilibrium, whereas at night as the temperatures inside may be warmer than outside temperatures, the heat flow switches directions and flows from the inside to the outside. Averaging this dynamic heat flow reduces the amount of heat actually going into the building and creates a mass enhanced ' $R$ ' value that is higher than the original calculated ' $R$ ' value (Wilson 1998). The mass enhanced ' $R$ ' value is only valid in thermal conditions in which the temperature outside fluctuates above and below the inside temperature and thus the direction of heat flow is reversed. As can be seen in Figure 78 in Section 5.3, outside temperatures do fluctuate above and below inside temperatures in the Fujian Province and thus the Tulous most likely do show a mass enhanced ' $R$ ' value that is slightly higher than the calculated R-.16 per inch. 


\subsection{Thermal Mass}

The Hakka Tulous have little to no insulation from their rammed earth walls and instead must rely on the high thermal mass that rammed earth provides. Thermal mass is the ability of a material to absorb, store, and release heat in an attempt to reach a temperature equilibrium with its surrounding temperature (Gorgolewski 2009). Materials that have a high density such as concrete and rammed earth require more heat energy to change their temperature where as materials with low density such as wood do not need a lot of heat energy in order to change temperatures. Concrete and rammed earth are known as materials with high thermal mass where as wood is known as a material with low thermal mass due to the amount of heat energy required to change their temperatures (Australia 2008). A good application of thermal mass is one in which internal temperatures of a structure are kept stable when compared to varying temperatures from the outside. For example, during the warm summer season a material with high thermal mass should absorb the heat from the outside while keeping the interior cool during the day. At night the material with high thermal mass should release the heat to keep the interior temperature stable when compared to the colder night temperatures outside. During the winter the material with high thermal mass should be heated by direct sunlight in order to release heat and keep the interior temperatures at a comfortable level. An example of an efficient use of thermal mass from the Your Home Project sponsored by the Australian government can be seen in Figure 77. 


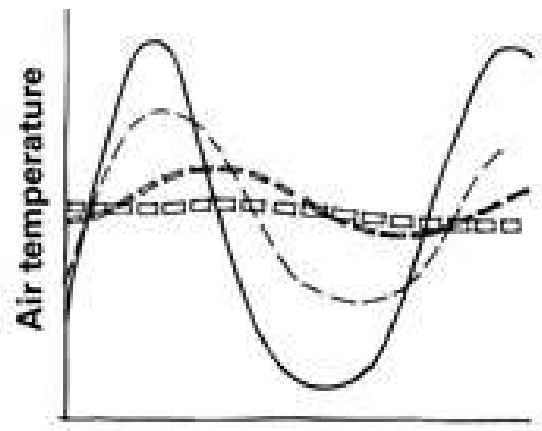

Time of day

- Outdoor temperature

- - light timber-framed building

-- Heavy building with external insulation

an Heavy building set into and partially covered with earth

Figure 77-Example of Efficient Use of Thermal Mass (Australia 2008)

In this figure one can see that while outside temperatures fluctuate throughout the day, the interior temperature remains fairly stable at a comfortable temperature for its inhabitants. Applying a high thermal mass material to a structure will not necessarily increase efficiency of that structure. Thermal mass must be correctly used if one desires to balance the diurnal temperatures experienced throughout the day and different seasons. If one fails to properly apply thermal mass to a structure the interior comfort of the structure may actually decrease due to the material constantly releasing heat during the warm summer days or absorbing all of the heat being producing during the cold winter days (Australia 2008). It is for this reason that several factors have to be reviewed before judging whether the application of a high thermal mass material is going to be a logical for a specific structure. Thermal mass applications are found to be efficient in climates that show a diurnal temperature range of more than $6^{\circ}$ Celsius with larger the difference between night and day temperatures meaning more efficiency of the application of thermal mass (Australia 2008). 
If the climate of the region permits the efficient use of a material with high thermal mass then the design of a structure using the material should be considered in order to create a comfort zone for inhabitants without the need for mechanical cooling or heating. For summer conditions it is important to consider that the material with high thermal mass should be properly shaded from the sun in order to avoid the material from becoming too saturated of heat and releasing heat during hot conditions. Also, an open environment should be allowed for the material with high thermal mass in order for it to be in direct contact with the cooler night temperatures so that the material can release its stored heat (Australia 2008). The material will already be heated from the hot surrounding air during summer conditions and thus is why direct contact with the sun is not necessary during the summer. During cooler winters however one would like for the material with high thermal mass to be in direct contact with sunlight in order to absorb the heat and release it later. Since it is known that the angle of incidence for the sun is higher during the summer than during the winter, a roof structure can be created that can take advantage of both extremities of summer and winter.

When designing a structure with materials high in thermal mass it is important that the material be efficient for the application. As discussed earlier concrete and rammed earth have high thermal masses of 2,060 $\frac{K J}{m^{3}-k}$ and 1,673 $\frac{K J}{m^{3}-k}$ respectively (Australia 2008). Steel on the other hand has a much higher thermal mass of $3,744 \frac{K J}{m^{3}-k}$ and softwood has a much lower thermal mass of $866 \frac{K J}{m^{3}-k}$ (Gorgolewski 2009). In Equation 16 one can see the relationship between heat energy and thermal mass where $\mathrm{Q}$ is the heat energy, $\mathrm{C}_{\mathrm{th}}$ is the thermal mass, and $\Delta \mathrm{T}$ is the change in temperature.

$$
\mathrm{Q}=\mathrm{C}_{\mathrm{th}} * \Delta \mathrm{T}
$$


What this Equation means is that a material with high thermal mass needs much more heat energy to change temperature than a material of low thermal mass. For example if we are to consider $1 \mathrm{~m}^{3}$ of both rammed earth and a softwood, it would take twice as much heat energy in the rammed earth than the softwood in order to change the temperature equally in both materials. Another way to look at it is one would need twice the volume of a softwood than rammed earth in order to experience the same temperature change. If one were to only consider thermal mass then one could easily say that steel is the most effective material for thermal mass with a thermal mass of $3,744 \frac{K J}{m^{3}-k}$. This is not true however due to thermal conductivity. Thermal conductivity is the property that determines how a material gives off heat. If a material has too high thermal conductivity it would release heat too quickly and the heat release effect desired in diurnal climate conditions would be neglected. A material that has too little thermal conductivity would do the exact opposite and not allow heat to flow through it such as in rubber (Australia 2008). To compare, steel has a thermal conductivity of $55 \frac{W}{m-k}$, concrete $1.0 \frac{W}{m-k}$, rammed earth .91 $\frac{W}{m-k}$, and softwood .13 $\frac{W}{m-k}$ (Tierrafino 2010, Australia 2008). As can be seen here steel releases heat at a rate of over 55 times faster than that of rammed earth and thus is why steel is not used for its high thermal mass. Another important property is the reflectivity of a material, typically you would want a dark or textured surface so that the heat will not be reflected away, this is an issue for winter as one wants the surface to be in direct contact with the sun and not so much of an issue for summer conditions as the surrounding heat from the air warms up the material of high thermal mass (Australia 2008).

In modern construction, materials with high thermal mass are typically placed inside the building, this is known as reverse mass construction. The thought process behind this is that during the summer the material will absorb the heat from the warmer surrounding air and during 
winter, direct sunlight will be absorbed by the high thermal mass of the material in order to release it at cooler night temperatures. With reverse mass construction, good application of windows and insulation must be used to achieve the desired results. During the summer, the insulation will prevent excess heat from coming in and prevent the material of high thermal mass from excess absorption of heat. In the winter, placement of windows is important so that the sun can come into direct contact with the material of high thermal mass in order to heat it up so that it may release the heat later. The insulation will then keep the heat that is released from the material of high thermal mass within the building (BlueScope Steel 2009).

The Hakka Tulous, in some cases thousands of years old, did not have the luxury of reverse mass construction due the need of extensive windows and insulation. Instead, the Hakka people found other ways to use the application of the high thermal mass provided by the rammed earth. As can be seen in both Figure 78 and Figure 79, courtesy of Minoru Ueda, the Hakka people achieved thermal comfort without the use of insulation (Ueda 2009). 


\section{7-Day Temperature Data}

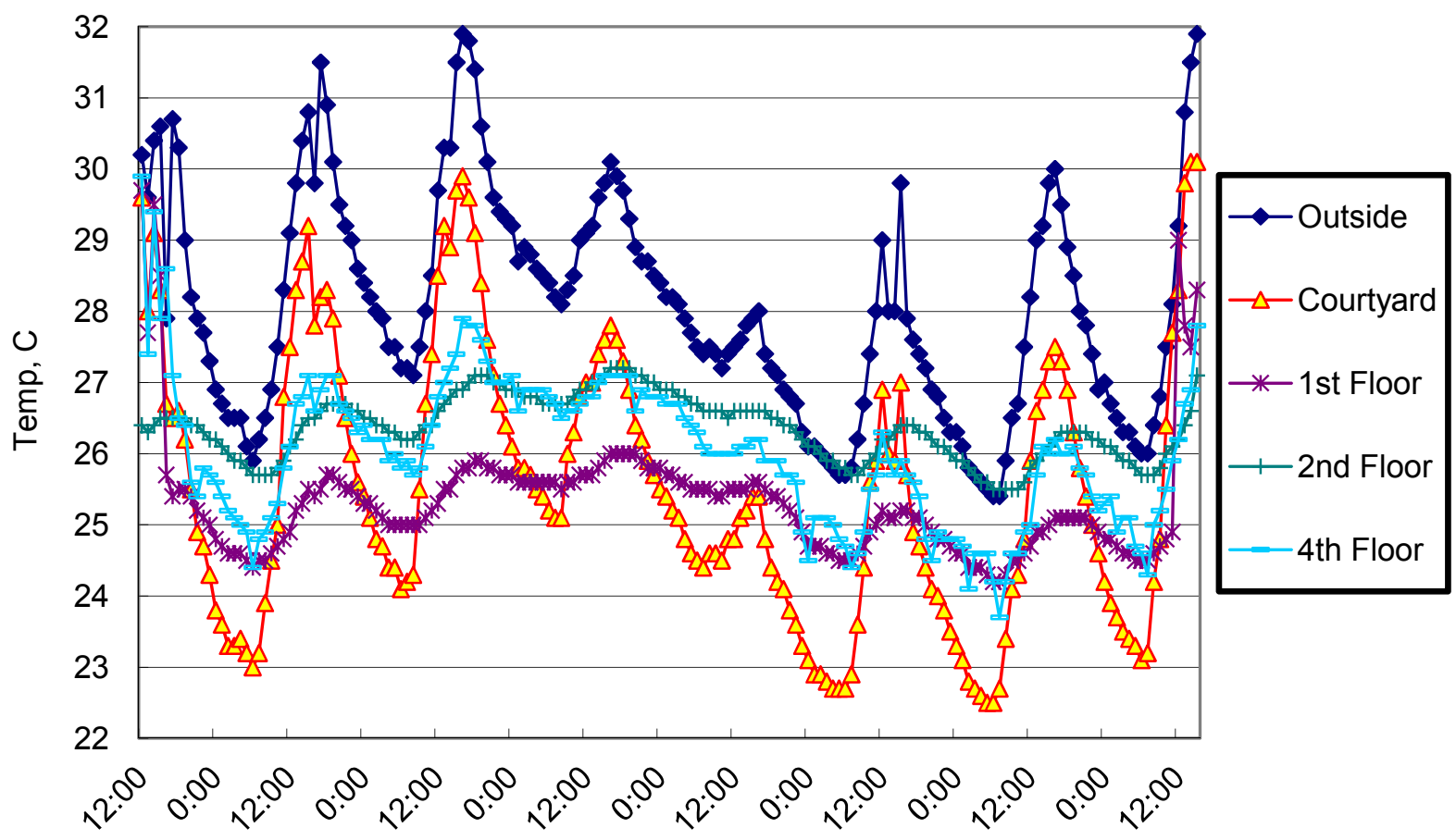

Time, hr

Figure 78-Seven Day Temperature Data Chengqi Tulou (Ueda 2009) 


\section{Day Humidity Data}

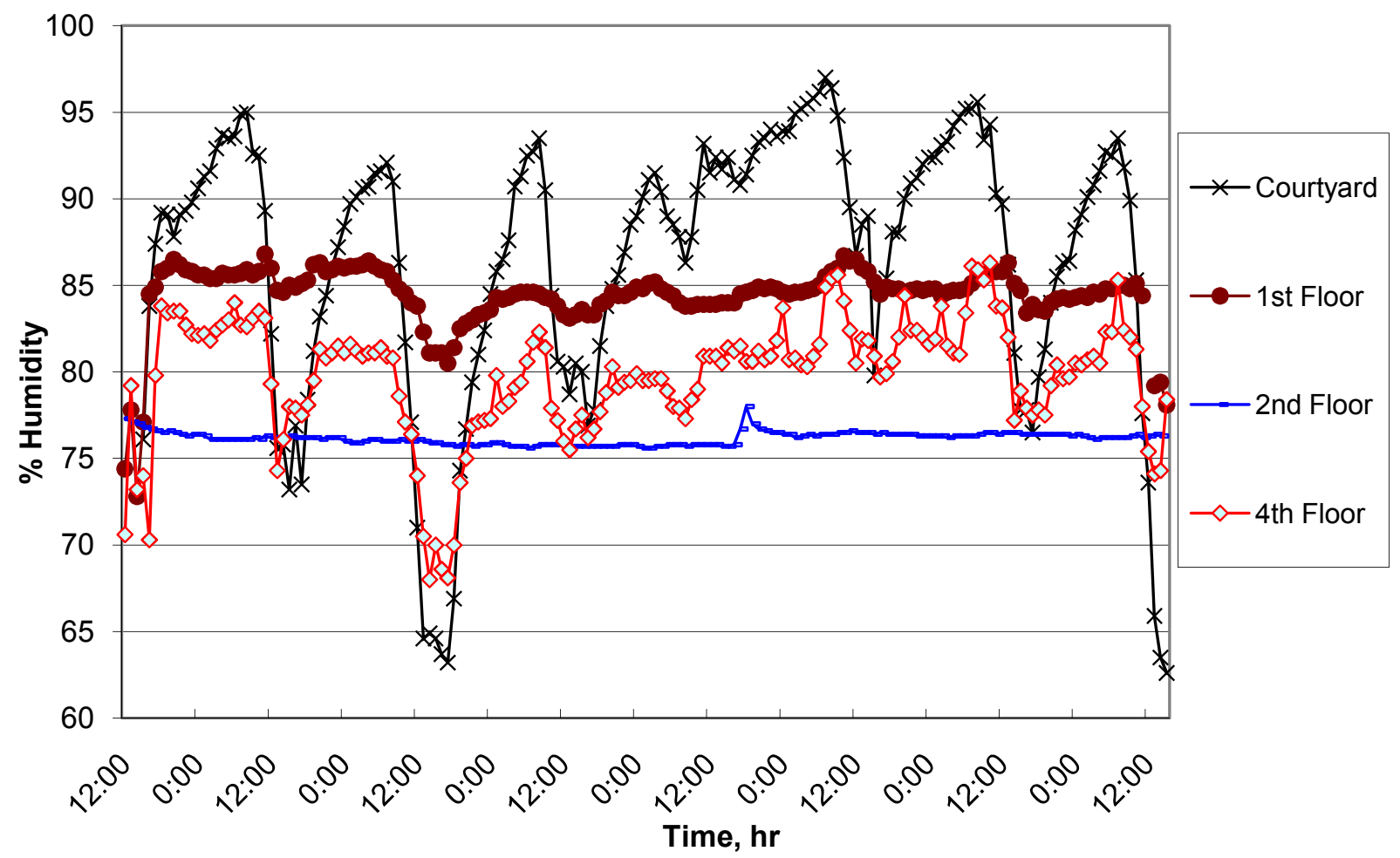

Figure 79-Seven Day Humidity Data Chengqi Tulou (Ueda 2009)

As displayed in Figures 78 and 79, Minoru Ueda, a Japanese Architect, has recorded temperature and humidity data for one week in the summer of 2009 at the Chengqi Tulou. Minoru Ueda recorded temperatures and humidity outside, inside the courtyard, and inside the rooms on the $1^{\text {st }}, 2^{\text {nd }}$, and $4^{\text {th }}$ floors. As can be seen in Figure 78 , the outside temperatures in both the courtyard and outside the Tulou are diurnal and range more than $7^{\circ}$ Celsius, which already tells us that the application of thermal mass is efficient for the climate. The chart also shows the success of the application of the rammed earth walls with their high thermal mass as the $1^{\text {st }}, 2^{\text {nd }}$, and $4^{\text {th }}$ floor interior temperatures are very stable, staying within a comfort zone and showing temperature fluctuations, in most cases, of no more than $1^{\circ} \mathrm{C}$. The most efficient region in the Tulou is the $1^{\text {st }}$ floor where temperatures stay between $24.5^{\circ} \mathrm{C}$ and $26^{\circ} \mathrm{C}$, never 
fluctuating by more than $1^{\circ} \mathrm{C}$ in any given day. The $2^{\text {nd }}$ floor fluctuates between $25.5^{\circ} \mathrm{C}$ and $27^{\circ} \mathrm{C}$, also not fluctuating by more than $1^{\circ} \mathrm{C}$ in any given day. The $4^{\text {th }}$ floor is the least efficient interior area during summer hours as temperatures range from $24^{\circ} \mathrm{C}$ to $28^{\circ} \mathrm{C}$ fluctuating a little over $2^{\circ} \mathrm{C}$ in any given day. The lower floors are more efficient than the upper floors due to the fact that heat rises and also the $1^{\text {st }}$ floor is used for cooking and dining whereas the $3^{\text {rd }}$ and $4^{\text {th }}$ floors are used as living space, which means that all the heat generated during cooking flows up to the living areas. Even considering this efficiency decrease as we go up in height in the Tulou, all floors remain in a comfort zone for their inhabitants regardless of outside diurnal temperature changes. This remains true when also considering the humidity data in Figure 79. The humidity data shows that while humidity fluctuates outside in the courtyard to values as high as $97 \%$, the interior humidity percentage remains constant with the most efficient floor remaining at $76 \%$ humidity throughout the entire week. The Hakka people most likely live on the top floors rather than the lower floors due to winter conditions. In the winter, one would expect a reversal of efficiencies with the top floors being more efficient than the lower floors due to heat rising into the upper floors. As displayed from the data above, the thermal comfort zone is achieved all year round due to the effective use of thermal mass from the rammed earth walls.

In order to efficiently use thermal mass, the Hakka people, knowingly so or not, designed the Tulous in an intuitive way. First off, we know that the material used, rammed earth, is a great material for this application with its high thermal mass and good thermal conductivity. The walls, made from rammed earth, are high in volume, some coming to nearly 2 meters in thickness and 20 meters in height. This provides a structural purpose as well as a defense purpose, but also provides a very generous volume that can absorb the heat surrounding it. Note 
that the walls however are not of uniform thickness as one goes up in the structure as seen previously in Figure 4.

As stated by Your Home Project of Australia, high mass construction should be situated on the bottom of multi story construction due to the fact that heat does rise (Australia 2008). The rammed earth walls of the Hakka Tulous do in fact decrease in volume as one goes higher in the structure. Most likely the Hakka people made the walls thinner as they went higher due to structural reasons as the load decreases on the wall as one goes up, however there is also a benefit to the thermal comfort of the structure. The reduction of volume of the rammed earth reduces the thermal capacity of the material in these upper layers also making the area more comfortable during the hot summer seasons.

The outside walls are also very rough as can be seen in Figure 80, absorbing rather than reflective sunlight that plays a very vital role during the winter season.

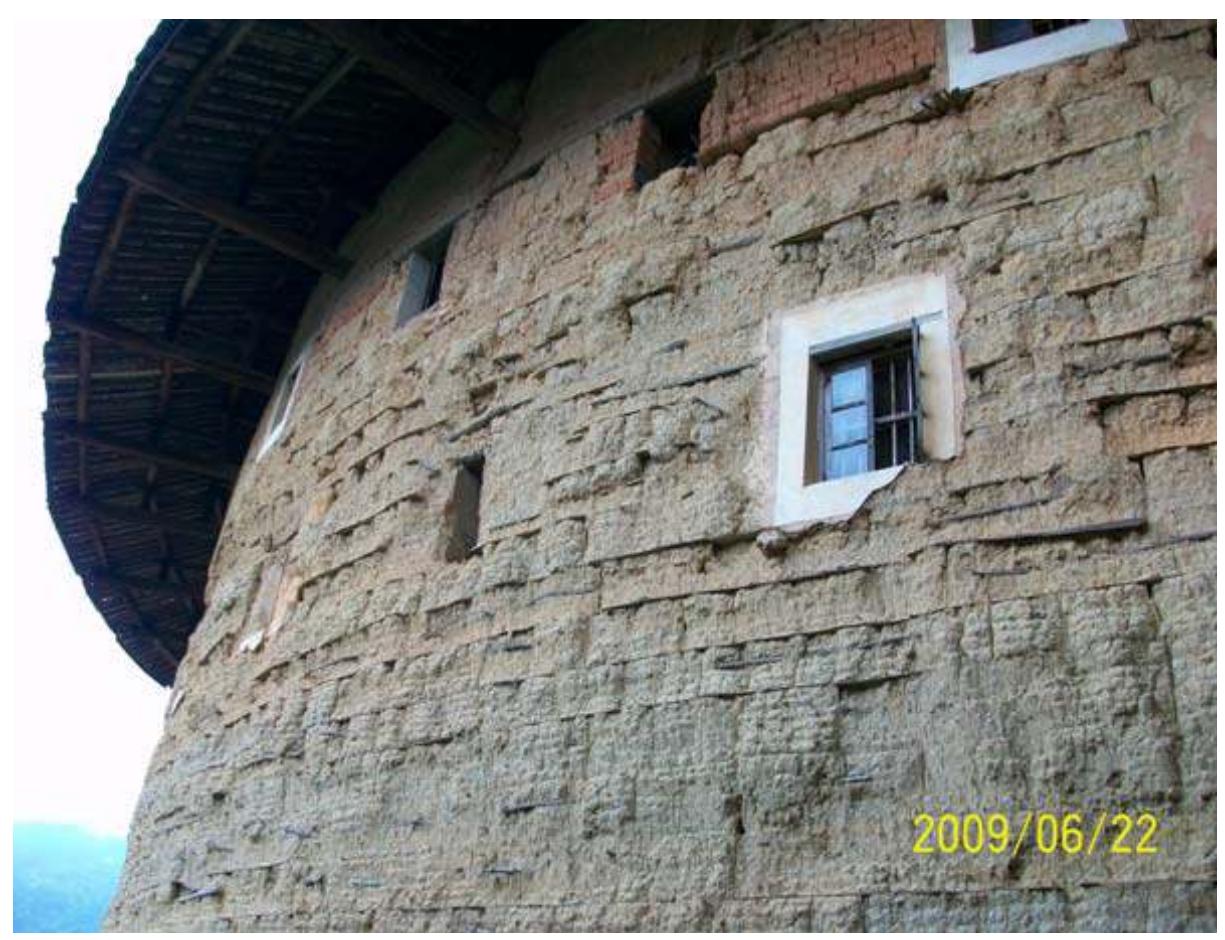

Figure 80-Rough Rammed Earth Walls of Chengqi Tulou 
The roof structure that can also be seen in the figure above, extends nearly 10 feet out, not only protected the rammed earth walls from weathering effects which include monsoons and storms experienced in the region, but also shading the rammed earth walls during the summer (UNESCO 2008). As previously mentioned, during the summer the angle of incidence from the sun is much higher and thus a large extended roof such as this one prevents the rammed earth walls from constant contact with the sun, preventing the rammed earth walls from becoming over saturated in heat and thus ineffective in maintaining a stable interior temperature. The round structure of the Tulou as well as the openness of the structure also allows winds to go around and through the structure cooling the rammed earth walls initiating the heat release cycle that is experienced during the cooler nights of the summer.

\subsection{Conclusions}

The Hakka people found ways to live in thermal comfort without the need of mechanical heating or cooling in both the summer and winter seasons due to their effective use of rammed earth construction. This was also done without the use of insulation, which would help maintain heat within the structure during the winter seasons. The Hakka people live on the upper part of the structure knowing that heat rises in order to combat lack of insulation provided by the rammed earth walls. Modern construction can take what the Hakka people created and make it even more efficient, allowing even the lower floors to be living areas during the winter season. As stated by Sustainable Energy Authority, Victoria, mud bricks, similar to rammed earth, are very efficient during the summer however during the winter tend to be less efficient due to their small ' $R$ ' value, or thermal resistance, allowing the cool air to take heat away from the structure. 
Modern construction can take advantage of using both insulation and natural earth construction in a way that is shown in Figure 81 (Melbourne 2002).
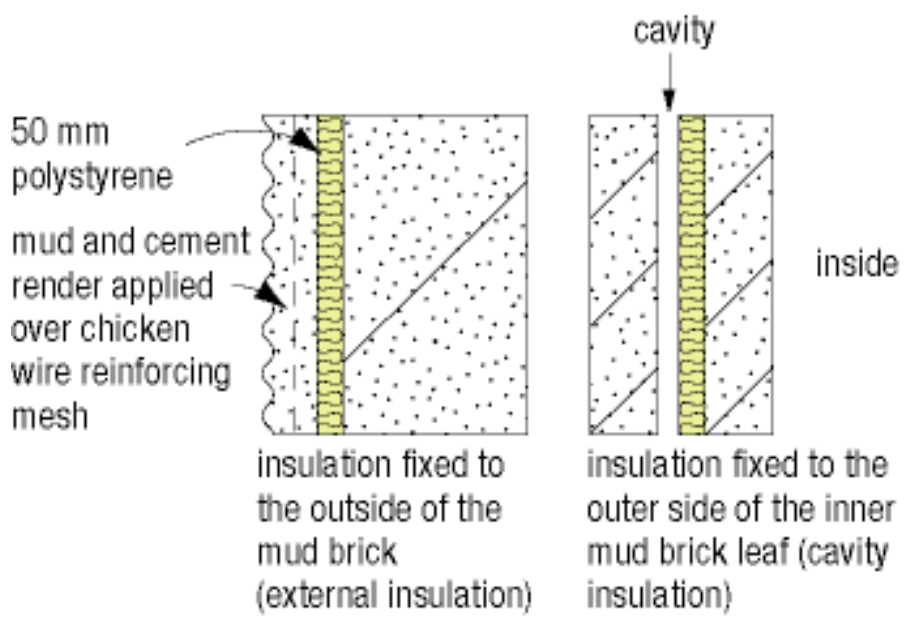

Figure 81-Intergrating Insulation with Natural Construction

The Hakka Tulous are remarkably thermally efficient using only the high thermal mass of the rammed earth walls to do so. Hakka people were and are able to live in comfort all year round due to their innovative use of the high thermal mass provided by the rammed earth material. Such construction shows that comfortable living is possible in completely natural structures without the need for mechanical heating or cooling. In the future one can integrate the technologies mastered by the Hakka people and combine them with modern materials such as ones with good insulation properties to further make such natural living more efficient and comfortable. 


\section{CHAPTER 6 DISCUSSION, CONCLUSIONS, AND RECOMMENDATIONS}

\subsection{Discussion}

Through this study one can see that there are numerous benefits that rammed earth construction offers the Hakka Tulous. The material is structurally sound as proven by the hundreds of years of service being offered by the Hakka Tulous even through numerous natural disasters. In the US applications of rammed earth are rare and the best known is the earth building code entitled, "New Mexico Earthen Building Materials Code (New Mexico 2003)." This code limits rammed earth buildings to no more than 2 stories and states that ultimate compressive strengths of rammed earth samples must be more than 300 psi. Such standards may be overally conservative as the Hakka Tulous have survived in a highly prone earthquake region and were built up to 5 stories in height while material testing has shown ultimate compressive strengths lower than 300 psi. In ASTM's "Standard Guide to Design of Earthen Wall Building Systems," it is stated that wall height to thickness ratios should be limited to no more than six times in high seismic risk zones and to no more than eight times in medium seismic risk zones. Such limitations would mean that the Huanji Tulou, with a wall thickness of 1.8 meters, should have a wall height no taller than 10.8 meters as it is in a high seismic zone, or even 14.4 meters if it were in a medium seismic zone (ASTM 2010). In reality the structure stands at 20 meters in height and has survived many strong earthquakes, while finite element modeling also confirms that the structure is built to withstand the maximum considered earthquake which once again leads one to believe that such guides and codes possibly underestimate the strength of rammed earth. This study shows that rammed earth can be trusted as a building material and that future 
research could gain the confidence of engineers with further advancement of rammed earth building codes.

Rammed earth also provides the Hakka Tulous with thermal comfort during both summer and winter periods due to the material's high thermal mass. The Hakka people have also used local wood, for columns and beams, and bamboo strips to build the strong internal structures that make up the floors, roof, as well as supporting columns of the structure. The Hakka Tulous are built completely from natural materials that have survived the Hakka people for hundreds, if not thousands, of years. These structures, although old, also provide their tenants with quite modern living standards.

Seeing the modern lifestyle that rammed earth structures can offer their tenants, many people may question what is the difference between rammed earth construction and that of modern concrete construction? Modern construction focuses much more on the use of concrete in structures as it too has a high thermal mass and even higher material strength than that of rammed earth. The benefit to using rammed earth lies in the zero $\mathrm{CO}_{2}$ emissions of the product when compared to that of concrete. Rammed earth is a completely natural material that involves a timely production process involving compressing a natural mixture of earth, organics, and other materials. This process releases zero $\mathrm{CO}_{2}$ during and after the fabrication process of rammed earth. Cement production on the other hand, a common ingredient in concrete, releases anywhere from $5-10 \%$ of the world's total $\mathrm{CO}_{2}$ emissions into the earth's atmosphere (Dodson 2006). As already known, $\mathrm{CO}_{2}$ emissions have been an important topic of debate as of recent as the gas is listed as one of the more common greenhouse gases in existence. With the Hakka Tulous serving as a prime example of what rammed earth construction can offer, rammed earth could prove as a viable building material option over that of concrete. Even when one is to 
consider the LEED green building certification program developed by the U.S. Green Building Council, USGBC, one could expect only the highest certification for the Hakka Tulou rammed earth buildings (AETN 2010). The LEED certification is based on, "energy savings, water efficiency, $\mathrm{CO}_{2}$ emissions reduction, improved indoor environmental quality, and stewardship of resources and sensitivity to their impacts (USGBC 2010)." The Hakka Tulous represent the highest level of LEED certification as the structures show the greatest energy savings with no additional heating and cooling required and there are zero $\mathrm{CO}_{2}$ emissions thanks to the main building material of rammed earth. Rammed earth also provides the interior space with humidity control and the rammed earth walls blend in well with the natural surroundings of the Fujian province. These attributes along with the efficiency of the rammed earth walls makes the Hakka Tulou structures deserving of the highest LEED certification. Rammed earth has stood the test of time in historic constructions and due to its numerous advantages can surely be seen as a viable building material option of the future.

\subsection{Conclusions}

In order to verify that rammed earth is a viable building material option this study has examined how the material has been successfully implented in historic Hakka Tulou structures that have existed for several centuries. Material tests were performed on several types of samples from five different Tulou locations. Strength parameters were taken from these tests and used in FE modeling for analysis of possible autogenous healing scenarios as well as earthquake response analysis of the Tulou structures. Load testing was also performed in order to test the structural integrity of the interior wooden system and lastly thermal data was reviewed to verify the thermal efficiency provided by the rammed earth of the structures. 


\section{Material Sample Tests}

After analyzing several earth samples from the Fuxing Tulou, Wuyun Tulou, Chengqi Tulou and Zhencheng Tulou, no correlation with the strength of the rammed earth and the age of the structure was noted. For example, the Fuxing Tulou, the oldest at 1,240 years old, is the second strongest of the samples tested with a modulus of elasticity of 6,318 psi and an ultimate compressive strength of 282 psi as tested by the Xiamen University. Rebound hammer results also show that rammed earth from the Fuxin Tulou had the second hardest earth tested overall. After performing an energy-dispersive x-ray spectroscopy analysis on the Fuxing sample, it was found that one of the dominant elements of the sample is calcium. None of the other samples from other Tulou locations have calcium as a dominant element and only one other sample displayed any calcium at all. Calcium is the main component of lime which is used commonly in many building materials such as concrete and mortar and has also been accredited with autogenous healing of cracks in concrete. It is strongly believed that calcium has played a role in allowing the rammed earth at the Fuxing Tulou to retain its high strength for 1,240 years; hence the composition of the material, rather than its age, appears to directly impact the strength of rammed earth.

\section{$\underline{\text { Load Testing }}$}

Load testing of both the internal floor and roof system at the Chengqi Tulou shows that the construction methods and materials used still provide a structurally sound living environment even after hundreds of years. During testing, a two point load of up to $550 \mathrm{lbs}$ was centered on the middle third of both a floor beam and roof beam resulting in strains that were all lower than 
100 microstrain. Such results show that the dead and live loads had a minimal effect on the response of the structure. The results can be attributed to the design of the internal wooden systems as well as the building material, China-Fir. China-Fir is a high strength wood whose high decay resistance to fungi and termites can also attribute to its long term success. It is interesting to note that even after using low structural properties for wood used in these Tulous, the system resulted in only a maximum stress of 128 psi, not nearly enough to cause any type of failure, which is around 500 to 10,000 psi depending on the species. Thus the durability of the strong internal frame structures of the Tulous can be attributed to both the design as well as material used.

\section{Autogenous Healing}

Reports of self healing cracks in the rammed earth walls were also analyzed for their validity in this study. It had been reported that a strong earthquake had caused a $20 \mathrm{~cm}$ wide crack in the rammed earth walls of the Huanji Tulou and that it has healed down to $5 \mathrm{~cm}$ wide years later. The study has found that although the story of the self healing crack cannot be entirely ruled out, there is reason to believe that with the existence of lime, some type of autogenous healing could occur, especially under creep deformation of rammed earth walls over a long time frame. Finite Element modeling has shown that the crack developed due to a weak lintel above a window causing higher residual stresses in the rammed earth above it. This stress concentration created a weak point that was exploited when external forces from an earthquake further increased stresses until a crack was created. The field study showed that the Huanju Tulou did not use internal reinforcement (wood, bamboo, etc.) within its rammed earth walls. Such reinforcement would at least double the strength of the rammed earth walls and would have 
prevented such a crack from occurring. FE modeling shows that with a temperature change of $70^{\circ} \mathrm{F}$ the crack could close by $50 \%$, however such results are reversible based on temperature reversal and the Fujian Province experiences mild winters making such a temperature flux very unlikely. The model's results combined with the fact that no calcium was found in Huanji rammed earth samples during EDS testing, lead one to believe that such large autogenous healing is not possible at the Huanji Tulou. Although there is a possibility that autogenous healing could occur if lime were present, this phenomena itself is limited to a much smaller scale as shown by current research regarding autogenous healing in concrete members.

\section{Earthquake Response}

FE modeling was also used to show how the rammed earth structures have been able to survive strong earthquakes experienced in the region for so many centuries. Models of Tulous were created with and without their internal structure in order to show how well the rammed earth itself reacts to earthquake forces. After applying the maximum considered earthquake for the region as per ASCE 7-05, it was found that a maximum stress of 140 psi developed in the rammed earth walls. This value is lower than the ultimate compressive stress of the rammed earth samples tested however would most likely cause cracking due to rammed earth being weaker in tension. Deflection was also a concern as the model showed a max deflection of 2.5 meters when using only the weakest rammed earth tested $(\mathrm{E}=1,706 \mathrm{psi})$. This problem however was alleviated when using internal reinforcement and/or stronger rammed earth as max deflections reduced to 0.5 meters. After adding the internal wooden system to the model and using only the weakest rammed earth tested $(\mathrm{E}=1,706 \mathrm{psi})$, maximum stresses of only $14.6 \mathrm{psi}$ and a maximum deflection of .2 meters were found. These results show that even for a 
maximum considered earthquake, a Tulou experiences very little stresses and is thus not affected by the large earthquake forces. The high mass of rammed earth structures, in particular the Hakka Tulous, help dissipate the lateral loads experienced from earthquakes and thus the structure as a whole experiences much lower stresses than would a more modern light frame structure.

\section{$\underline{\text { Thermal Evaluation }}$}

Finally, this study has found through the use of the temperature and humidity data that the Hakka people truly do live in thermal comfort without the need of any excess heating/cooling. During peak temperatures in a summer day, data shows that there is a difference of nearly $20^{\circ} \mathrm{F}$ between outdoor temperatures and indoor temperatures of the Hakka Tulou. Also, seven day data show us that although outside temperatures fluctuate by over $10^{\circ} \mathrm{F}$ during the week, indoor temperatures maintain a comfortable temperature and only fluctuate by $3^{\circ} \mathrm{F}$. Similar results were found for humidity as the rammed earth walls maintained a stable humidity rate for the inhabitants throughout the seven days of data recording. Such findings can be attributed to rammed earth's high thermal mass, 1,673 $\frac{K J}{m^{3}-k}$, and low thermal conductivity, $.91 \frac{K W}{m-k}$, which allow the material to absorb much thermal energy and release the thermal energy in a slow, controlled manner as shown by the temperature data. Based on these findings it is further shown that rammed earth, specifically its application to Hakka Tulous, is a highly energy efficient natural building material.

Through material testing and analysis this study has examined how the Tulou structures have maintained their structural stability while also providing thermal comfort. Readers of this 
thesis are encouraged to review additional technical papers and reports for more information on research activities and findings as a result of this exploratory research (Liang and Hota 2010, Liang et al. 2010, Liang et al. 2011). In short, the final results of this study can be concluded with the following five main points:

- $\quad$ Strength of Rammed Earth Dependent on Composition Not Age

- Internal Wooden System Structurally Sound Due to use of China-Fir (High Decay Resistance)

- $\quad$ Self-Healing of Crack Most Likely False

- $\quad$ Rammed Earth Very High Resistance to Earthquakes (High Volume Dissipates Lateral Force)

- $\quad$ Rammed Earth Very Thermal Efficient Due to High Thermal Mass/Low Thermal Conductivity

\subsection{Recommendations}

In order to better understand the primary building material of the Hakka Tulous, rammed earth, more in depth research needs to be performed on the material for use in modern construction. Due to the difficulty of collecting uniform samples from their in situ environments, there was limitation on the number of samples tested and accuracy able to be performed during testing. It is suggested that rammed earth samples be constructed and tested in a controlled environment in order to ensure accurate results. Variables such as composition of the rammed earth samples as well as moisture content could be tested in order to fully understand how ingredients and humidity impact the strength of rammed earth. By studying rammed earth in a controlled environment, one may be able to find exactly how certain variables change the 
characteristics of rammed earth. This information could then be used in future standards for rammed earth construction. In specific interest to the Constructed Facilities Center at West Virginia University, rammed earth could be used in future collaboration with green composites to create the ultimate environmentally friendly structure. 


\section{REFERENCES}

Aaberg-Jørgensen, Jens. "Case of Survey." Chinadwelling.dk. 2003. Web. 30 Apr. 2010.

$<\mathrm{http}: / /$ www.chinadwelling.dk/>.

AETN, 2010. AETN Press Conference. History made for tomorrow : Hakka Tulous. October 21, Beijing, China: http://tv.people.com.cn/GB/150716/13023973.html

Angelbeck, Donald I. "Lime Fly Ash Aggregate Sludge Paving Material - Patent 4105463."

Patent Searching and Inventing Resources. University of Toledo, 1978. Web. 25 May 2010.

$<$ http://www.freepatentsonline.com/4105463.html >.

ASCE 7. Chapter $11 \&$ 12. Minimum Design Loads for Buildings and Other Structures. ASCE 705. 109-42. Reston, VA: American Society of Civil Engineers/Structural Engineering Institute, 2006. Print.

ASTM Standard E2392/E2392M-10, 2010, "Standard Guide for Design of Earthen Wall Building Systems," ASTM International, West Conshohocken, PA, 2003, DOI: 0.1520/E239210E01, www.astm.org.

Australia. Department of the Environment, Water, Heritage and the Arts. Your Home Technical Manual. By Chris Reardon, Caitlin McGee, and Geoff Milne. 4th ed. Commonwealth of Australia, 2008. Print. See Section 4.9, Thermal Mass

Bambus . "Mechanical Properties of Bamboo." Entwerfen Mit Bambus. Web. 06 Apr. 2010. $<$ http://bambus.rwth-aachen.de/eng/reports/mechanical_properties/referat2.html $>$.

Barbero, Ever J. Introduction to Composite Materials Design. Philadelphia, PA: Taylor and Francis, 1999. Print. 
Benham, P. P., and Frederick Victor Warnock. Mechanics of Solids and Structures. London: Pitman, 1973. Web.

$<$ http://www.staff.vu.edu.au/sokolov/ansys/Thoeries/Benham/Ch15\%20Theories\% 20of\%20Yiel ding/15.2.PDF $>$.

BlueScope Steel. Sustainable Building Solutions:Thermal Mass. Tech. 7th ed. Vol. 1. BlueScope Steel, 2009. Print.

Dodson, Sean. "A Cracking Alternative to Cement." Guardian.co.uk. 11 May 2006. Web. 29 June 2010.

$<$ http://www.guardian.co.uk/technology/2006/may/11/guardianweeklytechnologysection.carbone missions $>$.

Earth Materials . "Earth Materials: Sustainable Sources." Web. 29 June 2010.

$<$ http://earth.sustainablesources.com/>.

Encyclopedia. "Fujian." The Columbia Encyclopedia, Sixth Edition. 2008. Encyclopedia.com. 26 Mar. $2010<$ http://www.encyclopedia.com $>$.

Engineering Toolbox. "Earth or Soil - Weight and Composition." The Engineering ToolBox, 2005. Web. 11 May 2010. <http://www.engineeringtoolbox.com/earth-soil-weightd_1349.html>.

FEMA. Designing for Earthquakes a Manual for Architects. [Washington, D.C.]: U.S. Dept. of Homeland Security, FEMA, 2006. Print. http://www.wbdg.org/ccb/FEMA/fema454.pdf

Friedman, Daniel. "Thermal Expansion: Table of Coefficient of Thermal Expansion of Building Materials." InspectAPedia.com Building \& Environmental Problem Diagnostic \& Repair Encyclopedia. 5 Sept. 2006. Web. 25 May 2010. $<$ http://www.inspectapedia.com/exterior/Coefficients_of_Expansion.htm>. 
Geotechnical. "Young's Modulus for Soil." Geotechnical Information Website. Web. 06 Apr. 2010. <http://www.geotechnicalinfo.com/youngs_modulus.html $>$.

Gorgolewski, Mark. "Thermal Mass in Buildings." Canam Info Tech. 5 (Fall 2009). Canam. Canam Group Inc. Web. $<$ http://www.canamsteeljoist.ws/www/v4/newslet.nsf/va_redir/ch_especialv5n3>.

Green, David W., Jerrold E. Winandy, and David E. Kretschmann. "Mechanical Properties of Wood." Wood Handbook-Wood as an Engineering Material. Madison: U.S. Department of Agriculture, 1999. 4-1--43. Print.

Halabe, Udaye B. Nondestructive Material and Structural Evaluations. Publication. West Virginia University. 2009. Print.

Halabe, Udaya B., Samer H. Petro, and Hota V.S. GangaRao. Nondestructive Evaluation Methods for Highway Bridge Superstructures. Rep. no. CFC 95-215. 1995. Print.

Hong, Zhang. "Tulou: The Earthen Architecture of Fujian's Mountain Villages." China Today. 2006. Web. 25 May 2010. <http://www.chinatoday.com.cn/English/e2008/e200811/p64.htm>.

Jacobsen, Stefan, and Erik J. Sellevold. "Self Healing of High Strength Concrete after Deterioration by Freeze/thaw." Cement and Concrete Research 26.1 (1996): 55-62. Science Direct. 15 Feb. 1999. Web. 25 May 2010.

Jacquin, P. A., C. E. Augarde, and C. M. Gerrard. Analysis of Historic Rammed Earth Construction. Rep. New Dehli, 2006. Print. Structural Analysis of Historical Constructions.

Liang, R, G. Hota, D. Stanislawski and Y Lei. 2011. Thermal and Mechanical Responses of Hakka Tulou Rammed Earth Structures: Lessons to Be Learned for a Sustainable Future, Proceedings of 2011 NSF Engineering Research and Innovation Conference, January 4-7, 2011, Atlanta, Georgia 
Liang, R, G. Hota, D. Stanislawski, Y. Lei, Y Li, and Y. Jiang. 2010. Material and Structural Response of Historic Hakka Rammed Earth Structures, Proceedings of the 85th Annual Meeting of the West Virginia Academy of Science, p32, April 10, 2010, Morgantown, West Virginia

Liang, R and G Hota. 2009a. SGER: Material and Structural Response of Historic Hakka Rammed Earth Structures Annual Report of Grant NSF CMMI-0908199 Submitted to NSF, December 30, 2009.

Liang, R and G. Hota. 2009b. Hakka Tulou and Science: A NSF Project Prospectus Forum on Hakka Tulous: Lessons to Be Learned, Past, Present and Future, June 24, 2009, Xiamen University, Xiamen, China

Liang, R, G. Hota, J Ostrowski, and Y Lei. 2009. Applying Hakka Wisdom to Future Sustainable Structures: A Proposal, Forum on Hakka Tulous: Lessons to Be Learned, Past, Present and Future, June 24, 2009, Xiamen University, Xiamen, China

Liang, R and G Hota. 2010. SGER: Material and Structural Response of Historic Hakka Rammed Earth Structures, NSF Award ID\# 0908199 Annual Report 2010, Submitted on $12 / 30 / 2010$

Liu, Lanbo. "Stable Continental Region Earthquakes in South China." Pure and Applied Geophysics 158 (2001): 1583-611. Print.

Lu Xixian, Wang Delong, Zhou Ming. 1987. Influence of the extractives on Chinese fir wood upon their natural resistance to fungus and termite damages. Scientia Silvae Sinicae, 22(4): 454462. (in Chinese) < http://lykx.csf.org.cn/qikan/manage/wenzhang/19870409.pdf> .

Melbourne. "Thermal Mass." Energy Smart Housing Manual. Melbourne: Sustainable Energy Authority Victoria, 2002. 36-41. Print. 
Morell, J. J. "Decay Resistance of China-fir (Cunninghamia Lanceolata (Lambert) Hooker)." All Business. Forest Products Journal, 1 May 2001. Web. 26 Mar. 2010.

$<$ http://www.allbusiness.com/sector-11-agriculture-forestry/forestry-logging/1180457-1.html >.

New Mexico 2003. Earthen Building Materials Code. Title 14, Housing and Construction.

Chapter 7, Building Codes General. http://www.sanco-bg.com/NM_Earthen_Building_Code.htm

Plastics New Zealand . "EPS as Thermal Insulation." Plastics New Zealand Incorporated, 2003.

Web. 30 Apr. 2010. <http://www.plastics.org.nz/page.asp?id=468>.

Reinhardt, Heins-Wolf, and Martin Jooss. "Permeability and Self-healing of Cracked Concrete as a Function of Temperature and Crack Width." Cement and Concrete Research 33.7 (2003): 98185. Science Direct. July 2003. Web. 25 May 2010.

Rhydwen, Ranyl. "Hemp." Advanced Environmental and Energy Studies B3 (2007): 38. University of East London. Web. 25 May 2010.

$<$ http://gradschool.cat.org.uk/graduateschool/downloads/Module_B3.pdf $>$.

Sargentis, Fivos G., A. Chatzimpiros, and N. Symeonidis. "Determination Method of Thermal Conductivity of Building Parts in Situ through IR Imaging by Minimizing the Influence of Environmental Parameters." Diss. National Technical University of Athens, 2009. Print.

Step Warmfloor. 2010. "6.2 R-Values for Building Materials." Step Handbook. Web. 30 Apr. 2010. <http://www.warmfloor.com/literature/HANDBOOK/STEP\%20Handbook.pdf>.

Termkhajornkit, Pipat, Toyoharu Nawa, Yoichi Yamashiro, and Toshiki Saito. "Self-healing Ability of Fly Ash-cement Systems." Cement and Concrete Research 31.3 (2009): 195-203. Science Direct. Mar. 2009. Web. 25 May 2010. 
Tibbets, Joe M. "Rammed Earth: Developing New Guidelines for an Old Material." Building

Standards Sept.-Oct. 1998: 8-16. Web. 29 June 2010.

$<\mathrm{http}: / /$ www.dcat.net/resources/buildingstandards_sepoct98_ramearth.pdf $>$.

Tierrafino . "Tierrafino Finish." Technical Data Sheet. Tierrafino. Web. 30 Apr. 2010.

$<$ http://www.tierrafino.com/pdf/Tierrafino\%20Finish\%20TDS.pdf $>$.

Ueda, Minoru, 2009. Chengqi Tulou Thermal Date from Data Logger, July 7, 2009

UNESCO . Fujian Tulou. Rep. no. 1113. UNESCO, 2008. Print

USGBC . "What LEED Is." USGBC: U.S. Green Building Council. U.S. Green Building Council, 2010. Web. 29 June 2010.

$<$ http://www.usgbc.org/DisplayPage.aspx?CMSPageID=1988>.

Wang, Fuping. A History of The Tulou Buildings. Fuzhou: Haifeng House, 2008. Print.

Wikipedia. "World Map Temperate" Wikipedia, the Free Encyclopedia. Web. 27 Apr. 2010. $<$ http://en.wikipedia.org/wiki/File:World_map_temperate.svg>.

Wilson, Alex. "Thermal Mass and R-value: Making Sense of a Confusing Issue."

BuildingGreen.com. Environmental Building News, 1 Apr. 1998. Web. 30 Apr. 2010.

<http://www.buildinggreen.com/auth/article.cfm/1998/4/1/Thermal-Mass-and-R-value-MakingSense-of-a-Confusing-Issue/>.

Yang, Fuwei, Bingjian Zhang and Qinglin Ma, "Study of Sticky Rice-Lime Mortar Technology for the Restoration of Historical Masonry Construction", Acc. Chem. Res., 2010, 43 (6), pp 936$944<$ http://pubs.acs.org/stoken/presspac/presspac/full/10.1021/ar9001944>

Zhang, Peizhen, Zhi-xian Yang, H. K. Gupta,, S. C. Bhatia, and Kaye M. Shedlock.

"Implementation of Global Seismic Hazard Assessment Program (GSHAP) in Continental Asia." 
Global Seismic Hazard Assessment Program. Web. 29 June 2010.

$<$ http://www.seismo.ethz.ch/gshap/eastasia/eastasia.html>.

Zimmerman, Jens, Jan Zapletal, and Clemens Dohler. CoCoon Contextual Constructions:

Longyang. Publication. Berlin: Technical University of Berlin, July 2005. Print. 


\section{APPENDIX A- SAND FORK FLOOR JOIST LOAD TESTING}

Sand Fork Elementary School, Sand Fork, WV. Testing was done in Fall 2009. Refer to text description under Section 3.6.2 Floor System, pages 72-73

\begin{tabular}{|c|c|c|c|c|c|c|}
\hline Floor & Room & Loading & $\begin{array}{c}\text { Beam Span } \\
\text { (feet) }\end{array}$ & $\begin{array}{c}\text { Max } \\
\text { Strain }^{* 3} \\
\mu \varepsilon\end{array}$ & $\begin{array}{c}\operatorname{Max} \delta \\
\text { (in) }\end{array}$ & Remarks \\
\hline \multirow[t]{3}{*}{2} & Room 203 & 40 psf on 1 joist & $20.00^{\prime}$ & 52 & 0.04 & $\begin{array}{c}A=139 \\
\text { in/B=101 in*1 }\end{array}$ \\
\hline & & 40 psf on 2 joists & $20.00^{\prime}$ & 95 & 0.09 & “6 \\
\hline & & 80 psf on 1 joist & $20.00^{\prime}$ & 106 & 0.09 & “6 \\
\hline \multirow[t]{3}{*}{2} & Room 214 & 40 psf on 1 joist & $20.00^{\prime}$ & 32 & 0.03 & At Center Line \\
\hline & & 40 psf on 2 joists & $20.00^{\prime}$ & 61 & 0.06 & “6 \\
\hline & & 80 psf on 1 joist & $20.00^{\prime}$ & 65 & 0.07 & “6 \\
\hline \multirow[t]{3}{*}{2} & $\begin{array}{c}\text { Principal's } \\
\text { Office }\end{array}$ & 40 psf on 1 joist & $20.00^{\prime}$ & 18 & 0.02 & $\begin{array}{c}A=156 \\
\text { in } / B=84 \text { in }\end{array}$ \\
\hline & & 40 psf on 2 joists & $20.00^{\prime}$ & 36 & 0.04 & “" \\
\hline & & 80 psf on 1 joist & $20.00^{\prime}$ & 39 & 0.05 & “ \\
\hline \multirow[t]{3}{*}{3} & Room 310 & 40 psf on 1 joist & $23.08^{\prime}$ & 46 & 0.05 & At Center Line \\
\hline & & 40 psf on 2 joists & $23.08^{\prime}$ & 79 & 0.06 & “ \\
\hline & & 80 psf on 1 joist & $23.08^{\prime}$ & 90 & 0.08 & “6 \\
\hline \multirow[t]{3}{*}{3} & Room 313 & 40 psf on 1 joist & $25.75^{\prime}$ & 19 & 0.03 & At Center Line \\
\hline & & 40 psf on 2 joists & $25.75^{\prime}$ & 38 & 0.05 & “ \\
\hline & & 80 psf on 1 joist & $25.75^{\prime}$ & 52 & 0.06 & “" \\
\hline \multirow[t]{3}{*}{3} & Hallway & 40 psf on 1 joist & $20.00^{\prime}$ & 64 & 0.04 & At Center Line \\
\hline & & 40 psf on 2 joists & $20.00^{\prime}$ & 104 & 0.07 & “ \\
\hline & & 80 psf on 1 joist & $20.00^{\prime}$ & 123 & 0.07 & “6 \\
\hline \multirow[t]{2}{*}{3} & $\begin{array}{c}\text { Conference } \\
\text { Room }\end{array}$ & 40 psf on 1 joist & $25.83^{\prime}$ & 20 & 0.02 & $\begin{aligned} \mathrm{A} & =202 \\
\text { in/ } \mathrm{B} & =108 \text { in }\end{aligned}$ \\
\hline & & 40 psf on 2 joists & $25.83^{\prime}$ & 32 & 0.03 & “ \\
\hline \multirow[t]{3}{*}{3} & Library & 40 psf on 1 joist & $23.25^{\prime}$ & 98 & 0.09 & At Center Line \\
\hline & & 40 psf on 2 joists & $23.25^{\prime}$ & 184 & 0.17 & “ \\
\hline & & $\begin{array}{c}1000 \text { lb conc. } \\
\text { load }^{* 2}\end{array}$ & $23.25^{\prime}$ & 234 & 0.16 & “ \\
\hline
\end{tabular}

${ }^{*} \mathrm{~A}+\mathrm{B}=$ total length

$*^{2}$ Concentrated Load distributed over a length of 3 feet on each side of center line. Actual conc. load applied $=2000 \mathrm{lbs}$ over two joists.

$*^{3}$ Compression Values were typically higher than tension values 